Aristide Briand

Assemblé Nationale (Chambre des députés), France

(4 mars 1905)

\title{
Rapport fait le 4 mars 1905
}

\section{au nom de la commission relative à la séparation des Églises et de l'État et de la dénonciation du Concordat chargée d'examiner le projet de loi et les diverses propositions de loi}
Un document produit en version numérique par Claude Ovtcharenko, bénévole, Journaliste à la retraite, sud de la France Courriel: c.ovt@wanadoo.fr

Dans le cadre de la bibliothèque numérique. Les classiques des sciences sociales Site web: http://classiques.uqac.ca/

Une bibliothèque développée en collaboration avec la Bibliothèque

Paul-Émile-Boulet de l'Université du Québec à Chicoutimi Site web: http://bibliotheque.uqac.ca/ 
Cette édition électronique a été réalisée par Claude Ovtcharenko, bénévole,, à partir de :

Rapport fait le 4 mars 1905 au nom de la commission relative à la séparation des Églises et de l'État et de la dénonciation du Concordat chargée d'examiner le projet de loi et les diverses propositions de loi

\section{Par Aristide Briand}

Source: Journal officiel des débats de l'Assemblée nationale. Texte recueilli dans les Annales.

Polices de caractères utilisée :

Pour le texte: Times New Roman, 14 points.

Pour les citations : Times New Roman, 12 points.

Pour les notes de bas de page : Times New Roman, 12 points.

Édition électronique réalisée avec le traitement de textes Microsoft Word 2004 pour Macintosh.

Mise en page sur papier format

LETTRE (US letter), 8.5”’ x 11”')

Édition numérique réalisée le 18 février 2007 à Chicoutimi, Ville de Saguenay, province de Québec, Canada.

\section{\& Fait avec}




\section{Table des matières}

\section{Culte catholique.}

\section{DE CLOVIS A MIRABEAU}

La pragmatique sanction

Le concordat de Bologne.

La déclaration de 1682

\section{DE LA RÉVOLUTION AU CONCORDAT}

La constitution civile du clergé.

Le concordat de 1801

\section{DU CONCORDAT AU SYLLABUS}

Le Concordat de 1817

Campagne séparatiste

Le Syllabus

$\underline{\text { DE } 1870 \text { A } 1905}$

\section{LE BUDGET DU CULTE CATHOLIQUE}

\section{Culte protestant}

\section{ÉGLISES SÉPARÉES DE L’ÉTAT}

\section{Culte israélite}

Consistoire central

Consistoires départementaux

Commissions administratives

Ministres du culte

Conclusion 


\section{Législations étrangères}

Espagne ; Portugal.

Russie ; Grèce ; Roumanie ; Bulgarie ; Serbie.

Norvège ; Suède.

Prusse et états allemands.

Autriche.

Hongrie.

Italie.

Belgique.

Pays-Bas.

Grande-Bretagne et Irlande.

Suisse.

États-Unis.

Mexique.

Cuba.

Brésil.

Équateur.

\section{Analyse des propositions et projets de loi.}

Proposition Dejante

Proposition Ernest Roche

Proposition de Pressensé

Proposition Hubbard

Proposition Flourens

Proposition Réveillaud

Proposition Grosjean et Berthoulat

Proposition Sénac

Premier texte de la commission

Projet Combes

Projet du Gouvernement

\section{Discussion des articles}

\section{Conclusion}

Projet de loi présenté (auquel j'ai joint, pour comparaison, le texte voté et le texte actuel. Il est préférable d'utiliser Netscape pour une meilleure concordance des articles.) 
Rapport fait le 4 mars 1905 au nom de la commission relative à la séparation des Églises et de l'État et de la dénonciation du Concordat chargée

d'examiner le projet de loi et les diverses propositions de loi

\section{Par Aristide Briand}

Source: Journal officiel des débats de l'Assemblée nationale.

Texte recueilli dans les Annales.

Messieurs, en 1788, quelques années à peine avant la Révolution, il existait dans le royaume de France une moyenne de 130000 ecclésiastiques. On pouvait les répartir ainsi : 70000 appartenait au clergé séculier, parmi lesquels on comptait 60000 curés et vicaires ; 2800 prélats, vicaires généraux, chanoines de chapitres ; 5600 chanoines de collégiales ; 3000 ecclésiastiques sans bénéfices. Quant au clergé régulier, le chiffre des ecclésiastiques qu'il comprenait s'élevait à 60000 .

Ces chiffres sont empruntés à l'abbé Guettée, et Taine les donne comme authentiques. De Pradt, le célèbre diplomate ecclésiastique, le conseiller et le collaborateur de Napoléon, nous apporte un dénombrement analogue.

Ces 130000 ecclésiastiques possédaient, à la veille de la révolution, un tiers de la fortune de la France. Dans son rapport au comité ecclésiastique, le constituant Treilhard évalue à 4 milliards les biens du clergé ; et ce chiffre n’a rie d'exagéré. Ces 4 milliards rapportent annuellement de 80 à 100 millions ; et il faut joindre à ce revenu ce que 
produit au clergé la dîme ; soit 123 millions par an ; au total 200 millions.

Pour apprécier l'importance de ce revenu, en le chiffrant suivant la valeur qu'il aurait aujourd'hui, il faut parler de 400 millions. Il n'a été question ni du casuel ni des quêtes.

Et si nous avons placé ici, au début de ce travail, cet état succinct de la propriété ecclésiastique, à la veille de la Révolution française, c’est afin de donner une idée éclatante de ce qu'était la puissance matérielle de l'Église, en France, au moment où cette puissance, et l'autorité morale même du catholicisme vont être mis en question, et pour la première fois contestées au nom de principes qui s’attaquèrent non seulement aux manifestations extérieures de l'Église, à ses abus, à certains de ses dogmes, comme l'avait fait, par exemple, le protestantisme et l'orthodoxie russe, mais à son esprit même, à sa conception générale de la vie, et de la divinité.

Si par le seul effort des constituant et des conventionnels, cette énorme puissance matérielle a pu être sapée, détruite, anéantie - du moins pendant la période qui précède le Concordat de 1801 - c'est donc que les principes de la Révolution laïque eurent une vertu prodigieuse !

Hélas, nous ne saurions attribuer aux idées une aussi grande force qu'elles puissent saper ce qui est profondément enraciné. Si la sécularisation des biens du clergé put se produire, c'est qu'elle était déjà préparée par le mécontentement général qu'avaient causé les excès du haut clergé ou la dictature intolérable de la papauté.

En vous présentant ce rapport, nous avons pour objectif de prouver que la seule solution possible aux difficultés intérieures, qui résultent en France de l'actuel régime concordataire, est dans une séparation loyale et complète des Églises et de l'État. Nous montrerons juridiquement que ce régime est le seul qui, en France, pays où les croyances sont diverses, réserve et sauvegarde les droits de chacun. Nous voulons montrer aussi, et d'abord que cette solution est celle que nous indique l’histoire elle-même, étudiée sans parti pris ni passion. 
La sécularisation des biens du clergé par la Constituante ne fut pas une œuvre de haine, dictée par des principes opposés à ceux du catholicisme, ce fut une œuvre nationale exigée par l'ensemble de la nation, moins les prêtres, et aujourd'hui, ce n'est pas davantage pour satisfaire à des rancunes politiques, ou par haine de catholicisme, que nous réclamons la séparation complète des Églises et de l'État; mais afin d'instaurer le seul régime où la paix puisse s'établir entre les adeptes des diverses croyances.

Dans la première partie de cette étude, on verra comment les rapports entre l'Église catholique et l'État français ne cessèrent jamais d'être très troubles, malgré les services réciproques qu'ils s'étaient rendus dès l'origine de notre histoire. Sans insister sur la partie anecdotique, nous rappellerons avec quelques détails les principaux expédients grâce auxquels la royauté française crut pouvoir atteindre à des rapports sereins avec Rome, et comment elle n’y parvint jamais, pas plus d'ailleurs qu'à s'affranchir, par le gallicanisme, de la tutelle gênante du saint-Siège.

Dans une deuxième partie, nous étudierons les tentatives infructueuses des pouvoirs de la révolution et nous verrons comment le Concordat napoléonien permit à l'Église de se reconstituer et d'acquérir, au cours du dix-neuvième siècle, une puissance égale à celle que nous lui avons connue quelques années avant la Révolution. Nous nous efforcerons enfin, dans une troisième partie, de noter les protestations qui ses sont produites, au cours du dernier siècle, contre un état des choses aussi intolérable pour les catholiques que pour les libres-penseurs, ainsi que les remèdes apportés au jour le jour à un mal qui ne peut s’éteindre qu’avec le régime de la séparation. 


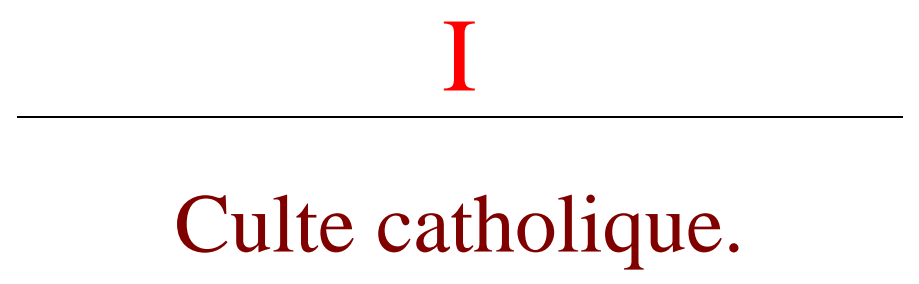

\section{DE CLOVIS A MIRABEAU}

L'adhésion de Constantin aux idées chrétiennes avait inauguré une ère nouvelle dans l'histoire du christianisme. Depuis le jour où Constantin présida le concile de Nicée (313), depuis le moment où, après avoir été le souverain pontife de la religion païenne, il se proclama, devenu chrétien, "empereur et docteur, roi et prêtre", les tendances de la religion de jésus se trouvèrent profondément modifiées. La parole de Galiléen : "Rendez à César ce qui est à César et à Dieu ce qui est à Dieu” fut désormais sans application ; une confusion s'établit entre le spirituel et le temporel ; l'Église emprunta, pour s'organiser, les cadres administratifs de l'empire, et elle fut amenée, par la succession des circonstances, à prendre en main une part considérable de la puissance temporelle.

Lorsque les Barbares envahirent la gaule, ils se trouvèrent en face d'une situation de fait : l'Empire tombé, l'évêque avait remplacé presque partout, le fonctionnaire romain et il apparut aux envahisseurs comme le véritable chef de la cité, ayant sa part de l'autorité judiciaire, administrant les fonds du municipe, percevant les impôts, ins- 
pectant les édifices publics et dirigeant les travaux de construction de voirie.

Le pouvoir de l'évêque était si bien établi dans la cité romaine qu'il devint un des éléments nécessaires à l'installation définitive des envahisseurs sur le vieux sol gaulois.

C’est la raison même de la conversion de Clovis. Le récit qu'en a fait Grégoire de Tours, avec les formes émouvante de sa foi naïve, nous dit quelle force avait alors la religion sur les volontés hésitantes des chefs barbares. Cet épisode de la conversion de Clovis a été vulgarisé, en une belle langue, par Augustin-Thierry ; il est dans le souvenir de tous et nous le notons ici, car il constitue la première étape des rapports de l’Église et de la France.

En même temps que Clovis, 3000 Francs se firent baptiser avec leur roi. Dès lors la victoire de Clovis sur les Burgondes et les Wisigoths fut préparée par les évêques orthodoxes qui, établis au milieu des populations égarées par l'hérésie arienne, se firent les agents du chef catholique. Et quels agents! Certes, de par leur fonction même, ils vivaient confinés dans chacun des royaumes barbares ; mais, malgré les frontières, ils étaient en relations les uns avec les autres et leur puissance était décuplée du fait qu'un chef étranger, l'évêque de Rome, coordonnait leurs actions et unifiait leurs efforts. Participant dès cette époque de la puissance romaine, les évêques gallo-romains furent les plus sérieux adversaires des rois ariens et c'est grâce à eux que Clovis, baptisé, put préparer la domination de la dynastie mérovingienne.

Nous avons des renseignements précis sur les complicités intérieures qui, au sein des nations ariennes, préparèrent la conquête des Francs, les évêques Tolisianus et Vérus sont expulsés, Quintianus doit s'enfuir de son évêché de Rodez; enfin nous avons la lettre par laquelle l'évêque le plus considérable de la fin du cinquième siècle, Avitius, métropolitain de Vienne, l'adversaire le plus passionné et le plus intelligent de l'hérésie arienne, félicite Clovis d'une conversion qu’il a d'ailleurs contribué à rendre inévitable. 
Cette lettre est le premier texte précis, dans lequel se manifestent les intentions, les secrets désirs, les espérances de Rome. On y sent déjà quelle force attend l'Église romaine de sa collaboration intime avec la nation, que préparent les conquêtes de Clovis. Cette lettre fait prévoir la conception romaine d'un roi de France, fils aîné de l'Église, et même la prétention qu'aura bientôt Rome, pour établir définitivement son pouvoir, de créer un monarque placé sous sa dépendance, et dont le pouvoir temporel s'étendit aussi loin qu'allait sa force spirituelle. La lettre du métropolitain de Vienne prévoit déjà l'empire chrétien de Charlemagne.

Grâce à l'appuis des évêques catholiques, Clovis va pouvoir triompher des Burgondes et des Visigoths ; mais l'église romaine ne perdra rien dans le marché conclu. Désormais, la royauté mérovingienne est liée à l'épiscopat, et nous assisterons bientôt à l'alliance des carolingiens avec Rome. Ce lent travail de la papauté qui, à deux reprises, à travers les siècles, fut sanctionné d'une manière éclatante par le concordat de Bologne, une première fois ; puis par la révocation de l'Edit de Nantes, commence son action méthodique et persévérante. Il y a une diplomatie ecclésiastique qui, dans ces périodes troublées, fut d'autant plus féconde en résultats qu'elle émanait d'un point fixe, Rome, où convergeaient toutes les forces d'intelligence, toutes les forces d'argent de l'Europe civilisée.

La mainmise de la papauté dans les affaires intérieures de la royauté franque ne s'établit pas cependant sans d'assez grandes difficultés. En face des prétentions romaines, il y eut, dès l'origine, une tendance de la nation à vivre de ses propres ressources et de sa propre pensée, à l'abri de toute ingérence extérieure. Mais, à l'époque qui nous occupe, cette tendance est encore hésitante et imprécise. La loi qui règle les rapports de l'Église et de la royauté franque est la loi du chaos. Nous avons remarqué que, à l'arrivé des barbares, les évêques gallo-romains avaient une puissance administrative et judiciaire. Ils l'ont conservée. Il existe une juridiction ecclésiastique dont nous aurons l'occasion de parler et qui subsiste jusqu'au dix-septième siècle. Cette situation de fait, accrue encore par le prestige que leur donne la foi superstitieuse des peuplades barbares, propice à l'accroissement de leurs biens temporels, les rend puissants et redoutables. Mais ils ne sont pas encore placés sous la domination directe et impérative de la papauté. 
Théoriquement, les élections canoniques se faisaient alors par le peuple et par le clergé. Survivance de la primitive Église, le suffrage des croyants y maintenait encore dans les rangs du clergé le mouvement de la vie. Il est vrai que cette élection n’était qu'un des actes par lesquels était institué un évêque. Il fallait, par surcroît, la confirmation du roi et le consentement du métropolitain.

Tel était, du moins, la règle, mais en fait, on dut la rappeler fréquemment aux premiers rois qui avaient inauguré un véritable droit de nomination directe. saint Rémi ayant consacré prêtre un certain Claudius, les évêques protestèrent, et saint Rémi répliqua qu’il avait agi ainsi par ordre du roi. L'évêque Quintinius meurt ; le roi ne reconnaît pas le nouvel élu. Il en nomme un autre. Nous empruntons à l'Histoire générale de MM. Lavisse et Rambaud un troisième fait des plus significatifs : en 562, un synode de saintes, présidé par métropolitain, a destitué un évêque nommé par Clotaire et mis à sa place Heraclius. Quand ce dernier vint chercher la confirmation auprès de Charibert, le roi le fit jeter sur un chariot rempli d'épines et conduire à l'exil ; puis il envoya “des hommes religieux" qui rétablirent le destitué. Le métropolitain dut payer une forte amende et les autres évêques furent punis de même.

Les évêques eurent une revanche à l'occasion d'un synode qui tenta de mettre quelques régularité dans la nomination aux grades ecclésiastiques. L'édit de 614 rétablit les élections canoniques pour le clergé et pour le peuple ; il maintient l'institution royale, mais avec cette réserve que "si l'on nomme quelqu'un du palais, ce soit pour ses mérites personnels".

Cet édit avait pour objectif de réduire l'arbitraire royal. Il établit également par un texte le droit de l'Église à des privilèges de juridiction ainsi que ses privilèges d'immunités. Il constitue une victoire de l'aristocratie ecclésiastique qui tend, de plus en plus, à se former en un corps distinct dans la nation.

Sous la dynastie mérovingienne, le roi conserve cependant un certain nombre de droits acquis. C'est lui qui préside les conciles et les synodes, et l'on sait que, parfois, dans ce chaos où le temporel et le 
spirituel voisinent et même se confondent, le roi a souvent employé les conciles aux affaires publiques. Gontran convoqua tous les évêques de son royaume pour les faire décider de sa querelle avec Sigebert. IL prétendit faire juger Brunehaut par un concile ; c’était une extension abusive de son droit. La coutume était qu'il jugeât les évêques, comme président d'un synode. Son droit à la présidence des conciles et des synodes est dès lors incontesté. Les conciles ne se réunissent qu'avec qu'avec son autorisation, lorsqu'il l'ordonne ; pour être applicables, les décisions des conciles doivent être confirmées par lui. On découvre déjà les forces qui limiteront la puissance de Rome et permettront au gallicanisme de naître.

Mais nous n’avons pas dit assez les services réciproques de la papauté et des dynastie franques. Pendant que sous la dynastie mérovingienne une aristocratie ecclésiastique se forme, limitative de la domination abusive des rois, toute la politique de Rome consiste à mettre obstacle aux tendances des divers clergés à se former en église nationales, indépendantes de la papauté. Telle est la situation réciproque des combattants à l'avènement de la maison carolingienne.

La diplomatie romaine remporta une première victoire décisive, pendant le principat de Charles-Martel. Elle fit preuve ainsi d'un très grand mérite, car Charles-Martel ne faisait pas précisément profession de favoriser les dessins de l'Église. Son autorité se manifesta d'abord contre les ecclésiastiques. Il dépose Rigobert, évêque de Reims (717) ; il fait saisir Euchère, évêque d'Orléans, qui est conduit sur son ordre à Cologne. Évêques et abbés sont déposés en foule ; leurs biens - évêchés et abbayes - sont distribués aux proches de Charles-Martel. Ces biens, malgré les protestations de Rome, ne furent jamais, dans la suite, restitués à l'Église ; et c'est une preuve historique de la facilité avec laquelle les souverains de France disposèrent de ce qui appartenait au clergé. Mais si Rome dut se soumettre elle fit payer d'une autre façon ce sacrifice au puissant maire du palais. C'est sous le principat de Charles-Martel, et avec sa collaboration, que la papauté commence à imposer à l'Europe son hégémonie morale et matérielle. Mais dans quelles circonstances? Le moine Winfrid avait reçu du pape la mission d'évangéliser la Frise, puis la Germanie. Son apostolat consistait à prêcher l'unité religieuse sous l'égide du catholicisme romain. 
En même temps qu'une fois agissante, l'obéissance aux volontés du saint-Siège apostolique était exigée des fidèles.

Au printemps 723, Boniface obtint de Charles-Martel une lettre qui plaçait sous son patronage l'évangélisateur de la Germanie.

Le prince des Francs avait agi en politique avisé. La force d'expansion de l'idée chrétienne permettait à l'influence des Francs de se répandre en dehors. La mission de Boniface fut couronnée de succès. L’église de Germanie fut crée. Le nom de Boniface acquit un prestige énorme.

Il se préoccupa, dans la suite, de réformer l'église d'Austrasie ; une série conciles eurent lieu furent tenus en Austrasie et en Neustrie ; enfin, en 745, un concile général de tout le royaume des Francs permit de constater quelle force avait acquise l'activité du pontife romain. Quelques années après, en 748, Boniface qui présidait un concile annuel fit voter une formule de soumission au siège de Rome. L'Église de Gaule, qui avait contribué à asseoir la dynastie mérovingienne et qui était devenu assez puissante pour se soustraire à l'arbitraire des rois, se soumet, à son tour, à l'autorité extérieure de la Rome pontificale. Une nouvelle étape a été franchie. De plus en plus, la politique romaine collabore à l'établissement de la puissance royale, qui rendra possible la fondation de l'empire chrétien de Charlemagne. Dans une circonstance critique, pour se défendre contre les Lombards, elle avait déjà fait appel à Charles-Martel. Étienne II s’adresse à nouveau à pépin. IL fait le voyage de Paris et conclut bientôt avec le prince des Francs une alliance décisive qui ouvre définitivement l'ère de la puissance romaine, en même temps qu'elle contribue à établir en France la domination de la dynastie capétienne.

Cette domination fut surtout assurée par une cérémonie, qui empruntait aux croyances religieuses du temps, une portée immense. Pépin venait d'être élevé au trône de France. Suivant la coutume, il y avait eu élection. Mais, au moment où, avec ses deux fils, il allait entreprendre une guerre contre les Lombards, le pape lui donna l'onction sainte, ainsi qu'à ses deux fils. 
Dans l'Histoire générale de Lavisse et Rambaud, l'importance essentielle de cette intervention papale est marquée en quelques phrases décisives : "Le sacre était une nouveauté chez les Francs. Aucun des Mérovingiens, pas même Clovis, ne l'avait reçu. Cette cérémonie mystique élevait le roi au-dessus du peuple, d’où il était sorti. Les Francs avaient élu pépin, mais le jour du sacre, le pape leur a interdit à jamais de se servir de leur droit d'élection ; ni eux, ni leur descendance ne pourront prendre un roi dans une autre race, celui-ci ayant été élu par la divine Providence pour protéger le siège apostolique. désormais les "reins” du roi et de ses fils sont sacrés. Dieu y a mis le pouvoir d'engendrer une race de princes que les hommes, jusqu'à la fin des temps ne pourront renier sans être reniés par le Seigneur. Autrefois les guerriers portaient leur chef sur le bouclier, au bruit des armes et des acclamations : à saint-Denis, ce n'est pas un homme, c'est une dynastie qui a été élue au chant des cantiques. Le Seigneur a repris aux hommes le pouvoir de faire des rois. C'est lui qui "les choisit dès le sein de leur mère”. La raison de régner, la source de l'autorité royale sera désormais la grâce de Dieu.”

La force morale qu'en recueillit la royauté capétienne est incontestable ; mais celle-ci ne fut pas en reste avec la papauté. Elle contracta envers celle-ci des obligations que Rome sut lui rappeler au moment voulu. Pour l'instant, elle obtint d'être débarrassée des Lombards, elle se fit donner un pouvoir temporel. En 756, le roi des Francs remet les clefs de vingt-deux villes entre les mains du pape ; il est vrai que, quelques temps auparavant, Étienne II avait écrit aux Francs : "Selon la promesse qui nous a été faite par le Seigneur Dieu notre rédempteur, je vous prends entre toutes les nations, vous, peuple des Francs, pour mon peuple spécial.”

Cette collaboration intime de la papauté et de la royauté capétienne aboutit, comme c'était le dessein secret de Rome, à la fondation de l'Empire chrétien de Charlemagne ; mais cette création, contraire aux tendances de l'Europe à se former en nationalités distinctes, est bientôt anéantie et Rome, qui a échoué du côté des Francs, renouvelle sa tentative de concert avec les princes germaniques.

Cette attitude de la papauté facilite le développement des tendances du clergé français à se créer une vie propre, indépendante de Rome. 
La royauté capétienne continue à trouver son principal appui dans le clergé. Charlemagne a réorganisé l’Église. Il a conservé, et même accru, l'autorité administrative des évêques. Certes, cette puissance abandonné au clergé n’est pas sans dangers. Grâce à ce pouvoir politique considérable, l’Église accrut encore ses biens. En 851, le concile de Soisson obtint que certains crimes, entre autre l'inceste, soit soumis à la juridiction ecclésiastique. Hugues Capet conserve avec les dignitaires de l'Église une union intime. La féodalité refuse à la royauté capétienne son appui. Celle-ci trouve dans la société ecclésiastique la base de son action et les ressources nécessaires à son établissement. Il s’agit de lutter contre les éléments anarchiques de la féodalité ; les évêques et les abbés favorisent la tendance de la royauté nouvelle vers la centralisation et l'unité ; ils sont membres actifs des assemblés administratives et judiciaires; ils fournissent au roi des subsides et même des ressources pour la guerre.

Mais cette collaboration intime de la royauté et de l’Église ne favorise nullement les prétentions romaines. Malgré les tentatives que fera Rome pour se rapprocher de la France, après les déboires de sa politique germanique, il lui faudra patienter jusqu'au concordat de Bologne (1516) pour ressaisir son influence prépondérante dans les affaires intérieures de notre pays.

Elle s'est faite d'ailleurs de plus en plus arrogante avec Grégoire VII. Elle a accru ses prétentions à la domination universelle. Elle les a précisées dans des textes définitifs, dans des formules, sous des images. Seul, le pontife romain peut être appelé œcuménique. Son nom est unique dans le monde. Il ne peut être jugé par personne. L'Église romaine ne s'est jamais trompé et ne se trompera jamais. Le pontife romain a le droit de déposer les empereurs. Il y a ainsi vingtsept propositions qui affirment à la face du monde la suprématie du pape sur l’Église et les princes.

Ces principes n’ont pas été inventés de toute pièces par Grégoire VII. Ils sont en germe dans le droit canonique et dans les décisions antérieures des conciles ; mais c'est ce pape, célèbre à juste titre dans l'histoire de l'Église, qui a coordonné ces éléments divers et a dressé le monument juridique de la théocratie romaine. 
Armée de cette charte théorique de ses droits, la papauté a voulu en appliquer les principes au gouvernements des sociétés. Elle a voulu établir son autorité indiscutée sur les évêques et les prélats de toutes les nations chrétiennes. Mais elle a trouvé en face d'elle les princes, qui, par un usage consacré, avaient conservé la nomination aux grades ecclésiastiques.

La guerre qui s'ensuivit entre la papauté et la royauté germanique est demeurée célèbre sous le nom de "Querelle des investitures". Sans doute, Rome fut finalement vaincue ; mais à la suite de quelles luttes $! . .$.

Au début de cette querelle, Grégoire VII avait déposé Henri IV, en des termes que l'histoire a conservés et qu'il n'est pas inutile de citer : “...Pour l'honneur et la défense de ton église, disait-il, au nom du Dieu tout puissant, du Père, du Fils et du saint-Esprit, par ton pouvoir et ton autorité, je nie au roi Henri, qui s'est insurgé avec un orgueil inouï contre ton Église, le gouvernement de l'Allemagne et de l'Italie ; je délie tous les chrétiens du serment de fidélité qu'ils lui ont prêté ou qu'il lui prêteront ; je défends que personne ne le serve comme on sert un roi.” Quelque temps après, Henri IV faisait pénitence ; il allait à Canossa, accordant à la papauté la plus belle victoire qu'elle ait jamais remportée sur une puissance temporelle.

En France, Philippe I ${ }^{\mathrm{er}}$ ne laissa point Grégoire VII s'immiscer dans sa politique intérieure. Avant lui, Hugues Capet avait défendu contre la cour de Rome l'indépendance de ses églises. Au concile de saintBast avaient été proclamées les libertés gallicanes. Mais cette attitude s'expliquait par le fait que la papauté n'était alors qu'un instrument entre les mains des empereurs germaniques et qu'il eût été dangereux de favoriser l'intervention d'influences étrangères.

Avec Philippe I ${ }^{\mathrm{er}}$, la situation a changé. Les papes ont rompu avec l'empire germanique et ils ont entrepris la réforme morale du clergé, abandonné à tous les abus, à toutes les déchéances, à tous les vices. Cependant Philippe I ${ }^{\mathrm{er}}$ résiste. Quelques après, Louis le Gros se montre moins énergique dans la lutte contre Rome. Malgré tout, il maintient résolument son droit d'intervention dans les élections ecclésiasti- 
ques. Philippe Auguste (1180-1225) ; tout éclatant du prestige de ses victoires, accentue encore cette tendance. Il contraint les évêques à se présenter devant sa cour de justice. Il leur enjoint de participer aux frais de la guerre ; soucieux de mettre obstacle aux ingérences pontificales, il ne craint pas d'engager pour cela la lutte avec Innocent II ; en un mot, il prépare la naissance d'un esprit laïque et national, en opposition avec les prétentions de la théocratie romaine. saint Louis continue son œuvre et ce monarque très chrétien fut un des plus fervent défenseur de la société laïque.

Loin de se plier devant la papauté, il obtint d'elle des concessions. Sous son règne, les ecclésiastiques sont astreints à payer les décimes, douzièmes et centimes. C'est le moment héroïque des croisades. Le clergé est appelé à prendre sa part des charges qu'elles occasionnent. Saint Louis obtint aussi que les clercs mariés ou commerçants soient enlevés à la juridiction ecclésiastique.

C’est sous le règne de saint Louis que vécut Guillaume II, cet évêque de Paris qui aurait plutôt sacrifié les intérêts de Rome que ceux de la politique royale.

Les tendances antiromaines de saint Louis étaient tellement connues qu'on lui a attribué la paternité d'un document considéré aujourd'hui comme apocryphe, et connu sous le nom de Pragmatique sanction de saint Louis ou Édit sur les élections ecclésiastiques et les libertés gallicanes.

Que ce document ait été rédigé sous l'inspiration du roi très chrétien ou qu'il ait été composé plus tard de toute pièces, au moment où il s'agissait de préparer et de rendre possible la "pragmatique sanction" de Bourges, il est une chose certaine c'est que saint Louis n'en aurait contesté ni l'esprit ni les expressions.

Ce document si intéressant pour l'histoire des origines du gallicanisme débute ainsi : Ludvicus, Deo Gratia rex Francorum, et le commentateur qui croit à l'authenticité de la pragmatique, fait remarquer, en une note, que "les princes de la troisième race se dirent rois par la grâce de Dieu, non seulement par pitié, mais encore pour marquer leur autorité souveraine et leur indépendance des papes, qui s’étaient, vers 
ce temps là, arrogé, sans apparence de raisons, le prétendu droit d'excommunier les souverains et de disposer de leurs royaumes.”

Il n'est pas sans intérêt historique de marquer ici l'importance essentielle de ce simple petit détail.

Quelle était, à l'époque de Clovis, la conception que se faisait la papauté de ces rapports avec les princes temporels ? On connaît la comparaison, chère à la papauté entre le soleil et la lune ; entre l’Église romaine qui éclaire le monde et la royauté qui en reçoit les rayons.

Une autre figure illustre les théories romaines de la subordination des rois à l'égard de la papauté : "Il y a deux glaives : le glaive spirituel et le glaive temporel ; tous les deux appartiennent à l'Église ; l'un est tenu par elle, par la main du pape ; l'autre est tenu pour elle par la main des rois, tant que le pape le veut ou le souffre. En outre, l'un des glaives doit être subordonné à l'autre, le temporel au spirituel.”

Ces théories se sont manifestées dans plusieurs concile de l'époque. A aucun moment la papauté n’a admis qu'il y eut égalité de droit entre les deux pouvoirs.

C'est donc une nouveauté, qui caractérise bien la conception des rois de la dynastie capétienne, que cette prétention de recevoir directement de Dieu la grâce qui les consacrait rois. Bossuet en tirera plus tard de beaux effets. Nous les notons ici comme une première étape décisive vers la fondation en France d'une Église anglicane (Je suppose qu'il s'agit d'une faute de composition, c'est gallicane qu'il aurait fallut écrire !), indépendante du pouvoir romain.

Les différents célèbres entre Philippe le Bel et Innocent III vont nous permettre de déterminer encore la marche ascendante des idées gallicanes. Elles vont prendre corps et s'organiser en système, grâce au patriotisme des légistes.

Philippe le Bel déclarait net, dès 1297, qu'il ne tenait sa royauté que de Dieu seul. il affirmait ainsi, de façon catégorique, l'indépendance 
du pouvoir temporel. Il montra bientôt comment il prétendait se libérer de la domination envahissante des pontifes romains.

Le pape venait de lancer sa bulle dite clericis laïcos, par laquelle il interdisait à tout ecclésiastique de rien payer à un laïc sans y avoir été autorisé par le saint-Siège, et cela sous peine d'excommunication. Prétention plus étonnante encore : Rome frappait d'interdit les villes qui imposaient le clergé.

Philippe le Bel prit une décision capable de faire réfléchir la papauté. Il interdit toute exportation d'or et d'argent hors du royaume. C’était réduire à néant les ressources que Rome recevait de son Église de France.

Le pape protesta, puis céda. Il est vrai que vingt-trois évêques français le suppliaient de revenir sur sa précédente bulle. Il autorisa la perception, par les laÏcs des droits féodaux, qu'autorisaient les coutumes du royaume. Les dons d'argent et les prêts, consentis à des laïcs par les prélats, furent punis. Le roi de France put lever, dans certains cas, des subsides sur le clergé. Le pape alla lui-même jusqu'à remettre à Philippe une partie de la collecte de terre sainte et une année des revenus des bénéfices vacants, et le garanti de la censure ecclésiastique. Quelques années après, de nouvelles difficultés se présentent. Elles atteignent un état aigu. Philippe est amené à faire ouvrir, devant la cour de Senlis, une procédure contre le pape, pour "lèse-majesté, rébellion, hérésie, blasphème, simonie”. mais le pape accuse Philippe de "tyrannie, mauvais gouvernement, fausse monnaie". Dans une grande assemblée, à Notre-Dame, le roi affirme la doctrine de l’indépendance absolue du pouvoir royal ; Boniface VIII répond que "toute créature humaine est soumise au pontife romain". Des lettres frappant Philippe d'excommunication sont envoyées en France. On saisit le porteur des lettres à Troyes ; on le jette en prison, après l'avoir dépouillé. Le pape prétend, par une bulle, détacher sept princes ecclésiastiques de France et les dégager de toute fidélité au roi capétien. Un complot contre Boniface VIII est organisé par de Nogaret. Le palais pontifical de d'Agnani, où se trouvait le pape (été 1303), est envahi. Boniface déclare qu'il "aime mieux renoncer à la vie qu'à la tiare". Il mourut quelques jours plus tard à Rome. 
Les années qui suivront consacrèrent le triomphe définitif de la royauté capétienne. Le vœu intime de Philippe le Bel avait toujours été de supprimer l'ordre militaire des Templiers. Il y parvient. Les templiers étaient riches à l'excès. Ils avaient ouvert des crédits, pratiqué l'usure, leurs caisses regorgeaient d'argent, on les poursuivit comme hérétiques, les Dominicains les interrogèrent à la mode inquisitoriale. leurs biens furent mis sous séquestre ; 137 frères passèrent par le fer et par le feu.

Un moment il y eu du flottement. La papauté était récalcitrante. Alors, Philippe ressuscita son idée de poursuivre Boniface VIII. Il était mort. On fit le procès de sa mémoire... Finalement, tout s’arrangea. Boniface VIII ne fut pas considéré comme hérétique, mais les Templiers furent sacrifiés. On prononça la suppression de l'ordre en concile de Vienne (1311-1312). Philippe s'empara du numéraire et converti en caisse royale la caisse du Temple.

Au cours de cette époque troublée, parallèlement aux actes se développent les idées d'un droit national opposé aux prérogatives de Rome. C'est pendant les luttes, dont nous venons de donner une brève impression, entre Philippe le Bel et Boniface VIII, que, pour la première fois, le roi de France en appelle des déclarations du pape à un concile général. La supériorité des conciles nationaux, par rapport au saint-Siège deviendra une de thèses les plus chères du clergé gallican.

Nous ne sommes pas encore au moment de la déclaration gallicane de 1682, nous ne sommes même pas encore à la pragmatique sanction de Bourges ; mais nous constatons l'élaboration doctrinale de ces deux actes essentiels dans l'existence de l'Église libre de France. Les légistes de l'an 1300, les Guillaume de Nogaret, les Pierre Flotte, les Enguerrand de Marigny préparent, dans leurs écrits et par leurs actes, les événements importants qui vont suivre. Tandis que Philippe le Bel posait, sur le terrain des faits, le grave problème de la séparation de l’Église romaine et de l'État, ses conseillers légistes le posaient sur le terrain des idées.

Nous passerons sur les événements qui suivirent. Ils sont importants cependant pour l'histoire de la papauté. C'est le grand schisme d'Occident, d'abord bicéphale, puis tricéphale. Ce sont les conciles 
qui, peu à peu, s'établissent en limitateur de la puissance romaine. C'est le concile de Constance qui, en 1418, malgré la fuite du pape, se déclare œcuménique et proclame que "tout chrétien, y compris le pape, lui doit obéissance pour ce qui concerne la foi, l'extinction du schisme et la réforme générale de l'église, dans son chef et dans se membres." C'est le concile de Bâle (1431) qui abolit l'impôt des annates, principal revenu des papes.

Eugène IV, alors pape, adresse une encyclique aux princes de l'Europe, disant qu'un concile a émis la prétention de porter atteinte à ses prérogatives et de diriger l'Église, en ses lieu et place. Il transfère le concile à Ferrare. Celui de Bâle se maintient et nomme un antipape.

Quelle est, dans ce conflit, l'attitude du roi de France ? Elle est d'un homme prudent, d'un politique avisé. Charles VII se déclare pour Eugène IV ; mais, au même moment, il travaille à recueillir, dans le décret de Constance et de Bâle, ce qui peut être favorables aux théories gallicanes, et avec ces éléments il crée le statut nouveau de l’Église de France, la pragmatique sanction de 1438.

\section{La pragmatique sanction}

Retour à la table des matières

Charles VII avait déjà eu l'occasion, a plusieurs reprises, de faire montre de sentiments nationaux dans la questions des rapports entre l'Église de France et la papauté. Un des commentateurs de la pragmatique constate que, tout jeune encore - il n'était que dauphin - Charles VII ayant été chargé de gouvernement publia, en mars 1418, sous le nom de son père, des lettres qui rétablissaient l'ancien droit des Églises de France et du Dauphiné, relativement aux élections et collations des bénéfices, "sans aucun égard aux réserves expectatives et aux autres prétendus droits de la cour romaine, dont il ordonnait de faire cesser les exactions”.

Plus tard, Charles VII avait aussi publié d'autres lettres relatives à la collation des bénéfices, "non par rapport à l'ordre des nominations, 
mais par rapport aux personnes qui pouvaient être nommées”. De tout temps, constate le commentateur, les rois de France avaient défendu qu'aucun étranger ne fût reçut à aucun bénéfice du royaume (lettre du 10 mars 1831)(plutôt 1431 ?) Mais leur défense avait été mal observée. Charles VII l'avait renouvelée dans des lettres adressées au concile de Constance. Charles VII en fit, dans la suite, comme nous le disons, signifier de semblables. Le pape favorisait le "parti anglais “donnant les bénéfices dans les États de Charles à ceux qui tenaient ce même parti. Depuis qu'Eugène IV avait succédé à Martin V, Charles l'avait fait prier de conférer les bénéfices considérables et de dignité “aux personnes nobles et de grand mérite, de la loyauté, prud'homie, prudence et littérature desquels il était dûment informé”. Mais Eugène continuait de donner les bénéfices à des étrangers et même, parfois, a des ennemis du roi, “ce qui était préjudiciable à l'État, et même dangereux, car, par là, non seulement les finances passaient en main ennemies, mais des forteresses importantes, dépendantes de grands bénéfices, se trouvaient confiées à des personnes pouvant en abuser”.

Les tendances nationales de Charles VII se présentèrent encore à mesure qu'il prit l'habitude du pouvoir.

De graves problèmes avaient été posés au concile de Bâle. Charles VII convoqua son clergé pour en étudier les éléments. On vit à cette assemblée extraordinaire cinq archevêques, vingt-cinq évêques et un grand nombre de prélats. L'assemblé s'ouvrit le 1er mai 1438 mais elle ne fut complète que le 5 juin. Des envoyés avaient été dépêchés de Bâle et de Ferrera, porteurs de requêtes. On leur donna aux uns et aux autres, de bonnes paroles et on fit un examen minutieux des décrets du concile de Bâle, afin de juger s'ils étaient bien conformes aux exigences de l'Église gallicane. Tous les membres de l'assemblée étaient d'accord pour considérer les libertés de l'Église gallicane non comme des privilèges, mais comme des droits “acquis”, mais comme des droits primordiaux, essentiels, nécessaires à l’Église de France et à toute Église qui veut demeurer à l'abri des atteintes que tous les papes s'efforcent trop souvent de lui porter.

Le travail fut terminé le 7 juillet, et c'est le même jour que Charles VII publia l'édit célèbre intitulé : “Pragmatique sanction sur l'autorité 
des conciles généraux, la collation des bénéfices, élections expectatives, appellations, annotés, etc.”

Le préambule de ce document important constitue un violet et amer réquisitoire contre les abus du saint-Siège. Les Églises de France sont victimes de cupidités insatiables. Des "usurpations très graves" sont commises et d'"intolérables entreprises" accomplies. L'argent du royaume est entraîné "en des régions étrangères". D’autre part, le culte du Christ s'atténue : c'est la faveur qui règle l'avancement des clercs. Il convient donc de recourir, pour les maux de l’Église, aux remèdes indiqués par le concile de Bâle.

Les deux premiers articles de la pragmatique déclarent que les conciles sont supérieurs à toute autre autorité en matière de foi et de discipline. Un concile œcuménique devra être convoqué tous les dix ans.

Les autres articles interdisent la fête des fous et les spectacles donnés dans les églises, limitent l'incontinence des clercs. Mais les articles qui intéressent surtout le clergé gallican sont ceux qui diminuent, dans de notables proportions, les droits du saint-Siège en matière de bénéfice ecclésiastiques et de procès. Évêques et abbés devront être élus par les chapitres et les couvents. Le pape n'aura plus le droit de consacrer le nouvel élu, sauf le cas où celui-ci se trouverait à Rome au moment de son élection. La pragmatique déclare supprimer les annates et le pape ne pourra juger les procès en appel qu'une fois que les plaideurs auront épuisé toutes les juridictions.

Faut-il ajouter maintenant que cette charte du clergé gallican ne fut pas toujours appliquée ? Charles VII fit lui-même des entailles chaque fois qu'il eût intérêt à se faire venir du saint-Siège.

C'est l'histoire continuelle des rapports entre la royauté française et la papauté. Aux exigence de la foi et des principes se mêlent des raisons d'ordre politique ou d'intérêt privé qui les dénaturent. C'est ainsi que la pragmatique fut bientôt viciée de par la volonté même du roi de France. Elle donnait aux chapitres le droit d'élection des évêques et des abbés. Les rois jugèrent bientôt que l'autorité des chapitres en se- 
rait trop considérablement accrue et qu'elle limiterait la leur et ils s'entendirent avec Rome pour défaire ce qu'ils avaient fait.

En 1463, Louis XI déclare la pragmatique abolie. Elle n'avait d’ailleurs jamais été reconnue par le saint-Siège.

Cette abolition fut complétée par la convention de 1470. Il est vrai que le roi obtenait du pape l'engagement de ne nommer que des Français et de tenir compte de la recommandation du roi. Nous entrons dans une période où la papauté reprend progressivement son influence. C'est le moment où Machiavel, alors ambassadeur en France (1501), écrivait au cardinal d'Amboise : “Les Français n'entendent rien à la politique; autrement, ils ne laisseraient pas l'Église si grande.”

\section{Le concordat de Bologne.}

En 1515, François 1er se rencontre à Bologne avec le pape Léon X. Un accord s'établit entre eux pour le gouvernement de l'église de France. L'année suivante, le concordat de Bologne est signé. Il consent l'abolition de la pragmatique sanction de Bourges. Le roi et le peuple se donnent réciproquement des attributions, qu'ils n'avaient pas eues jusque-là. Le roi se réserve la nomination des évêques et des abbés ; le pape institue les prélats et reçoit l'annate des biens ecclésiastiques. Par l'article 40 du traité de 1516, les prélats ont l'obligation, dès qu'ils sont institués, de payer au pape une somme équivalente au montant des revenus annuels de l'église ou de l'abbaye.

C’est cette contribution flétrie et supprimée par la pragmatique qui a reçu le nom d'annate.

Le résultat de cet accord de la royauté française avec Rome fut d'établir en France un pouvoir étranger, favorable, certes, dans certains cas, aux intérêts personnels du roi, mais nuisible au pays. Des abus furent dénoncés sous Henri II, dans les perceptions romaines. De 
multiples compétitions se produisirent, lorsqu'un bénéficiaire, élu d'après les canons des conciles, se trouvait en rivalité avec celui qu'avait nommé le roi. On portait alors l'affaire devant le grand conseil. Et quels abus n'entraîne point parfois la nomination royale ! Les évêques, abandonnant le soin de leurs diocèses laissèrent leurs vicaires les administrer et ils allèrent aux Tuileries se confondre dans la mêlée des courtisans. Le roi tira de ce clergé domestique d'excellents fonctionnaires. Napoléon recherchera plus tard dans un concordat calqué sur celui de Bologne les avantages qu’y avait trouvé François I ${ }^{\mathrm{er}}$.

Les grands corps de l'État - parlement, Université - avaient vu le danger et s'étaient opposés à l'enregistrement du Concordat, puis à son exécution. Nous empruntons à la Bibliothèque historique le texte des protestations du parlement :

"La cour, toutes chambres assemblées, voyant et considérant les grandes menaces dont on usait à son égard, ayant tout lieu d'appréhender sa propre dissolution, qui entraînerait celle du royaume, craignant que si aucunes étaient suscitées à l'occasion du délai de la publication du Concordat, on ne lui impute des malheurs qui pourraient arriver ; craignant encore que les alliances faites ou à faire avec les autres princes chrétiens ne fussent rompues ou empêchées par le refus d'enregistrement, et après que la cour a fait tout ce qui lui était humainement possible pour obvier à cette publication et enregistrement, par devant et en présence de sir Michel Blondel, évêque et duc de Langres, pair de France, comme authentique personne, elle a protesté et proteste, tant en général qu'en particulier, conjointement et divisement, qu'ils n'étaient et ne sont en liberté et franchise, et si la publication a lieu, ce n'était ni de l'ordonnance ou du consentement de la cour, mais par le commandement du roi, force et impression cidessus déclarées, que ce n'était point leur intention de juger les procès conformément au Concordat, mais de garder, observer comme auparavant les saints décrets de la pragmatique sanction, dont le procureur du roi aurait appelé, tant pour et au nom de la cour, que de tous les sujets du royaume ; la cour adhérant à ce premier appel et y persistant, appelle de nouveau au pape mieux informé, au premier concile général et à celui et à ceux auxquels il appartiendra.” 
Si le Concordat, contre lequel le pouvoir laïque et national protesta dans les termes que nous venons d'indiquer, favorisa l'existence d'un épiscopat de courtisans, il y eu cependant dans le clergé français une majorité d'évêques et de prélats attachés aux libertés gallicanes qui unirent leur protestation à celle de l'Université et du parlement. Il suffit de lire les Mémoires du clergé pour en être convaincu. On y voit que “ l’Église de France n’a jamais approuvé le concordat de 1516, et ne le reconnaît pas comme règle de discipline”.

Mais un nouveau fait va contribuer à atténuer, pour un temps assez long, les protestations du clergé gallican. Les abus de la cour de Rome, les vices et les dépravations du clergé de la renaissance italienne, la domination envahissante de la papauté avaient permis aux tendances des chrétiens évangélistes de se traduire dans une doctrine nouvelle, qui va avoir ses savants, ses héros et ses martyrs. Le protestantisme profite du besoin général qu'on avait au quatorzième siècle d'une vie religieuse plus réelle et plus profonde que celle des du catholicisme romain, immobilisé dans le dogme et dans la pratique minutieuse des cérémonies dont les sens échappait à la plupart de ceux qui s'y soumettaient par contrainte. La religion avait été transformée par les papes en un simple moyen de gouvernement ; Luther affranchit la conscience. En Vingt années, la moitié de la chrétienté rompt avec le chef et les dogmes du catholicisme.

Il y eu un protestantisme français. Il naquit parmi les humanistes, impressionnés par la lecture de l’Évangile, retrouvé parmi les textes de l'antiquité grecque et latine. “ Ils étaient habitués à un culte qui attribuait une importance capitale aux observances, aux rites, aux pratiques, qui réclamait leurs dévotions pour la vierge, les saints et les saintes ; ils lisent le texte même du nouveau Testament et tout disparaît : il ne reste que Jésus-Christ : lui, toujours lui !”

Le clergé gallican se sentit anéanti par le développement de l'idée évangélique et le résultat fut qu’il resserra ses liens avec Rome. On le verra bientôt lorsqu'il s'agira de “recevoir” en France les décrets du concile de Trente.

Ce concile avait été réuni, sur l'initiative de la papauté, pour tenter de rétablir l'unité brisée de l'Église catholique (1545-1563). On 
s'attacha, d'une part, à maintenir la pureté du dogme, et, d'autre part, à rétablir la discipline au sein du clergé et à en réformer les mœurs. Pour donner aux décrets de ce concile une force inusitée, on décida que les décrets concernant le dogme exigeraient la foi et que seraient déclaré hérétiques ceux qui refuseraient à y souscrire. Outre ces graves décisions, le concile avait également décidé que le jugement des évêques serait réservé au pape, que les juridictions ecclésiastiques conserveraient la faculté de prononcer des peines temporelles amende ou emprisonnement - et que leurs privilèges seraient maintenus aux ordres religieux.

La "réception" du concile de Trente en France occasionna de multiples péripéties. On examina la question en conseil du roi. Les décrets furent furent vivement critiqués par le chancelier de l'Hôpital qui les accusait de "trahir les libertés de l’Église gallicane”. Catherine de Médicis, alors régente, qui voulait ménager les Huguenots, promit "de faire exécuter le concile en particulier, sans le publier en général”. Cette réponse politique marque le début des guerres de religion.

Elles avaient eu déjà leurs prodromes tragiques. A Paris, les premiers bûchers furent montés de 1525 à 1528, bien avant, par conséquent, le concile de Trente. François $\mathrm{I}^{\mathrm{er}}$, qui venait d'unir son action à celle de la papauté, était hésitant. Le 24 juin 1539, on publie l'édit général contre les luthériens, Étienne Dolet, condamné comme athée à l'occasion d'un dialogue de Platon, monte au bûcher le 3 avril 1546 ; la chambre ardente, instituée sous Henri II pour expédier les procès d'hérésie, émet quatre cent trente-neuf sentences, dont soixante condamnations capitales. Et les édits se succèdent. Le chef d'œuvre classique, le monument de cette législation est l'édit de Chateaubriand (27 juin 1551), véritable code de la persécution. Tout est réglé dans ces quarante-six articles avec une précision juridique, depuis la surveillance minutieuse de l'imprimerie jusqu'à la dénonciation de ceux qui lisent la Bible. Interdiction de tout emploi public, même d'une place de régent, à quiconque ne produirait pas un certificat de bon catholique ; ordre aux procureurs généraux de se livrer à une enquête sur les magistrats et officiers de justice de tout rang, pour sévir contre ceux qui seraient suspects de négligence dans la punition des luthériens ; défense aux simples particuliers, que la pitié pourrait égarer, d'adresser aucune supplique ou demande de grâce en faveur d'un hé- 
rétique; interdiction, sous les peines les plus graves, de favoriser l'émigration à Genève ; "et, pour ce que plusieurs sans aucun savoir, en prenant leurs repas ou bien en allant aux champs, parlent, devisent et disputent des choses concernant la foy et les cérémonies de l’Église et font des questions curieuses et sans fruit ; défense à toutes personnes non lettrées, de quelque estat qu'ils soient, de ne faire plus d'ores en avant telles propositions, questions et disputes; commandement très exprès à tous d'aller assidûment à la messe avec due révérence et démonstration“. Enfin comme sanction, outre les pénalités habituelles, une disposition nouvelle "le dénonciateur recevra le tiers des biens confisqués au dénoncé“ (L’Histoire universelle de Lavisse et Rambaud). Il y a plus : un autre édit, celui de Compiègne (1557), unifie la peine : ce sera la mort.

En 1555, l’Église réformée de Paris s’était fondé. En mai 1558 elle réunit 5000 à 6000 personnes au Pré-aux-Clercs et, dans cette assemblée, on distingua deux neveux du connétable de Montmorency, d'Andelot et l'amiral de Coligny. En 1559, eut lieu le synode des Églises réformées de France.

Parallèlement à ce mouvement ascendant de l'idée protestante, se produit, au sein du parlement, un mouvement d'idées qu'il est nécessaire de signaler, car il révèle une nouvelle conception du droit et il prépare les vues juridiques d'après lesquelles nous envisageons aujourd'hui le problème des rapports de l'Église et de l'État, du spirituel et du temporel. Le Tiers apparaît, avec ses formes de pensées, ses notions juridiques, sa conception particulière de la vie. C’est Pierre Séguier et de Harlay, à la Chambre de la Tournelle, se refusant à prononcer la peine de mort pour choses de religion. Audacieuse prétention ? C’est Anne du Bourg qui, en une séance solennelle des Chambres réunies - le roi est présent - revendique la liberté de pensée : “Ce n'est pas chose de petite importance de condamner ceux qui, au milieu des flammes, invoquent le nom de Jésus-Christ !” Anne du Bourg est envoyée au bûcher. Après la mort de Henri II, une trêve se produit. Les États généraux sont convoqués, le Tiers formule ses prétentions : les causes de la détresse publique sont les richesses et le luxe du clergé. Les nobles et les communs sont d'accord pour émettre l'avis que l'on rembourse les dettes publiques en vendant les biens de l'Église, estimés à 120 millions de livres. Le connétable et le duc de Guise de- 
mandent à l'église 15 millions de livres. Elle offre 9 millions et demi, qui seront payés en six ans et elle remboursera les dettes de l'Hôtel de Ville de Paris. En général, le Tiers est favorable aux protestants. Entre les extrêmes, se place le parti des Politiques, qui prépare notre doit moderne. A une époque où, catholiques et protestants, d'accord en cela avec l'opinion publique, jugeaient impossible l'existence simultanée dans un pays de deux religions, dès 1504 (???), les Politiques émirent cette idée que c'est le rôle de l'État de garder la neutralité, d'accorder aux deux cultes m'existence légale et de faire respecter le droit de chacun. Suprême ironie à l'instant où l'on assiste aux massacres de la saint-Barthélémy que célèbre le pape par des actions de grâce, où le dominicain Jacques Clément poignarde le roi Henri II (ou III ?), coupable de faiblesse à l'égard des hérétiques, où Henri IV doit abjurer afin de régner.

Le premier acte politique de Henri IV fut de se réconcilier avec le saint-Siège, en promettant de "faire observer le décret du concile de Trente, excepté aux choses qui ne se pourront exécuter sans troubler la tranquillité”. Le deuxième acte fut l'édit de Nantes (13 avril 1598).

Cet édit célèbre, après avoir constaté que le culte catholique était rétabli là où il avait été supprimé et après avoir reconnu au clergé la totalité de ses biens et droits antérieurs, assurait à la religion réformée la légalité. Il ne garantissait cependant l'exercice du culte que là où il existait déjà. Il fut donc, comme auparavant, défendu de pratiquer le culte réformé à Paris, ainsi que dans un certain nombre de villes d'où les protestants avaient été exclus par de récentes capitulations. Ils y purent cependant demeurer à la condition d'avoir leur prêches dans les faubourgs. Dans ces dispositions accessoires, les droits civils étaient reconnus aux protestants, ainsi que l'accès des emplois publics, universités, collèges et hôpitaux. Amnistie générale était proclamée en faveur de quiconque avait été condamné pour sa foi.

Le constant effort de la papauté va tendre maintenant à rendre éphémère cette victoire de l'esprit laïque. L'édit autorise le clergé à reprendre, moyennant indemnité, tous ceux de ses biens qui, depuis quarante ans, avaient été aliénés. ce travail de reconstitution territoriale occupa d'abord les ressources d'ingéniosité de la diplomatie catholique. Elle sait quelle influence décisive a l'argent, que c'est le nerf 
non seulement de la guerre, mais de toutes les luttes, politiques ou idéales et qu'avec de l'argent, à propos employé, on peut agir efficacement sur les rois eux-mêmes.

Si l'on envisage, d'une façon superficielle, le résultat obtenu par la diplomatie ecclésiastique, le grand événement de la révocation de l'édit de Nantes, apparaît dans un énorme relief, et d'autant plus important et décisif que les ruines, morales et matérielles, qu'il a causées, ont été plus grandes.

Mais cette révocation de l'édit de nantes, si l'on étudie les événements qui l'ont précédée, accompagnée et suivie ne peut pas être considérée comme une victoire de la papauté. Elle fut l'acte nécessaire, inévitable, de celui qui, pour asseoir davantage sa domination absolue, voulut réaliser l'unité de l'Église de France, croyant, comme il était encore commun au dix-septième siècle, que l'on peut, par la persécution, extirper la foi des consciences, et éteindre la pensée dans les cerveaux.

Le concordat de Bologne, fruit d'un accord entre la royauté française et la cour de Rome, avait enlevé la nomination des évêques et des prélats au clergé pour la confier au roi. En échange de cet abandon de privautés, qu'elle avait, elle aussi, revendiquées, la papauté avait reçu des compensations pécuniaires.

Ce nouveau privilège de la royauté permit aux souverains français, et aux ministres, qui conseillaient leur politique, d'élever aux dignités importante de l'épiscopat des hommes dont le dévouement et la fidélité pouvaient paraître sûrs. L’épiscopat n’y gagna point en dignité. Un clergé domestiqué permit à Louis XIV de triompher plus facilement dans ses conflits avec Rome. Il prétendait devenir le chef incontesté de l'Église de France. Sa politique fut antiromaine, car il voulait annihiler toute autre autorité que la sienne. Elle devait être antiprotestante, pour que son église fut plus forte, en étant unifiée, et que sa puissance temporelle s'accrût de la force agissante d'une foi incontestée.

Cette réalisation totale du gallicanisme, qui se produisit sous le règne de Louis XIV, fut préparé par l'action des pouvoirs qui se succédèrent en France depuis la mort de Henri IV. 
Ce fut, en premier lieu, sous la régence de Marie de Médicis, l'action des États généraux de 1614, où le tiers état, au premier article de son cahier, posait comme loi fondamentale “qu'il n'y a personne en terre, quelle qu'elle soit, spirituelle ou temporelle, qui ait aucun droit sur le royaume, le roi ne tenant sa couronne que de Dieu seul.” ce fut ensuite Richelieu qui, dès son arrivée aux affaires, se trouva en opposition avec le pape et inaugura une politique essentiellement laïque. Sous son inspiration, ou du moins sans qu'il y eût opposition de sa part, des livres son imprimés où l'on se plaint de “l'oppression que le pouvoir des papes fait subir à la France”. Il interdit aux prédicateurs toute allusion désagréable au gouvernement et, au besoin même, il leur fait obligation d'en faire l'éloge. Une assemblée de prélats se réunit en 1641. Il l'épure, lorsqu'elle lui parait dangereuse. Deux archevêques et quatre évêques, opposés à ses projets, doivent quitter la ville ; les lettres royales qui leur enjoignent de partir se terminent ainsi : “Je prie Dieu, monsieur l'archevêque, qu'il vous donne une meilleure conduite.”

Le jour où, devenu majeur, Louis XIV prit en mains les rênes du gouvernement, l'archevêque de Rouen, Harley de Champvallon, fut reçu par le roi : "Sire, lui dit-il, j’ai l'honneur de présider à l'assemblée du clergé de votre royaume. Votre majesté m’avait ordonné de m'adresser à $\mathrm{M}$. le cardinal Mazarin pour toutes les affaires ; le voilà mort; à qui Sa Majesté veut-elle que je m'adresse à l’avenir ?“ “- A moi, monsieur l’archevêque, je vous expédierai bientôt.”

Ce fut lui, en effet, qui expédia toutes les affaires de son royaume. On connaît la formule : “L’État, c’est moi !” Il l'étendit aux choses de l'Église et Bossuet légitima ses prétentions dans des écrits où aboutissent, pour se transformer en un système cohérent, toutes les tendances qui s'étaient fait jour dans les assemblées de la bourgeoisie et qui affirmaient la royauté de droit divin, la supériorité des conciles sur les papes et l'indépendance du clergé français vis-à-vis de la cour de Rome.

Il devint impossible à un évêque d'établir une correspondance avec la cour de Rome, sans avoir au obtenu préalable une autorisation régu- 
lière émanant du roi. L'usage des relations directes entre Rome et les évêques de France se perdit bientôt. Le clergé devient un corps de fonctionnaires, sur lequel Louis XIV conserve une autorité sans limites, ce qui fait écrire à Fénelon que "le roi est beaucoup plus chef de l’Église que le pape... L’Église de France, privée de la liberté d'élire des pasteurs, est un peu au-dessous de la liberté dont jouissent les catholiques sous l'empire du Grand Turc."

Louis XIV pensait que le roi, représentant l’État, était le seul propriétaire de la fortune publique. Il en résultait pour lui le droit de disposer librement des biens ecclésiastiques. C’est lui, d'ailleurs, qui répartissait les bénéfices. Chaque fois qu'il devait communier le lendemain il se mettait d'accord avec son confesseur pour donner des titulaires aux postes vacants. On remplissait la “feuille des bénéfices” qui était soumise au pape, par simple formalité.

Le souverain absolu intervint aussi dans les affaires de l'Église pour régler, ou plutôt pour achever d'anéantir son droit séculaire de juridiction. Le droit à une juridiction temporelle ecclésiastique datait de l'empereur Constantin. Au douzième siècle, en France, cette juridiction appartient non seulement aux évêques, mais aux autres ecclésiastiques : archidiacres, archiprêtres, chapitres, abbés des monastères. Elle s'exerçait au moyen des cours de chrétienté, qu'on appela par la suite des officialités.

La compétence des ces cours là était très étendue. Il suffisait d'être tonsuré pour en être justiciable et les historiens constatent que vers 1288, il y eut jusqu'à 20000 marchands qui "se faisaient donner par les barbiers couronne de clercs, pour profiter d'une procédure qui, à cette époque là, était plus raisonnable que celle de la justice féodale”. Outre les clercs, les veuves, les orphelins, les croisés, les écoliers des universités étaient, dans certain cas, soumis à leur compétence.

Les matières de la juridiction ecclésiastique avait à connaître étaient relative à la foi, à la discipline ecclésiastique. Dans le domaine temporel, elles jugeaient tous les procès qui avaient trait au mariage, aux propriétés du clergé, aux testaments, aux conventions confirmées par serment. Elle jugeait encore les crimes contre la religion, tels le sacrilège, le blasphème, la sorcellerie et tous les crimes commis dans des 
lieux saints. Elle édictait des peines, qui consistaient en des pénitences, emprisonnement et amendes, lesquelles étaient attribuées à des œuvres de piété. Elle excommuniait fréquemment aussi. Mais, sous prétexte que Ecclesia abhorret a sanguine, elle transmettait aux cours séculières les coupables qui méritaient la peine de mort ou les mutilations douloureuses.

Cette juridiction fut d'abord combattue par les barons féodaux ; de Philippe le Bel à François I ${ }^{\mathrm{er}}$, sa compétence fut réduite. Des édits avaient transmis aux juges séculiers la connaissance des questions immobilières, des restrictions se trouvent réunis dans l'édit que prit Louis XIV en 1695 et qui traite en même temps de l'érection des cures, des fabriques, de l'entretien des églises et des cimetières, de la surveillance des maîtres et des maîtresses d'école par le clergé, des prières publiques.

L'Église fut définitivement soumise à la justice civile, car, d'autre part, au moyen de l'appel comme d'abus, les juges séculiers pouvaient s'immiscer dans les affaires spirituelles elles-mêmes. Cette théorie de l'appel comme d'abus avait été élaborée par les légistes. Tout acte qui semblait contraire aux libertés de l'Église gallicane put être supprimé par le parlement comme abusif. L'auteur de cet acte pouvait même être condamné à l'amende et à la saisie de son bénéfice. Et Fénelon de s'écrier :" Ce n'est plus de Rome que viennent les empiétements et les usurpations ; le roi est en réalité plus maître de l’Église gallicane que le pape ; l'autorité du roi sur l’Église a passé aux mains des juges séculiers ; les laïques dominent les évêques.”

Louis XIV avait atteint son but. Il avait un clergé impuissant à réagir contre son empreinte. On constata à quel point il était indépendant de Rome, au moment du conflit avec la papauté, à propos du droit de régale.

En vertu de ce droit séculaire, le roi de France percevait à la place des évêques décédés ou démissionnaires, les revenus de leurs diocèses, tout le temps de leur vacance, et ils nommaient aux bénéfices dont l'évêque avait, comme tel, la collation. 
Il est juste d'ajouter qu'à plusieurs reprises, le saint-Siège avait protesté contre la deuxième de ces prérogatives. D’autre part, certains diocèses s'étaient rachetés à prix d'argent et il y en avait un certain nombre qui n’avaient jamais été soumis au droit de régale.

Cet édit amena les protestations de deux évêques atteints. Les autres ne protestèrent point. Innocent XI se rangea du côté des plaideurs ; mais à la suite de diverses péripéties, une assemblée du clergé réunie à paris, au couvent des Grands-Augustins, confirma la régale universelle (1681)

\section{La déclaration de 1682}

Le pape refuse de s'incliner ; il annule les actes de l'assemblée générale du clergé de France et demande aux évêques de se rétracter ; mais avant que sa lettre soit parvenue à destination, le clergé de France a signé une déclaration, divisée en quatre articles et rédigée de la main même de Bossuet. En voici le texte. Il est important, car cette déclaration constitue la charte essentielle du clergé de France.

"Plusieurs personnes s'efforcent en ce temps-ci de ruiner les décrets de l'Église gallicane et ses libertés, que nos ancêtres ont soutenu avec tant de zèle, et, de renverser leurs fondements appuyés sur les saints canons et la tradition des pères. D'autres, sous prétexte de les défendre, ne craignent pas de donner atteinte à la primauté de saint-Pierre et des pontifes romains, ses successeurs, instituée par Jésus-Christ, et à l'obéissance que tous les chrétiens leur doivent, et de diminuer la majesté du saint-Siège apostolique, respectable à toutes les nations où la vraie foi est enseignée et où l'unité de l'église se conserve. D'un autre côté, les hérétiques mettent tout en œuvre pour faire paraître cette autorité, qui maintient la paix de l'Église, odieuse et insupportable aux rois et aux peuples, et pour éloigner par ces artifices les âmes simples de la communion de l’Église leur mère, et par là de celle de JésusChrist. Afin de remédier à ces inconvénients, nous, archevêques et évêques assemblés à paris par ordre du roi, représentant l'Église gallicane avec d'autres ecclésiastiques députés, avons jugé, après mûre 
délibération, qu'il est nécessaire de faire les règlements et la déclaration qui suivent :

"Que saint-Pierre et ses successeurs, vicaires de Jésus-Christ, et que toute l'Église même, n’ont reçu d'autorité de Dieu que sur les choses spirituelles et qui concernent le salut, et non point sur les choses temporelles et civiles ; Jésus-Christ nous apprenant lui-même que son royaume n'est pas de ce monde, et, en un autre endroit, qu'il faut rendre à César ce qui appartient à César, et à Dieu ce qui appartient à Dieu. Qu'il faut s'en tenir à ce précepte de saint Paul : que toute personne soit soumise aux puissances supérieures, car il n'y a point de puissance qui ne vienne de Dieu, et c'est lui qui ordonne celles qui sont sur terre : c'est pourquoi celui qui s'oppose aux puissances résiste à l'ordre de Dieu.

"En conséquence, nous déclarons que les rois ne sont soumis à aucune puissance ecclésiastique par l'ordre de Dieu, dans les choses qui concernent le temporel, qu'ils ne peuvent être déposés directement ou indirectement par l'autorité des chefs de l'Église ; que leurs sujets ne peuvent être exemptés de la soumission et de l'obéissance qu'ils leur doivent, ou dispensés du serment de fidélité ; que cette doctrine, nécessaire à la paix publique, et autant avantageuse à l'Église qu'à l'État, doit être tenue comme conforme à l'Écriture sainte et à la tradition des pères de l'Église et aux exemples des saints.

"Que la plénitude de puissance que le saint-Siège apostolique et les successeurs de saint-Pierre, vicaires de Jésus-Christ, ont sur les choses spirituelles est telle néanmoins que les décrets du saint concile oecuménique de Constance, contenus dans les sessions 4 et 5, approuvés par le saint-Siège apostolique et confirmés par la pratique de toutes l'Église et des pontifes romains, et observés de tout temps religieusement par l'Église gallicane, demeurent dans leur force de vertu, et que l'Église de France n'approuve pas l'opinion de ceux qui donnent atteinte à ces décrets ou les affaiblissent, en disant que leur autorité 
n’est pas établie, qu'ils ne sont point approuvés ou que leur disposition ne regarde que le temps du schisme.

“Qu'il faut régler l’usage de l'autorité apostolique par les canons faits par l'esprit de Dieu et consacrés par le respect général de tout le monde; que les règles, les mœurs et les constitutions reçues dans le royaume et dans l'Église gallicane doivent avoir leur force et leur vertu et que les usages de nos pères doivent demeurer inébranlables ; qu'il est de même de la grandeur du saint-Siège apostolique que les loi et les coutumes établies du consentement de ce siège et des Églises aient l'autorité qu'elles doivent avoir.

\section{IV}

"Que, quoique le pape ait la principale part dans les questions de foi, et que ses décrets regardent toutes les Églises, et chaque Église en particulier, son jugement n'est pas réformable, si le consentement de l’Église n’intervient.

"Ce sont les maximes que nous avons reçues de nos pères et que nous avons arrêté d'envoyer à toutes les Églises gallicanes et aux évêques que la saint-Esprit y a été établis pour les gouverner, afin que nous disions tous la même chose, que nous soyons tous dans le même sentiment et que nous tenions tous la même doctrine.”

Le parlement de Paris enregistre le lendemain un édit par lequel il était défendu d'enseigner ou d'écrire rien qui fut "contraire à la doctrine contenue dans la déclaration”. Désormais les quatre articles devront être enseignés dans les séminaires.

Innocent XI, en réponse à la déclaration, refusa l'institution canonique aux évêques qui, étant prêtres, auraient assistés, comme délégués à l'assemblée de 1682 et signé la déclaration. Or, comme Louis XIV se gardait bien d'en nommer d'autres, il arriva qu'en janvier 1688, trente-cinq églises cathédrales se trouvaient sans pasteurs. 
Innocent XI meurt en 1689. Son successeur, Alexandre III, déclare nulle la déclaration de 1682. Le conflit devient de plus en plus aigu ; mais il meurt à son tour et, avec Innocent XII l'entente a lieu. Louis XIV donnera des ordres pour que l'édit ne soit pas observé et le pape s’inclinera devant les volontés du roi, en ce qui concerne le droit de régale.

Cependant, les parlementaires n'abdiquèrent pas. Ils ne cessèrent d'appliquer, dans leur jurisprudence, les quatre articles de la déclaration. Au dix-huitième siècle, ils reparaîtront dans les édits royaux. On les verra aussi rappelés dans les articles organiques du Concordat de 1801.

Trois ans après la déclaration du clergé gallican, le 17 octobre 1685, Louis XIV signait l'édit de révocation de celui de Nantes, corollaire de la déclaration et qui devait, dans l'esprit du roi, réaliser l'unité du culte en France. Les réformés furent autorisés à demeurer en France. Autorisation précaire, puisque tout culte public leur était interdit et que leurs enfants devaient être élevé dans le catholicisme. Il avait été ordonné précédemment que les notaires et huissiers protestants abandonnent leur charges à des catholiques (1682) ; que les officiers protestants de la maison du roi devraient abandonner leur place ou se convertir au catholicisme (1683) ; que les épiciers fermeraient leurs boutiques, sous peine de $3000 \mathrm{fr}$. d'amande. Une déclaration royale avait interdit aux sages-femmes protestantes "de se mêler d'accoucher”.

Par le fait de ces décisions, 10000 familles protestantes s'étaient expatriées avant la révocation. Vauban estime à 100000 le nombre des protestants qui désertèrent la France à la suite de l'édit, avec 60 millions de francs. Cette exode causa la ruine du commerce ; les flottes ennemies furent grossies de 9000 matelots, les meilleurs du royaume; leurs armées de 600 officiers et de 12000 soldats plus aguerris que les leurs.

Cette révocation avait été préparée par une action patiente et minutieuse du clergé français. Louis XIV n’était encore qu’un enfant qu'il entendait Choiseul, l'évêque de Comminges, lui dire : "Nous ne demandons pas à Votre Majesté de bannir encore de votre royaume cette 
malheureuse liberté de conscience qui détruit la liberté des enfants de Dieu, s’il n'est en votre pouvoir d'étouffer l’hérésie d'un seul coup, de la faire du moins périr peu à peu.”

Le clergé réclama d'abord que l'on observât strictement l'édit de Nantes, sans tenir aucun compte des événements survenus depuis sa promulgation. Louis XIV fit envoyer des commissaires dans les provinces. Des temples furent démolis sous le prétexte qu'ils se trouvaient sur des lieux où le culte public n'avait pas été fait en l'année 1593 et 1597, ainsi que l'indiquait l'édit de Nantes. Le 17 juin 1681, une déclaration paraît "portant que les enfant de la R.P.R. pourront se convertir à l'âge de sept ans et défend à ceux de la R.P.R. de se faire élever dans les païs étrangers”. On n'a jamais pu noter pareille atteinte à l'autorité du père de famille. Faut-il parler des dragonnades qui suivirent? Les protestants avaient huit jours pour devenir catholiques ; ensuite ils étaient chargés par des troupes, que conduisaient des évêques.

Louis XIV avait voulu réaliser l'unité du culte français. Il avait également pris part à la lutte contre les jansénistes - Port-Royal avait été rasé - et aussi contre les inoffensifs quiétistes. La conséquence inévitable de cette politique se produira bientôt: aucun pouvoir humain n’empêchera de naître la philosophie du dix-huitième siècle.

"La politique inepte du gouvernement eut deux conséquences également funeste pour la royauté et pour l'église, écrit M. Debidour, dans l'introduction de son important et consciencieux travail sur le sujet qui nous occupe (Histoire des rapports de l'Église de l'État en France, de 1789 à 1870 - Armand Colin, Paris) ; La première fut d'enhardir la magistrature au point que, dès le milieu de dix-huitième siècle, elle pût ébranler le vieil édifice de l'absolutisme monarchique et que, par le seul exemple de ses résistances, elle rendit la Révolution inévitable ; la seconde fut de rendre ridicules et odieuses les querelles théologiques, les persécutions, les d'affaiblir singulièrement la foi dans les classes supérieures et moyennes de la nation, de faire enfin le jeu des philosophes qui s'emparèrent dès lors de l'opinion et familiarisèrent bientôt beaucoup d'esprit avec l'idée de rejeter non seulement l'infaillibilité du pape, mais toute autorité sacerdotale, toute religion révélée. ce n'est plus dans l'Augustinus ou dans les Réflexions mora- 
les de l'ancien testament que l'on va chercher des arguments : c'est dans l'Encyclopédie et dans le Dictionnaire philosophique. Le mot d'ordre n'est plus de faire son salut, mais de fonder la liberté."

Les dernières années du règne de Louis XIV illustrent cette vérité démontrée par l'histoire, qu'un pouvoir temporel ne peut être que l'ennemi de Rome ou son jouet. Louis XIV, on vient de le voir, s'était rapproché de Rome, en deux circonstances ; Rome empiéta. Le jansénistes avaient contesté l'infaillibilité du pape ; la compagnie de Jésus, émanation agissante de la papauté, convainquit le souverain absolu de la nécessité d'une publication urgente de la célèbre bulle Unigenitus (1713). Or, cette bulle ne conseille rien moins que l'obéissance aveugle aux ordres du saint-Siège que Louis XIV avait mis tant d'acharnement à combattre. Quelques temps après, les jansénistes en ayant appelé des décisions du saint-Siège au concile, celui-ci ne put avoir lieu. Le pape reprenait la prééminence perdue.

Le parlement repoussa la bulle et, lorsque sous le règne de Louis XV, par ordre de l'archevêque de Paris, plusieurs curés exigèrent des mourants la déclaration qu'ils adhéraient à la bulle Unigenitus ou un billet de confession provenant d'un prêtre non janséniste, le parlement invita l'archevêque à retirer son mandement. Le roi casse l'arrêt du parlement. Mais celui-ci ne se tient pas pour battu, et le conflit se poursuit et s'aggrave. Louis XIV en arrive à exiler les membres du parlement (1713); mais aucune juridiction ne veut s'incliner devant les décisions du roi. Finalement Louis XIV cède au parlement. Billets de confession, refus des sacrements sont interdits, et Benoît XIV déclare que les ordonnances de l'archevêque ne seront applicables qu'à ceux qui seraient "publiquement et notoirement réfractaires à la bulle Unigenitus” (1756). Le parlement a triomphé.

Le triomphe s’accompagne d'une réaction contre les jésuites. Gallicans, philosophes, encyclopédistes, sociétés secrètes se liguent contre eux. La faillite du P. Lavalette, ruiné à la Martinique, faillite dont les jésuites se refusent à solder le déficit, permet au procureur général du parlement de Paris d'examiner les statuts de l'influente compagnie. En 1764, elle est supprimée par un édit royal. En 1776, une commission, dite des réguliers, est nommée par le roi pour réformer "le clergé régulier”. Un édit du 24 mars 1778 prépare la disparition d’un grand nom- 
bre de monastères. Les protestants profitent de la détente générale ; l'édit de novembre 1787 leur rend l'état civil. Ce sont les signes avant-coureurs de la prochaine liquidation. Cependant le clergé romain est toujours le premier de la nation. Il est le plus riche, il est encore le puissant, au moment ou va s’ouvrir la période de la Révolution française.

\section{DE LA RÉVOLUTION AU CONCORDAT}

$\underline{\text { Retour à la table des matières }}$

La suppression de la dîme, dans la fameuse nuit du 4 août, inaugure, pour le clergé, un ordre social nouveau. L'histoire des discussions, qui agitèrent alors l'Assemblée nationale, est suffisamment connu et nous ne l'entreprendrons pas ici. On sait qu'après avoir affirmé solennellement les droits de l'homme, l'Assemblée, inquiète à l'annonce des troubles et des violences qui affligeaient les provinces, lasses d'être pressurées, dans un mouvement spontané déclara que l'impôt serait désormais payé par tous les membres de la nation, que les droits féodaux seraient rachetables, et que les servitudes seraient radicalement abolies.

Ces sacrifices, acceptés du clergé et de la noblesse par le souci de sauver du naufrage l'existence même de leurs ordres, provoquèrent un bel enthousiasme. Avec une égale sincérité, chacun affirmait son dévouement à la chose publique par l'abandon d'un de ses privilèges, d'un de ses droits séculaires. Il se produisit comme un entraînement à la renonciation. A deux heures du matin, tout était consommé. Aussitôt, les membres du clergé, se ressaisissant, accusèrent l'Assemblée de précipitation.

Le 11 août, Camus se vit obligé de combattre le maintien des Annates, réclamé par de prétendus banquiers "en cours de Rome”, qui 
en faveur de leur proposition se disaient partisan d'une entente entre la France et l'Italie. Camus déclara que les richesses expédiées à Rome étaient perdues pour la France.

La veille, Sieyès avait démontré qu'il avait été bien entendu, le 4 août, que la dîme appartenait, en toute légitimité, à l'État et que ce n'est point platoniquement que des sacrifices avaient été faits à l'intérêt national. Le projet d'arrêté destiné à sanctionner les décisions prises pendant la nuit du 4 août était en butte aux attaques sournoises de deux ordres qui s’étaient, contre eux-mêmes, dépouillés de leurs plus chers privilèges. Mais, en dépit de tous leurs efforts, la nation eut le dessus. Le 11, tous les articles furent décrétés.

Le régime féodal était à tout jamais anéanti. Les dîmes de toute natures se trouvaient détruites, "sauf à aviser aux moyens de subvenir d'une autre manière à la défense du culte divin”.

L'État paraissait donc, par cette formule, reconnaître une obligation le liant au clergé. Cependant, dans les écrits du temps, inspirés clairement par le tiers ordre, on lit que le prêtre doit vivre désormais de l'autel et que les fidèles doivent contribuer à la dot du pasteur. Assurément, la situation de l'État vis-à-vis du clergé n'apparaissait pas encore aux membres de l'Assemblée nationale sous un jour très clair.

Le tiers état réformateur se contentait du résultat positif atteint : 133 millions de livres, soit 250 millions de francs (1901), revenant à la partie la plus travailleuse de la nation, au lieu d'aller annuellement grossir les recettes du budget clérical.

Des obligations nouvelles, du fait même de cette suppression, liaient-elles l'État au clergé ? Rien ne paraît moins certain. mais il n'est pas moins vrai qu'une situation équivoque venait de surgir, situation qui durera jusqu'au 10 octobre, jour où Talleyrand spécifiera nettement les droits de la nation sur le clergé.

L'évêque d'Autun était partisan de l'accomplissement total des réformes. Il était d'avis que l'État devait assumer toutes les charges qui pouvaient le rendre tout-puissant. Mais l'état des finances n'était-il pas tel qu'on ne saurait sans imprévoyance l'engager dans une série 
illimitée d'innovations ? Et, puisque impérieuses sont les transformations de la société, à quelles ressources extraordinaires l’État a-t-il le droit de faire appel ?

Ce sont ces idées que Talleyrand développa, le 10 octobre, avec une clarté remarquable.

Ces ressources extraordinaires ? mais où les trouver, sinon dans les biens du clergé ? Et qu'on ne vienne point prétendre que l'Assemblée fera subir à cet ordre la faix d'une nouvelle charge. Les "charges politiques” ne peuvent être qu'allègrement consenties.

L’évêque d'Autun envisage ensuite les droits qu'a l'état de s’approprier les biens ecclésiastiques.

La nation souveraine peut sans conteste mettre la main sur les biens vacants des associations qu'elle juge inutiles. Cela est indiscutable. Peut-elle réduire le revenu des bénéficiaires vivants ? Oui, si elle laisse au clergé ce qui est nécessaire à sa subsistance. Le surplus, elle l'emploiera au soulagement des déshérités de la nature et de la fortune, se substituant, de cette manière, à l'Église qui, jusqu'alors, avait le soin de l'assistance et qui y était tenue selon l'intention première des donateurs du clergé.

La totalité des fonds du clergé s'élève à la somme de 70 millions et les dîmes, qui doivent être acquittées quelque temps encore, à 80 millions.

Une fois en possession de la fortune cléricale, c'est la subsistance de quatre-vingt mille ecclésiastiques qu'il faudra assurer. Talleyrand explique comment il entend les voies et moyens de cette opération.

Par la vente du capital, estimé 2 milliards, l’État rembourserait les rentes viagères et les rentes perpétuelles sur le roi. Le déficit serait comblé. Il resterait - 100 millions étant assurés au clergé - 35 millions pour former le premier fond d'amortissement, destiné à adoucir la prestation de la dîme jusqu'au jour où elle serait définitivement abolie. 
De nombreux applaudissements accueillirent la lecture de ce projet, dont l'impression fut ordonnée au nombre de 1200 exemplaires.

Cependant il ne devait pas être donné à l'évêque d'Autun d'attacher son nom à la réalisation de cette grande opération financière.

Il est indéniable que son rapport avait montré à tous l'opportunité de la réforme, mais la leur avait fait apparaître complexe, difficile, savante ; mais ce n'est point un tel langage qu'entend une assemblée politique. C'est ce que comprit Mirabeau avec son sens affiné de conducteur de majorités. Aussi, deux jours plus tard, le 12 octobre, inopinément, comme d'une manière épisodique, Mirabeau, en peu de mots, demande que la propriété du clergé fasse retour à la nation "à charge par elle de pourvoir à l'existence des membres de cet ordre“, et que la disposition de ces biens soit telle qu'aucun curé ne puisse avoir moins de 1200 livres avec le logement.

Le principe de la nationalisation était ainsi posé.

Quand, le lendemain 13, la discussion s'ouvrit, la droite fit remarquer qu'un tel procès de propriété ne devait se juger qu'à la dernière extrémité. Et les membres du clergé tentèrent l'impossible pour éluder la question.

Mais on alla aux voix et l'Assemblée décréta que la proposition de Mirabeau allait être examinée.

Camus affirma que l'État ne peut toucher aux propriétés de l’Église, sans s'exposer à détruire ce “corps social”. Plusieurs abbés s'essayèrent à prouver que la propriété du clergé ne peut être revendiquée par l'État, sinon contre tout droit et contre toute justice. L'abbé d'Eymar renforça son opinion de cette assertion que c'est vouloir porter atteinte à la religion que de salarier le clergé.

Mais Barnave revint au fait : la distribution des fonds assignés au service religieux appartient-elle à la nation? Il est deux sortes de biens : ceux qui ont pour source la nation et ceux qui viennent des fondateurs. Ces derniers appartiennent également de droit à la nation. 
Les fondations ayant pour double objet l'assistance et le payement d'un service public ne sont qu'un dépôt entre les mains du clergé. Et Barnave déclare que, sans le bon vouloir de l'État, le clergé ne pourrait manifester aucune activité propre ; les biens ecclésiastiques ne peuvent lui appartenir. Puis, quittant le domaine de la théorie, Barnave montre que l'État de chose national nécessite la nationalisation. La suppression des dîmes a dépouillé inégalement le clergé ; il y a là une injustice à réparer. Enfin, dernier argument, par la vente des immeubles de l’Église, l'État évite la banqueroute.

L’abbé Maury répliqua que l'Assemblée, en tolérant le procès de la propriété ecclésiastique allait au-devant d'un péril social ; à remonter à l'origine des propriétés, on aboutit à la loi agraire. En outre, c'est ébranler les assises de l'État, car si le clergé n'est pas propriétaire des biens fonds, s’il est doté par le fisc, au premier revers dans les finances, les particuliers refuseront de payer. La religion seule est la sauvegarde de l'empire.

L’ancien gouverneur de la Guyane, Malouet, apporta au milieu de cette passionnante discussion une note personnelle.

Pour lui, il reste indiscutable que les biens du clergé sont propriété nationale. L’État doit en régler l'emploi, afin que leur double destination soit rigoureusement remplie : entretien du clergé et soulagement des pauvres. Mais il ne saurait les aliéner sans méconnaître ses devoirs essentiels vis-à-vis de l'Église et vis-à-vis des malheureux ; s'il lui est permis de disposer du revenu de ces propriétés, ce ne peut être que les années où, grâce à une meilleure administration, les ministères de l’Église étant entretenus et les pauvres secourus, un excédent résulterait des exercices.

Ce modus vivendi n’était pas conçu sans habileté. Il rallia de nombreux curés qui formèrent ainsi un parti intermédiaire, une minorité agissante moins faible. Contre les questions de principe, que la majorité posait inlassablement, on ne pouvait rien. Thouret proclamait que le clergé ayant cessé d'être un corps politique, son droit de propriété était inexistant puisque la loi ne connaît que les propriétaires réels. Ces corps ne peuvent donc pas posséder ; sans spoliation, la nation peut 
donc reprendre au clergé les biens qu'elle lui avait seulement permis de posséder.

Les représentants du clergé s'évertuaient à rétorquer ces arguments de droit et de fait par un ensemble d'affirmations sèches, raides, scolastiques. Le clergé est une personne morale, disait-ils ; il peut être propriétaire. Le travail, les acquisitions sont de suffisants titres de propriété ; mais en réalité il a acquis à deniers comptants et par échanges ; ces actes ne sont pas ceux d'un usufruitier, mais d'un propriétaire.

Ce débat juridique eût pu s'éterniser si Mirabeau, le 30 octobre, n'était venu trancher la question avec son éloquence et sa logique coutumières. Loin d'accorder au clergé une qualité d'usufruitier, il ne voit en lui que le dispensateur des biens qui, depuis un temps immémorial, était à la disposition du roi. Et il démontre qu'il doit être le principe que la nation est seule propriétaire des biens de son clergé.

Le 2 novembre, il combat de nouveau, avec une force dialectique encore plus puissante, le second discours de l'abbé Maury, tissé de menaces et sophismes canoniques. Il répond aussi, moins sèchement toutefois, aux paroles de l'archevêque d'Aix. Et il n'est pas une seule raison, parmi celles que le clergé met en ligne, qui résiste à ses arguments politiques et théoriques.

"Vous allez décider une grande question, dit-il. Elle intéresse la religion et l'État. C'est moi, messieurs, qui ai eu l'honneur de vous proposer de déclarer que la nation est propriétaire de tous les biens du clergé.

“Ce n’est point un nouveau droit que j’ai voulu faire acquérir à la nation ; j'ai seulement voulu constater celui qu'elle a, qu'elle a toujours eu, qu'elle aura toujours, et j'ai désiré que cette justice lui fût rendue, parce que ce sont les principes qui sauvent les peuples et les erreurs qui les détruisent.”

Suivant Mirabeau, la nation a le droit "d'établir ou de ne pas établir des corps". "Ce n’est point la réunion matérielle des individus qui forme une agrégation politique. Il faut qu'elle ait une personnalité dis- 
tincte et qu'elle participe aux effets civils. Or de pareils droits, intéressant la société entière, ne peuvent émaner que de sa puissance.”

Par la suite, la société, ayant le droit d'établir, ou de ne pas établir, des corps, a également "le droit de décider si les corps qu'elle admet, doivent être propriétaires ou ne l'être pas”.

“La nation, dit-il, a ce droit, parce que si les corps n'existent qu'en vertu de la loi, c'est à la loi à modifier leur existence ; parce que la faculté d'être propriétaire est au nombre des effets civils, et qu'il dépend de la société de ne point accorder à tous les effets civils : des agrégations qui ne sont que son ouvrage ; parce qu'enfin la question de savoir s’il convient d'établir des corps est entièrement différente du point de déterminer que ces corps soient propriétaires.”

M. l’abbé Maury avait prétendu qu’aucun corps ne peut exister sans propriété. Mais Mirabeau lui répond :

“Quels sont les domaines de la magistrature et de l'armée ? Quelle était donc la propriété du clergé dans la primitive église? Quels étaient les domaines des membres des premiers conciles? On peut supposer un état social sans propriété, même individuelle, tel que celui de Lacédémone, pendant la législation de Lycurgue. Pourquoi donc ne pourrait-on pas supposer un corps quelconque, et surtout un corps du clergé, sans propriété ?”

Mirabeau continue en disant que partout où des corps existent, la nation "a le droit de les détruire, comme elle a eu celui de les établir"

“Il n’est aucun acte législatif qu'une nation ne puisse révoquer; elle peut changer, quand il lui plaît, les lois, sa constitution, son mécanisme.”

Il ajoute que l'Assemblée devant laquelle il parle n'est pas seulement législative, mais constituante, et qu'elle a, pour cela seul, tous les droits que peuvent exercer les premiers individus qui formèrent la nation française. 
Appliquant les principes au clergé, Mirabeau en déduit que la nation a le droit de décider que "le clergé ne doit plus exister comme agrégation politique”.

Et si elle exerce ce droit, qu'en résultera-t-il ? que deviendront les biens du clergé ?

Mirabeau envisage plusieurs hypothèses : Retourneront-ils aux fondateurs ? Seront-ils présidés par chaque église particulières ? Serontils partagés entre tous les ecclésiastiques ? La nation en sera-t-elle propriétaire ? Il lui paraît évident que seule la dernière est légitime.

“Tous les biens de l’Église n’ont pas des titulaires; les titulaires mêmes n'ont pas des détenteurs, et il faut nécessairement que des biens qui ont une destination générale aient une administration commune.

"Il ne reste donc que la nation à qui la propriété des biens du clergé puisse appartenir ; c’est là le résultat auquel conduisent tous les principes."

Mais une question se pose alors : sera-t-il de l'époque de la loi, que la nation sera propriétaire, ou l'aura-t-elle toujours été ? Faut-il, comme dit M. l'abbé Maury, tuer le corps du clergé pour s’emparer de ses domaines? Ou bien est-il vrai que l'Église n'a jamais eu que l'administration, que le dépôt de ces mêmes bien :

Mirabeau soutient cette deuxième thèse :

"En effet, dit-il, si tout corps peut être détruit, s’il peut être déclaré incapable de posséder, il s'ensuit que ses propriétés ne sont qu'incertaines, momentanées et conditionnelles ; il s'ensuit que les possesseurs des biens, dont l'existence est aussi précaire, ne peuvent être regardés comme des propriétaires incommutables, et qu'il faut par conséquent supposer pour ces biens un maître plus réel, plus durable et plus absolu."

“... C’est pour la nation entière que le clergé a recueilli ses richesses ; c'est pour elle que la loi lui a permis de recevoir des donations, 
puisque, sans les libéralités de fidèles, la société aurait été forcée ellemême de donner des revenus, dont ces propriétés, acquises de son consentement, n’ont été que le remplacement momentané. Et c’est pour cela que les propriétés de l’Église n’ont jamais eu le caractère de propriété particulière.”

D’ailleurs, ne rentrent-elles point dans la même catégorie que celles qu'on a appelées le domaine de la couronne ? Est-ce qu'il ne serait pas au pouvoir de la nation de l'aliéner, d'en retirer le prix et de l'appliquer au payement de la dette ?

Pour décider cette question, Mirabeau compare les propriétés de l'Église avec toutes les autres propriétés qui lui sont connues. Elles n'en possèdent aucun des caractères.

"Ils n’ont pas été donnés à des individus, mais à un corps ; non pour transmettre, mais pour administrer ; non à titre de salaire, mais comme un dépôt ; non pour l'utilité de ceux qui devaient les posséder, mais pour fournir des dépenses qui auraient été à la charge de la nation.”

Par contre, les possessions de l'Église ont la même origine, la même destination, les mêmes effets que le domaine de la couronne.

"Les biens, comme le domaine de la couronne, sont une grande ressource nationale. Les ecclésiastiques n'en sont ni les maîtres, ni même les usufruitiers ; leu produit est destiné à un service public ; il tient lieu d'un impôt qu'il aurait fallu établir pour le service des autels, pour l'entretien de leurs ministres ; il existe donc pour la décharge de la nation.

“C'est donc pour son intérêt personnel, et, pour ainsi dire, en son nom, que la nation à permis au clergé d'accepter les dons des fidèles ; et, si le clergé cesse de posséder ces biens, la nation seule peut avoir le droit de les administrer, puisque leur destination est uniquement consacrée à l'utilité publique.”

A la suite de ce discours, la sécularisation des biens du clergé fut votée par 568 voix, contre 346 et 40 nulles. 
Par ce vote, l'Assemblée n'avait, à vrai dire, fait que poser le principe. Comment l'appliquer dans la pratique ? mais des conséquences forcées découlaient naturellement de ce vote.

Le 13, Treilhard proposa de mettre le scellé sur tous les bénéfices, excepté les cures ; ce qui fut décrété sur-le-champ. D’autre part, le comité des finances s’inquiétait de l'état du trésor. Le 19 décembre, un plan de son rapporteur, Le Coulteux de Canteleu, proposait la création d'une caisse destinée à recevoir le produit de la vente des biens du clergé, caisse devenue nécessaire par le fait des votes précédents, particulièrement celui du 17 décembre, par lequel Treilhard, au nom du comité ecclésiastique, réclame la suppression de tous les couvents et maisons religieuses "dont l'inutilité est évidente". Ne seraient conservés que les ordres qui se consacrent à l'étude et au soulagement des malades. Le comité prévoyait des pensions pour les religieux quittant le monastère.

De telles dispositions étaient inspirées par un sévère souci d'équité. Mais elle n'eurent pas le don de plaire au haut clergé qui ne se fit point faute de manifester violemment son mécontentement. Déjà, il adressait des menaces directes à l'État, encouragé qu'il était par ceux de ses membres qui avaient passé la frontière.

L'Assemblée, prise par l'urgence de débats nouveau, ne put discuter le projet de Treilhard que le 11 février 1790.

L'évêque de Clermont formula des vœux tendant à ce que les ordres monastiques reprissent leur ancienne splendeur ; l'évêque de Nancy proclame que le catholicisme est une religion d'État. La séance du 13 fut des plus tumultueuses. En face des insolences de la droite, la majorité jugea trop modérées les propositions de Treilhard et elle décréta que désormais la nation ne reconnaissait plus les vœux monastiques et toutes les congrégations furent supprimées. Les établissements de charité et d'éducation étaient cependant maintenus provisoirement.

Cette loi porta au comble l'irritation du clergé. Des tentatives contre-révolutionnaires furent signalées en divers diocèses ; et, avant 
tout opération financières, les immeubles de l’Église, que l’État avait repris, étaient discrédités en chaque province.

D’autre part, la dîme n'étant due que jusqu'en 1791, l'entretien du clergé devenait un problème pressant. Mais, comme les domaines ecclésiastiques répondaient seuls de cet entretien, il s'agissait de les arracher à l'Église qui les détenait encore.

Tout d'abord l'Assemblée eut souci de rassurer les futurs acquéreurs des biens dits du clergé. Et comment, sinon en mettant à la charge de l’État la dette totale du clergé ?

Ensuite, le 9 avril, le rapporteur du comité des dîmes, le jurisconsulte Chasset donna communication d'un projet de décret aux termes duquel le traitement de tous les ecclésiastiques serait payé en argent. A cet effet, une somme déterminée serait inscrite au budget de l'État. Et les anciens bien ecclésiastiques, tenus en état par les départements et par les villes, administrés par des citoyens élus, produiront des revenus qui serviront uniquement à payer les intérêts de la dette publique.

Chasset fixait les frais du culte à 130 millions.

Il était donc possible, avec une telle somme, d'assurer un traitement convenable aux membres du clergé. Mais c'est le principe même du salariat, que l'Église repoussait ; et elle ne pouvait se faire à l'idée qu'elle était dépossédée de son titre de propriétaire. Il lui paraissait que, sans richesse matérielle, son prestige avait cessé d'être, ainsi que toute autorité morale et toute domination temporelle.

Ainsi, est-ce solennellement, au nom de tous les établissements religieux, que l'évêque de Nancy déclare ne pouvoir consentir au décret et à tout ce qui s'ensuivrait. L'archevêque d'Aix crut nécessaire d'user de moyens de conciliation et fit une offre de 300 millions hypothéquée sur les biens du clergé, qui en payerait les intérêts et en rembourserait le capital par des ventes progressives. Mais l'archevêque achevait son discours d'apaisement en évoquant la "puissance ecclésiastique”, ce qui déplut à nombre de membres. Don Garbo fut encore plus maladroit. "Il faut décréter, dit-il, que la religion catholique, apostolique et 
romaine est et demeure, et pour toujours, la religion de la nation, et que son culte sera le seul autorisé.” Un tel fanatisme, qui eut été compréhensible un siècle plus tôt, déchaîna le tumulte et ce fut au milieu de propositions et de contre propositions, de harangue menaçantes que le projet Chasset fut adopté dans son économie essentielle.

Le clergé n'était plus désormais qu'un corps de fonctionnaires salariés par l'État. En moins d'un an, l'Église catholique avait perdu tous se privilèges : son pouvoir temporel, assise inébranlable de sa domination spirituelle, lui était ravi par l’État, maître de ses propre destinées.

Elle ne souffrit point partielle déchéance. Ses ministres s’enrôlèrent dans les rangs des ennemis de la révolution, tandis que la nation après avoir détruit l'édifice de l'ancienne Église, se donna pour devoir d'établir selon ses vues un nouvel ordre de choses religieux.

\section{La constitution civile du clergé.}

$\underline{\text { Retour à la table des matières }}$

Le 6 février 1790, l’Assemblée avait chargé son comité ecclésiastique de dresser un plan de réorganisation du clergé. afin d'accélérer ses travaux, elle adjoignit à ce comité quinze nouveaux membres qui, pour éviter les fâcheuses critiques, furent choisis parmi les amis de l’Église.

L’Assemblée avait à cœur de se tenir en dehors des matières spirituelles. Son rôle, elle désirait le borner à déterminer législativement les rapports que l'État devait entretenir avec l'Église, à établir de nouveaux principes qui subordonneraient le clergé, service public, à l'administration nationale.

Il paraît surprenant que les réformateurs de l'Assemblée constituante n'aient pas perçu ce qu'il y avait, dans leur tentative, de contraire à la réalité, à la nature même des choses. Prétendre transformer le clergé en un corps de salariés, soumis à l'État, n'était-ce point méconnaître le caractère de l'Église catholique, universelle, romaine, 
n'était-ce pas renouveler l'erreur du gallicanisme, aboutissant à la bulle Unigenitus?

La temporalité était l'unique domaine où les constituants se donnaient le droit de légiférer. Mais dès l'instant où l'État fait intervenir son autorité dans les matières de juridiction ecclésiastique, n’est-il pas fatal de le voir aux prises avec des questions de droit canon ? On croirait vraiment que nos grands laïcisateurs avaient perdu le souvenir d'une époque, pourtant récente, où s'était affirmée avec tant de force la toute-puissance de Rome sur son clergé. D’autre part, si les visées de leur politique étaient de susciter à nouveau une Église gallicane, comment n'eurent-ils pas la prévoyance de la mettre à l'abri de toute réaction, en s'assurant le dévouement de la plus forte partie du clergé ?

Mais ce serait aller, croyons nous, contre la vérité historique, que de prêter aux hommes de 1789 un projet aussi résolu dans leur esprit.

L'Église temporelle n'existait plus; aucun des privilèges d'autrefois ne subsistait. Cependant, la crédulité religieuse ne paraissait pas avoir reçu des atteintes sérieuses ; à cette loi il fallait des serviteurs. L'État commit l'erreur de s'imaginer qu'il lui était possible de les créer de toute pièces, de sa propre autorité ; et cette assemblée, qui se révoltait quand on lui proposait de décréter le catholicisme religion nationale, s'asservit à une collectivité d'hommes vivant du commerce des croyances, tout en prétendant les soumettre à son despotisme, elle qui proclamait la liberté.

A cette époque de la Révolution, la paix et la liberté religieuse eussent pu être réalisées, si les esprits plus avisés avaient su reconnaître dans le principe de la séparation des Églises et de l'État, la solution de bon sens, la solution logique.

Bien au contraire, dans l'état des choses qu'elle prétendait instaurer, l'Assemblée nationale manifesta une légitime susceptibilité au sujet de son indépendance. Elle se montra indignée, quand le pape Pie VI prononça, le 29 mars 1790, la condamnation des principes révolutionnaires. Et dans la crainte que ce clergé, qu'elle voulait à son service, ne 
prit au pied de la lettre les paroles enflammées du saint-Siège, elle se décidera à rompre en visière avec Rome.

Mais, d'autre part, l'Assemblée ne fut pas longtemps sans s’apercevoir que des ecclésiastiques français, avec lesquels elle désirait négocier, lui échappaient chaque jour. Par tous les diocèses ils lançaient de fougueux mandements, encourageant la levée de libelles incendiaires, fanatisant les populations et leur ouvrant le paradis si elles marchaient d'une belle ardeur à la guerre sainte. De terribles émeutes ensanglantaient le Midi et l'Ouest ; les anciennes congrégations devenaient des armées et les autorités civiles, harcelées, insultées, menacées, ne pouvant plus arrêter le flot des émeutiers catholiques, faisaient le sacrifice de leurs jour.

Un tel spectacle eut dû ouvrir les yeux de l'Assemblée. En quels rangs du clergé avait-elle la possibilité de recruter ses troupes? L’Église toute entière s’insurgeait contre la nation !

Mais non, La Constitution civile, en dépit des événements, fut portée à l’ordre du jour le 29 mai et le 12 juillet, le projet était décrété.

Elle donna lieu à des débats extrêmement laborieux. Le clergé répétait comme une antienne que les pouvoirs de l'Église sont inaliénables, imprescriptibles et illimités, que Jésus-Christ n’a pas donné aux empereurs le gouvernement ecclésiastique et qu'enfin la législation, la juridiction, l'enseignement sont ses droits inviolables.

Devant une pareille irréductibilité, il apparaissait difficile de composer. Les constituants ne se laissèrent pas rebuter, tant ils avaient conscience que la nécessité sociale leur commandait la réglementation civile de l'Église. Ils avaient beau entendre et souffrir des panégyriques du pape dans ce goût : "Le pape a la primatie d'honneur et de juridiction sur toute l'Église”, ils ne s'émouvaient pas et persistaient dans leur intention de soustraire le clergé français au pouvoir romain. N'est-ce pas Robespierre qui déclarait l'obligation pour l'État d'attacher étroitement les prêtres à la société, de leur inculquer la nation de l'intérêt public? 
Les représentants ecclésiastiques révoltés contre les "hérésies” des réformateurs n'avaient pas à leur égard d'épithètes assez blessantes. L'une d'elles était que l'on “conduisait la nation au presbytérianisme !“ La majorité fit bon accueil à l'accusation. On proclama qu'en effet elle travaillait à fonder une Église gallicane, libérée à tout jamais des doctrines ultramontaines.

Ainsi sa constitution civile se ressent-elle, dans toute se parties, de ce souci de création politique, de cet effort, pour dresser l'édifice juridique où s’abritera la nouvelle Église.

Elle se divise en quatre parties : la première est consacrée aux offices ecclésiastiques, la seconde à la nomination aux bénéfices, la troisième a rapport au traitement des ministres de la relation et le quatrième établit les dispositions de la loi de résidence.

Le principe du titre $\mathrm{I}^{\mathrm{er}}$ est que la configuration des diocèses reproduira les divisions départementales de l'empire. Les seuls titres reconnus par l'administration sont ceux dévêques et de curés ; par la suite, les offices autres que les évêchés et les cures sont abolis. De plus, l'évêque ne devient qu'un président de consistoire ; le conseil, qui l'assiste, donne souverainement son avis. Ainsi désormais l'évêque ne sera plus le soldat obéissant du pape et, partant, les appels en cours de Rome ne seront plus possibles.

Le titre II réglementait la procédure de la nomination aux bénéfices. Les évêques et les curés seraient les élus du peuple. En effet, ne sontils pas assimilés aux fonctionnaires civils ? Or ceux-ci sont nommés par une assemblée électorale ; et, comme tels, les ecclésiastiques seront soumis à toutes les formalités ordinaires jusques et y compris celle du serment. Quant à l'investiture, elle serait donnée par le métropolitain du diocèse. Solliciter la confirmation du pape eût été un acte de rébellion contre l’État.

Les curés étaient élus parmi les prêtres ayant exercé le sacerdoce pendant cinq ans. Après avoir prêté le serment consacré d'être fidèle à la nation, à la loi et au roi, l'élu était admis à recevoir l'investiture canonique. Les curés avaient toute latitude pour choisir leurs vicaires. 
On voit que la direction de l'Église était mise tout entière dans les mains du pays. C'est ce que les adversaires de la loi se refusaient à tolérer ; mais la disposition qui dépassait leur entendement était celle qui dépossédait le pape du droit essentiel du pontificat: le droit d'accorder ou de refuser l'institution canonique. Ils n'avaient pas de mots pour exprimer l'effet d'un tel outrage sur leur âme de chrétien. Quant à l'obligation du serment, c'était la consécration du schisme ; les prêtres qui, cédant aux mesures coercitives de la nation, jureraient respect à la constitution seraient déchus de leur dignité de ministre de Dieu. Mais les défenseurs du projet ne se dérobaient pas aux attaques. Et, tout d'abord, ils justifiaient l'élection en rappelant l'état primitif de l'Église, véritable démocratie. Et, pour exprimer la raison de l'éloignement où la Constitution tenait le pape, ils demandaient si le souverain pontife pouvait être autre chose, aux yeux des Français, que l'évêque de Rome.

Le titre suivant, qui faisait bénéficier le clergé d'avantages pécuniaires, fut adopté sans difficultés. La gauche de l'Assemblée s'éleva contre cette loi qui rentait trop magnifiquement, à son avis, ceux-là qui n'étaient plus que des fonctionnaires. La réclamation demeura sans écho.

En outre, Robespierre invoqua la justice de l'Assemblée en faveur des ecclésiastiques "vieillis dans le ministère et qui, à la suite d'une longue carrière, n'ont recueilli de leurs travaux que des infirmités". Libéralement, de nombreuses pensions de retraite furent octroyées aux invalides.

Enfin, par la loi de résidence, objet du titre IV, il était interdit aux évêques de s'absenter de leur diocèse sans y être autorisé par le directoire du département; leur absence ne pouvait s'élever au delà de quinze jours. De même, les curés et les vicaires n'avaient pas le droit de séjour ailleurs que dans leur cure ; si des nécessités impérieuses les réclamaient ailleurs, le directoire du district examinait leur demande de congé.

Aussi l'Assemblée ne pouvait-elle accorder aux ecclésiastiques le droit de poser leur candidature à des emplois qui les auraient obligés à rester éloignés de leur offices. Cependant exception est faite pour les 
élections à l'Assemblée nationale et, d'autre part, la raison d'interdire au clergé au clergé l'entrée des divers conseils administratifs de leur commune ne subsistait plus ; l'Assemblée même avait tendance à encourager les prêtres à s'occuper des affaires publiques, puisque son ambition était de doter la nation d'un clergé patriote et libéral.

Chaque article donna lieu à de violents débats ; lentement, péniblement on atteignit le 12 juillet et l'ensemble de la loi fut adopté.

Quelques jour plus tard, le 24, Chasset, au nom du comité ecclésiastique, déposa un projet de loi sur les retraites, destiné à compléter les dispositions relatives au traitement du clergé. Les évêques supprimés, selon les propositions du comité, devaient jouir des deux tiers, à la condition que le tout n'excédât pas 30000 francs; les évêques conservés se démettant de leurs fonctions recevaient pareille somme.

Il ne parut à aucun des membres de la majorité que la loi n'était pas suffisamment favorable au personnel de l'Église. On demanda même qu'il ne fut rien donné à ceux qui ne prouvaient pas que leur retraite était nécessitée par des raisons valables. Mais, par esprit de conciliation et pour s'assurer le dévouement de tout le clergé, les vues du comité furent adoptées.

Les largesses de l'Assemblée, loin de désarmer les ecclésiastiques, ennemis de la constitution, prirent l'aspect d'une faiblesse et l'incitèrent d'avantage à la rébellion.

Le clergé démasqua sa politique. Il s’efforçait d'agir à la fois sur l'esprit du roi et sur celui du paysan ; l'un et l'autre étaient sensibles aux prédictions fanatiques. A celui-ci, il évoquait le roi, déchu de son autorité. A celui-là, il parlait du maître de tous les rois, du vicaire de Jésus-Christ, couvert d'invectives, bafoué, dont l'autorité spirituelle se trouvait compromise, sinon détruite, par les lois hérétiques de la Constituante.

Mais Pie VI, malgré son désir d'entre en lutte contre la France révolutionnaire, hésitait, tergiversait, tant il avait souci de ne point exposer son domaine d'Avignon. 
De son côté, le roi, pris entre les incitations du clergé et les menaces réservées de l'Assemblée, balançait à prendre une décision. Tout - son éducation, ses intérêts, ses influences - complotaient à lui faire opposer son veto à la promulgation de la loi. Mais une telle indépendance vis-à-vis des législateurs ne pouvait que mettre sa couronne en péril. dans son irrésolution, il réclama le secours du pape ; celui-ci répondit que le dernier mot sur la constitution appartenait au sacré collège. Dès lors, Louis XVI, mis au pied du mur, promulgua, le 24 août, la loi religieuse.

Les évêques décidèrent de combattre sans le secours du pape ni du roi. L'archevêque d'Aix lança un manifeste qui, après la réfutation des théories laïques, provoquait à la guerre civile. Désormais, l’Assemblée allait avoir, à l'ordre du jour de ses séances, des interpellations incessantes sur les troubles cléricaux.

Sans tarder, elle prit des mesures énergiques pour vaincre la révolte de l'Église. Tous les évêques et les curés en fonction furent tenus de prêter le serment constitutionnel, dans la huitaine, sous peine de perdre leurs offices. Ce décret, présenté par Veydel, fut rendu le 27 novembre, grâce à un discours de Mirabeau, qui légitima, avec une abondante éloquence, tout ce que l'Assemblée pourrait tenter pour assurer le respect de ses droits.

Mais le roi ne peut se résigner à sanctionner le décret. Le peuple se soulève contre son souverain que Rome subjugue. L’émeute gronde. Le roi est soupçonné de trahison. Et ce sera le premier ébranlement sérieux que son royaume subira. Les assauts furieux et répétés de l'Église contre le pouvoir national prépareront la mesure trop tardive, qui deviendra le salut public, la séparation des Églises et de l’État.

Il ne nous appartient pas d'exposer ici tous les événements religieux qui se placent entre la Constitution de 1790 et le décret du 27 novembre 1793. Avec eux, nous sommes dans la période de l'insurrection. Et, s’ils forment comme une trame serrée, si les actes législatifs auxquels ils donnent naissance paraissent découler légèrement les uns des autres, c'est qu'à toute cette agitation il n'était qu'un aboutissant politique : la dénonciation de l'erreur législative de 1789, de la constitution civile du clergé. 
Et si, par la force de choses, on en arriva à abandonner l'Église, c’est que les législateurs acquirent l'expérience que toutes les mesures qu'ils peuvent prendre à l'égard du clergé révolté serait insuffisant à assurer l'ordre et le respect de l'État laïque.

Le 18 septembre 1794, la Convention, par mesure de financière, sur proposition de Cambon, vota un projet, qui d'abord posait en principe que la République française ne payerait plus les frais ni les salaires d'aucun culte.

Ce principe, Cambon le dit formellement, était "dans tous les cœurs”. Il n’était donc pas dicté uniquement par un état des choses financier ; il résultait des leçons de l'expérience. "Proclamez un principe religieux, dit Cambon, de suite il faudra des temples, qui devront être gardés par des personnes, qui s'en prétendront les ministres ; ils demanderont des traitements ou des revenus. S'ils réussissent dans leur première demande, ils élèveront bientôt de nouvelles prétentions, et, sous peu, ils établiront des hiérarchies et des privilèges.”

On ne saurait mieux faire apparaître le danger que fait courir à l'État une union avec l'Église. Mais, nous l'avons dit, ce n'est pas d'un coup que les conventionnels de 1794 arrivèrent à posséder une conscience aussi nette des intérêts supérieurs des deux partis. De 1790 à 1794, l'étape fut longue, ardue ; sanglante à plusieurs reprises, la solution finale ne manqua pas d'être présentée, formulée même et désirée.

C'est d'abord la rupture des relations diplomatiques avec le Vatican, lorsque le pape, prévoyant l'annexion d'Avignon, refusa de recevoir notre ambassadeur, $M$. de Ségur. Dès que la nouvelle fut connue à Paris, le 30 mai 1791, le nonce fut informé d'avoir à quitter aussitôt la France. Rien alors ne put mettre un frein à la violence des ecclésiastiques contre la constitution civile ; et de nombreux curés assermentés, cédant à leur tendance ultramontaine, violèrent toutes les prescriptions de la loi à plaisir afin de la rendre inexistante. Ils ne tardèrent pas à atteindre leur but ; la Constitution, qui avait donné naissance à un nouveau clergé maintenant en révolte, n’était rien autre, à la fin de 1791 ; qu'un poids mort, qu'un monument législatif tout en façade, 
sans vertu, sans sanction, au nom duquel il fallait verser le sang, puisque l'Église, en portant ses coups contre la Constitution, visait en plein cœur la nation. Il est donc tout naturel que, dès cette époque, de bons esprits aient cru politique pour l'Assemblée de détruire ellemême son œuvre.

André Chénier, dans une lettre adressée au Moniteur, le 22 octobre, disait que les prêtres cesseront d'être dangereux le jour où la nation se désintéressera des religions : “ les prêtres ne troublent point les États quand on ne s'y occupe point d'eux”.

Le 6 février 1792, l’Assemblée législative demanda au ministre de l'intérieur, M. Cahier de Gerville, un tableau général de la situation du royaume. Celui-ci lut, à la séance du 18 février, un exposé détaillé de l'état de la France. Ce qui avait trait aux troubles religieux occupe la majeure partie de son rapport ; et, en matière de conclusion, il exprimait de judicieuses pensées qui étaient le signe d'un nouvel état d'esprit.

Tout ce que peut faire une bonne constitution, c'est favoriser toutes les religions sans en distinguer aucune. Il n'y a point en France, de religion nationale. Chaque citoyen doit jouir librement du droit d'exercer telle pratique religieuse que sa conscience lui prescrit, et il serait à désirer que l'époque ne fut pas éloignée où chacun eût la charge de son culte. Le fanatisme est comme un torrent qui détruit et renverse toutes les barrières qu'on lui oppose et qui s'écoule sans ravage lorsqu'on lui ouvre les issues... L'intérêt des prêtres ne doit entrer pour rien dans le combinaisons du législateur. La patrie attend une loi juste qui puisse entrer dans le code de peuples libres, et qui dispense de prononcer ici les mots : Prêtres et religions.

Le 18 novembre 1792, au cours d'un important débat sur le régime des impôts, Cambon monte à la tribune de la Convention et formule le principe de la séparation tel qu'il découlait de la situation financière de l’État :

“Ayant à nous occuper de l'état des impositions en 1793, nous devons nous poser cette question : si les croyants doivent payer pour leur culte. Cette dépense pour 1793, qui coûterait 100 millions, ne peut pas 
être passée sous silence, parce que la trésorerie nationale ne peut pas la payer. Il faudrait donc que le comité des finances eut l'impudeur de venir demander le sang du peuple pour payer des fonctions non publiques. Votre comité a regardé cette question sous tous les points de vue. Il s'est demandé : qu'est-ce que la Convention? Ce sont des mandataires qui viennent stipuler pour tout ce que la société entière ne pourrait stipuler elle même. Ils ne doivent point fixer des traitements lorsque chacun y peut mettre directement la quotité. Alors il s'est dit : faisons l'application des vrais principes qui veulent que celui qui travaille soit payé de son travail, mais payé par ceux qui l'emploient.”

Cependant, en dépit de toute les raisons puissantes qui militaient en faveur de la proposition de Cambon, Robespierre, Danton et quelques autres se rangèrent d'un côté tout opposé. Selon eux, l'État devait continuer à salarier son clergé pour ne point aggraver par une suppression radicale le caractère de sédition qui éclatait de toutes parts ; et la motion que Cambon développa en plusieurs séances fut définitivement écartée.

Il la reprit lui-même deux ans plus tard, quand la Convention décimée ne pouvait plus lui opposer ses antagonismes d'autrefois. La situation financière ne laissait pas que d'être encore plus alarmante, et les derniers conventionnels eux-mêmes trempés dans la tourmente terroriste, ayant appris jusqu'à quels crimes pouvait aller l'esprit d'insubordination du clergé, inclinait vers l'unique solution capable de dissiper l'équivoque de 1790. Tous étaient partisans d'une rupture avec tous les errements des premières heures de la Révolution que, par une fausse conception des rapports du clergé et de l'État, il avait paru bon de conserver. Mais, sauf le financier Cambon, nul ne s'aventurait à exprimer l'esprit de la nouvelle politique.

Ce mérite revint à Grégoire qui, le 23 décembre 1794, fit la lumière sur les velléités communes à tous les conventionnels et formula les véritables principes de liberté en matière religieuse. Car il n'était pas suffisant de dire que, la constitution civile n'existant plus, l'Église avait seule à prendre souci d'elle même. Grégoire s'élève au dessus du moment et spécifie qu'absolument, dans tous les pays et dans tous les temps, l'État n’a pas à légiférer en ce qui concerne les choses cultuelles. 
"Le gouvernement, dit-il, ne peut adopter, encore moins salarier aucun culte, quoiqu'il reconnaisse à chaque citoyen le droit d'avoir le sien. Le gouvernement ne peut donc, sans injustice, refuser protection, ni accorder préférence à aucun. Dès lors, il ne doit se permettre ni discours, ni acte qui, en outrageant ce qu'une partie de la nation révère, troublerait l'harmonie ou romprait l'égalité politique. Il doit les tenir tous dans la juste balance, et empêcher qu'on ne les trouble et qu'ils ne troublent.

Ils faudrait cependant proscrire une religion qui n'admettrait pas la souveraineté nationale, la liberté, l'égalité, la fraternité dans toute leur étendue ; mais, si un culte ne les blesse pas, et que tous ceux qui en sont sectateurs jurent fidélité aux dogmes politiques, qu'un individu soit baptisé ou circoncis, qu'il crie Allah ou Jéhova, tout cela est hors du domaine de la politique”.

On ne peut pas mieux dire. Nous sommes loin de l'opinion terre à terre de Cambon. Mais Grégoire, sans doute, pêchait par le défaut contraire ; il perdait son époque de vue et disait la législation d'un siècle plus calme. Il réclamait que les autorités fussent chargées de garantir à tous les citoyens l'exercice libre de leur culte, en prenant les mesures que commandaient l'ordre et la tranquillité. Mais permettre le libre exercice du culte, n’était-ce point déchaîner la fureur homicide du clergé contre la Révolution ? Néanmoins, l'Assemblée manifesta clairement, avant de passer à l'ordre du jour, qu'elle était assez détachée des religions pour laisser les prêtres à leur pratique, “à la condition, dit Legendre, qu'ils ne rétrécissent point l'esprit public”.

Les événements donnèrent raison à la Convention.. Il n'était pas un point de la France où il ne fallut réprimer des émeutes cléricales, sinon des batailles rangées ; la messe était un acte subversif. Et ce ne fut que lorsque la Vendée, définitivement écrasée, réclama, comme une justice, la libre pratique des cultes que la Convention crut possible de détendre sa politique de défense révolutionnaire.

Le 21 février, elle étudia un projet de décret ne réglementant que la police des cultes. C'était tout un ensemble de garanties contre tout culte qui deviendrait exclusif ou dominant ; la liberté de chacun était 
minutieusement protégée. Plus d’oppression vis-à-vis de l’Église, mais une large et sévère surveillance.

Les communes ne pourront acquérir ni louer de local pour l'exercice des cultes ; il ne peut être formé aucune dotation perpétuelle ou viagère, ni établi aucune taxe pour entretenir les prêtres. Aucun signe particulier à un culte ne peut être élevé, fixé sur quelque lieu que ce soit, sauf les églises et dans les maisons particulières. La République interdit en outre les exhibitions d'emblèmes, les proclamations confessionnelles, le port de tout insigne sacerdotal.

Les sanctions à toute cette série de prescriptions, nécessaires à rendre réelle la liberté de conscience, étaient des amendes de 100 à 1000 livres et des emprisonnements d'un mois à dix ans.

A la faveur de cette loi, l’ancien clergé constitutionnel se réorganisa promptement. Le 17 mars, il lança une encyclique, à laquelle adhérèrent de nombreux évêques assermentés. Sa politique fut d'amener à lui les membres du clergé réfractaire ; mais il n’y réussit pas.

D’ailleurs, bien que très agissant, le clergé gallican avait perdu toute popularité. Les croyants se tournaient vers l'Église dite orthodoxe, vers les insermentés et les émigrés. Chaque jour, les prêtres proscrits rentraient nombreux, et ils n'avaient rien de plus empressé, aussitôt sur le sol de la République, que d'user de la liberté nouvelle pour combattre les idées, les institutions et les hommes de la Révolution. Si bien que les menées audacieuses des anciens réfractaires provoquaient à la Convention, le 17 avril 1795, un violent débat qui aboutit au décret du $1^{\mathrm{er}}$ mai, condamnant à mort tous les émigrés saisis ; les prêtres insermentés avaient un mois pour franchir la frontière.

Le clergé antinational ne tenait, en effet, aucun compte du décret sur la liberté des cultes; il disait la messe dans des églises qui lui étaient interdites et prêchait ouvertement le royalisme.

La loi du 21 février fut donc encore prématurée, puisque la révolte contenue éclata plus violemment que jamais. Cependant, la République, pour ne point exaspérer les esprits et pour faire cesser la guerre civile, mit toutes les église non aliénées à la disposition des prêtres qui 
feraient acte de soumission aux lois du pays. Mais ce nouveau serment, le clergé voulut pas le prêter, et il considéra cette formalité comme un prétexte pour mettre encore en mouvement ses compagnies d'émeutiers. La Convention dut encore voter des lois de bannissement et compléter la loi sur la police des cultes.

Les prêtres gallicans, par contre, protestèrent de leur égal respect pour l'autorité civile et pour l'autorité papale ; mais leurs efforts pour apaiser la lutte de l'Église romaine et monarchique contre la République n'aboutit pas. Les prêtres réfractaires violèrent chaque jour la loi sur la police des cultes. Le Directoire, pour anéantir les ennemis de la nation, se résout alors à attaquer directement la papauté ; Contre les prêtres insoumis, il vote des lois de salut public. Mais les Anciens ne le suivent pas dans cette voie ; ils désiraient plutôt l'indulgence à l'égard des révoltés ; et, le 5 septembre 1796, les prêtres étaient admis à prendre jouissance des biens qui avaient appartenu à l'Église d'autrefois.

D’un autre côté, par l’intermédiaire du général Bonaparte, le Gouvernement fait pressentir le pape pour le décider à prêcher aux réfractaires la soumission à l'État. Le saint-Siège, qui apercevait dans la République de sérieux symptômes de désagrégation, ne se hâtait point d'acquiescer; le triomphe de la contre-révolution l'assurait d'un meilleur avenir. En effet, elle était déjà triomphante. Les réfractaires, par la loi du 24 août étaient solennellement amnistiés ; il fallut que la république, dans un sursaut d'énergie se défendit par la loi du 19 fructidor, véritable coup d’État révolutionnaire. Le clergé insoumis et le pape subirent les durs effets de cette loi. Celui-là, par des prescriptions en masse, rapides et sans conditions ; celui-ci par par la lutte qu'il eut à soutenir dans sa ville pour empêcher que ne se dresse, en face de son pouvoir, un gouvernement démocratique.

A Rome, on ne recula point devant l'assassinat de l'ambassadeur Basseville et du général Duphot ; et la république dut lancer contre son ennemi une armée qui fit prisonnier celui dont la Révolution avait tant à redouter.

Mais le régime de fructidor ne fut pas sans réveiller le fanatisme. Partout, ce sont des insurrections ; les provinces sont travaillées par 
les prêtres qui, bien que bannis, viennent de nouveau ensanglanter la France. Plus qu'aux périodes troublées que le pays vient de vivre, la passion contre-révolutionnaire fanatise les esprits et devient, cette fois, invincible. Le directoire était au dessous de sa tâche. Bonaparte s’offrit en sauveur.

Il voulut d'abord la restauration religieuse. Rien n'était plus politique pour l'accomplissement de ses ambitions. Un clergé gallican ne pouvait être utile à Bonaparte, puisque ce clergé, en dehors de Rome, était sans autorité sur le pays. Il était donc de toute nécessité que les relations avec le saint-Siège fussent reprises. Mais un tel acte devait se produire à son moment. Bonaparte n'apporta aucune hâte malencontreuse dans la poursuite de ses desseins.

La pacification religieuse, il l'obtint par des mesures pondérées, où les concessions mutuelles s'équilibraient habilement. Son ambition n'était, semble-t-il, que d'assurer la plus complète liberté des cultes ; il y arriva sans secousses. Que lui demander de plus ? Le clergé, autrefois réfractaire, entretenait librement avec le saint-Siège les relations qui lui convenaient. Sous ce régime, la France revenait au calme.

\section{Le concordat de 1801}

Toutefois, Bonaparte poursuivait son idée. Pour exercer sur le pays le pouvoir du maître, il avait besoin de rétablir en France les pratiques religieuses d'autrefois ; de plus, pour la complète réussite de ses ambitions politiques, il fallait qu'il pût mettre à leur service la complaisance, sinon la complicité du souverain pontife.

Dès la nomination du nouveau pape, le 15 mars 1800, le premier consul commença ses avances. Du premier coup il offrait à Pie VII ses anciens États. Par la même occasion, il lui demandait son avis sur l'état des choses ecclésiastiques en France. Mais le gouvernement consulaire ne paraissait pas suffisamment stable au saint-Siège pour qu'il engageât d'emblée des négociations. 
Ce fut seulement aux lendemains de Marengo que le pape, s'attendant à voire l'Italie envahie par les troupes françaises, fit entendre à Bonaparte qu'il était prêt à entamer des pourparlers. Selon le désir du premier consul, c'est à Paris qu'ils s'ouvrirent. L'archevêque Spina, bien que délégué officiel du pape, était néanmoins sans pouvoirs pour traiter quoi que ce fût. Mis en face du représentant du Gouvernement, il exposa d'une façon si casuistique les prétentions du saint-Siège, que l'accord entre eux ne put établir.

Le plan de Bonaparte n’était pas compliqué.

L’État salarie les ministres du culte. On fait table rase : réfractaires et constitutionnels donnent leur démission. Le premier consul désigne les titulaires; le pape donne l'institution canonique. Les évêques nomment les curés. L’Église accepte la confiscation des biens ecclésiastiques. tout le clergé prête serment de fidélité au Gouvernement.

Sur ces bases l'entente est possible.

Mais Rome a d’autres visées.

En premier lieu, elle veut qu'il soit proclamé que le catholicisme est religion d'État en France. Quant au réfractaires, aux ennemis de la République, ils avaient trop mérité de l’Église pour que le saint-Siège pût les contraindre à donner leur démission. Quant aux évêques constitutionnels, il exigeait que tous reconnussent publiquement leurs erreurs.

D'autre part, le pape s'opposait aux règlements de police, quels qu'ils fussent. L'état civil n'avait aucun droit de commandement, de surveillance sur l'Église omnipotente. Enfin, en ce qui concerne les biens, il faisait abandon de ce qui avait été aliéné ; mais il voulait que l’Église pût recevoir des biens-fonds par voie de legs ou de donation.

Tels étaient le desiderata du pape en face de ceux du premier consul. Bonaparte aima mieux attendre l'écrasement de l'Autriche avant de conclure avec Rome. De son côté, le pape désirait connaître 
les résultats de la guerre avant de prendre de sérieux engagements avec le gouvernement français.

Mais, après le traité de Lunéville, alors que les armées françaises occupaient tout le territoire de l'Église, Pie VII, par la force des choses, dut négocier avec le premier consul. Le délégué de Rome réclama Ferrare, Bologne et Ravenne. Il n'eut rien. Napoléon ne voulait point entendre parler de restitutions tant que le concordat, tel qu'il l'avait conçu et rédigé, n'aurait pas obtenu l'agrément du pape. Et, pour brusquer les choses, le premier consul expédia à Rome le diplomate Cacault, qui avait pour mission de forcer la main du pape. Mais il n'aurait pu y parvenir. Le pape avait fait dresser un contre-projet par une congrégation de cardinaux, et il se préparait à connaître la réponse qu'allait lui faire le premier consul, quand il reçut un avis officiel qu'un délai de cinq jours lui était accordé pour accepter le Concordat présenté par la France.

Aussitôt le pape envoie à Paris un négociateur, muni des pleins pouvoirs, le cardinal Consalvi, qui, voyant sur place combien les hommes du gouvernement et des hauts fonctionnaires étaient contraires à l'idée d'un concordat, eut la crainte de laisser échapper l'occasion de traiter avec Bonaparte s'il ne lui faisait pas de pénibles mais nécessaires concessions.

On ne parla plus d'une religion d'État ; il fut question d'une religion catholique "qui est celle de la majorité des Français”. Sur tous les autres points, Napoléon resta intraitable. Il exprima même le désir de voir l’Église soumise, sans arrière-pensée, à un règlement de police.

Le cardinal Consalvi ne se permit aucune objection. Le 15 juillet 1801, le Concordat était signé, mais ne fut mis en vigueur qu'au mois d'avril 1802, après l'établissement de la législation à la police de cultes.

Il est indiscutable que le mécontentement contre le premier consul fut très vif dans toutes les sphères politiques fidèles aux principes de la Révolution. Le conseil d'État même le désapprouva par son silence. Le clergé constitutionnel, qui voyait de nouveau s'ouvrir l'ère des bulles pontificales et qui, en sa qualité, n'ignorait pas tout ce dont étaient 
capables la rouerie et l'astuce du gouvernement romain, fit part à Napoléon de ses justes alarmes. Le Sénat, le Corps législatif souffraient pour la dignité nationale, car alors même que le Concordat était favorable aux intérêts de l'État français, il n'en restait pas moins que la France venait de conclure un accord avec le pape ; or la France de la Révolution ignore Rome ; elle ne saurait négocier avec le maître de l’Église.

Mais par ses règlements de police, Bonaparte ne doutait pas de voir se calmer l'émotion des révolutionnaires. Le Concordat devait lui attirer les bonnes grâces de l’Église ; ultérieurement il présenterait son interprétation de l'acte consenti avec la papauté, le correctif nécessaire, tous les tempérament propres à faire de l'Église, l'esclave docile de l'État.

On comprend que le premier consul n'ait éprouvé aucun besoin de dévoiler sa pensée entière, il le ferait seulement le jour où le pape serait pris, pieds et poings liés, dans le piège du Concordat. D’ici là, il lui paraissait politique de laisser le champ libre à la cour de Rome, de l'encourager même à se donner des airs d'autorité souveraine.

\section{DU CONCORDAT AU SYLLABUS}

Comme l'organisation concordataire de l'épiscopat pressait, Napoléon fit des efforts pour que le pape usât sans tarder des prérogatives que lui conférait l'accord de 1801. En effet, il était temps que la nouvelle église fût organisée sur les bases solides que l'on avait prévues. Mais rien n’était moins facile. Pour nommer des évêques, n’était-il pas nécessaire d'obtenir la démission des occupants ? Or Bonaparte avait à cœur de réserver l'honneur épiscopal aux anciens constitutionnels ; tandis que Rome ne pouvait se décider à les faire rentrer dans la 
communion de l'Église s'ils ne se soumettaient pas aux formalités humiliantes de l'abjuration publique de l'erreur gallicane. Rome se montrait irréductible. Pour lui forcer la main, Napoléon tenait en réserve ses fameux articles organiques, dont il fit donner lecture au légat du pape, dès que celui-ci eut légitimé les nouvelles circonscriptions diocésaines et rendu possible le fonctionnement régulier de l’Église concordataire.

Quelle est donc l'économie générale de ces articles organiques que Napoléon considérait comme le chef-d'œuvre de ses ressources astucieuses ? Etaient-ils réellement de nature à mettre en échec l'autorité romaine ?

Ce serait une grave erreur de le croire. Un siècle d'expérience a démontré la fragilité et l'insuffisance de ces précautions que le saintSiège n’a jamais voulu reconnaître.

En premier lieu, Napoléon céda aux instances du pape, qui se refusait à observer toutes les prescriptions du règlement. Ainsi l'article 17 ordonnait l'information pour les candidats à l'épiscopat par-devant l'ordinaire du lieu de leur résidence. Rome qui se considère comme "la source de l'épiscopat”, ne souffre pas de rester en dehors de l'acte préparatoire à l'institution canonique, puisque cette institution est le lien avec lequel elle a toujours tenu en laisse le monde chrétien et les empires. La question était donc d'importance ; le pouvoir du saintSiège en France en dépendait. Néanmoins, Napoléon se rangea à l'avis du pape.

Ensuite, quelles étaient les innovations de ces articles? L'enseignement des quatre propositions du clergé ? Mais ce n'était point une invention de l'esprit révolutionnaire, puisqu'elles dataient de 1682 ; et, par la suite, d'ailleurs, certaines des dispositions qui émanaient de cet esprit, tombèrent en désuétude.

Cependant, il est indéniable que, sur certains points, le nouveau règlement affirme la prépotence du pouvoir laïque. Mais, après les années que la France venait de vivre, et qui avaient consacré dans les mœurs un nouvel état des choses, les législateurs ne pouvaient pas suivre une marche opposés aux tendances de l’opinion publique. 
Enfin, cette loi sur la police des cultes n'est pas le contrepied du Concordat lui-même, ainsi qu'on aurait voulu le faire entendre. Le Concordat, au dire des intéressés, satisfait pleinement les besoins de la religion ; au culte, il assure la liberté et la sûreté, il lui accorde des temples et des ministres. Les articles organiques ne démentent d'aucune manière ces dispositions. D'autre part, l'accord de 1801 est exempt de matière bénéficiale ; le clergé peut, de lui-même, pourvoir au nécessaire, le superflu seul est interdit. Le règlement de 1802 reste aussi étranger à cette question.

En outre, ce soit-disant correctif de la convention avec Rome ne répare pas ce qu'avait d'antinational cet acte quand il stipule que le Gouvernement français doit nommer les évêques dans un délai donné, alors que le pape n'a point de terme pour instituer. C'était mettre la France en état d’infériorité vis-à-vis de Rome.

Avec le pape, Napoléon essaya de jouer au plus fin ; mal lui en prit. Sa soi-disante Église, qu'il voulait docile à ses ordres, ne fut rien autre que romaine. Jamais, même au temps de la monarchie, elle se montra plus dépendante du saint-Siège ; dépouillée de ses biens temporels, comment aurait-elle pu vivre en dehors des volontés de Rome ? Elle était une indigente à qui il n'était plus possible de se tracer librement un plan d'existence conforme à ses goûts, à son tempérament.

Napoléon a donc mis entre les mains du pape une arme dangereuse pour la France. Le salaire, loin de produire un lien d'attachement entre celui qui donne et celui qui reçoit, contribue plutôt à les éloigner l'un de l'autre. En 1801, cette vérité était moins sensible. On a voulu assimiler le clergé aux autres serviteurs de l'État ; le clergé a d'abord protesté, sa dignité lui faisait un devoir de refuser ce qu'il considérait comme une aumône ; par la suite, il a bien voulu consentir à recevoir son salaire, mais il se vengea en se dévouant tout entier à Rome contre la France.

Cependant Rome crut de bonne foi avoir été jouée, quand elle connut les articles organiques. Dans le consistoire de 1802, le pape formula véhémentement ses plaintes contre un règlement de police 
élaboré et dicté sans son consentement. Mais n'eut garde de mécontenter le 1er consul, le concordat dépassant ses espérances.

Les démêlés de Napoléon 1er avec le pape n’entrent pas dans le cadre de ce rapide exposé historique. Quels sont les actes législatifs qui sanctionnent les relations de l'État avec Rome ? Telle et la question que jusqu'ici nous avons eu en vue et qui, au début du nouvel état des choses crées par le premier consul, sacré empereur, revêt à nos yeux une importance spéciale, puisque nous entrons dans la période contemporaine de ces relations.

Le pape, en retour de la consécration religieuse du nouvel empereur, comptait bien recevoir Bologne, Ravenne et Ferrare ; en outre, il espérait, à brève échéance, de la magnanimité de Napoléon, le rétablissement des ordres religieux et l'abolition des articles organiques. Sa déception fut cruelle, car il n'obtint rien et, dès ce jour sans doute, il n'aspira qu'au retour des Bourbons. La prise d'Ancône exaspéra encore d'avantage ses sentiments d'hostilité à l'égard de l'empire. Plus tard, l'occupation de Civita-Vecchia mit le comble à son indignation. Le mariage de raison entre l'Église et l'État avait eu pour effet, presque immédiat, de susciter querelles sur querelles. Napoléon, il est vrai, était un prince trop remuant ; mais, de son côté, le pape apportait tout son mauvais vouloir à l'expédition des affaires religieuses de la France. Et ce n'est point tant parce qu'il an avait contre l'empereur, mais bien plutôt parce que traiter avec l'autorité laïque lui était insupportable. Lorsqu'il réclamait avec tant d'insistance la restitution de toutes les parties de son domaine temporel, c’était pour que l'intégrité de son autorité spirituelle sur son armée cléricale ne fût pas atteinte par une diminution de sa puissance matérielle et qu'il pût mieux écraser les États du poids de sa domination. Dès qu'il lui paraît que, sur les champs de bataille, Napoléon court à un échec, aussitôt il s'applique à entraver lui-même ses relations avec la France, à rendre son administration religieuse plus tracassière, lente, compliquée. Mais, de plus en plus, Napoléon fait sentir à la cour de Rome que c'est sa déchéance temporelle qu'il vise et qu'il obtiendra, si les relations ne s'améliorent pas ; l'invasion de l’État pontifical par le général Miollis était un commencement d'exécution du projet impérial qui se réalisa définitivement, quelques jours plus tard, par la main-mise sur la puissance spirituelle du pape. Tout le sacré collège fut épuré des cardinaux qui 
entretenaient des intelligences avec les Bourbons, et, le 17 mai 1809, les États pontificaux étaient annexés à l'empire. La papauté temporelle n’était plus. Néanmoins, le pape conservait son autorité spirituelle.

Napoléon n'hésita pas à s'y attaquer ; l'enlèvement de Pie VII n’a pas d'autres raison, et il est indiscutable que la destruction du saintSiège était dans la pensée de l’empereur.

La seule vengeance permise au pape ne pouvait être que le refus de l'institution canonique. Et du reste, le Concordat subsistait-il réellement ? L'une des parties contractante avait enfermé l'autre à Savone !

Napoléon ne trouvait pas l'expédient capable de mettre un terme à ces difficulté inextricables. Il s'en remit du soin de la chercher à une commission ecclésiastique, mais ce n'est pas une solution qu'il lui demandait. Il désirait être simplement instruit sur les véritables droits de l’Église.

Les travaux de la commission traînèrent, puis furent brusquement interrompus par le vote d'une loi réglant les rapports du pape et de l'empereur. L'État pontifical formait deux départements français. Le pape ne disposerait désormais que de son autorité spirituelle ; deux millions de revenus lui étaient assurés et l'empire aurait la charge des dépenses du sacré collège et de la propagande. En outre, les quatre propositions de 1682 étaient proclamées lois de l'empire.

Le Gouvernement donnait ensuite l'ordre à tous les cardinaux romains d'évacuer les domaines pontificaux, et il faisait saisir les archives du Vatican.

Les menées, qui s'exercèrent autour de la captivité du pape, les complots royalistes, qui, sourdement, se tramaient dans l'ombre, éveillèrent les soupçons de l'empereur. Il vit que le schisme conduisait à la restauration et se décida à convoquer une seconde commission ecclésiastique pour parer du danger.

Elle se proposa trois objets principaux : $1^{\circ}$ prévenir les communications avec le pape ; $2^{\circ}$ faire adopter une mesure relative à l'institution canonique ; $3^{\circ}$ faire rendre la liberté au pape. 
Quand la commission et terminé ses travaux, à la fin mars 1811, quatre de ses membres allèrent en députation auprès du pape lui annoncer que l'empereur consentait à revenir au Concordat de 1801 si les évêques nommés étaient institués ; que, de plus, il pourrait se rendre à Rome, s’il prêtait le serment prescrit par le Concordat. S'il refuse, il résidera à Avignon, avec la liberté d’administrer à sa guise le spirituel, et un concile d’Occident sera convoqué.

Le pape, en réponse aux négociateurs, rédigea une note par laquelle il s'engageait à accorder l'institution canonique aux sujets nommés, mais il ne signa que le premier article des quatre propositions.

Il est compréhensible que devant toutes ces intrigues l'opinion restât confondue. La convocation d'un concile œcuménique pour le 9 juin 1811 fut un nouvel événement qui attira l'attention du monde catholique.

Ce concile était formé de tout l'épiscopat de France, d'Italie et d'Allemagne ; il se tint à l'archevêché de Paris. Son objet était de régulariser l'ordre de l'institution canonique. M. de Pradt fait remarquer que les Italiens paraissent plus gallicans que les Français et ceux-ci plus Italiens, plus Romains que gallicans : voilà qui indique que l'un des effets les plus remarquables de Concordat avaient été de rapprocher l’Église de France de la Rome papale.

Dès l'ouverture du concile, lecture fut donnée d'un message impérial ; c'était une violente critique de l'attitude du pape, depuis la signature du Concordat. L'intention formelle de Napoléon s'y trouvait formulée, d'instituer dorénavant les évêques selon les formes antérieures au Concordat, sans que jamais un siège pût vaquer au delà de trois mois. Cette volonté du maître, que l'on sentait planer menaçante déplut au concile ; ses membres demandèrent que la liberté de discussion fût respectée par le Gouvernement et, comme il n'en était rien, chacun s'employa à déranger l'ordre des travaux.

La commission des évêques proposa de déclarer le concile compétent pour statuer sur l'adoption du mode d'institution par le métropolitain, quand il y avait nécessité. Pareille proposition ne manqua pas 
d'être repoussée; le concile entendait que le pape, en matière d'institution, fût le seul maître de déclarer incompétent ; c'était aller au devant de la dissolution. Des discussions sans fin prirent naissance. Napoléon s'apercevait qu'un sentiment de vive hostilité contre sa personne se manifestait en toute occasion. Loin de devenir conciliant, il montra à tous que sa volonté était prépondérante. Les ministres déclarèrent au Corps législatif que le Concordat n'existait plus et que les évêques assemblés n'avaient pour objet que de pourvoir aux sièges vacants. Dès lors, toute idée de réconciliation paraissait bannie. De son côté, le concile n'eut plus à cacher son jeu ; il affirma sa politique romaine.

Cependant, désireux de préparer un terrain d'entente, Napoléon essaya de faire prendre le change à la commission du concile en lui annonçant que le pape entrait dans ses vues. La supercherie était trop évidente. Le concile, un instant abusé, s’abrita de nouveau sous l’autorité suprême du pape.

Napoléon prit un décret de dissolution et envoya au donjon de Vincennes les chefs de l'opposition.

Le procédé ne fut pas sans produire quelque effet sur l'esprit des prélats ; ils se montrèrent disposés à venir à résipiscence pour peu qu'on les y engageât. Napoléon aussi désirait transiger à tout prix. Le concile démembré fut de nouveau réuni ; le projet impérial se trouva être du goût de tout le monde et son adoption se fit sans difficulté.

Il était donc admis que les sièges épiscopaux ne pourraient être vacants plus d'un an ; l'empereur nommerait les candidats et, dans les six mois, le pape devrait donner l'institution canonique. En cas de refus, le plus ancien évêque de la province ecclésiastique présidait à l'institution.

Ce décret devait être soumis à l’approbation du pape.

Une seconde députation, composée de cinq cardinaux, fut envoyée à Savone. Le pape accéda à tout ce qui lui était proposé et sanctionna le décret du concile. 
Le bref du pape paraissait être selon les désirs de Napoléon; néanmoins, celui-ci crut lire entre les lignes l'expression d'une indépendance invincible, de revendications temporelles, et il se demanda s'il n'était pas joué. Il en eut bientôt la certitude quand, après un long retard, les bulles d'institution canonique parurent ; le pape parlait en maître comme si Rome était son domaine. Les bulles ne furent pas publiées.

A cette époque, les événements de Russie pressaient Napoléon ; aussi voulait-il en finir avec la question du pape. Rien ne semblait plus difficile. Pie VII se refusait à renoncer à la souveraineté de Rome et Napoléon retardait la publication du bref parce que les prétentions papales y étaient trop visibles. D'autre part, l'absence de conseillers apostoliques auprès de lui interdisait au pape d'entamer de nouvelles négociations.

Napoléon avait hâte de brusquer les choses. Il fit connaître au pape que, si le bref n'était pas révisé, le droit d'instituer les évêques ne appartiendrait plus. Le pape répondit qu'il n’obéirait pas aux injonctions tant qu'il ne jouirait pas d'une pleine liberté. Nouvelle sommation, et, cette fois, plus autoritaire que jamais. Mais elle resta sans résultats. Il fut donc notifié au pape que les Concordats étaient abrogés et qu'il n’aurait plus à intervenir dans l'institution canonique.

Le clergé, s’étant, à maintes occasions, montré outré de la conduite de l'empereur à l'égard du pape, ne se contint plus et fulmina au grand jour contre le maître de la France. La réponse ne se fit pas attendre.

Un décret du 15 novembre 1811 porte un coup terrible à l'enseignement religieux, en exigeant que les élèves des institutions libres suivent les cours des établissements laïques et en inscrivant que toutes les écoles pour candidats à la prêtrise soient soumises à l’Université ; que, du reste, il n’en soit toléré qu'une par département. En outre, les élèves des séminaires n'obtiendront aucune sorte de bourses, et ils seront soumis au service militaire. Les arrestations de prêtres loyalistes se multiplient à ce moment, et les chapitres doivent obéissance aux évêques nommés par l'empereur. Enfin, le pape est transféré de Savone à Fontainebleau, ce qui paraît aggraver le caractère de sa captivité. 
Mais après le désastre de Russie, l'empereur revint plus conciliant. L'alliance avec l'Église lui parut une consolation à ses déboires ; il fit tout pour aboutir à un rapprochement. Le 29 décembre 1812, l'empereur écrivit ses intentions à Pie VII. Peu de temps après, l'évêque de Nantes se présenta auprès du pape en négociateur. Mais cette première tentative resta vaine. Napoléon alla lui-même à Fontainebleau, le 18 janvier. Quelques jours suffirent pour amener une entente parfaite, et le 25 janvier, le Concordat de 1813 était signé.

Le pape devait exercer le pontificat en France et dans le royaume d'Italie de la même manière et dans les mêmes formes que ses prédécesseurs. C'était déjà une sérieuse concession à l'Église. Mais le but de ce concordat était d'établir une institution canonique régulière : il fallait que les vacances indéterminées de sièges devinssent impossibles. Sur ce point, il paraît que Napoléon a pu dicter ses propres instructions. Six mois étaient accordés à l'empereur pour nommer et six mois au pape pour instituer ; les six mois expirés, le métropolitain, et à son défaut l'évêque le plus proche, aurait à procéder à l'institution.

Mais, Pie VII avait bien tenu à signifier qu'il acceptait ces dispositions par “considération à l'état actuel de l’Église.”

Napoléon, heureux d'être enfin parvenu à une résolution acceptable, offrit au pape $300000 \mathrm{fr}$. Pie VII les refusa. Il ne pouvait se résoudre à accepter la paix, et il attendit une occasion pour revenir sur ses engagements.

En effet, l'article sur l'institution des évêques était, à ses yeux, la négation même de la souveraineté spirituelle, et toutes les concessions qu'avait pu lui faire Napoléon ne rachetaient pas ce douloureux sacrifice. Pourtant, l'empereur étant allé jusqu'à l'extrême limite des concessions que pouvait permettre le souci de son prestige et la sauvegarde de ses droits.

N'avait-il pas, avec l'abandon des articles de 1682, remis au pape les évêchés de ses états pontificaux ? 
Mais qu'était cela pour le pape ? Ce qu'il réclamait, c’était l'intégrité de sa puissance et, ne reculant pas devant une nouvelle rupture, il refuse les bulles instituant les nouveaux évêques. Puis, par une lettre datée du 24 mars, il reprit sa parole. Le lendemain même parut un décret rendant obligatoire le concordat de 1813 à tous les archevêques, évêques et chapitres, et déférant aux cours impériales, et non plus au conseil d’État, le recours comme d'abus.

Il n'était plus possible de conclure un accord. Napoléon s'y résigna. Il pourvu d'évêques les diocèses vacants et s'interdit toutes relations avec Pie VI. Dans la suite, il réfléchit que se réconcilier avec le pape serait d'un heureux effet sur l'esprit de ses ennemis, et il fit dire à son prisonnier que la souveraineté temporelle ne lui serait plus contestée s'il agréait l'amitié de l'empereur. Pie VII se refusa à de nouvelles ouvertures, "la restitution de ses états, disait-il, étant un acte de justice".

Pareille situation eût été sans issue si les coalisés, en abattant l'empire, n'avaient en même temps rendu au chef de l'Église sa pleine et entière liberté.

Ils la lui rendirent trop complète pour que les Bourbons pussent échapper à son emprise théocratique. Ce furent eux qui, en livrant l'État aux chaînes de l'Église, permirent à celle-ci de reprendre un nouvel essor, une puissance qui pèsera sur tout un siècle et contre laquelle le pouvoir laïc n’essaya de lutter que par intermittence.

Après Coblentz, une nouvelle génération sacerdotale envahissait la France. L’Église devint double. Il y avait plusieurs évêques pour un seul siège, et le clergé resté en France n'était que toléré. Une refonte le ferait disparaître.

Telles étaient les disposition d'esprit des hommes de la Restauration à l'égard de l'Église, de la Révolution et de l'empire. Leur programme réformiste était dicté par la même haine des années vécues depuis 1789.

Les rapports entre l'Église et l'État redevenaient ce qu'ils étaient sous la monarchie. Par conséquent, l’Église reconquérait sa puissance 
temporelle. Les anciens diocèses étaient reconstitués et le clergé doté en biens-fonds ou en rente perpétuelles. Les ordres religieux pouvaient accroître leurs biens indéfiniment. Les évêques réfractaires, connus sous le nom de "petite Église", émettaient encore d'autres prétentions.

Louis XVIII n'était pas d'avis de les suivre jusqu'au bout de leurs prétentions. La charte proclame la liberté des cultes, mais elle dit que le catholicisme est la religion de l'État. Les prêtres constituaient son entourage et le circonvenaient. Après avoir détruit l'Université, le 17 février 1815, Louis XVIII proposa à Rome de rétablir le concordat de François $\mathrm{I}^{\mathrm{er}}$; mais Pie VII répondit que le Concordat de 1801 avait été librement consenti par lui.

Le retour de Napoléon interrompit les négociations.

La seconde Restauration déchaîna les fureurs réactionnaires que l'on connaît. Elle voulut, plus encore que la première, l'Église toutepuissante. Non seulement le parti des prêtres réclamait la restitution des biens non vendus, mais même une inscription de rentes au grand livre de la dette publique. Ses revenus eussent été de 82 millions. La chambre introuvable regimba contre de telles prétentions. Il y eut des royalistes assez avisés pour affirmer que l'État avait le droit de supprimer les corporations ; que, par suite, la propriété de ces corporations appartenaient légitimement à l'État. L'article concernant le retour à l’Église des domaines non vendus fut seul voté.

L’Église ne se tint pas pour battue. La souveraineté par l'argent lui échappant en partie, elle réclama le monopole de l'enseignement afin d'imprimer une empreinte ineffaçable sur l'esprit des générations futures et d'assurer ainsi son règne moral.

Louis XVIII se vit déborder par les prêtres et leurs partisans ; il inclina vers un léger libéralisme et fit reprendre les négociations avec Rome.

Le 25 août 1816, l'ambassadeur du roi auprès du souverain pontife put enfin expédier à son gouvernement un projet de concordat. Le concordat de 1516 serait rétabli, mais celui de 1801 n’était pas annulé. Seuls, les articles organiques devaient être établis. En outre, le pape 
exigeait la démission des évêques qui ne reconnaissait point le Concordat de 1801.

Ces propositions n'eurent pas le don de plaire à Paris. Le gouvernement monarchique n’était point opposé aux articles organiques.

\section{Le Concordat de 1817}

$\underline{\text { Retour à la table des matières }}$

De nouvelles négociations aboutirent. Le 11 juin 1817, le quatrième concordat avait pris forme. Son apparition remua extrêmement l'opinion. Elle donna naissance à un nombre considérable d'écrits, la plupart contre cette convention.

On était, en effet arrivé à une époque où tout acte religieux émanant de Rome inspirait une vive défiance. La plus violente critique porta sur ce point que le Concordat est tout de matière bénéficiale, alors qu’il n’y a plus de bénéfices. Et ces bénéfices, il n’est pas dit quel en sera le nombre ni qui les payera.

L'opinion se révoltait contre l'abolition des articles organiques, parce que publiés, disait le Concordat, sans l'aveu du saint-Siège et, parce que contraires à la doctrine et aux lois de l'Église. Or en quoi atteignaient ils ces lois ? On ne saurait le spécifier exactement ; mais il est probable que le principal grief du pape consistait à reprocher à ces articles la liberté qu'ils accordaient aux ordinaires d'informer sur les évêques nommés.

Enfin, l'augmentation des sièges épiscopaux paraissait exorbitante ; l'État oubliait trop que c'était le contribuable qui devait en faire les frais. "L'ordre religieux se maintient par tributs publics, les établissements religieux ne peuvent être multipliés que par impôts.” cette vérité, M. Frayssinous la méconnaissait trop, lorsqu'il disait qu'il est bon de multiplier les sièges pour qu'il y ait plus de prêtres et plus de vocations. A quoi M. de Pradt répliquait : "M. Frayssinous entend-il que la France devienne une tribu de Levi uniquement occupée à produire des prêtres et de provoquer des vocations ?’ D’autre part, les évêques 
choisis étaient ceux qui s'étaient signalés par une longue opposition à la constitution civile, à la Révolution et à l’Empire.

L’opinion publique n'était donc pas sans inquiétude. Pour la rassurer, le Gouvernement publia un projet de loi garantissant les libertés. Mais il n'atteignit que difficilement son but.

Le Concordat paraissait antinational au premier chef. Il était contraire au droit public, au gouvernement constitutionnel, au droit du gallicanisme. La France s'était laissée imposer quatre-vingt douze diocèse ; elle avait toléré que le pape, pour pourvoir à l'entretien de l'Église, assignât lui-même une dotation en bien-fonds ou en rente de l’État.

Dans toutes ces dispositions, le Concordat et la bulle de circonscription avaient l'aspect d'une provocation à la société nouvelle.

On a dit qu'à cette époque la France devenait une "terre d'indemnités”. Rien n'est plus vrai. Le budget de 1818, à la charge du Trésor, était de 29 millions, et encore faut-il ajouter à ce chiffre les dépenses locales, les suppléments de traitements, les entretiens de cathédrales, d’évêchés, etc., etc.

Mais le Gouvernement se ressaisissait. Il décida qu'un projet de loi serait présenté aux Chambres pour rendre la convention de 1818 plus acceptable ; mais, peu après, il le retira, pour ne pas courir le risque d'aller à un échec. Il aima mieux se contenter d'envoyer à Rome un négociateur pour amender le Concordat ; ce fut le comte Portalis. Un accord eut lieu entre Rome et la France sans qu'il y eut abrogation du Concordat. Il constitue la France en pays d'obédience, c'est à dire que les évêques en fonction ont l'autorisation d'administrer les nouveaux diocèses. Cet accord, qui n'avait pour but que de pourvoir aux sièges vacants, fait dépendre du pape tout l'ordre religieux.

Le clergé se plaignait d'avoir été tenu à l'écart de cette dernière négociation avec Rome ; on pouvait lui répondre qu'il avait pris soin de faire défendre ses intérêts par le pouvoir temporel. Cette observation qui faisait écrire à un homme d'État de l'époque : "Le clergé continue d'attacher son salut à la protection du temporel.” 
Le temporel d'alors ne méritait pas le reproche de ne pas assez prendre soin du clergé.

Dans son rapport, le ministre de l'intérieur trace au roi le tableau ancien et nouveau de l’Église en France.

Avant 1815, le budget du clergé actif était de 11500000 fr.

En 1819, il est de 25 millions. Les pensions ecclésiastiques se montent à 11 millions.

Et cette somme de 33 millions était doublée, chaque année, par les suppléments de traitement que votaient les conseils généraux et les communes.

Le traitement des curés de 1re et de 2e classe augmentait en proportion de l'âge. Les vicaires généraux et chanoines étaient inscrits pour une somme de $5000 \mathrm{fr}$. Les archevêques et évêques pour la somme de 10000 à 50000 fr. Les séminaires recevaient un supplément de pension de $300000 \mathrm{fr}$. Les congrégations religieuses avaient à se partager la somme de $200000 \mathrm{fr}$. Et pour la réparation des églises, on prévoyait une somme de $650000 \mathrm{fr}$.

Le clergé manifestait cependant le plus vif mécontentement. Dans leur lettre au pape, les évêques, sous prétexte de réclamer l'exécution du Concordat, se plaignent de la précarité de leur traitement. Le roi dut s'engager à faire jouir le clergé "d'une position stable et définitive” et d'augmenter le nombre des sièges épiscopaux, selon sa promesse et selon les "formes constitutionnelles".

Mais, répondant au clergé, le pape annonce que le Concordat est suspendu, parce que la création des quarante-deux nouveaux sièges est cause d'embarras financiers et que le royaume ne cesse d'apporter des obstacles à l'exécution du Concordat.

Les évêques en fonctions conservaient l'administration des circonscriptions, conformément à la bulle de 1801, et le pape instituait les évêques nommés aux sièges vacants. 
L’avortement du Concordat exaspéra le parti clérical. Jamais, a-t-on écrit, la cour de Rome n’a reçu “d’hommage aussi ardents”. Et quand les royalistes et les ultramontains arrivèrent au pouvoir, après la chute du libéral Decazes, l’église triompha pleinement.

Dix-huit nouveaux sièges furent crées. La France était soumise à Rome. Les contestations n'étaient plus possibles, puisque le Gouvernement avait aliéné se droits de gouvernement libre. La question primordiale qui parut nécessiter le Concordat, la régularisation de l'institution canonique, n'a plus sa raison d'être; les ultramontains agissent comme bon leur semble, suivant les intérêts de l'Église universelle.

La Révolution de 1830 ne fut pas irréligieuse, mais les hommes qui en bénéficièrent paraissaient résolus à repousser les entreprises théocratiques et à débarrasser le Gouvernement des doctrines ultramontaines. Ils ne purent y réussir, soit que leur énergie combative n'égalât pas celle du parti clérical, soit que la conscience des nécessités politiques modernes leur fit défaut.

Et cependant le programme d'action anticlérical était dicté, pour ainsi dire, par l'église elle-même. Elle visait, pour l'instant, à l'anéantissement de l’Université ; il était donc de toute nécessité de protéger et d'affermir celle-ci. Les congrégations, affluant de tous côtés, attendait la chute de la rivale pour s'emparer de l'enseignement et arrêter l'essor des idées d'émancipation ; il importait d'appliquer les lois contre certaines d'entre elles et de dissoudre les autres. Rien de tout cela ne fut fait.

Le clergé séculier, aux ordre de Rome, put, sans risques ni péril, mener la contre-révolution, de concert avec le clergé régulier. Ils firent tourner au cléricalisme le plus éhonté, le Gouvernement de Juillet ; ils dénaturèrent l'œuvre révolutionnaire de 1848 ; ils préparèrent le coup d'État de Décembre et triomphèrent sous ce régime, qui abattit définitivement l'enseignement universitaire, favorisa les congrégations, protégea le concile de 1869 et accomplit, en moins de vingt ans, un tel effort de réaction, que la troisième République en est réduite à étayer 
l'édifice politique de la Révolution sapé, durant près d’un siècle, par ses pires ennemis.

Le labeur est immense, car les crimes commis contre la liberté sont innombrables ; mais nous atteignons le moment où nous verrons la chaîne se renouer.

Déjà, par la libération de l’Université, par la loi sur les congrégations, un vaste terrain est reconquis. Nous voici un jour où la séparation de l'Église et de l'État mettra fin à ce mariage insensé, contre nature, de deux parties qui ne parlent pas le même langage et qui sont d'espèces différentes.

En 1830, il est incontestable cependant qu'une victoire fut remportée. On supprima de la charte que le catholicisme est la religion d'État. Un pareil acte contenait comme l'engagement implicite de rompre tous les liens concordataires avec l'Église. Lamenais, d'ailleurs, ne s'y trompera point quand, un peu plus tard, il écrira que la séparation est inscrite dans la charte du 7 août.

Cependant, en l'absence de toute nouvelle réglementation, les principes du Concordat de 1801 et des articles organiques constituèrent la base des rapports entre le Vatican et le gouvernement français. Mais le pouvoir laïque restait incapable de faire respecter ce Concordat, qui n'avait pour raison d'être que de l'asservir à l'Église ; tandis que les obligations de l'État vis-à-vis du clergé étaient énormes, celui-ci demeurait en dehors de tout engagement. Il y a plus : le clergé combattait l'esprit dont s'était inspiré le Concordat en travaillant à ruiner l'autorité civile et à se substituer à elle.

\section{Campagne séparatiste}

Retour à la table des matières

Certains ecclésiastiques répugnèrent à jouer ce rôle, non par pure moralité, mais pour assurer le repos à leur conscience et pour combattre avec plus d'indépendance ; ils s'élevèrent contre le Concordat et 
en demandèrent la suppression. Un grand mouvement d'opinion prit ainsi naissance: Lamennais, Montalembert, Lacordaire, tous ultramontains déterminés, en étaient les promoteurs. Leur conception n'était pas sans grandeur. Partisans de la prédominance du spirituel sur le temporel, ils revendiquaient pour l'Église une indépendance absolue. Libre, elle saurait conquérir la suprématie à laquelle elle est appelée par la loi divine, s'emparer de ce qui est de sa compétence et que l'État s'est approprié. L'Église seule a pour mission de régénérer l’humanité.

Lamenais et ses sectateurs ne pouvaient désavouer les conquêtes de la Révolution, puisque, dans leur pensée, l'Église se substitue à l'État pour réaliser le bonheur des peuples. Dès lors, l’Église doit être ellemême et non plus compromettre sa cause en servant des dynasties et des oligarchies ; et, en se séparant de l’État, en refusant fidélité aux factions politiques, en n'étant qu'universelle et apostolique, il ne serait plus possible de l'abîmer d'accusation affreuses : complaisances envers le gouvernement, convoitises temporelles, atteintes aux droits de l'homme.

Pour vivre sa vie propre, il ne fallait à l'Église que la liberté et l'égalité. Et, à la monarchie de Juillet se réclamant de la Révolution de 1789, ce sont toutes les liberté que Lamenais demandait pour elle : liberté des cultes, de l'enseignement, de la presse, de réunion. Afin de mieux défendre, avec sa belle ardeur, ses théories, Lamenais fonda, en octobre 1830, un journal politique, l'Avenir, qui, dès son premier numéro, indiquait sa tendance :

"Tous les amis de la religion doivent comprendre qu'elle n'a besoin que d'une seule chose, la liberté. Sa force est dans la conscience des peuples, non dans l'appui des gouvernements. Elle ne redoute de la part de ceux-ci que leur dangereuse protection, car le bras, qui s'étend pour la défendre, s'efforce presque toujours de l'asservir..." La campagne de l'Avenir dura un an. Elle fut ardente, impétueuse, mais remarquable par sa logique et sa bonne foi. Maints articles fourmillent d'argument en faveur de la séparation, qui, si elle doit affranchir l'Église d'une tutelle qui lui fait horreur, n'en sera pas moins féconde en avantages pour l'État. 
Et l'on ne saurait dire que l'opinion de Lamenais demeurait sans écho. Innombrables sont les lettres que le directeur de l'Avenir recevait des membres du clergé et qu'il publiait à la bonne place. Plusieurs prêtres d'un diocèse du Nord lui écrivent que le clergé "ne sera hostile à aucun gouvernement qui lui laissera toutes les libertés et tous les droits spirituels qu'il tient de la divine institution. Plus de nominations aux évêchés et aux cures par les hommes du pouvoir, plus de budget ecclésiastique. Nous voulons une liberté large, sauf la soumission aux lois et au droit commun”.

Un autre groupe de curés signe cette autre déclaration : "Nous ne demandons au Gouvernement ni protection ni privilèges. Nous préférons notre indépendance et la liberté à de prétendus bienfaits. Entre Dieu et le Trésor, il faut choisir. La liberté de notre conscience, de notre culte, de notre hiérarchie, voilà notre premier besoin.”

Les appréciations de la presse parisienne sur la campagne de l'Avenir furent très divers. Le Globe dit que l'État continuera à payer le clergé, parce qu'il ne pourra se passer d'un Salvum fac. Le Courrier français souscrit à l'opinion de Lamennais. Liberté pour tous ; par ce moyen, on déchargeait le budget national de 36 millions. La Gazette de France craint que la suppression du budget des cultes n’entraîne la chute de la plus grande partie des établissements ecclésiastiques. Le Journal des Débats fait des réserves ; il s'étonnerait qu'on accordât à une classe d'hommes une liberté sans surveillance, que nul ne possède dans l'État. A cette objection, l'Avenir répond : “L’État connaît le citoyen ; il ignore le prêtre ; le prêtre n'est atteint par l'État que quand il viole une obligation de citoyen."

Cependant, le Courrier français, favorable à la séparation, se demandait si "ce projet plairait aux archevêques, évêques et aux prêtres catholiques. L'archevêque de Paris consentirait-il jamais à renoncer à son palais épiscopal, à ses 100000 fr. de traitement et à Conflans ?” Et le Courrier raille M. de Frayssinous possesseur de "canapés soyeux", d'un "billard”, entouré de "toutes les jouissances de la vie”.

Ces encouragements permettent à Lamenais de triompher. Il proclame que "la religion ne peut être sauvée que par la liberté, et que la 
condition de cette liberté est la séparation totale de l’Église et de l’État”.

Et, à tous ceux qui veulent des atermoiements, il demande "si les rapports qui unissaient l'Église à l’État, lorsque celui-ci était catholique, peuvent subsister lorsqu'il a cessé de l'être”.

Alors, prenant une plus exacte conscience de la justice de la cause qu'il défend, à ses arguments secs, rudes, impitoyables il mêle des invectives, un esprit sarcastique, dont ses adversaires se montrent confondus :

"Si Néron ressuscitait, écrit-il, et qu'il envoyât un prétorien vous demander un Te Deum, on vous condamnerait à le chanter. S'il réclamait votre bénédiction avant de frapper le ventre de sa mère et que vous eussiez l'audace de la lui refuser, tous les préfets de l'empire vous adresseraient une proclamation, au nom de l'honneur et de la patrie, pour vous rappeler que vous vivez des bienfaits de l'État. Car, entendez-le : ils exigent de vous des prières dont votre conscience ne reste pas juge et ils l'exigent en n'invoquant qu'une raison ; c'est que vous êtes payés ; ils n’ont pas besoin d'être justes : vous êtes payés.

"Ils n'ont point de compte à vous rendre : vous êtes payés... Catholiques! voilà ce que vous coûtent les millions de l'État : la liberté de conscience."

Ainsi, par respect pour la dignité de l'église la séparation de l’Église et de l’État s'imposerait.

Elle s'imposerait, parce que, nous dit Lamennais, "L’Église veut accomplir ses destinées”. De quel droit l'État peut-il l'en empêcher? Si ces destinées sont périlleuses pour lui, il saura intervenir, pensent aujourd'hui les partisans de la séparation.

On connaît la fin de Lamennais et de ses théories, Celles-ci, il n'en faut pas douter, furent partagées par l'ensemble du clergé, par les humbles curés qui aspiraient à "n'avoir que dieu pour patrimoine". Mais elles furent désavouées par l'idole même de Lamennais, par le 
pape. Quant aux évêques, ils refusaient de devenir pareils aux "prolétaires”. Le 15 novembre 1831, l’Avenir dur cesser de paraître.

Mais les opinions qui y furent si âprement défendues ayant produit un certain ébranlement dans l'Église, le pape, par son encyclique du 15 août 1832, fulminait contre les principes de 1789, que le Concordat approuvait ; et, fait étrange, la séparation y était condamnée, comme attentatoire à la puissance spirituelle.

Les amis de Lamennais poursuivirent la lutte dans un sens qui ne pouvait que plaire à Rome. Ils ne parlèrent plus de séparation, mais réclamèrent la liberté d'enseignement et la liberté d'association.

La monarchie de Louis-Philippe s'inféodant de jour en jour au clergé, on ne voit pas ce qui pouvait empêcher le Gouvernement de céder aux instances de l'Église. Le budget des cultes atteignit la somme de 34491000 fr. en 1840 et il augmentait chaque année, selon une proportion constante. Grâce à un nombre considérable de sociétés religieuses militantes, les associations s'emparaient de tout le territoire français. Les couvents et fabriques ouvraient leurs caisses aux dons et legs ; la "main-morte" devenait formidable. les congrégations non autorisées violaient la loi, sûres de l'impunité et essaimaient leurs établissements en tous les départements, en toutes les régions. On disait que les jésuites sortaient "de dessous terre" ; et, dès qu'ils apparaissaient en quelque endroit, c'étaient des acclamations enthousiastes. Les doctrines des disciples d'Ignace de Loyola formaient la substance de l'enseignement donné dans des écoles religieuses. Une "association catholique”, composée d'éléments divers, se posait comme l'étatmajor de cette guerre à outrance contre la société civile ; elle encourageait les combattants et leur indiquait les tactiques de faire triompher Rome.

La mission des soldats du Christ était aisée, le gouvernement luimême ouvrant les partes aux ennemis de l'État.

Dès lors, grassement renté, officiellement protégé, libre de s'enrichir, bien stupide eût été le clergé s'il ne s'était plaint que la monarchie ne lui accordait pas les faveurs, les avantages auxquels il déclarait avoir droit. Selon ses dires, l’autorité laïque n’avait pas à lui 
mesurer ses libéralités ou plutôt, la restitution des pouvoirs spirituel ou temporel dont la Révolution l'avait frustré.

Louis-Philippe pensait sans doute comme le clergé. Et quand l'archevêque de Paris vint lui dire que l’Église réclamait la liberté de l'enseignement, s'il n'avait tenu qu'à lui de la décréter, il n’aurait pas su refuser à l’Église un régime sous lequel elle comptait écraser les dernières libertés.

Mais elle ne doutait pas du succès. Guizot, en 1836, lui avait donné des preuves certaines de son dévouement en autorisant la création d'établissement libres. En 1843, ses dispositions d'esprit ne paraissent pas moins favorables ; il se devait d'élaborer une loi enfin efficace, démolissant les derniers remparts du monopole universitaire.

En effet, le principe de la liberté de l'enseignement fut consacré par la loi ; mais le ministre Villemain, peu favorable aux jésuites, l'ayant présenté, le parti clérical ne voulut pas considérer la force qu'il en retirait. La surveillance et l'inspection de l'État étaient à ses yeux des survivances d'une époque impie, et l'article qui obligeait les directeurs à déclarer qu'ils n'appartenaient à aucune congrégation non autorisée était condamnable au premier chef par les lois de l’Église. Il disait que la liberté d'ouvrir des institutions, presque sous condition n'avait rien de loyal. Et Villemain se voyait voué aux gémonies, alors qu'il s’était efforcé de plaire à Montalembert et de mécontenter les Troplong, les Dupin, qui proclamaient les droits de l'État sur l'éducation publique.

De nouveau, l’Église fit entendre un branle-bas de combat. Elle réédita ses accusations contre l'État qui, dans ses écoles, encourageait le parricide, l'homicide, l'inceste, l'adultère, l'infanticide, etc. Le Gouvernement subissait les pires affronts, souffrait les menaces. Il n'était plus possible de faire face au débordement des passions cléricales. C'est alors que l'on remarqua, au palis Bourbon, parmi les partis de gauche, un courant d'opinion en faveur d'une rupture entière avec l'Église. Déjà en 1843, Lamartine, à la tribune, avait avoué qu'il ne connaissait qu'un moyen à l'État pour résister aux assauts des factions cléricales : la séparation. Quand, un an après, la loi Villemain fut mise en discussion, cette opinion, bien que prévalant chez les républicains, n’osa s'affirmer avec force et conviction. 
Le 24 mai 1845 à la suite de débats passionnés, la loi sur l'enseignement secondaire, amendée dans un sentiment clérical, fut adoptée par la Chambre des pairs. La surveillance et l'inspection n'appartenait plus à l'État, mais à un conseil de l'enseignement. C’était dire que l’Université n’avait plus la confiance du pays.

Cependant, la Chambre des députés ne paraissait nullement disposée à voter la loi. Thiers, rapporteur du projet, énumérait toutes les garanties auxquelles l'État ne pouvait renoncer. Son rapport bannissait les complaisances que l'on serait tenté d'accorder aux partis de l'Église. Et, timidement encore, il laissait entrevoir la nécessité pour le gouvernement d'enchaîner le cléricalisme par une loi sur les congrégations

Jamais les jésuites n’avaient été aussi redoutables. Incroyables était leur pouvoir sur les croyants ; et l'Église tout entière se trouvait entre leurs mains. Poussé par eux, l'archevêque de Lyon ne venait-il pas de condamner les articles organiques ?

Il avait une opinion favorable à la répression. Thiers ouvrit les hostilités ; il démontra que les lois sur les congrégations n’avaient cessé d'être en vigueur et que les évêques français inféodés à l'ordre des jésuites constituaient un "péril national”.

Son ordre du jour était explicite mais le Gouvernement ne cacha pas qu’il aimait mieux s’entendre avec Rome. Il en fut ainsi décidé.

Les jésuites s’organisèrent pour la résistance. Et, quand Rome répondit au Gouvernement que les jésuites n'existeraient plus en France, ils étaient prêts à interpréter à leur façon la volonté du pape. Ce fut une duperie.

Du reste, ce qui suivit montre amplement que Thiers et les autres avaient été joués.

Le comte de Salvandy, succédant à Villemain, élabora, à son tour, un nouveau projet de loi sur l'enseignement, de concert avec des 
conseillers à sa dévotion. L’Université n'était plus consultée. Le ministère l'avait achevée.

Aussi l’Église, reprenant confiance, assura le succès des élections de 1846. Ses candidats annonçaient que "la lutte pour la liberté religieuse n'aurait ni fin ni trêve”. Ils devinrent, au Parlement, une majorité importante. Et, pour le gouvernement, les élections prenant le caractère d'une indication formelle, la tolérance vis-à-vis de l'Église devint politique.

Sous le couvert même de l'État, qui cessait de jour en jour d'être laïque, les congrégations prirent une nouvelle vigueur, tandis que les professeurs, les fonctionnaires civils se voyaient dénoncés, persécutés, poursuivis. La délation des hommes et des doctrines était à l'ordre du jour.

Et le clergé, inassouvi, continuait à se plaindre. Son porte-parole auprès du pape fut l'archevêque de Paris lui-même. Le projet de loi Salvandy était devenu insuffisant. D'ailleurs, à quoi bon cacher son jeu? L’Église disait bien haut qu'elle voulait l'anéantissement de l’État.

Ainsi, durant tout le règne de Louis-Philippe, la lutte de l'Église contre l'État fut surtout dirigé contre l’Université. C’était elle qu'il fallait abattre pour que l'écroulement de tout l'édifice laïque s’ensuivit.

On sait que la révolution de 1848 fit surgir un état d'esprit à la fois socialiste, républicain et catholique. Sans doute, les idées de Lamennais avaient germé.

Dans ce retour aux doctrines de la primitive Église et à l'évangile, où la bourgeoisie libérale reconnaissait, sans difficulté, les rudiments d'un bon gouvernement démocratique, le haut clergé ne se berçait pas d'illusions. Ses visées n'avaient pas cessé d'être la conquête intégrale du pouvoir spirituel par l'enseignement et la soumission absolue de la France à l'ultramontanisme. 
Nul doute qu’à cette époque le clergé plébéien n’ait éprouvé une sincère sympathie envers les sentiments fraternitaires, mais chez les catholiques de haute volée, l'attachement aux opinions démocratiques n'était que calcul ; les faits qui suivirent ne le prouvèrent que trop.

Lamennais et certains de ses amis restèrent fidèles à leurs idées. Ils s'imaginaient que la séparation de l'Église et de l'État était une mesure qui ne pouvait que trouver bon accueil au sein d'une Assemblée libérale. Erreur ; la Constituante, après avoir affirmé qu'il est des devoirs et des droits antérieurs aux lois positives accorde la liberté à tous les cultes, sans renoncer à salarier le clergé.

Il est vrai que le Concordat, avec ses articles organiques, apparaissait comme un monument législatif quelque peu démodé, depuis qu'une Constitution, animé d'un souffle nouveau, régissait les Français. De bons esprits pensèrent que les rapports entre l'autorité et le pouvoir spirituel réclamaient une consciencieuse révision. Le comité des cultes eut à examiner des propositions ; mais aucune n'aboutit, les ecclésiastiques du comité ayant fait ressortir que les législateurs français, sans le consentement et les lumières du pape, ne pouvaient s’autoriser à refondre les lois concordataires.

En revanche, le comité consacra de longues séances à discuter des propositions de réforme, qui toutes s’inspiraient du souci de républicaniser le sacerdoce. Mais de nouveau on rencontra l'opposition des évêques. L’idée de 1789, d'appeler le peuple à l'élection des évêques, sans être théoriquement combattue, fut repoussée comme impraticable. De même, il ne fut pas possible de faire admettre que les desservants, ne jouissant pas de l'inamovibilité curiale fussent en droit d'être assimilés aux curés après cinq ans d'exercice. Mais les évêques avaient trop grand soin de défendre l'intégrité de leur autorité despotique pour qu’on pût leur adhésion à de telles formules.

Voilà qui montre suffisamment que l'Église, loin d'abandonner les privilèges qu'elle tenait du Concordat, manifestait, à chaque occasion, sa ténacité à défendre pied à pied le statu quo de 1801. Ce qui suivra fera jaillir les idées cachées et montrera que ses ambitions, sans limites, encore non avouées, aspiraient jusqu’à détrôner l'État. 
Pour atteindre à ses fins, elle avait sa politique. Rien ne lui aurait servi de découvrir son jeu ; avant de ruiner le prestige de l'État et de le démanteler, elle avait à l'utiliser.

L'autorité temporelle du pape étant mise en danger par les révolutions, qui allaient changer la face de l'Europe et constituer de nouvelles nationalités, le clergé n'eut de cesse, avant d'avoir convaincu le Gouvernement que les traditions françaises lui commandaient de courir au secours de Rome. Mais pour qu'un pareil acte pût s'accomplir, elle aperçut fort bien qu'une toute autre politique gouvernementale devait être inaugurée. N'est-ce pas elle qui a contribué de toute son influence au succès du coup d’État qui confia les destinées de la France au plus dangereux des princes ? En tant que président de la République, Louis-Napoléon lui avait donné les plus sérieux gages de son dévouement ; grâce à lui, le pape rentrait en possession de ses États et, par la suite, de sa puissance temporelle et l'enseignement prenait d'emblée un caractère nettement anticlérical. La main mise sur l'éducation, l'Église ne pensait réaliser que plus tard cet article de son programme ; d'un coup sa prédominance s'établissait au centre même du pouvoir national. C'était une seconde campagne de Rome, selon le mot de Montalembert, une “campagne de Rome à l'intérieur”. Le comte Falloux, ministre de l’instruction publique, la mena à bien.

Il présidait lui même la commission à qui était confié le soin d'élaborer la nouvelle loi. Thiers faisait fonction de vice-président, obéissant aux ordres de Dupanloup, de Montalembert, de Riancey. Les débats furent vivement menés ; mise en discussion en janvier 1850, la loi fut votée le 15 mars de la même année.

En voici les dispositions essentielles :

Un conseil supérieur de l'Université groupait huit membres de l'Université, trois archevêques, un évêque, un ministre protestant, un ministre de la confession d'Augsbourg, trois conseillers d'État et trois membres de l'Institut ; chacun d'eux était élu par ses pairs ; le gouvernement ne désignait que trois représentants de l'enseignement libre. 
Les attributions de ce conseil étaient suffisamment vastes pour priver l'Université d'une direction directe et effective de l'enseignement ; règlements d'examens, de concours, programmes, surveillance des écoles libres, autorisations de livres, créations de facultés, de lycées, etc., etc.

D’autre part, les conseils académiques dirigeaient sans contrôle enseignement primaire et enseignement secondaire qui étaient, l'un et l'autre, accessibles aux religieux. Le titre de ministre du culte suffisait pour professer dans les écoles primaires et aucune autorisation administrative n'était requise pour ouvrir une école libre, secondaire ou primaire.

De tous côtés, la loi ouvrait des voies d'accès à l'envahissement du clergé.

L'Église triompha et dès lors ne se crut plus tenue à cacher l'audace de ses entreprises. Après l'enseignement, l'assistance publique devint l'objet de ses convoitises. Le gouvernement n'eut garde de la mécontenter ; dans toutes les lois sur la bienfaisance, l'influence cléricale fut favorisée et devint prépondérante.

Le Concordat lui-même n’était plus observé. Les évêques quittaient leurs diocèses ; ils allaient à Rome recevoir des bulles pontificales. Bien plus, ils se plaçaient en dehors du droit commun sans être inquiétés ; les conciles, les synodes se multipliaient, alors que pour les autres citoyens la liberté de réunion avait disparu.

Il est tout naturel que les conséquences financières de cette renaissance cléricale aient été importantes. En 1848, le budget des cultes était de 42 millions ; en 1852, de 44 millions ; en 1858, il dépassait 46 millions.

En outre, l'État subventionnait de nombreuses communautés. Et les couvents, par les dons et legs autorisés et par des fidéicommis, atteignaient un chiffre de fortune considérable. En 1859, les congrégations étaient propriétaires de 14660 hectares de terre ; la valeur des immeubles leur appartenant s'élevait à 105 millions ; leurs valeurs en portefeuille restaient ignorées. 
Quant aux congrégations non autorisées, rien ne s’opposait au développement de leur influence et de leurs richesses.

Les prescriptions de l’autorité laïque était impunément violées.

La loi Falloux portait ses fruits. Les écoles primaires n’avaient qu'à de rares exceptions des instituteurs laïques. Et, dans l'enseignement secondaire, le nombre des lycées et des collèges diminuait, tandis que les établissements libres se multipliaient et prospéraient. En 1850, 914 écoles dirigées par des évêques, des prêtres séculiers ou des congrégations, étaient signalées ; en 1854, elles étaient au nombre de 1081. D’autre part, des séminaires pour enfants possédaient au bas mot 25000 élèves.

Enfin, les ordres hospitaliers prenaient une influence toujours plus grande. Les hôpitaux s'ouvraient aux sœurs de la charité ; les petites sœurs des pauvres, en moins de quatre ans, acquéraient pour plus de 25 millions de francs de biens-fonds déclarés. Des sociétés de propagande, sous le couvert de la charité, agitaient l'opinion et rendaient l’Église plus militante, plus active qu'elle n’avait jamais été.

Napoléon III laissait donc l’Église prendre soin de ses intérêts en lui accordant toutefois la plus large protection. Il n'avait que le soucis de marcher sur les brisées de son oncle et il rêvait d'être sacré pareillement par le saint-Siège. Mais celui-ci entrevoyait l'affaire sous l'aspect d'un marché ; il imposait ses conditions : abolitions des articles organiques et de la loi sur le mariage civil. Napoléon résista et les négociations avortèrent.

Le résultat fut un changement dans la politique de l'empire. La loi Falloux fut amendée dans un sens plus libéral : le nombre des académies passa de 86 à 16 et les recteurs jouirent d'une plus grande indépendance vis-à-vis de l'épiscopat.

Mais l'empereur allait avoir d'autres occasions de lutter contre l’ultramontanisme vainqueur. 
Pie IX, mis en goût par la puissance temporelle et spirituelle que depuis longtemps Rome n'avait pas possédée à un tel degré, formait le projet d'en finir avec les principes de la Révolution. L’Église, il se l'était promis, devait dépasser son omnipotence, en absolutisme, en intransigeance, tout ce que les papes rois du moyen âge avaient pu rêver.

En premier lieu, l'Église avait à s'affirmer infaillible. Pie IX n'avait pour cela qu'à agir en souverain absolu, au mépris de tout concile œcuménique. Il proclama donc, de sa propre autorité, le dogme de l’Immaculée conception de la Vierge, le 8 décembre 1854.

L’épiscopat, que Rome n'avait pas consulté, ne se rebiffa point, tant il s'était donné corps et biens, à l'ultramontanisme. Mais Napoléon témoigna quelque humeur contre Pie IX, qui décelait trop ouvertement sa fiévreuse ambition. Ensuite, l'empereur se rapprochait de VictorEmmanuel ; et ce ne pouvait être qu'au préjudice du pape, car un des premiers articles du programme piémontais était le démembrement de l'État pontifical. Dès que l'empereur le sut, il mit au service de la cause italienne l'armée et l'argent de la France ; mais, dès que son entourage lui présenta qu'il s'aliénait l'Église s’il persistait dans sa politique internationale, il signa avec l'Autriche les préliminaires de Villafranca.

Cependant, le peuple italien, qui voulait, à tout prix, réaliser l'unité nationale, ne comprit pas que l'on arrêta la révolution. Le traité de Villafranca disait, en effet, que la confédération italienne aurait le pape comme président honoraire, à la condition qu'il introduisit dans son royaume les réformes indispensables. Mais de telles stipulations ne pouvaient être prises au sérieux ; le pape se refusait à les admettre, tandis que les initiateurs du mouvement populaire entendaient que le mouvement unitaire ne reçût aucune entrave.

Cette agitation détruisit la bonne entente qui jusque-là avait régné entre l'empire et l'Église. Napoléon, attaqué par le haut clergé, encourageait ceux-là qui prêchaient au pape l'abandon de sa souveraineté temporelle. Et lui-même écrivit à Pie IX de renoncer à ses légations qui naturellement, par la force de choses, se détachaient de lui. 
La réponse du souverain pontife fut une encyclique déclarant qu'en vouloir à son autorité spirituelle équivalait à haïr son pouvoir spirituelle, et que les États du saint-Siège étaient la légitime propriété, non de la papauté, mais du monde catholique.

Ces véhémentes protestations n'empêchèrent pas l'annexion des légations pontificales au Piémont. Pie IX en fut réduit à excommunier ses spoliateurs.

Alors, le catholicisme, sans distinctions de nuances, déclare la guerre à l'Empire, “fauteur de désordre”, choryphée de l'anarchie. L’on vit se répandre des brochures cléricales, où les théories les plus séditieuses se donnaient carrière. D'un autre côté, les partis démocratiques reprochaient à l'empereur d'avoir manqué à ses engagements par le traité de Villafranca.

Le gouvernement impérial se maintient en protestant du dévouement de l'empereur au saint-Siège et en donnant des ordres pour que les troupes françaises quittassent Rome.

Cette duplicité ne pouvait qu'aggraver l'état de choses. L'empereur crut trouver un modus vivendi ; il fit connaître au pape qu'il était prêt à lui garantir l'intégrité des possessions qui ne lui avaient pas été confisquées, et que les puissances catholiques ne lui refuseraient pas un subside et un corps de troupe. L'orgueil du pape était trop irréductible pour qu'il acceptât ; c'est à l'aristocratie catholique qu'il se résolut à jeter un appel désespéré. On sait que ce ne fut pas en vain.

Un nouveau Coblentz sembla renaître à Rome, et l'irritation de Napoléon s'accrut d'autant.

L’audace du pape précipita le dénouement. Son armée, défaite à Castelfidardo, mit fin aux hésitations. Cavour ouvrit à Turin le premier Parlement italien.

L’Église, blessée au cœur, gémit et se révolta. Les mandements épiscopaux prirent la couleur d'appels à la guerre civile ; ils suscitèrent parmi les croyants la plus vive émotion. Et bientôt toute la bourgeoisie conservatrice, et même libérale, manifesta à l'égard de 
l'empereur une indignation telle que celui-ci, en manière de réponse, tempéra son absolutisme gouvernemental. Le sénat et le Corps législatif furent autorisés à juger la politique impériale, et le prince Napoléon eut toute la liberté pour combattre à la tribune la puissance temporelle de la papauté. On vit alors les partisans cléricaux de Napoléon passer dans le camps de l'opposition, exhaler leurs lamentations en face de leurs espoirs ruinés.

Napoléon, aigri par cette agitation, n’aurait pas répugné à se rapprocher de Rome ; mais Pie IX repoussait toutes les ouvertures de transactions comme injurieuses pour sa dignité. D'ailleurs, il n'était pas sans agir ; 280 ecclésiastiques venaient, par son ordre, d'affirmer l'inviolabilité des domaines pontificaux et de jurer fidélité à une théocratie absolue, négation radicale de tous les principes du droit moderne.

Toutes ces démonstrations accusaient plus profondément le divorce moral entre l'État laïque et l’Église. Napoléon le sentit tellement qu'il engagea la Russie et la Prusse à reconnaître le nouveau royaume d'Italie. Mais, cédant aux instances de certains conseillers, craignant que sa majorité d'autrefois ne tournât à la légitimité ou à l'orléanisme, Napoléon imprima à sa politique une direction nouvelle. A l'Italie, qui réclamait Rome pour capitale, il ne répondit pas ; au parti clérical qui, depuis des mois l'outrageait et le vilipendait, il fit des avances pour la constitution d'un ministère conservateur. Le maintien du pouvoir temporel du pape devint, aux élections de 1864, l'article primordial du programme des candidatures.

Néanmoins, Pie IX ne sut aucun gré à l'empereur de ce revirement. Il ne craignit pas de lui créer des embarras, dès qu'il en eut l'occasion. De vive force, il imposa la liturgie romaine au diocèse de Lyon. Et il s'obstina dans ses errements gouvernementaux, si opposés, si contraires aux principes de 1789.

Il est vrai que la France blessait les convictions du souverain pontife. Après l'opposition gouvernementale, de bons catholiques battaient en brèche sa politique théocratique. Au congrès de Malines, Montalembert fit le procès de l'Inquisition et réclama toutes les liberté, jusques et y compris celle de "l"erreur". 
De telles “hérésies” décidèrent enfin Pie IX à rompre les liens qui créaient quelques solidarité entre lui et les États laïques, à condamner radicalement les sociétés issues de la Révolution. La convention du 15 septembre 1864, par laquelle la France et l'Italie s'engagèrent à respecter Rome, si l'ordre n’y était pas troublé, parut au pape une menace dissimulée, d'autant plus que les deux gouvernements lui avaient laissé ignorer les négociations.

\section{Le Syllabus}

Retour à la table des matières

Pie IX n’y tint plus et se sépara avec éclat d'une société qu'il abominait. Le 8 décembre 1864, l'encyclique Quanta cura apprit au monde la rupture complète du droit laïque et des principes théocratiques, la déclaration de guerre ouverte, sans trêve ni merci, que le pape adressait aux gouvernements qui refusent de se soumettre à sa puissance temporelle et spirituelle. Et pour qu'il n'y eût pas d'équivoque, Pie IX spécifia dans le Syllabus les quatre-vingt propositions qualifiées: Erreurs principales de notre temps, que Rome tiendrait pour hérétiques.

La prépotence du pouvoir civil, la libre recherche de la vérité, les droits de la conscience, la neutralité scolaire, le droit civil, le suffrage universel, la police des cultes, la civilisation moderne, l'indépendance de la morale et de la philosophie vis-à-vis du catholicisme, la science, la liberté de la presse et de la parole, tels sont les objets principaux que le souverain pontife vise et réprouve. Enfin la séparation de l'Église et de l'État est la cinquante-cinquième proposition, que l'on ne saurait formuler sans encourir les foudres de la Rome papale.

Les catholiques se voyaient donc dans la nécessité de prendre parti pour l'État ou pour l'Église ; de proclamer celle-ci supérieure à celuilà ou d’abjurer leur foi. 
Beaucoup d'entre eux - le plus grand nombre - avaient, depuis longtemps, promis obéissance à Rome ; quant aux intolérants, ils résistèrent dans leur conscience aux injonctions de la papauté. Les évêques lancèrent des mandements destinés à faire connaître aux fidèles l'esprit de l'encyclique et du Syllabus ; dans leur chaire, ils commentèrent abondamment les deux documents romains. Un seul gallican osa les critiquer. Le gouvernement impérial, qui vainement s'opposa à la propagation des paroles papales, mis moralement en demeure de se prononcer, répondit, selon la coutume, d'une façon détournée, en projetant de faire décréter la gratuité et l'obligation de l'enseignement primaire. Duruy fut chargé du rapport. Mais Napoléon, circonvenu par Thiers et par un certain nombre de conservateurs, qui réagissaient contre l’opposition républicaine, désavoua le rapport Duruy.

Puis, quelque temps après, Pie IX ayant réprimandé les ecclésiastiques fidèles à l'empereur, Napoléon, las de cette ingérence continue de Rome dans ses affaires, se rapprocha de l'Italie unifiée, en ordonnant le rappel du corps d'occupation.

Cependant, comme il apparaissait de bonne politique de ménager les ultramontains, il déclara respecter la souveraineté temporelle du saint-Siège.

Mais il est nulles transactions qui puissent tempérer l'ardeur du clergé militant ; l'œuvre laïque de Duruy était maintenant le point de mire de l'Église. Que prétendait-il inaugurer ? La soumission des congrégations enseignantes au droit commun. Rome encourageait ses fidèles de France de ses prédications théocratiques. Pie IX, au mois de juin 1867, exaltait le Syllabus devant 450 évêques et projetait, ce même jour, la réunion d'un concile œcuménique pour décider que la politique nouvelle du saint-Siège sera enseignée comme un dogme et que l'infaillibilité pontificale deviendra un acte de foi. Il rêvait d'une monarchie papale et tenait à s'assurer le concours des évêques dans les luttes futures ; ceux-ci, après la destruction de l'Église monarchique, n'avaient plus que le pape comme objet de sincère attachement. Contre les révolutions politiques et sociales, qui pouvaient de nouveau survenir, ils estimaient que l'Église trouverait la force de résister aux assauts de ses adversaires dans la fusion intime des pouvoirs ecclésiastiques, dans l'absolutisme de ses doctrines et de ses commande- 
ments. Ce coup d’État religieux jugé nécessaire, un concile œcuménique fut convoqué pour le 8 décembre 1869.

Dans sa bulle d'induction de 1868, le pape indiquait que le but du concile était de fortifier la discipline ecclésiastique ; d'examiner et de déterminer ce qu'il convient de faire "en ces temps si calamiteux “ pour proscrire les "sectes impies" et "redresser les erreurs qui bouleversent la société civile”. De nouveau, le gouvernement impérial allait être anathémisé par le prochain concile ; ce n'était point douteux. Et pourtant il avait sacrifié à cette Rome intolérante la précieuse amitié de la jeune Italie, vaincue à Mentana par l'armée même de Napoléon. Contre ce pouvoir exorbitant du saint-Siège, qu'il avait à la fois louangé et blâmé, critiqué et protégé, il ne lui était plus possible de conclure une alliance pour la suprême sauvegarde du droit moderne.

Les intentions de l'Église ne pouvaient cependant faire illusion aux gouvernements des puissances dites catholiques. Pour lutter contre "l'esprit du siècle”, contre le “mal”, il n'était à ses yeux qu'un procédé : ériger en lois positives, en dogmes, le contenu et de l'encyclique et du Syllabus, affirmer les droits inébranlables de Sièges apostolique.

Du reste, la bulle de convocation, le 29 juin 1868, fut commentée dans la basilique de saint-Pierre en des termes tels que les fidèles et les dirigeants des nations purent avoir un avant-goût de ce que seraient les prochains débats du concile. Le concile, disait le doyen des protonotaires apostoliques, devra "réprimander tout vice et repousser toute erreur, afin que notre auguste religion et sa doctrine salutaire reprennent partout une vigueur nouvelle, qu'elles se propagent de jour en jour, qu’elles reconquièrent leur légitime empire”.

Les convocations furent faites aux cardinaux, aux évêques, aux abbés, selon les traditions des précédents conciles. Seulement, pour la première fois, les "princes laïques" ne reçurent aucune invitation. N'étaient-ce pas eux qui, autrefois, convoquaient les conciles, les imposaient au pape ? Benoît XIV remarquait même que la présence des princes ou celle de leurs ambassadeurs relevait l'éclat des conciles. 
La bulle de Pie IX ne faisait que s'adresser indirectement à ces "princes laïques” en un langage quelque peu dédaigneux : "Nous voulons croire, disait-elle, que les souverains et les chefs des peuples, particulièrement les princes laïques, reconnaissent de plus en plus avec quelle abondance tous les biens découlent de l’Église sur la société humaine..."

Mais n'était-ce pas consacrer, par une situation de fait, la rupture politique entre les États moderne et l'Église, que de ne point inviter les princes laïques à assister aux travaux du concile ? Par la publication de l'Encyclique et du Syllabus, Pie IX s'était inscrit en faux contre l'esprit même du Concordat de 1801 : la reconnaissance par la papauté de la Révolution de 1789 et de toutes les réformes juridiques, politiques et sociales qui en découlaient, sécularisation de l'État, expropriation des biens du clergé, abolition des corporations religieuses, etc. ne point consulter le pouvoir civil, c'était donc confirmer ouvertement la dénonciation du Concordat par Rome elle-même.

Et il parait indiscutable que la séparation de l'Église d'avec l'État laïque était une volonté expresse du saint-Siège ; mais c'était une séparation morale, en quelque sorte, la dénonciation d'un Concordat fondé sur des théories impies, mais aussi la conservation de ce même Concordat en tant qu'il assure à l'Église des avantages pécuniaires. La casuistique seule peut expliquer cette subtilité.

La bulle d'induction présentait aussi une nouvelle doctrine : celle de l'infaillibilité pontificale. Une telle innovation suffisait à infirmer la valeur légale du Concordat, l'Église revêtant un caractère spirituel et temporel qu'elle n'avait pas au temps des négociations de 1801. Il eût été opportun pour nos hommes politiques et nos jurisconsultes de l'époque d'envisager la situation nouvelle créée par l'Église et de s'éloigner du pape, puisqu'il prétend être roi du monde spirituel et temporel, tout-puissant, infaillible, avec qui, par conséquent, ne saurait être conclu ni contrat ni concordat. Des avantages, des privilèges, comment les lui concéder, les lui reconnaître, puisqu'il n’est aucun prince du temporel au-dessus de lui ?

Le concile s’ouvrit le 8 décembre 1869 à la basilique de Bramantes et de Michel-Ange. Dès le début, il apparut que l'Église aurait recours 
à la pire intransigeance pour combattre le principes laïques. L'archevêque de Paris, plus libéral que ses coreligionnaires, en informe l'empereur et n’hésite pas à faire appel à son intervention. Il avoue d'abord que la liberté de discussion n'est pas respectée ; puis :

"Je me demande, dit-il, si l'intérêt général, l’intérêt de de la société religieuse et civile n'exige pas qu'on nous vienne en aide. Le gouvernement de l'empereur ne pourrait-il pas faire connaître au gouvernement pontifical les appréhensions que les débuts du concile causent même à des esprits sérieux et non prévenus, et lui laisser entrevoir les conséquences possibles des tendances et des agissements signalés... ? ne faudrait-il pas dire au public... que l'on veille à ce que les intérêts dont l'État est le défenseur soient suffisamment sauvegardés et à ce que la bonne entente, établie entre les deux autorités par le Concordat, ne soient pas compromise comme elle le serait certainement, si les résolutions du concile étaient trop peu en rapport avec les institutions, les lois et les habitudes de la France ? “

Mais le gouvernement impérial se montrait résolu à se désintéresser, comme incompétent, des objets que le concile discutait. Cependant, le 21 janvier, les pères du Concile reçurent un schéma sur la constitution de l’Église, le schéma nommé de Ecclesia. Il est divisé en quinze chapitres ; vingt et un canons le complètent.

Les chapitres affirment que l'Église est un "corps mystique” qu'elle est une société parfaite, spirituelle et surnaturelle, que son unité est indivisible, que la communion avec elle assure, qu'elle est indéfectible, infaillible dans l'enseignement, qu'elle possède une puissance de juridiction, que le pape jouit d'une primauté de juridiction et de garanties temporelles. L'un des chapitre envisage les rapports de l'Église et du pouvoir laïque ; et, cette fois, le concile émet l'opinion que la séparation de l'Église et de l'État ne saurait s'imposer. Bien plus, la loi divine la condamne, car l'État a pour devoir primordial de protéger la seule vraie religion ; et le concile ajoute qu'il ne sera plus question de séparation le jour où les maîtres du pouvoir temporel reconnaîtront que l’Église est plus précieuse que leurs États.

Mais l'Église n'attend pas ce jour, sans doute encore lointain, pour prétendre qu'elle a le droit de veiller à l'enseignement, de fonder en 
toute liberté les ordres religieux qu’il lui plaira d’acquérir, de posséder sans tolérer l’ingérence du pouvoir civil.

Les canons qui suivent donnent à ces différents postulats l'armature dogmatique :

“Si quelqu'un dit que l'infaillibilité de l'Église est restreinte aux choses contenues dans la révélation divine et qu'elle ne s’étend pas aussi à toutes les vérités nécessaires à la conservation intégrale du dépôt de la révélation ; qu'il soit anathème.

“Si quelqu'un dit que les lois de l'Église n’ont pas la force d'obliger tant qu'elles n’ont pas été confirmées par la sanction du pouvoir civil, ou qu'il appartient audit pouvoir de décréter en matière de religion, en vertu de son autorité suprême ; qu'il soit anathème.”

Les canons concernant les rapports de l'Église et de l'autorité laïque ne revêtent pas une bien grande importance; ils sont conformes, à cette idée, que la société civile et la société religieuse sont l'une et l'autre deux sociétés indépendantes. La première procède de Dieu immédiatement; la seconde, médiatement. Il paraissait donc que l'Église se fit tolérante, puisqu'il n'était plus admis que la société laïque était soumise à la puissance ecclésiastique.

Mais, dès qu'il eut connaissance de ces canons, le gouvernement impérial s'émut. Le comte Daru, ministre des affaires étrangères, trouva exorbitant que le concile tranchât, de sa propre autorité, des questions politiques, et envahit ainsi un domaine où il ne lui appartenait pas de pénétrer. Le pouvoir d'agir, de légiférer, de commander en dehors de l'autorité laïque, l'Église ne saurait avoir le droit de se l'arroger et il importait de le lui contester.

Ainsi pensait M. Daru ; mais il n'était pas libre de parler au nom du ministère, car celui-ci s'opposait à ce que la politique de l'empire visà-vis du saint-Siège devint agressive. Rome pouvait donc empiéter sur les droits de la société civile, sans crainte de nous voir intervenir.

Le 6 mars 1870, Pie IX estima qu'il était temps de faire proclamer le dogme de l'infaillibilité. Il fit donc distribuer le schéma, concernant 
la question qui lui tenait le plus à cœur. Mais ses dispositions d'esprit furent mieux indiquées dans un bref, qu'il adressait au bénédictin Gueranger, auteur de la Monarchie pontificale :

"Les adversaires de l'infaillibilité sont des hommes qui, tout en se faisant gloire du nom de catholiques, se montrent complètement imbus de principes corrompus, ressassent des chicanes, des calomnies, des sophismes pour abaisser l'autorité du chef suprême que Christ a préposé à l'Église et dont ils redoutent les prérogatives. Ils ne croient pas, comme les autres catholiques, que le concile est gouverné par le saintEsprit.”

Le comte Daru s'était autorisé à rappeler le concile au droit public français. Le 19 mars, le cardinal Antonelli lui répondit qu'il s’étonnait que le projet de constitution de l'Église pût faire naître des alarmes, les thèses et les principes du concile ayant été de tous temps ceux de l'Église ; un bon catholique ne peut nier que la mission de l'Église soit de conduire les hommes à une foi surnaturelle. Et puis, insinue avec impertinence le cardinal Antonelli, l'État français n’a-t-il pas le concordat pour le protéger ? "Les rapports de l'Église et de l’État sur des objets de compétence mixte ayant été réglés par ce pacte, les décisions que le concile du Vatican viendrait à prendre en semblable matière n'altéreraient pas les stipulations spéciales conclues par le saintSiège tant avec la France qu'avec d'autres gouvernements, toutes les fois que ceux-ci de leur côté ne mettent point d'obstacle à l'entière observation des choses convenues.”

Il est certain qu'ainsi que le faisait obligeamment entendre le cardinal Antonelli, le Concordat pouvait être invoqué contre un excès d'audace de l'Église. Mais d'autre part, et c'est un cercle vicieux, si les enseignements du schéma de Ecclesia avait sur les esprits l'influence, prévue par l'Église, le Concordat, violé par les catholiques, deviendrait inexistant. M. Émile Ollivier, lui-même en convient, et il va jusqu'à prévoir l'apparition d'un nouveau Concordat tout pénétré de l'esprit théocratique.

Cependant les schémas de Ecclesia et ses canons n'étaient pas les actes du concile qui donnaient surtout lieu aux inquiétudes des défenseurs de l'ordre laïque. Le schéma sur l'infaillibilité seul, assombris- 
sait l'avenir. Cette infaillibilité absolue, personnelle, dictatoriale, apparaissait comme un élément de subversion pour les États et pour l'Église, car elle avait trop de points de contact avec les conditions politiques des sociétés.

Il fut convenu, en conseil des ministres, qu'un mémorandum serait adressé au pape, protestant contre les maximes qui subordonnent la société civile à la société religieuse ; mais le ministère spécifie que son intention n'est que morale. Quel effet dès lors pouvait-elle produire sur Rome?

Les débats suivirent leur cours. Et le 24 avril, la constitution de fide était adopté. C’était toute une série de propositions dogmatiques sur la création, la révélation, le rapport de la raison avec la foi.

La discussion de l'infaillibilité était impatiemment attendue de tout le monde catholique. Et il n'était pas une puissance étrangère qui se désintéressât des résolutions du concile à ce sujet. Les croyants approuvaient et blâmaient ; en Angleterre, en Allemagne, on tendait vers la protestation. La France était profondément divisée.

Le 13 mai la discussion s'ouvrit. Les discours furent nombreux et passionnés. Une des raisons justifiant l'infaillibilité fut qu'il faut “garantir la divine certitude avec laquelle la révélation chrétienne s'est transmise jusqu'à nous”. La minorité contre l'infaillibilité ne combattait pas la doctrine, mais la définition dans le moment présent, son opportunité.

La constitution relative à l'infaillibilité fut enfin adoptée le 18 juillet.

Elle est divisée en chapitres. Le premier a trait à l'institution de la papauté apostolique ; les suivants dissertent sur la perpétuité et la nature de cette primauté, enfin sur le "magister infaillible" du souverain pontife.

Il y est dit que l'infaillibilité est destinée à affermir les bases de l’Église. Le concile en donne la définition : 
"Le pontife romain, lorsqu'il parle ex cathedra, c'est à dire lorsque, remplissant la charge de pasteur et de docteur de tous les chrétiens, en vertu de sa suprême autorité apostolique, il définit qu'une doctrine sur la foi ou sur les mœurs doit être crue par l'Église universelle, jouit pleinement, par l'assistance divine qui lui a été promise dans la personne du bienheureux Pierre, de cette infaillibilité dont le divin rédempteur a voulu que son Église fût pourvue en définissant la doctrine touchant la foi et les mœurs; et par conséquent de telles définitions sont irréformables d'elles-mêmes et non en vertu du consentement de l’Église.”

Tel est le dogme. Anathème contre celui qui y contredirait.

On en voit toutes les conséquences. Le pape désormais ne consultera plus l'épiscopat avant de formuler ses définitions, qui sont définitives, irréformables, obligatoires, grâce uniquement à "l'assistance divine” ; le pape demeure le seul maître.

Contre lui, les "princes laïques” ne sauraient opposer leurs théories, leurs politiques; vainement, ils prétendraient l'influencer, le circonvenir, l'amener à composition ; l'ère des pactes est définitivement close. D'autre part, le pouvoir pontifical s'isole de l'épiscopat pour ne point s'exposer à des menées personnelles, dont les suites fatales seraient l'affaiblissement de sa toute puissance.

Les évêques, qui constituèrent au concile la minorité opposante, firent leur soumission. Et le Gouvernement français lui-même ne mit aucun obstacle à la publication de la Constitution. Il est vrai que des événements plus graves occupaient alors son attention.

L’Italie seule répondit au concile. En septembre 1870, elle anéantissait la puissance temporelle du pape ; c’était obéir à la logique de son histoire. Il n'en est pas moins vrai que ce coup cruel porté à la soidisant invulnérabilité du pontificat déchaîna la réaction ultracatholique qui, se réclamant du Syllabus, rompit en visière avec la troisième république et l'eût mise en péril si les partis démocratiques n’avaient sonné le ralliement en face de l'ennemi commun. 


\section{DE 1870 A 1905}

$\underline{\text { Retour à la table des matières }}$

On vient de voir comment la papauté, poursuivant son évolution naturelle, avait fait inscrire dans sa constitution l'infaillibilité du chef suprême de l'Église, infaillibilité qu'elle avait déjà revendiquée au cours des siècles et qu'elle imposait désormais à ses fidèles comme un article de foi.

Ce dessein persévérant d'atteindre à la domination universelle se manifesta en France au lendemain des événements de 1870, à l'heure où la nation venait de se donner la forme républicaine. A mesure que la démocratie se développera dans notre pays, à mesure que les esprits s’éveilleront plus nombreux aux vérités scientifiques, apparaîtra plus profond l'abîme qui sépare le catholicisme romain de la civilisation moderne. Des mois seront édictées pour dégager progressivement les intelligences enfantines de l'obscurité du dogme. De là des luttes, des crises, dont on a perdu le souvenir. Avant qu'un Parlement ait pu envisager comme possible - et prochaine - la séparation complète des Églises et de l'État, des mesures de transition ont dû être prises, qui toutes ont provoqué les protestations les plus vives à la cour de Rome. Nous les allons indiquer brièvement et l'on verra que depuis trentecinq ans la société laïque a marché, d’un pas mesuré mais sûr, vers son émancipation définitive.

En 1873, l'Église romaine est toute-puissante. En pleine crise nationale et sociale, au moment où l'Assemblée nationale expédiait les affaires de France, dans une pétition, les évêques n’avaient pas craint de réclamer le rétablissement du pouvoir temporel du pape. Habile aux expédients parlementaires, $\mathrm{M}$. Thiers avait su faire enterrer la protestation par le renvoi pur et simple au ministère des affaires étrangères, malgré l'intervention de l'évêque Dupanloup. le 24 mai consacre le règne du clergé. Une délégation de la Chambre s'est retirée des obsèques civiles de $\mathrm{M}$. le député Brousses. Dans un ouvrage d'une belle 
tenue littéraire, qui prend par instant l'allure d'un pamphlet, MM. Yves Guyot et Sigismond Lacroix font un exposé de la situation du clergé, que nous ne pouvons mieux faire que de citer :

"Mis en possessions d'églises, d'édifices innombrables, dont la flèche domine les villes, tous les hameaux, dont les cloches remplissent l'air, attestent qu'il est partout et que nul ne peut lui échapper, de séminaires où il élève ses recrues, le clergé prélève sur le budget de l'État une somme de 49 millions, qui chaque année augmente; le budget de l'instruction publique est de 36 millions.

“Ce n'est pas tout : du département et des communes, il touche une somme minimum de 31 millions ; soit une part dans l'impôt général de 80 millions. A ces 80 millions, vous, nous tous, libres penseurs, contribuons.

“Ce n'est pas tout: ces hommes qui sont au conseil supérieur de l'instruction publique, ce sont des évêques et des archevêques; ils sont encore dans le conseil départemental de l'instruction publique ; ils nomment et destituent l'instituteur. Voici le curé qui entre dans l'école, la loi de 1850 à la main, disant à l'instituteur : Vous devez, avant toute autre, l’instruction religieuse.

"Le prêtre est partout : il a l'assistance publique, on le trouve dans les prisons, à l'armée, sur chaque vaisseau. L’armée lui prête ses canons et ses armes pour célébrer ses fêtes. Généraux, fonctionnaires, magistrats, professeurs suivent ses processions et courbent la tête sous la bénédiction de l’évêque.

“Quant à ses charges, il n’en a pas ; il est exempt du service militaire, il en fait exempter ses acolytes...

"Et quand le prêtre a pris sa place partout, dans toute la société, quand il tient l'éducation d'une main, l'assistance de l'autre, il descend dans la congrégation. Les articles 291 et 292 du code pénal lui sont inconnus. La congrégation se forme, se développe, enfonce ses racines dans le sol, en fait émerger de vastes casernes, d'immenses bâtiments, séquestre, enferme des multitudes, fouille de ses tentacules toutes les couches sociales pour en aspirer la vie et la richesse.” 
La solution de MM. Yves Guyot et Sigismond Lacroix était celle que nous préconisons aujourd’hui : répondre aux principes de persécution du clergé, par des principes de liberté ; rejeter les prêtres dans leurs églises, pour que soit affranchie la société laïque.

Depuis que ces lignes ont été écrites, la solution qu'elles préconisaient n'a pas été atteinte ; mais des mesures de défenses ont été prises par la société laïque pour lutter contre l’ingérence cléricale ; elles sont présentes dans tous les esprits. Les noms de Gambetta, de Jules Ferry surtout, de Paul Bert, de Goblet, de Waldeck-Rousseau et de Combes demeurent attachés au souvenir de ces mesures, de ces réformes essentielles.

C'est Jules Ferry, qui, en 1879, a fait voter la loi réorganisant le conseil de l'enseignement public, et les conseils académiques. L’élément ecclésiastique qui s’y était glissé à la faveur de la loi Falloux en était éliminé. C'est Jules Ferry qui fit voter la loi restituant à l'État le monopole de la collation des grades universitaires, supprimant les jurys mixtes, obligeant les élèves des établissements libres d'enseignement supérieur à prendre leurs inscriptions dans les facultés de l'État ; et enlevant le droit d'enseigner ou de diriger un établissement d'instruction à tout membre d'une congrégation non autorisée.

Mais cette dernière disposition, adoptée par la Chambre, fut repoussée par le Sénat. C’est le fameux article 7. Jules Ferry suppléa à cette lacune de loi, en prenant les décrets du 29 mars 1880, qui, au nom des lois existantes, prescrivaient la dissolution des congrégations non autorisées. Il était encore ministre de l'instruction publique dans le cabinet Freycinet. Il les fit appliquer quelques temps après, comme président du conseil. Il est de nouveau ministre de l'instruction publique en 1882, et il fait voter la loi prescrivant la gratuité, l'obligation et la laïcité de l’instruction primaire.

L'œuvre laïque de Jules Ferry se continue par la loi qui faisait participer les séminaristes aux obligations militaires. Enfin, le ministère Waldeck-Rousseau fit voter cette loi sur les associations qui, depuis que la République existe, fut réclamée comme le prélude indispensable à la séparation, notamment par M. Gobelet. On va voir comment, 
appliquée par M. Combes, avec une énergie à laquelle tous les républicains ont rendu hommage, elle devait logiquement avoir pour conséquence la séparation.

Mais il convient auparavant, par quelques faits empruntés à notre histoire depuis trente ans, de répondre à ceux qui prétendent que le Concordat a réalisé la pacification religieuse dans le pays.

En réalité, le Concordat ne fut jamais observé, dans sa lettre par la papauté. Il n’y eut d'accord entre elle et la France qu'au moment où Rome espérait pouvoir reprendre, dans notre pays, sa suprématie perdue.

Trois occasions permirent surtout au clergé ultramontain de manifester ses secrètes tendances.

Rarement, la crise fut plus aiguë qu'en mai 1877. Elle fut le contrecoup d'une décision de la Chambre italienne. Celle-ci avait voté une loi sur les abus du clergé, qui avait soulevé l'indignation de la papauté. Au cours d'une allocution, qu'il prononça à l'occasion d'un consistoire, Pie IX dénonça comme des persécutions dirigées contre l’Église certaines mesures législatives, telles que la conversion de la mainmorte ecclésiastique, la sécularisation de l'enseignement public ; et il invita les évêques à agir auprès de leurs gouvernements en faveur du saint-Siège opprimé.

Un certain nombre de députés et de sénateurs français, appartenant à la droite du Parlement, firent, à ce propos, une démarche auprès de M. Decazes, alors ministre des affaires étrangères, lequel répondit évasivement. Obéissant aux injonctions papales, des évêques faisaient parvenir au Gouvernement des mandements. L’évêque de Nimes annonçait que "le pouvoir temporel des papes revivrait après quelques secousses profondes où s'engloutiraient peut-être bien des armées et bien des couronnes”. Dans une lettre au maréchal de Mac-Mahon, l'évêque de Nevers le suppliait de "renouer la chaîne des anciennes traditions de notre France, et de reprendre sa place de fils aîné de l'Église”. L'évêque de Nevers avait pris également soin de faire parvenir copie de cette lettre à tous les maires de son diocèse, en réclamant leur concours officiel à la propagande des évêques. 
Pour répondre à cette agitation anticoncordataire, M. Jules Simon, alors président du conseil, interdit le colportage de la pétition "dont les termes sont offensant pour les pouvoirs publics d'un pays voisin et ami”. Certaines tolérances, dont on usait à l'égard du clergé catholique, furent restreintes. A la Chambre des députés, une interpellation signée des président des trois gauches, permit à M. Jules Simon de faire connaître "les mesures qu'il avait prises et se proposait de prendre pour réprimer les menées ultramontaines dont la recrudescence inquiétait le pays”.

M. Jules Simon constate, dans son discours, que "le clergé et la religion catholique ont en France autant et peut-être plus de liberté qu'ils n'en ont jamais eue. Ainsi, les évêques se rassemblent en synodes sans autorisation; ils se rendent sans autorisation à la cour de Rome ; ils possèdent... Enfin, on publie des bulles et des brefs pontificaux, et je dois dire que si c'est sans autorisation qu'on les publie, c'est aussi sans légalité ; jamais de telles infractions n'auraient été tolérées par les régimes précédents”.

M. Jules Simon promet, en terminant, de faire appliquer la loi ; mais c'est Gambetta qui exprima le sentiment de la gauche.

"Il faut savoir, dit-il, que depuis 1870, depuis qu'on a proclamé le dogme qui a fait que du pape le docteur infaillible des vérités de l’Église, le clergé et l'épiscopat français ne comptent plus d'opposants, ne comptent plus de résistants, et quand Rome a parlé, tous sans exception, les prêtres, les curés, les évêques, tout le monde obéit.

"L’esprit clérical, avec habileté et la souplesse qui le caractérisent, a commencé, au début, par être fort modeste en ses prétentions. Il s'est contenté de demander une humble place au soleil ; puis, quand cette place a été obtenue, il n’a cessé de ridiculiser, de couvrir de ses sarcasmes la déclaration de 1682, c'est-à-dire les anciens principes de l’Église de France”.

En terminant, l'orateur déclare qu'il ne veut défendre le Concordat que tout autant que le contrat sera interprété comme un contrat bilaté- 
ral qui oblige l’Église et la tient, comme il oblige l’État et le tient. "Il faut que, malgré le mépris que peuvent inspirer au robuste bon sens de la France ces menées coupables, le Gouvernement déclare qu’il entend délivrer la France des étreintes de la politique ultramontaine.”

L’ordre du jour suivant, accepté par le cabinet fut voté comme conclusion des débats :

"La Chambre, considérant que les manifestations ultramontaines, dont la recrudescence pourrait compromettre la sécurité intérieure et extérieure du pays, constituent une violation flagrante des droits de l'État, invite le Gouvernement, pour réprimer cette agitation, à user des moyens légaux dont il dispose, et passe à l'ordre du jour.”

Une nouvelle levée de crosses se produisit, en 1891, au moment où des pèlerins français se permirent, à Rome, d'acclamer le "pape roi". M. Gouthe-Soulard trouva cette manifestation de son goût et le déclara hautement. Sa réponse à une circulaire demandant aux évêques de suspendre leurs pèlerinages, le fit traduire devant la cour d'appel de Paris. “On nous offre l'apaisement, disait-il, avec un gouvernement qui a déclaré que le cléricalisme est l'ennemi, qui a brisé le Concordat en supprimant les traitements ecclésiastiques, qui a dispersé les congrégations vouées à l'enseignement, à la prédication, au soulagement des pauvres et des malades, qui a frappé d'une taxe les congrégations autorisées, qui a édicté l'obligation du service militaire pour le clergé, qui a chassé la religieuse des salles d'asile et de l'hôpital ! Nous ne voulons pas de cet apaisement ; ce serait de l'avilissement."

Une interpellation du sénateur Dide permit à $M$. de Freycinet de s'expliquer au nom du Gouvernement. Le président du conseil fit allusion, en commençant, aux manifestations épistolaires des évêques qui avaient suivi la condamnation de M. Gouthe-Soulard.

"Il résulte de la lecture de ces documents, dit-il, qu'une partie des membres du clergé affiche la prétention d'être au-dessus des lois... Ils sont allés jusqu'à soutenir cette thèse que le ministre de la justice, appliquant la loi à l'un d'eux, le tribunal devant lequel il comparaissait n’avait pas la qualité pour juger. Cette doctrine ne s'est jamais manifestée d’une manière aussi claire. 
"Si les moyens que la loi met au service du Gouvernement ne suffisent pas pour faire respecter les droits de l'État, nous n’hésiterons pas à proposer aux Chambres les moyens complémentaires qui pourraient nous faire défaut.

"Je sais bien que de ce côté-ci (la droite), on ne reconnaît pas la valeur des articles de loi auxquels je fais allusion. On affecte de séparer les lois organiques du Concordat. Je sais que cette prétention a été élevée et l'honorable M. Buffet me fait un signe d'assentiment qui semble indiquer que, sans doute, il partage cette opinion.

“M. Buffet, - Complètement !

"M. le président du conseil. - Eh bien ! je déclare, quant à moi, que je la trouve renversante.

“... Les évêques sont, j’imagine, des citoyens français. Est-ce que les lois organiques ne sont pas des lois applicables comme les autres lois ? Si ces lois répugnent à leur conscience, qu'ils ne sollicitent pas un siège épiscopal. Personne ne les y a contraints...

“Nous voulons vivre en paix ; mais nous ne voulons pas être dupes.

"Le cabinet qui siège sur ces bancs ne croit pas avoir le mandat, ni des Chambres ni du pays, d'accomplir la séparation des Églises et de l'État, ni de la préparer ; mais nous avons le mandat de faire respecter l'État, et si la séparation devait s'accomplir à la suite de l'agitation à laquelle je viens de faire allusion, la responsabilité en tomberait sur ses auteurs et non sur nous."

Après le discours du président du conseil on adopta l'ordre du jour suivant :

"Le sénat, considérant que les manifestations récentes d'une partie du clergé pourraient compromettre la paix sociale et constituent une violation flagrante des droits de l’État.

“Confiant dans les déclarations du Gouvernement. 
“Compte qu'il usera des pouvoirs dont il dispose ou qu'il croira nécessaire de demander au Parlement, afin d'imposer à tous le respect de la République et la soumission à ses lois, et passe à l'ordre du jour."

Cet ordre du jour porte, entre autres signatures, celle de M. Ranc. Au cours de la séance, $M$. René Goblet avait affirmé ses préférences pour la séparation des Églises et de l’État.

Cette thèse fut également défendue, quelques jours plus tard, à la Chambre des députés, par M. Pichon, à l'occasion d'une interpellation de M. Hubbard.

L'orateur constate que, depuis le Syllabus, le clergé ultramontain n’a jamais cessé d'intervenir dans les affaires intérieures. Le pape intervient directement par des brefs. Dans leurs mandements, les évêques invitent à voter pour les candidats catholiques. Dans un moment critique pour lui, le clergé conseille au maréchal Mac-Mahon, dans le cas où il ne serait pas soutenu par le sénat, "de pourvoir au salut de la France d'une autre manière. Il faut faire appel à la nation, après vous êtes assuré de l'armée”. C’est la théorie du coup d’État. Ce qui importe à l'Église, ce n'est pas la tranquillité de l'État, mais le succès de sa doctrine, qui est celle du Syllabus.

Au cours de cette discussion, le principe de la séparation avait été nettement posé. Il l'avait été déjà d'ailleurs par M. de Freycinet, dans sa déclaration, après les élections de 1885. “L’intervention du clergé dans nos luttes politiques, et récemment encore dans les élections, disait-il, est pour les esprits sages le sujet de sérieuses préoccupations. Chacun a compris qu'une telle situation ne saurait se perpétuer et que le grave problème de la séparation des Églises et de l'État ne tarderait pas à s’imposer irrésistiblement.” Et, en 1881, M. Ferry disait déjà : “ Si nous voyons, aux élections prochaines, ce que nous avons vu à une époque toute récente, s'il se fait une collusion entre les préfets de la France et les ennemis de la République, alors nous demanderons la séparation; nous qui ne la voulons pas, nous vous dirons alors: l'heure est venue." 
Chaque fois que le problème se posait ainsi avec précision, la nécessité d'une loi préalable sur les associations apparaissait à l'esprit. C’est à M. Waldeck-Rousseau qu'il appartint de la faire voter.

C’est dans son discours de Toulouse, le 28 octobre 1900, que M. Waldeck-Rousseau exposa, pour la première fois, le problème avec une pleine lucidité.

Après avoir prévu que la loi nouvelle qu'il allait proposer aux Chambres aurait pour résultat de ne soumettre qu'au droit commun les associations, il ajoutait :

"Il s’agit ensuite, par la même loi, de faire face au péril qui naît du développement continu, dans une société démocratique, d'un organisme qui, suivant une définition célèbre dont le mérite revient à nos anciens parlements, "tend à introduire dans l'État, sous le voile spécieux d'un institut religieux, un corps politique dont le but est de parvenir d'abord à une indépendance absolue, et, successivement, à l'usurpation de toute autorité..."

“Je parle en homme qui n'est animé d'aucun esprit sectaire, mais simplement de l'esprit qui a dominé non seulement la politique de la Révolution, mais toute la politique historique de la France.”

Dans ce même discours, M. Waldeck-Rousseau avait fait allusion aux agitations politiques des moines. En janvier avait eu lieu, en effet, le procès des Assomptionnistes qui avait permis de constater l'intervention de cette congrégation militante dans les élections de 1898.

La congrégation fut dissoute comme illicite, et le lendemain du jour où elle était condamnée, le cardinal de Paris, M. Richard, allait rendre visite aux pères assomptionnistes.

Le Gouvernement lui demanda des explications et le blâma. Il supprima, en même temps, les traitements de l'archevêque d'Aix, des évêques de Montpellier, Versailles, qui avaient écrit aux pères assomptionnistes des lettres de félicitations ou d'encouragement. 
Comme on le voit, le clergé ultramontain n’avait pas abdiqué.

Le 31 janvier 1901 fut voté le premier article de la loi ; elle devait être bientôt adoptée définitivement par les deux Chambres.

Le 3 octobre, expirait le délai imparti aux congrégations religieuses pour se conformer aux prescriptions de la nouvelle loi.

Sur 753 congrégations non autorisées (14 d’hommes et 606 de femmes), 53 congrégations d'hommes avaient sollicité leur autorisation et 482 congrégations de femmes. Les jésuites s’étaient dispersés.

Quelque temps après, en juin 1902, M. Waldeck-Rousseau ayant abandonné le pouvoir, M. Combes recueillit la lourde responsabilité de faire respecter la loi nouvelle. Il le fit avec une énergie à laquelle il convient de rendre hommage. 321 voix l'approuvèrent à la Chambre lorsqu'il affirma que les ministres de son cabinet étaient “ bien décidés à assurer la suprématie de la société laïque sur l'obédience monacale”. Cette majorité lui fut fidèle et le bloc ne se déjugea point lorsqu'il s’agit de tirer de la loi de 1901 toutes les conséquences que nécessite son application intégrale.

L'action cléricale se manifesta, à cette occasion, sous différentes formes. L'agitation gagna la rue. La Bretagne fut en proie aux excitations cléricales les plus violentes. Des officiers en service commandé refusèrent de procéder à des expulsions. Enfin, le 15 octobre, se produisit la manifestation traditionnelle de l'épiscopat ultramontain. Une pétition fut adressée par soixante-douze archevêques et évêques aux membres du Parlement pour les prier de se monter favorables aux demandes d'autorisation formulées par certaines congrégations religieuses. C'était une nouvelle et flagrante violation du Concordat. Le conseil des ministres déféra “comme d'abus" au conseil d'État cette pétition des membres de l'épiscopat. Puis le traitement de M. Perraud fut supprimé. L’année suivante, en avril et mai 1903, des moines furent accueillis dans les églises concordataires. Il y eut, à ce propos, des bagarres, notamment dans les églises d'Aubervilliers et de Belleville.

Le 19 mai, M. Combes dut répondre à une interpellation sur "la légalité des circulaires par lesquelles était interdite la prédication dans 
les églises aux moines sécularisés.” dans sa réponse à M. Gayraud, le président du conseil se demande si "le Concordat et les articles organiques, qui en sont le développement prévu et voulu, ne créent des obligation qu'à l'État, ou si les prescriptions s'imposent également au pouvoir ecclésiastique.”

“Tout le monde sait, ajoutait M. Combes, que l’État n’a a sa disposition que des armes insuffisantes pour garantir ses droits et les faire triompher.

“L’appel comme d'abus fait sourire, et lorsqu'il est réclamé par le ministre des cultes pour l'honneur des principes, il lui attire le plus souvent, de la part de l'ecclésiastique incriminé, une belle protestation publique, à laquelle nombre de se collègues s'empressent de s’associer.

"La suppression du traitement est d'un mode moins solennel et d'un usage plus efficace, comme tous les coups qui frappent à la bourse. La généralité du bas clergé la redoute. Pour le haut clergé, c’est un jeu de la braver, quand ce n'est pas un calcul prémédité, en raison des avantages pécuniaires qu'il en retire, sous forme de souscriptions et d'offrandes. Reste la prison sur la paille très peu humide... On peut se demander seulement s'il serait sage d'y recourir systématiquement.

“... Quant à nous, déclarait M. Combes, puisqu’on nous demande notre sentiment, nous estimons préférable de faire l'opinion publique juge de la conduite de l'épiscopat. Notre raison est que les rapports entre l'État et l'Église catholique sont entrés, depuis quelque temps, dans une phase nouvelle.”

Le président du conseil montre comment la procédure de l'entente préalable, imposée par le pape Pie IX et le cardinal Antonelli à la faiblesse des ministres de la République, a permis au pouvoir ecclésiastique d'installer à la tête de la plupart des diocèses de France les candidats de ses préférences par le refus d'agrément dont il a frappé les candidats du pouvoir civil. Alors de constantes viciations du Concordat se sont produites, si bien que l'opinion publique se demande ce qu'elle doit augurer d'un tel spectacle. 
“ Pour peu que le spectacle se prolonge, elle sera amené à rejeter sur le Concordat la responsabilité d'un ordre des choses, où les écarts de conduite et les intempérances du clergé s'enhardissent par l'insuffisance même des moyens de répression. Puis, la logique aidant, l'opinion publique inclinera forcément à conclure que le Concordat de 1801 a fait son temps, et que le seul remède au désordre moral dont il s'agit ne peut se trouver que dans l'une ou l'autre de ces solutions : ou bien la séparation de l’Église et de l'État suivant une formule qui fera l'Église libre sous la souveraineté de l’État, ou bien une révision sérieuse et efficace des règlements de police jugés nécessaires pour le maintien de la tranquillité publique par l'auteur même du Concordat.”

A la suite de ce discours, on se demanda vers quelle solution penchait alors M. Combes. Dans les discours qu'il prononça ensuite aux banquets démocratiques de Marseille, de Tréguier et de ClermontFerrand, il parle de légiférer sur les rapports de l'Église et de l'État, mais sans autre précision. Sans doute, il souhaitait une transformation prochaine des liens concordataires entre le Vatican et la France ; mais se fera-t-elle dans le sens de la liberté pour l'église ou dans le sens d'une aggravation des articles organiques.

Ce n'est qu'au banquet d'Auxerre que M. Émile Combes se prononça ouvertement en faveur de la séparation des Églises et de l’État. Une commission parlementaire s'était constituée à la Chambre et un projet de loi était résulté de ses travaux. De plus en plus, au sein du parlement une opinion se formait, nettement favorable au principe de séparation. $\mathrm{M}$. Combes y vit une indication assez nette et il collabora même, on le verra, par le dépôt d'un projet de loi, à l'œuvre qui s’élaborait dans le sein de votre commission.

Divers incidents nouveaux, et des plus graves, s'étaient d'ailleurs produits, qui mettaient à l'ordre du jour, d'une manière particulièrement pressante, la question des rapports de l'Église et de l'État. A l'occasion de la loi qu'avait déposé $\mathrm{M}$. Combes dans le but de supprimer l'enseignement congréganiste, une véritable rébellion des cardinaux s'était produite. Leur protestation prit la forme d'une lettre au Président de la République. Elle était nouvelle, elle était imprévue. Sans doute, elle était en contradiction avec l'esprit du Concordat, mais nul article ne lui était applicable. La chose finit ainsi qu'il devait arri- 
ver : au conseil d’État. Un fait plus grave, qui acquit une extrême importance par les événements qui s’ensuivirent, fut la protestation que le pape, récemment élu, Pie IX, adressa aux chancelleries à l'occasion de la visite que le Président de la République venait de faire au roi d'Italie. En France, on fut presque unanime à trouver intolérable cette prétention du saint-Siège à porter un jugement sur notre politique extérieure. D’ailleurs, une phrase contenue dans les exemplaires reçus par les puissances catholiques, et dont le texte fut révélé par le journal l'Humanité, ne se trouvait pas dans la note qui avait été adressée au quai d'Orsay. Cette phrase laissait entendre que la même attitude de la part des autres puissances catholiques provoquerait le rappel immédiat du nonce. Ce document a sa place ici, car il aura exercé sur les événements une influence décisive.

“Des chambres du Vatican. - 28 avril 1904.

"La venue à Rome en forme officielle de $\mathrm{M}$. Loubet, Président de la République française, pour rendre visite à Victor-Emmanuel III, a été un événement de si exceptionnelle gravité que la saint-Siège ne peut laisser passer sans appeler sur lui la plus sérieuse attention du gouvernement que Votre Excellence représente.

“Il est à peine nécessaire de rappeler que les chefs d'États catholiques, liés comme tels par des liens spéciaux au pasteur suprême de l'Église, ont le devoir d'user vis-à-vis de lui des plus grands égards, comparativement aux souverains des États non catholiques, en ce qui concerne sa dignité, son indépendance et ses droits imprescriptibles. Ce devoir, reconnu jusqu'ici et observé par tous, nonobstant les plus graves raisons de politique, d'alliance ou de parenté, incombait d'autant plus au premier magistrat de la République française, qui, sans avoir aucun de ces motifs spéciaux, préside en revanche une nation qui est unie par les rapports traditionnels les plus étroits avec le pontificat romain, jouit, en vertu d'un pacte bilatéral avec le saintSiège, de privilèges signalés, à une large représentation dans le SacréCollège des cardinaux, et par suite dans le gouvernement de l'Église universelle et possède par singulière faveur le protectorat des intérêts catholiques en Orient. Par suite, si quelque chef de nation catholique infligeait une grave offense au souverain pontife en venant prêter hommage à Rome, c'est-à-dire au lieu même du siège pontifical et 
dans le même palais apostolique, à celui qui contre tout droit détient sa souveraineté civile et en entrave la liberté nécessaire et l'indépendance, cette offense a été d'autant plus grande de la part de M. Loubet ; et si, malgré cela, le nonce pontifical est resté à Paris, cela est dû uniquement à de très graves motifs d'ordre et de nature en tout point spéciaux. La déclaration faite par M. Delcassé au Parlement français ne peut en changer le caractère ni la portée - déclaration suivant laquelle le fait de rendre visite n'implique aucune intention hostile au saint-Siège ; car l'offense est intrinsèque à l'acte d'autant plus que le saint-Siège n'avait pas manqué d'en prévenir ce même Gouvernement.

“Et l'opinion publique, tant en France qu'en Italie, n'a pas manqué d'apercevoir le caractère offensif de cette visite, recherchée intentionnellement par le gouvernement italien dans le but d'obtenir par là l'affaiblissement des droits des droits du saint-Siège et l'offense faite à sa dignité, droits et dignité que celui-ci tient pour son devoir principal de protéger et de défendre dans l'intérêt même des catholiques du monde entier.

“Afin qu'un fait aussi douloureux ne puisse constituer un précédent quelconque, le saint-Siège s'est vu obligé d'émettre contre lui les protestations les plus formelles et les plus explicites, et le soussigné cardinal secrétaire d’État, par ordre de Sa sainteté, en informe par la présente Votre Excellence, en vous priant de vouloir porter le contenu de la présente note à la connaissance du gouvernement de...

"Il saisit en même temps cette occasion de confirmer à Votre Excellence les assurances... etc., etc....

\section{“Cardinal MERRY DEL VAL.”}

Le résultat de cette protestation incorrecte fut le rappel de notre ambassadeur au Vatican. Vers le même moment, des plaintes qui avaient autrefois été portées contre deux évêques concordataires, MM. Le Nordez et Geay.- le premier du diocèse de Dijon, le second du diocèse de Laval.- eurent des suites. Les deux prélats furent sommés de comparaître devant le saint office. Ils opposèrent quelque résistance et 
finalement, ayant reçu une lettre du secrétaire d’État Merry Del Val leur enjoignant sous menace des plus graves sanctions canoniques, d'être à Rome dans la quinzaine, ils la remirent à leur chef hiérarchique, M. Dumay, directeur des cultes.

Il y avait là, de la part du saint-Siège, une nouvelle violation du Concordat, une atteinte des plus graves aux droits de l'État. Le ministre des cultes refusa aux deux évêques l'autorisation de comparaître devant un pouvoir étranger. Ceux-ci tentèrent d'abord de résister à Rome, puis sentant finalement leur position intenable dans leurs diocèses, ils les quittèrent un jour et allèrent se soumettre à l'autorité du saint-Siège, en implorant sa pitié. Le Gouvernement ne put que supprimer leur traitement.

Mais il continua à les considérer comme évêques, bien qu'ils eussent été destitués canoniquement par le pape.

La situation ne s'aggrava point en ce qui concerne M. Geay ; il n'en fut pas de même dans la circonscription de M. Le Nordez. Le pouvoir y était, en réalité, exercé par deux vicaires généraux, considérés comme représentants de l'évêque. Le ministre des cultes adressait sa correspondance à $\mathrm{M}$. l'évêque de Dijon et les vicaires répondaient, en empruntant la signature épiscopale. La fiction subsistait.

Mais les deux vicaires s'avisèrent de prendre des mesures contraires à l'esprit qui avait dicté auparavant le actes de M. Le Nordez. Celuici, se souvenant alors qu'il était encore évêque, et faisant acte de pouvoir administratif, les révoqua.

M. Combes ne pouvait qu'approuver cette solution.

Quelques jours après, M. Bienvenu Martin devenait ministre des cultes. C'est lui que M. Morlot interpella sur cette situation bizarre.

Le nouveau ministre des cultes fit des déclarations très nettes en faveur de séparation et la majorité républicaine de la Chambre s’y associa.(Texte de l'ordre du jour voté par la Chambre, le 10 février 1905, à la majorité de 386 voix contre 111: “ La Chambre, constatant que l'attitude du Vatican a rendu nécessaire la séparation des Églises et de 
l'État, et comptant sur le Gouvernement pour en faire aboutir le vote immédiatement après le budget et la loi militaire... passe à l'ordre du jour.”) Depuis, l'évêque de Dijon a désigné au Gouvernement deux vicaires généraux de son choix. Ils eurent l'agrément du ministre des cultes, et Rome, soudain conciliante, voulut bien les agréer aussi, accordant pour un instant à M. Le Nordez des pouvoirs qu'elle lui avait contestés.

Les Rapports de la République avec Rome en sont là au moment même où va s'ouvrir devant vous la discussion sur la séparation des Églises et de l’État.

\section{LE BUDGET DU CULTE CATHOLIQUE}

$\underline{\text { Retour à la table des matières }}$

Chaque fois qu'au cours des chapitre d'histoire qui précèdent nous avons rencontré un chiffre représentant les charges qui résultent pour l'État de son union concordataire avec l'Église romaine, nous nous sommes fait une obligation de la noter. Il nous parait cependant utile, au risque de faire des répétitions, de redonner ici, dans une brève notice, un état des divers budgets des cultes, depuis le Concordat de 1801 ; ne serais-ce que pour répondre par une statistique victorieuse à ceux qui prétendent que la France républicaine est demeurée dans la limite stricte des obligations budgétaires qu'elle a souscrites envers l’Église.

M. Clémenceau, s’appuyant sur les chiffres fournis dans son ouvrage par M. Charles Jourdain (Budget des cultes depuis le Concordat) et sur la statistique dressée par M. Nicolas (Budget de la France depuis le commencement du dix-neuvième siècle) avait déjà fait cet utile travail, qui fut publié en articles dans le journal l'Aurore. 
Nous nous sommes reportés à ces articles, aux sources qu'ils signalent, ainsi qu'a l'article inséré par M. Léon Say, dans son Dictionnaire des finances.

Il en résulte de nos recherches que le budget des cultes, consenti par la troisième République, est trois fois supérieur au premier budget concordataire, qui est celui de 1810. Les années précédentes, le Concordat n'avait pas été appliqué dans sa rigueur et l'on connut le budget insignifiant de 1802 (1 258197 fr) et celui de 1804 (4 millions environ)

Le premier budget, établi suivant les obligations concordataires, se répartissait ainsi :

Chap. 1er.- Service intérieur : traitement du ministre, des em-

315000 plyés et frais de bureau :

Chap. 2.- Traitement des ministres des cultes en activité (haut clergé) :

1480234

Chap. 3.- Curés et desservants

10660000

Chap. 4.- Pensions accordées par décrets impériaux

156000

Chap. 5.- Séminaires

700000

Chap. 6.- Dépenses diverses

535530

Chap. 7.- dépenses accidentelles

493230

\section{Total}

14370000

Aux termes du Concordat, l'État ne devait assurer que le traitement des archevêques et des évêques fixé, pour les archevêques à $15000 \mathrm{fr}$. et, pour les évêques, à $10000 \mathrm{fr}$., et celui des curés proprement dits qui étaient divisés en deux classes : dans l'une, on touchait $1500 \mathrm{fr}$., dans l'autre, $1000 \mathrm{fr}$.

Il n'était rien alloué aux autres titulaires ecclésiastiques. Le traitement des vicaires généraux et des chanoines restait à la charge des budgets locaux. Mais, dans la suite - première atteinte au Concordat - ces dépenses furent mises à la charge de l’État. 
Un arrêté consulaire du 14 ventôse an XI, assure à l'un des trois vicaires généraux de chaque évêché 2000 fr. et 1500 fr. aux deux autres, ainsi qu’à tous les vicaires généraux reconnus des évêchés. En 1819, ces traitements seront portés à 4000 francs, 3000 fr. et 1 $500 \mathrm{fr}$. On alloua depuis à ces derniers $100 \mathrm{fr}$. de plus.

Notons que ces nouvelles obligations consenties par l’État n’empêchaient point les départements et les grandes villes de voter des suppléments en faveur des vicaires généraux et des chanoines. Ils en ont joui jusqu’à ces dernières années.

Malgré les nouvelles charges qui résultèrent pour l'État de ces nouveau traitements, le budget des cultes atteignait à peine, en 1820, la moitié de ce qu'il est aujourd'hui. Il a fallu l'empire et le gouvernement de l'ordre moral pour lui donner l'extension considérable qu'on lui a vu prendre.

On va voir, d'après les chiffres de M. Léon Say, quelle progression il a subie de 1860 à 1875 . On notera ensuite un mouvement décroissant dû à ce que les gouvernements devenant démocratiques se sont refusés de plus en plus à accorder le concours de l'État au culte catholique, pour l'entretien des bourses dans les séminaires et pour les secours aux communautés religieuses. 
Voici la statistique de M. Léon Say :

\begin{tabular}{|c|c|c|c|c|c|}
\hline ANNEES & $\begin{array}{c}\text { CARDINAUX } \\
\text { Archevêques et évêques, } \\
\text { chapitre de saint-Denis, } \\
\text { chapelain de sainte- } \\
\text { Geneviève }\end{array}$ & $\begin{array}{c}\text { MEMBRES } \\
\text { des chapitres } \\
\text { et clergé paroissial }\end{array}$ & $\begin{array}{l}\text { BOURSES } \\
\text { des séminaires } \\
\text { et secours }\end{array}$ & $\begin{array}{l}\text { SERVICES } \\
\text { intérieur des édifices } \\
\text { diocésains. } \\
\text { Travaux d’entretien } \\
\text { et réparation }\end{array}$ & TOTAL \\
\hline $\begin{array}{l}1860 \\
1865 \\
1870 \\
1875 \\
1880 \\
1885\end{array}$ & $\begin{array}{r}1698975,78 \\
1895452,36 \\
1915896,69 \\
1983607,54 \\
1449609,12 \\
921712,76\end{array}$ & $\begin{array}{l}35876588,78 \\
38488749,34 \\
39271305,20 \\
39339597,19 \\
39076981,27 \\
38083359,59\end{array}$ & $\begin{array}{r}2007561,91 \\
2139550,19 \\
2086908,57 \\
2157943,32 \\
2021647,02 \\
903294,93\end{array}$ & $\begin{array}{l}8595 \text { 493,64 } \\
3110793,89 \\
2932138,70 \\
8707 \text { 307,20 } \\
7609226,27 \\
4291990,93\end{array}$ & $\begin{array}{l}48178620,11 \\
45634545,76 \\
46206249,16 \\
52188455,25 \\
50156871,62 \\
44200397,35\end{array}$ \\
\hline
\end{tabular}


Les chiffres empruntés par M. Clémenceau aux deux sources que nous avons indiquées sont assez sensiblement plus élevées, bien qu’ils permettent de noter une progression semblable. On trouverait la raison de cette différence, en analysant les chapitres qu'ils représentent. Nous les donnons ici tels qu'ils se trouvent dans les articles de $\mathrm{M}$. Clemenceau :

Le budget des cultes atteint :

\begin{tabular}{|l|c|l|l|}
\hline 1817 & 21900364 & 1856 & 47422136 \\
1820 & 24711777 & 1860 & 50088543 \\
1823 & 26677792 & 1867 & 54035667 \\
1826 & 30584581 & 1869 & 54532936 \\
1830 & 36513573 & 1871 & 49963526 \\
1831 (monarchie de juillet) & 34624789 & 1872 & 53216748 \\
1843 & 37687694 & 1876 & 53727995 \\
1846 & 38170855 & 1880 & 53443666 \\
1847 & 38970855 & 1882 & 53365866 \\
1848, environ & 40000000 & 1884 & 51407006 \\
1853 & 44498699 & 1886 & 46318763 \\
1855 & 45580880 & 1887 & 45649563 \\
& & & \\
\hline
\end{tabular}

Depuis cette époque, le budget des cultes s'est maintenu à ce taux approximatif, que différents rapporteur du budget des cultes, tels MM. Georges Leygues et Lasserre, ont donné comme étant la conséquence inévitable des obligations concordataires 


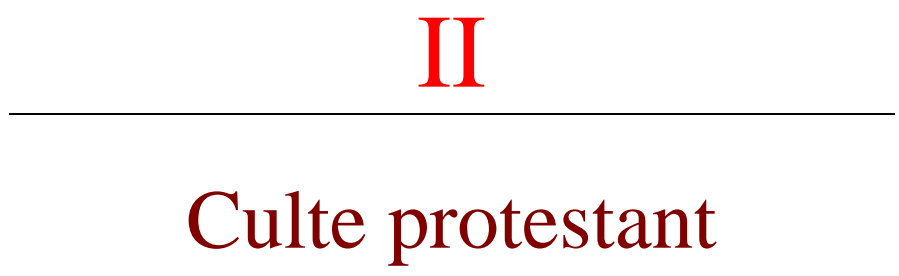

$\underline{\text { Retour à la table des matières }}$

Une loi de séparation des Églises et de l'État ne peut être vraiment équitable qu'à la condition de respecter la constitution interne de toutes les Églises et de leur permettre, au lendemain de l'abrogation du budget des cultes, une organisation telle qu'elles puissent réunir les ressources nécessaires à la continuation de leur œuvre. Briser leurs cadres ecclésiastiques, les forcer à adopter un régime contraire à leur traditions et à leur besoins, serait une mesure d'oppression. Il est donc au plus haut point important de connaître les principes et la forme ecclésiastique de chaque confession religieuse.

En ce qui concerne les Églises protestantes, notons, dès le début, les caractères généraux et la situation de fait qui les différencient toutes de l’Église catholique romaine.

$1^{\circ}$ L’Église catholique a une constitution monarchique. Un seul y commande, le pape, qui ne tient ses pouvoirs que de Dieu et les délègue au clergé, maître absolu en matière religieuse.

Les Églises protestantes françaises ont une constitution démocratique et parlementaire. C'est le peuple qui choisit ses représentants et qui, par eux, nomme son clergé. La prédominance ou l'égalité numérique de l'élément laïque est assuré dans tous les corps directeurs et dans toutes les assemblées délibérantes ;

$2^{\circ}$ Le centre et la tête de l'église catholique est à Rome. 
Les églises protestantes sont strictement nationales ;

$3^{\circ}$ Les circonscriptions ecclésiastiques de l'église catholique sont indépendantes les unes des autres et ne relèvent que du Vatican. L'archevêque de Paris n'a, par exemple, aucun pouvoir sur l'archevêque de Lyon. Chaque archidiocèse a son autonomie complète.

Les circonscriptions ecclésiastiques protestantes dépendent les unes des autres. Le système synodal, qui est celui de la plupart de ces Églises et des plus importantes, a pour base la paroisse, pour couronnement le synode national ayant autorité sur toutes les paroisses. Aucun groupement régional n’a et ne peut avoir une vie absolument indépendante.

$4^{\circ}$ L’Église catholique compte “nominalement” plus de 37 millions de fidèles, uniformément répartis sur tout le territoire français

Les Églises protestantes ont environ 650000 fidèles très inégalement dispersés dans toute la France. D’après le recensement officiel de 1872, le dernier qui ait tenu compte des opinions religieuses, un seul département compte plus de 100000 protestants.

12 départements en comptent de 10000 à 47000 .

16 départements en comptent de 4000 à 10000 .

23 départements en comptent de 1000 à 3000.

35 départements en comptent de 17 à 973.

ceci d'un façon générale, il n'est peut-être pas inutile de rappeler, à traits rapides, comment le culte protestant a été introduit en France, dans quelles circonstances et sur quelles bases ses Églises s'y sont constituées.

La réforme religieuse du seizième siècle avait trouvé, dans notre pays, d'ardents défenseurs. Les adeptes des idées nouvelles n’envisagèrent pas, il est vrai, à l'origine, la possibilité comme la nécessité d'une rupture avec l'Église romaine ; ils étaient plutôt disposés à croire que cette Église accepterait les réformes qu'ils réclamaient. Un long travail de préparation précéda l'organisation défini- 
tive du nouveau culte. Le mouvement réformateur trouva en Jean Calvin l'homme qui, par la puissance du génie, la netteté de l'esprit et le labeur infatigable, devait le faire aboutir à la création de ces Églises réformées de France, qui furent souvent appelées, du nom de leur célèbre fondateur : Églises calvinistes.

Ce fut, en effet, sur le modèle de la première Église réformée française, crée par Calvin en 1538 à Strasbourg, devenu l'asile des persécutés, que fut fondée à Meaux, en 1546, la première Église réformée de France. Dix ans plus tard, l’Église de Paris était “dressée”, suivant l'expression du temps, et si rapidement furent les progrès de la réforme religieuse que le 25 mai 1559 se réunissait dans cette ville le premier synode national où 72 Églises étaient représentées.

Le soucis de la défense des intérêts religieux, le devoir de faire connaître leurs doctrines, la nécessité d'une organisation ecclésiastique étaient la justification de cette assemblée dont les membres se réunissaient au milieu des feux de la persécution.

Dans ce synode furent posées les bases de cette organisation presbytérienne synodale - c'est-à-dire gouvernement de l’Église par des prêtres et des anciens - à laquelle les réformés devaient rester invariablement fidèles et qu'ils considèrent encore aujourd'hui comme la condition même de leur existence. Il sera intéressant d'en exposer les principes tels qu'ils furent par la suite définitivement établis, alors que les Églises réformées étaient sous le régime de l’édit de Nantes.

A la base se trouvait l'Église desservie par un ou plusieurs pasteurs ou ministres, nommés par le consistoire, conseil des anciens, élus "par le peuple”. Les ministres devaient être présentés à l'Église avant d'être nommés, le consistoire devant examiner et juger les protestations qui pourraient s'élever. "Le silence du peuple était tenu pour exprès consentement.” Chaque Église avait sa vie particulière et dans chaque Église nul pasteur ne pouvait prétendre à un rang plus élevé que celui de ses collègues et nulle Église ne pouvait "prétendre domination” sur une autre Église. Cependant, comme des intérêts communs existaient entre elles, des liens étroits les unissaient dans une gradation sagement étudiée. 
C’est ainsi que plusieurs Églises d'une même province formaient "un colloque", composé des divers pasteurs de ces Églises accompagné d'un “ancien” désigné par le consistoire. Le colloque était appelé à juger en première instance des différents qui s'élevaient dans les Églises qui le composaient.

Les Églises d'une même province se réunissaient en un synode appelé provincial, auquel chaque Église députait un pasteur et un ancien. Le synode réglait toutes les affaires ressortissant de la province, à l'exception de certaines questions et particulièrement les questions de doctrine sur lesquelles le synode national statuait définitivement.

Cette assemblée était composée de députés laïques et ecclésiastique. Chaque synode provincial élisait dans son sein, deux pasteurs et deux anciens et autant de membres suppléants, chargés de représenter les intérêts de la province au synode national qui s'appela ainsi, dans l’origine, et à travers les siècles gardera toujours ce caractère.

On peut dire que, dans les temps anciens, les églises réformées réalisèrent en pratique, surtout après la fin des guerres de religion, où le protestantisme cessa d'être un parti politique, le principe “de l'église libre dans l'État souverain”. Sans doute, elles eurent des écoles, des collèges, des académies, mais elles obéissaient à une nécessité que justifiait le caractère exclusivement catholique de tous les établissements d'instruction de l'ancien régime. Le caractère égalitaire et démocratique de ce gouvernement ecclésiastique, provenant de l'élection populaire et se maintenant par la libre discussion, suffit à expliquer l'invincible attachement qu'il a toujours inspiré aux protestants et leur désir unanime de le conserver.

L’Église réformée était en fait séparée de l’État, car si Henri IV, après l'édit de Nantes, accorda aux Églises une subvention “des deniers royaux", il ne s'en réserva pas le contrôle. Le synode national était chargé d'en assurer la distribution, du reste fort minime, car, en 1598 chaque pasteur ne reçut que 52 écus et 37 sols. Louis XIII maintint cette subvention pendant les premières années de son règne ; en 1628 elle cessa d’être payée. 
Le clergé catholique n'avait accepté que contraint et forcé l'édit de Nantes qui assurait la liberté du culte aux réformés. Avec une persévérance que rien ne lassa, il considéra que "la destruction de l’hérésie était sa principale affaire "(en 1660, on comptait en France 631 églises desservies par 711 pasteurs, et la population protestante représentait le dixième de la population totale.) Pendant trente ans (1655-1685), les assemblées générales du clergé de France ne cessèrent de demander et d'obtenir du gouvernement de Louis XIV des mesures persécutrices qui devaient aboutir à la révocation de l'édit de Nantes (18 octobre 1685)

Par une mesure aussi injuste qu'elle était impolitique, les Églises réformées de France furent condamnées à disparaître. Tous les pasteurs furent exilés, partout les temples furent démolis, tous les biens des Églises furent donnés aux hôpitaux catholiques et plus de cinq cent mille Français durent s'exiler pour sauvegarder la liberté de leur conscience. Les dragonnades dévastèrent les provinces protestantes et par milliers furent jetés dans les prisons et les bagnes les réformés qui ne voulurent pas accepter "la religion du roi". La persécution ne respecta pas même la mort et, sans respect de l'âge ou du sexe, les cadavres des réformés furent souvent jetés à la voirie. On comprend qu'un historien ait pu écrire : “ C'est une date à marquer au tableau noir des grands désastres nationaux, des déroutes humiliantes, des traités ruineux.” (A Soret)

Il pouvait sembler que les églises réformées ne se relèveraient jamais de leurs ruines ; mais trente années plus tard, un jeune homme âgé de vingt ans, Antoine court, qui a le mérite d'être appelé le restaurateur du protestantisme en France, réunissait le 21 août 1715 quelques réformés, restés fidèles à leur foi malgré les persécutions, et reprenait la tradition synodale. Les Églises se reconstituèrent lentement au milieu de danger sans nombre, pasteurs et fidèles étant sans cesse sous la menace de la mort ou du bagne, et de toute manière dans la condition la plus misérable du monde, car une législation odieuse refusait l'état civil aux protestants, faisait de leur mariage un concubinage et condamnant leurs enfants à la bâtardise.

A la veille de la Révolution française, lorsque fut promulgué l'édit de Tolérance de 1787 qui ne rendait aux protestants "que ce que le 
droit et la nature ne permettaient pas de leur refuser”, c'est-à-dire l'état civil, la réorganisation des églises était un fait accompli, alors même que le culte ne se célébrât, suivant une expression alors consacrée, qu'au désert, c'est-à-dire en plein air, la loi interdisant tout culte public aux réformés. Pendant tout les dix-huitième siècle, les églises réformées avaient été non seulement séparées de l’État, mais surtout persécutées par l’État.

Le 21 août 1789, les États généraux rendirent le célèbre décret ordonnant que nul ne devait être inquiété pour ses opinions, même religieuses, et posèrent ainsi le principe constitutif de la la liberté des cultes. mais en 1793 les Églises réformées subirent, comme l'Église catholique, une profonde crise qui amena la suspension du culte pendant plusieurs années. Lorsqu'elle eut pris fin, les protestants voulurent, une fois de plus, réorganiser leurs Églises et, au moment où le premier consul se préparait à signer le Concordat, quelques-uns de leurs représentants les plus connus demandèrent leur union avec l'État. Telle fut l'origine de la loi du 18 germinal an X, qui devait régler si longtemps les rapports entre les Églises protestantes et l'État. Avec la loi de germinal commençait une nouvelle période de l'histoire du protestantisme français. Si la liberté du culte était reconnue et proclamée, si même son clergé, naguère persécuté, recevait un salaire, il n'en était pas moins vrai qu'elle n'avait plus le privilège d'être une Église libre, maîtresse de ses destinées. Le principe de l'élection populaire avait disparu, les intérêts religieux étaient confiés aux plus imposés au rôle des contributions directes, l'égalité entre les ministres du culte n'existait plus, le plus âgé des pasteurs étant appelé à la présidence du consistoire devenu une création purement arbitraire. Si le synode provincial était encore maintenu, sa convocation était rendue si difficile qu'en fait il était impossible de le réunir. Quant au synode national, la loi du 18 germinal n’en faisait aucune mention.

Fidèles à toutes leurs traditions, les protestants français n’ont pas cessé au cours du siècle dernier, de demander une révision profonde de la loi de germinal, si contraire à l'esprit démocratique de la Réforme. Le décret-loi du 26 mars 1852 rétablit le suffrage paroissial et créa un conseil central des Églises réformées, dont les membres nommés d'abord par le Gouvernement, devaient par la suite être élus par les consistoires. Il semblait qu'ainsi dût être comblée la grave lacune 
qui laissait les Églises réformées sans représentation autorisée de leurs intérêts auprès du Gouvernement ; les consistoires qui les représentaient vivant dans une complète indépendance les uns des autres.

Mais rien ne devait égaler la ténacité des protestants dans la revendication de droits qu'ils estimaient indiscutables. En 1848, ils provoquèrent la réunion d'un synode général, mais sans l'autorisation du Gouvernement. Sa tâche fut de procéder à une révision de la loi de germinal. Après la guerre de 1870, cédant à leurs instances, M. Thiers, le 20 septembre 1871, rendait le décret qui convoquait les synodes provinciaux pour la nomination de leurs délégués au synode national qui se réunit à Paris le 6 juin 1872.

L'histoire du protestantisme français montre donc de manière évidente, que son organisation ecclésiastique, à l'abri de toute influence étrangère, exige, pour être complète, le fonctionnement régulier des synodes qui doivent être la représentation de toutes les Églises réformées de France. Limité à une action exclusivement religieuse, étranger, par cela même, aux questions politiques, le fonctionnement du synode national, loin d'être un danger, présente au contraire des garanties d'ordre, en raison du rôle d'arbitre qui lui est dévolu. Aussi rien ne parait plus justifié que de rendre possible, par un dispositif de la loi, la convocation des assemblées religieuses, sans lesquelles, comme le disait, en 1659, le modérateur du synode de Loudun, "la religion protestante ne saurait subsister”.

Quant à la séparation de l'Église et de l'État, on ne saurait oublier qu'elle a trouvé des défenseurs éloquents dans les Églises réformées, longtemps avant que la question se posât devant l'opinion publique. Dès 1829, le pasteur Samuel Vincent écrivait dans les Vues sur le protestantisme : "Je suis fortement convaincu que la séparation finale de l'Église et de l'État doit se réaliser un jour... Le changement sera sensible, sans doute, et beaucoup d'intérêts privés pourront en être lésés, mais le protestantisme n'a rien à craindre. La liberté sera pour lui la force et la vie, et, c'est à ce prix peut-être qu'il peut voir s'accomplir les destinées que l’avenir lui prépare”. Aussi demandait-il déjà l'abrogation du trop célèbre article du code pénal, relatif aux associations de plus de vingt personnes. "Il respire, disait-il, la jalousie et le despotisme, il tient en réserve la persécution pour tout mouve- 
ment de l'esprit ; il affranchit vingt personnes, la charte parle de tous les Français.” Mais nulle influence ne peut-être comparée à celle qu'exerça et qu'exerce toujours le penseur Vinet dont on peut dire qu'il fut le théoricien de la séparation de l'Église et de l'État, dans les Églises protestantes de langue française. "Aucune religion, a-t-il écrit, n’est digne du nom de religion si elle dit: “Mon règne n'est pas de ce monde”. Aucune religion n'est une religion si elle se propose l'alliance du pouvoir civil comme moyen ou comme but."

Conséquent avec ses principes, Vinet avait été l'un des fondateurs de l'Église libre du canton de Vaud. Son exemple devait trouver des imitateurs en France. Après la révolution de Juillet, quelques Églises s'étaient fondées, ne se rattachant pas aux Églises officielles. Le synode de 1848 amena une scission, plus profond, car, par suite de son refus de promulguer une confession de foi, les dissidents convoquèrent un synode constituant de nouvelles Églises le 20 août 1849, sous la présidence du pasteur Frédéric Monod, où treize Églises constituées et dix-huit en formation furent représentées. Les nouvelles Églises adoptèrent l'organisation presbytérienne synodale qu'elles ont toujours fidèlement maintenue et prirent comme dénomination le titre d'Union évangélique libre de France. Elles ont réalisé depuis cette époque, de la manière la plus complète, le principe de la séparation de l'Église et de l'État. Avoir pris courageusement l'initiative d'une aussi réforme est un titre d'honneur pour ces Églises qui, malgré leur petit nombre, une cinquantaine, ont donné un grand exemple. Il est impossible d'oublier qu'Edmond de Pressensé, disciple de Vinet, qui fut au cours de sa carrière politique le partisan résolu, le défenseur si autorisé de la séparation, était l'un des pasteurs de cette Église libre. (L’union des Églises libres de France se compose d'Églises situées dans les départements les plus divers : Ardèche, Tarn, Lot-et-Garonne, Gironde, Rhône, Deux-Sêvres, Charente-Inférieure, Seine, Aveyron. Ces Églises, au même titre que les églises réformées, ont un caractère national.)

Ce mouvement séparatiste ne s'est pas limité à l'union des Églises évangéliques libres ; il s'est produit au sein même des Églises réformées et a abouti à la formation de communautés indépendantes de l'État (En dehors de Églises reconnues par l'État, se trouvent de nombreuses communautés se rattachant cependant aux Églises réformées 
et qui au lendemain de la séparation en seraient parties intégrantes.), mais rattachées officiellement aux Églises réformées. Il est nécessaires, en effet, de faire remarquer qu'à côté de l'organisation administrative qui régit les rapports des Églises protestantes et de l’État, s'est constitué, depuis un quart de siècle, une double organisation de caractère purement officieux à laquelle se rattachent les deux grandes fractions qui se partagent le protestantisme français. Elles reproduisent l'une et l'autre, sous des noms divers, le type consacré des Églises de la réforme française. On peut y voir une préparation à la séparation ; c'est à ce titre qu'il n'était pas inutile d'en faire mention ; mais l'État est toujours demeuré étranger à ces organisations particulières.

D’autres Églises existent de type congrégationaliste, c'est-à-dire séparées de l'État, ne se rattachant à aucune organisation et ne dépendant que d'elles-mêmes. Elles sont très peu nombreuses et se trouvent sur le littoral de la Méditerranée, à Nice, Menton, Cannes, Hyères, saint-Raphaël, Antibes.

Il en est de même des Églises baptistes, qui se groupent en association régionales du Nord, de l'Ouest, de l'Est et du Midi.

Mention doit être faite de l'Église évangélique méthodiste de France, dont l'organisation se rapproche de celle des Églises presbytériennes synodales.

Les chiffres qui suivront donneront une indication à peu près exacte sur la situation et les forces respectives des diverses Églises protestantes à l'heure actuelle :

L’Église réformée de France comprend 101 consistoires dont dépendent 534 paroisses. Pour les desservir existent 639 places de pasteurs ainsi réparties :

$\begin{array}{lll}12 & \text { places hors classe Paris à } & 3000 \mathrm{fr} \text {. } \\ 100 & \text { places de 1ère classe à } & 2200 \mathrm{fr} \text {. } \\ 91 & \text { places de 2è classe à } & 2000 \mathrm{fr} \text {. } \\ 427 & \text { places de 3è classe à } & 1800 \mathrm{fr} .\end{array}$


Les 101 consistoires sont répartis en 21 circonscriptions synodales formant chacune un synode provincial.

Le synode national est composé des délégués laïques et ecclésiastiques élus chaque année par chaque synode provincial.

Le synode national n’a pas été réuni depuis l’année 1873.

L’église réformée possède, d'après un rapport établi en 1899, 887 temples ou oratoires et 162 presbytères, 120 temples appartiennent aux conseils presbytéraux, 50 aux consistoires, 325 aux communes, 87 à l'État, 20 à des particuliers. La propriété de 89 est contestée. Les oratoires appartiennent, 61 aux conseils presbytéraux, 78 aux consistoires, 38 aux communes, 6 à l'État, 84 à des particuliers, 2 aux départements et 36 sont contestés.

Quant aux presbytères, voici leur répartition :

23 aux conseil presbytéraux, 16 aux consistoires, 98 aux communes, 1 à l'État, 20 à des particuliers, 4 dont la propriété n'est pas déterminée. Ces chiffres sont exacts à quelques unités près, quelques temples et presbytères ayant été construits depuis cette époque (1899).

L’Église réformée possède deux facultés de théologie, l'une à Montauban, l'autre à Paris, celle-ci commune aux réformés et aux luthériens. Le budget de ces facultés dépend du ministère de l'instruction publique.

La population des églises réformées ne peut être donnée que d'une manière approximative, mais elle peut être évaluée à 550 000, ce chiffre étant à considérer comme un minimum. Les centres de population protestante sont dans le Gard, l'Ardèche, la Drôme, la Lozère, les Deux-Sèvres, la Seine, Tarn-et-Garonne, etc. Bordeaux, Lyon, Marseille, Nancy, Lille, Le Havre forment d'importantes églises. Au 25 novembre 1904, il n’y avait que neuf places vacantes dans l'Église réformée.

L’Église évangélique de la confession d’Augsbourg, désignée souvent sous le nom d'église luthérienne, comprend 6 consistoires et 49 
paroisses, réparties entre deux synodes particuliers, celui de Paris et celui de Montbéliard, dont les délégués forment le synode général, qui nomme une commission exécutive permanente chargée de la défense des intérêts de l’Église.

Les 62 places de pasteurs sont ainsi divisées :

$\begin{array}{lll}10 & \text { places, Paris à } & 3000 \mathrm{fr} . \text {; } \\ 5 & \text { places, 1ère classe à } & 2200 \mathrm{fr} . \text {; } \\ 7 & \text { places, 2è classe à } & 2000 \mathrm{fr} \text {. } \\ 40 & \text { places, 3è classes à } & 1800 \mathrm{fr} .\end{array}$

Paris et Montbéliard sont les deux centres de la population luthérienne qui s'élève à environ 80000 âmes.

On ne saurait oublier que, par la suite de l'annexion de l'Alsace et la Lorraine, l'église luthérienne a perdu près des trois quarts de ses membres, outre sa faculté de Strasbourg. L’église luthérienne comprenait alors 44 consistoires, elle n'en a plus que 6 aujourd'hui.

Les pasteurs de l'église luthérienne font leurs études à la faculté de théologie de Paris, où professent des professeurs luthériens et réformés. Au 20 octobre 1904 il n’y avait qu'une place vacante dans l’église luthérienne.

\section{Églises séparées de l’État}

$\underline{\text { Retour à la table des matières }}$

Nous avons dit qu'en dehors des églises officielles mais se rattachant d'une manière officieuse à l'église réformée, se trouvaient de nombreuses églises fondées par l'activité de la société centrale d'évangélisation. Ces églises sont considérées, en effet, comme des annexes des paroisses officielles, dans le ressort desquelles elles ont été fondées. Ces création d'églises sont dues au fait que le crédit réservé aux création d'églises nouvelles a été supprimé par la loi de fi- 
nances du 23 décembre 1880. Ces églises répandues par toute la France ne reçoivent aucune subvention ou traitement du Gouvernement bien qu'elles se rattachent à l'église réformée reconnue par l’État.

L’union des églises évangéliques de France comprend 61 églises ou station d'évangélisation desservies par 64 pasteurs ou évangélistes.

La population de ces églises peut être évaluée entre 12 et 15 000, répartie surtout dans le Tarn, le Gard, l’Ardèche, Paris.

L’église évangéliste méthodiste compte 27 églises desservies par 29 pasteurs, se trouvant principalement dans le Gard et la Drome. Leur population s'élève à 5 ou 6000 âmes.

Les églises baptistes sont congrégationalistes, chaque église étant indépendante, mais elles sont reliées cependant par l'unité doctrinale et la communauté du but poursuivie. Elles sont au nombre de 24, les principales dans les département du Pas-de-Calais, de l'Aisne et de l'Oise. On peut évaluer leur population religieuse à 2 ou 3000 âmes.

Les églises indépendantes fondées par la société évangélique de France ne sont souvent que des postes d'évangélisation. De même on doit citer un certain nombre d'église ne se rattachant à aucune organisation ecclésiastique comme les églises de menton, de Cannes, d'Antibes. Elles ont du moins toutes un caractère commun, c'est d’être séparées de l'État. 


\section{III}

\section{Culte israélite}

\section{Début}

Sous l'ancien régime, les juifs, soumis au bon vouloir de l'autorité royale, tour à tour expulsés, tolérés ou spoliés, ne jouissant d'aucun droit et n'avaient pas de culte constitué, leurs communautés n’avaient qu’une existence précaire.

Les penseurs et les écrivains qui, durant le cours du dix-huitième siècle, préparèrent le grand mouvement révolutionnaire ne furent pas sans réclamer des mesures de tolérance et de liberté pour les juifs de France. La monarchie atténua les rigueurs dont ils étaient l'objet et leur accorda même quelques privilèges. En juin 1776, notamment, et en janvier 1784, Louis XVI rendit des édits favorables aux israélites. "Nous voulons, disaient les lettres patentes de 1776, qu'ils soient traités et regardés ainsi que nos autres sujets nés en notre royaume et réputés tels.”

Peu d'année avant la Révolution, Malesherbes avait formé une commission chargée d'examiner les questions relatives à l'émancipation des juifs. Les événements se précipitèrent et ce fut l'Assemblée constituante qui accomplit l'œuvre de libération.

Dès le 3 août 1789, l'abbé Grégoire appelait l'attention de ses collègues sur la situation des juifs français. Joignant ses efforts à ceux de 
son collègue Grégoire, Clermont-Tonnerre portait la question à la tribune le 3 puis le 28 septembre 1789 .

Discutée avec ardeur et passion par Rewbell, l'abbé Maury et l'évêque de Nancy, la cause des juifs fut défendue par ClermontTonnerre, Duport, Barnave et Mirabeau, au cours des séances des 21, 23, et 24 décembre. Le premier résultat de ces délibérations fut un décret du 28 janvier 1790, confirmant les privilèges des israélites du Midi et leur reconnaissant les droits de citoyens. Le 26 février 1790, puis le 26 mai 1791, la municipalité de Paris fit des démarches auprès de l'Assemblée afin que les israélites de la capitale fussent compris dans les dispositions du décret de 1790.

Le 23 août 1789, la Constituante avait déjà proclamé le grand principe de la liberté de conscience. Elle le sanctionna par l'article 10 de la Déclaration des droits qui forma le préambule de la Constitution de 1791. S’appuyant sur ces principes, Duport soumit à l’Assemblée, le 27 septembre 1791, un projet d'émancipation des juifs, et dans la même séance, la Constituante rendit un décret qui accordait aux juifs français tous les droits du citoyen.

La Constitution de 1793 reconnut et garantit également le libre exercice de tous les cultes. Celle de l'an III, qui rétablit en fait et en droit la liberté religieuse, laissa aux citoyens, tous égaux devant la loi, le soin de pourvoir aux dépenses de leur culte. Les israélites, qui n'avaient jamais cessé de subvenir par eux-mêmes aux besoin des communautés, continuèrent à entretenir par des taxes rituelles et des contributions volontaires l'exercice de leur culte et le fonctionnement de leurs œuvres de charité et d'assistance.

Il n'existait cependant aucun groupement régulier, officiel, reliant les communautés entre elles. Les ministres de la religion n'étaient investis d'aucune autorité administrative. Ils devaient se conformer aux prescriptions de la loi leur enjoignant de ne donner la bénédiction nuptiale qu'à ceux qui auraient contracté mariage devant l'officier d'État civil. (Arrêté du 1er prairial, an X)

Cette organisation du culte israélite fut l'œuvre de Napoléon. Elle vint, après le Concordat et les lois organiques de l'an $\mathrm{X}$, compléter 
l'ensemble de la législation qui règle l'exercice des trois religions reconnues par l'État. Un décret du 30 mai 1806 convoqua à Paris une assemblée de juifs notables, désignés par les préfets, d’après le tableau suivant: Haut-Rhin, 12 membres ; Bas-Rhin, 15 ; MontTonnerre, 9 ; Rhin et Moselle, 4 ; Sarre, 1 ; Roër, 1 ; Moselle, 5 ; Meurthe, 7 ; Vosges, 7 ; Gironde, 2 ; Basses-Pyrénées, 2 ; Vaucluse, 2 ; Côte-d'Or, 1 ; Seine, 6.

Dans les autres départements, les préfets devaient désigner un délégué par 500 citoyens de religion juive.

Conformément aux disposition du décret de mai, les délégués se réunirent à l'hôtel de ville le 26 juillet. Ils étaient au nombre d'environ 120.

Napoléon Chargea Mathieu Molé, Portalis fils et Pasquier des fonctions de commissaires auprès de l'assemblée. Une commission de neuf membres fut nommée par les délégués et de concert avec Molé, Portalis et Pasquier, un règlement organique du culte mosaïque fut élaboré. L'Assemblée l'adopta à l'unanimité le 10 décembre 1806. En outre, la commission prépara un certain nombre de décisions doctrinales qui furent soumises à l'approbation et à la sanction d'une autre assemblée, le grand sanhédrin, composé en majeure partie de rabbins. Ce Sénat juif, qui composait soixante-et-onze membres, se réunit à l'hôtel de ville le 9 février 1807 et approuva les formules morales proposées par la commission des neuf et par les trois commissions supérieures. Ces formules, imprégnées de l'esprit moderne, résumaient les principes de doctrine morale et religieuse dont devaient s'inspirer les ministres du culte et les administrateurs de des communautés et des consistoires établis par le règlement organique. L'ordonnance de mai 1844, dont nous parlerons plus loin, et qui forme actuellement le principal corps de la législation concernant les israélites, le reproduit dans se grandes lignes.

Le règlement du culte mosaïque groupait les synagogue et communautés en consistoires départementaux ou en circonscriptions consistoriales comprenant plusieurs départements ; fixait le mode d'élection des consistoires et de nomination des rabbins ; plaçait les consistoires de province sous le contrôle d'un consistoire central à Paris. Il indi- 
quait le chiffre du traitement destiné aux rabbins, sans le mettre à la charge de l'État.

Un décret du 11 décembre 1808, signé au camp de Madrid, fixa le nombre des consistoires à treize, et les établit à Paris, Strasbourg, Wintzenheim, Mayence, Metz, Nancy, TRèves, Coblentz, Crefeld, Bordeaux, Marseille, Turin et Casal.

Deux ordonnances de Louis XVIII, l'une du 29 juin 1818, l'autre du 20 août 1823, apportèrent quelques modifications au règlement organique de 1806 et mirent la législation en rapport avec les besoins nouveaux crées par l'accroissement de la population.

Sous Charles X, un arrêté ministériel autorisa, en 1829, l'établissement d'une école centrale rabbinique à Metz. Un règlement fixa le nombre des élèves, le programme des études, le mode d'attribution des diplômes rabbiniques. L’école était placée sous la direction du consistoire de Metz et sous l'autorité du consistoire central de Paris.

Il était pourvu aux frais de premier établissement de l'école sur des fonds réservés du traitement de l'un des plus grands rabbins du consistoire central pour 1827. Les dépenses annuelles étaient payées au moyen d'une allocation au budget du consistoire central, laquelle devait être répartie entre les divers consistoires de province.

Les ministres du culte étaient payés, eux aussi, par les communautés et les consistoires. Ce fut seulement sous le règne de LouisPhilippe que le traitement des rabbins fut mis à la charge du Trésor. La proposition en fut faite par la Chambre, le 7 août 1830, au moment de la discussion de la charte par Viennet et Berryer. L'article du projet gouvernemental attribuait aux seuls ministre des cultes chrétiens un traitement de l'État. De Rambuteau proposa la suppression du "seuls" et son amendement fut adopté.

Le 13 novembre 1830, un projet de loi ainsi conçu fut présenté à la Chambre : 
“A compter du 1er janvier 1831, les ministres du culte israélite recevront des traitements du Trésor public”

Rapporté par Augustin Périer, le projet fut adopté à une grande majorité et passa à la chambre des pairs, présidée par Pasquier. Celle-ci, sur le rapport de Portalis, vota à son tour, par 57 voix contre 37, le 1er février, l'adoption du projet.

La loi du 8 février 1831 consacra ainsi l'égalité des différents ministres des cultes au point de vue des traitements. Deux ordonnances, l'une du 22 mars, l'autre du 6 août 1831, fixèrent les détails de ces traitements pour les rabbins. La période historique de l'organisation du culte israélite en France était close.

"Plusieurs dispositions de ces décrets et ordonnances sont encore en vigueur. Mais la législation du culte israélite est presque tout entière renfermée dans l'ordonnance fondamentale des 25 mai- 14 juin 1844, qui est pour ainsi dire la charte de ce culte - le décret du 15 juin 1850 sur les consistoires départementaux - le décret important du 29 août 1852 portant modification de l'ordonnance du 25 mai 1844 - le décret du 5 février 1867 sur les élections consistoriales - le décret du 12 septembre 1872 sur les élections des grands rabbins et rabbins. Il faut y ajouter divers dispositions légales relatives à l'administration des biens et à la comptabilité des consistoires, ainsi qu'aux inhumations et pompes funèbres.” (Baugey. de la condition légale du culte israélite.)

Nous nous proposons d'extraire des textes énumérés dans ce résumé les dispositions qui régissent actuellement le culte israélite.

Celui-ci est administré, sous le contrôle du consistoire central, par les consistoires départementaux et par les commissions administratives. 


\section{Consistoire central}

$\underline{\text { Retour à la table des matières }}$

Le consistoire central se compose d'un grand rabbin et d'autant de membres laïques qu'il y a de consistoires départementaux (actuellement neuf dans la métropole et trois en Algérie). Les membres laïques du consistoire central sont élus pour huit ans par l'assemblée des électeurs ; le grand rabbin est nommé à vie par un collège électoral composé des membres du consistoire central et des délégués choisis par les électeurs à raison de deux par circonscription consistoriale.

Le consistoire central est l'intermédiaire entre le ministre des cultes et les consistoires départementaux. Il est chargé de la haute surveillance des intérêts du culte israélite. Il approuve les règlements relatifs à l'exercice du culte. Il a le droit de censure à l'égard des membres laïques des consistoires départementaux ; il peut provoquer, pour des causes graves, la révocation de ces membres, et même la dissolution d'un consistoire départemental. Il délivre seul les diplômes du premier et du second degré pour l'exercice des fonctions rabbiniques, donne son avis sur la nomination des rabbins départementaux et des rabbins communaux ; il statue sur la révocation des ministres officiants, proposée par les consistoires départementaux. Enfin, il approuve le budget, ainsi que les comptes de l'ordonnateur de chaque communauté consistoriale, et délibère sur les tarifs proposés par les consistoires pour la quotité et le mode de perception des diverses taxes.

\section{Consistoires départementaux}

Chaque consistoire départemental se compose du grand rabbin de la circonscription et de dix membres laïques.

Le grand rabbin est nommé par le consistoire central sur une liste de trois candidats présentée par le consistoire départemental auquel s’adjoint une commission composée : 
$1^{\circ}$ d’un délégué nommé par les électeurs inscrits de chaque communauté ayant un ministre du culte rétribué par l’État.

$2^{\circ}$ d'un nombre égal de délégués choisis par les électeurs du cheflieu consistorial. Les membres laïques sont élus pour huit ans par les électeurs de la circonscription.

Le consistoire départemental a l'administration et la police des temples de sa circonscription et des temples et des établissements et associations pieuses qui s'y rattachent. Il fait, sous l'approbation du consistoire central, les règlements concernant les cérémonie religieuses relatives aux inhumations et à l'exercice du culte dans tous les temples de son ressort. Il institue auprès de chaque temple un commissaire administrateur ou une commission administrative qui agit sous sa direction et sous son autorité. Il représente en justice les synagogues de son ressort et exerce en leur nom les droits qui leur appartiennent. Il participe à la nomination du grand rabbin et à celle des rabbins communaux, dans les conditions ci-dessus énoncés ; il nomme les sous-rabbins, le ministre officiant et tous les agent du temple du cheflieu consistorial. Il surveille les ministres du culte de la circonscription consistoriale, sur lesquels il exerce des pouvoirs disciplinaires. Il est chargé de l'administration des biens de la communauté consistoriale, sur lesquels il exerce, en outre, vis-à-vis des communautés non consistoriales les attributions dévolues au consistoire central aux communautés consistoriales.

Outre son rôle administratif, le consistoire départemental a un rôle social ; ainsi, il est chargé par le règlement de 1806 d'encourager par tous les moyens possibles les israélites de la circonscription consistoriale à l'exercice des professions utiles et par l'arrêté du 17 avril 1832 de surveiller et d'encourager les écoles primaires israélites.

Enfin, l'article 22 de l'ordonnance de 1844 charge le consistoire d'adresser chaque année au préfet un rapport sur la situation morale des établissements de charité, de bienfaisance ou de religion spécialement destinés aux israélites. 
Il faut ajouter que le consistoire de Paris a été chargé par un décret en date du 1er juillet 1859 de l'administration de l'école centrale rabbinique, transférée à Paris le 1er novembre 1859. cette école, où sont formés les ministres du culte, est moins un séminaire qu'"un établissement d'enseignement supérieur, puisqu'on y est admis qu'à la condition de produire le diplôme de bachelier ès lettres. C'est la faculté de théologie israélite qui délivre des diplômes de licenciés en théologie aux élèves ayant quatre années de scolarité, et, à la fin de leurs études, des certificats d'aptitude au titre de sous-rabbin, rabbin ou grand rabbin (Baugey).” Son programme comprend, outre les études religieuses et théologiques, l'histoire de la philosophie, la littérature grecque, la littérature latine, le chaldéen, le syriaque, l'arabe, etc.

Ses circonscriptions consistoriales sont au nombre de neuf, savoir :

Circonscription consistoriale de Bayonne (2 000 âmes) : BassePyrénées, Hautes-Pyrénées, Haute-Garonne, Ariège, PyrénéesOrientales, Aude, Tarn, Aveyron, Tarn-et-Garonne, Gers, Lot, Lot-etGaronne, Landes.

Circonscription consistoriale de Besançon (2200 âmes) : Doubs, JUra.

Circonscription consistoriale de Bordeaux (3 000 âmes) : Gironde, Dordogne, Corrèze, Creuse, Haute-Vienne, Charente, CharenteInférieur, Vendée, Deux-Sèvres, Vienne, Maine-et-Loire, LoireInférieure, Mayenne, Ille-et-Vilaine, Morbihan, Côtes-du-Nord, Finistère.

Circonscription consistoriale d'Épinal (8 700 âmes) : Haute-Saône, Haute-Marne, Vosges, territoire de Belfort.

Circonscription consistoriale de Lille (3 800 âmes) : Nord, Pas-deCalais, Somme, Oise, Aisne, Ardennes, Marne.

Circonscription consistoriale de Lyon (2 600 âmes) : Rhône, Isère, Savoie, Haute-Savoie, Ain, Saône-et-Loire, Nièvre, Cher, Allier, Puyde-Dôme, Loire, Haute-Loire, Cantal. 
Circonscription consistoriale de Marseille (5 500 âmes) : Bouchesdu-Rhônes, Vaucluse, gard, Hérault, Lozère, Ardèche, Drôme, Hautes-Alpes, Basses-Alpes, Alpes-Maritimes, Var, Corse.

Circonscription consistoriale de Nancy (4 500 âmes) : Meurthe-etMoselle, Meuse, Yonne, Aube.

Circonscription consistoriale de Paris (50 000 âmes) : Seine, Seineet-Marne, Seine-et-Oise, Seine-Inférieure, Eure, Eure-et-Loir, Loiret, Loir-et-Cher, Indre, Indre-et-Loire, Sarthe, Orne, calvados, Manche.

Des chiffres indiqués pour chaque circonscription, il ressort que le total de la population israélite en métropole s'élève à 77350 âmes ; mais ces chiffres ne comprennent que les israélites connus comme tels n’étant basés sur aucun recensement officiel. Ils ne sont qu'approximatifs et certainement inférieur au nombre réel des israélites habitant la métropole, que l’on peut évaluer à 120000 âmes environ.

\section{Commissions administratives}

$\underline{\text { Retour à la table des matières }}$

Les commissions administratives sont instituées, par délégation du consistoire départemental, auprès de chaque temple de la circonscription. Dans la pratique, les électeurs de chaque communauté choisissent les membres de la commission chargé de l'administration de leur temple et font ratifier leur choix par le consistoire départemental. Les commissions administratives exercent surtout les attributions relatives aux biens qu'elles sont chargées d'administrer conformément aux prescriptions du décret du 27 mars 1893.

\section{Ministres du culte}

Les ministres du culte sont : le grand rabbin du consistoire central ; les grands rabbins des consistoires départementaux; les rabbins communaux, les sous rabbins et les ministres officiants. 
Le mode de nomination de grand rabbin du consistoire central et des grands rabbins des consistoires départementaux a été indiqué cidessus. Les rabbins communaux sont nommés par le consistoire départemental assisté d'une commission composée de délégués élus au scrutin de liste, moitié par le chef-lieu de la circonscription rabbinique, moitié par les autres communautés de cette circonscriptions, le nombre de ces délégués ne pouvant dépasser six.

Les sous-rabbins sont nommés par les consistoires départementaux.

Les ministres officiants sont élus par une assemblée, comprenant au moins cinq membres, tous désignés par le consistoire départemental.

\section{Conclusion}

$\underline{\text { Retour à la table des matières }}$

L'esprit qui a présidé à l'élaboration de ces divers textes qui ont établi le régime légal du culte israélite en France a été fort bien défini dans le rapport qui sert de préambule à l’ordonnance du 25 mai 1844.

Après avoir indiqué l'origine du décret du 16 mars 1808 et exposé la méthode suivie pour la confection de la nouvelle ordonnance, destinée à compléter ou à modifier les dispositions des textes antérieurs, le garde des sceaux, ministre de la justice et des cultes, termine son rapport par ces lignes, qu'il est bon de reproduire parce qu'elles caractérisent bien la charte constitutive du culte israélite :

"Dans son ensemble, cette ordonnance (celle de 1844) assure à l'autorité publique la légitime part d'influence qui lui appartient sur les intérêts administratifs du culte israélite, sans permettre que jamais elle s'immisce dans des questions dogmatiques auxquelles elle est étrangère, conciliant ainsi l'indispensable surveillance du pouvoir avec la liberté de conscience. Elle resserre les liens de la discipline et de la hiérarchie ; elle définit les droits et les devoirs des consistoires et des ministres du culte israélite ; elle obtint, lorsqu'elle n’était encore qu'en projet, l'assentiment des israélites éclairés, auxquels elle 
fut communiquée. Tous leurs coreligionnaires applaudiront, je n’en doute pas, à ses dispositions diverses.”

Les prévisions formulées par l'auteur de l'ordonnance de 1844 se sont réalisées. Grâce aux dispositions qu'elle contient, les communautés israélites se sont développées ; la centralisation et la hiérarchie établies par les pouvoirs publics, tout en permettant de donner satisfaction aux aspiration variées qui se manifestent dans toute collectivité, ont maintenu dans les diverses agrégations israélites l'unité et la concorde indispensables, surtout aux minorités.

IV

\section{Législations étrangères}

\begin{tabular}{|l|l|}
\hline Espagne; Portugal. & Pays-Bas. \\
Russie ; Grèce ; Roumanie ; & Grande-Bretagne et Irlande. \\
Bulgarie ; Serbie. & Suisse. \\
Norvège ; Suède. & États-Unis. \\
Prusse et états allemands. & Mexique. \\
Autriche. & Cuba. \\
Hongrie. & Brésil. \\
Italie. & Équateur. \\
Belgique. & \\
\hline
\end{tabular}

\section{Début}

$\underline{\text { Retour à la table des matières }}$

Au moment où vous vous apprêtez à régler d'après une conception nouvelle la situation juridique des Églises en France, il est assurément indispensable d'examiner quel est le régime légal adopté dans les autres pays. Pour décrire d'une manière complète les institutions politico-ecclésiastiques des nations étrangères, les rapports de droit et de 
fait entre les divers États de l'Europe ou du Nouveau-Monde, il faudrait de longues pages. Nous devons ici nous borner à des notions succinctes. Aussi bien une vue d'ensemble sur la législation étrangère suffira-t-elle pour faire comprendre la continuité de cette évolution qui, par des degrés successifs, conduit les nations de l'antique régime théocratique à celui de la complète laïcité.

Plusieurs pays d'Europe en sont encore à la première phase, théocratique ou quasi-théocratique, dans laquelle l'État est, sinon subordonné à l'Église, du moins étroitement uni à elle, reconnaît la prédominance d'une religion sur toute les autres et n'admet que des institutions sociales conformes aux principes de cette religion. D'autres, de beaucoup plus nombreux en Europe, ont atteint le second stade, celui de la demi-laïcité ; ils proclament les principes de la liberté de conscience et de la liberté des cultes, mais considèrent, néanmoins, certaines religions déterminées comme des institutions publiques qu'ils reconnaissent, protègent et subventionnent.

Enfin, dans quelques pays d'Europe et surtout dans plusieurs grandes républiques américaines, apparaît le troisième terme de l'évolution. L'État est alors réellement neutre et laïque ; l'égalité et l'indépendance des cultes sont reconnues ; les églises sont séparées de l'État. C'est surtout la législation des pays parvenus à cette troisième période qu'il convient d'étudier ici avec quelques détails.

L'Espagne est au nombre des rares pays d'Europe où les rapports entre l'Église catholique et l'État sont encore réglés par des actes bilatéraux, par des accords conclus avec le chef de l'Église, des concordats. Le régime concordataire tend, en effet, à disparaître de plus en plus. Le Concordat conclu en 1827 avec le royaume des Pays-Bas a été virtuellement abrogé ou dénoncé en Belgique par la constitution de 1831 ; le concordat conclu avec l'Autriche-Hongrie, en 1855, avait été dénoncé par le gouvernement autrichien en 1870, au lendemain de la promulgation du dogme de l'infaillibilité ; il a été abrogé par la loi autrichienne du 7 mai 1874. Celui qui était intervenu avec le grand duché de Bade avait été dénoncé en 1850. La création du royaume d'Italie et la loi des garanties du 13 mai 1871 ont mis à néant les divers Concordats conclus par le saint-Siège avec les divers États italiens, antérieurement à l'unification de la péninsule. Le Concordat qui 
a le plus récemment disparu est celui de la république de l'Équateur avec le saint-Siège qui datait de 1862. Une loi du 12 octobre 1904 l'a abrogé en tant que loi de la république, sans aucune dénonciation préalable.

On affirmait dans une discussion parlementaire récente, que toute législation destinée à régler dans notre pays la situation de l’Église catholique sur d'autres bases que celles adoptées en 1801 devait, pour être acceptable aux yeux des catholiques, n'être dictée qu'après entente, après “conversation” avec le représentant suprême de l’Église. peut-être est-il bon de faire une remarque à ce propos. il y a, sans doute, En Espagne, en Portugal, en Bavière, dans certains cantons suisses et au Monténégro, environ 28 millions de catholiques qui régissent des dispositions légales conformes à des Concordats écrits ou à des ententes verbales intervenus avec le saint-Siège ; en revanche, il y a en Italie 31 millions de catholiques, 20 millions en Autriche, 9 millions en Hongrie, 12 millions en Prusse, 6 millions en Belgique, 5 millions et demi dans le Royaume de Grande-Bretagne et d'Irlande, etc. pratiquant librement leur culte conformément à leurs législations nationales, lesquelles ont été promulguées sans aucune entente, sans aucune convention préalable avec la curie romaine. De même, dans le Nouveau-Monde, les législations d'un caractère concordataire ne s'appliquent qu'à un nombre de catholiques beaucoup moins grand que celui de leur coreligionnaires vivant au Canada, aux États-Unis, au Mexique, à Cuba, au Brésil, sous le régime de la séparation.

En Espagne, au contraire, le concordat de 1851 est toujours en vigueur ; il a même été complété récemment par un nouveau concordat relatif aux congrégations. D'autre part, l'Espagne et le Portugal sont les seuls pays d'Europe où la religion catholique soit encore reconnue effectivement comme religion d'État, au sens ancien de l'expression, comme 'religion dominante". Malgré cette union intime entre l’Église et l'État, vestige de l'antique subordination de l'État à l'Église, les principes de société moderne ont dû être proclamés dans les textes constitutionnels des deux royaumes de la péninsule ibérique. L’article 11 de la constitution espagnole porte que nul ne peut être inquiété pour ses opinions religieuses ni pour l'exercice de son culte, sauf le respect dû à la morale chrétienne ; en revanche, il prohibe toutes les manifestations et cérémonies publiques d'une religion autre que celle 
de l'État. En Portugal, l'article 146, paragraphe 4 de la constitution proclame le principe de la liberté de conscience ; mais les cultes autres que la religion d'État ne peuvent être exercés que dans des édifices n'ayant pas la forme extérieure de temples. Dans ces deux pays la religion catholique est, bien entendu, largement dotée par le budget.

La législation politico-ecclésiastique de ces pays présentent trop peu d'analogie avec celle qu'il peut être question d'établir dans un État laïque pour qu'il soit nécessaire d'en faire ici un examen approfondi. La même observation doit être faite en ce qui concerne ceux des pays d'Europe qui, bien qu'ayant proclamé et appliqué les principes modernes de la liberté de conscience et du libre exercice des divers cultes reconnaissent des Églises nationales et officielles, considèrent un ou plusieurs cultes comme des institutions d'État subventionnées et réglementées par l’État.

Le nombre de ces pays est encore considérable. Ce sont d'abord les pays de l'Europe orientale : la Russie, où l'Église orthodoxe, placée sous l'autorité suprême du saint-Synode et du tsar, a tous les caractères d'une grande institution d'État ; la Grèce, où la religion orthodoxe est essentiellement nationale, et qui est le foyer d'une propagande à la fois religieuse et politique en faveur de l'hellénisme. Ce sont la Roumanie, la Bulgarie et la Serbie, avec leurs églises également rattachées au rite grec orthodoxe, mais nationale et autocéphales, indépendantes de tout pouvoir religieux étranger et, en même temps, reconnues, organisées, dotées par l’État.

Dans les pays scandinaves la religion luthérienne est religion de l'État. En Norvège, beaucoup de fonctions publiques ne sont accessibles qu'à ceux qui professent la religion luthérienne. En Suède le libre exercice des cultes “étrangers” n’a été garanti qu’à une date relativement récente.

En Prusse, enfin, dans les autres États allemands, et en Autriche, il n'y a pas une religion "dominante”, une religion d'État exclusive de toute autre ; mais plusieurs religions ont un caractère officiel tout à fait semblable à celui des cultes reconnus de notre législation actuelle. 
Depuis la révolution de 1848, l'organisation des Églises protestantes (évangéliques) de la Prusse et d'autres États allemands a été profondément modifiée ; de monarchique, elle est devenue élective et synodale; et une indépendance presque complète a été reconnue l’Église pour l'administration de ses biens. Pourtant l'Église évangélique de Prusse, pas plus que celle d'autres États allemands, n'est une Église libre et séparée de l'État. Le souverain temporel est en même temps le chef de l'Église le summus episcopus ; l'organisation intérieure de l'Église est réglée par l'ordonnance du roi en sa qualité de chef de l'Église ; les rapports de l’Église et de l’État sont réglés par le Landtag. Les traitements et pensions du clergé protestant sont fixés et payés par l'État. Les rapports de la Prusse avec l’Église catholique ne sont guère moins étroits. celle-ci est aussi une Église officielle dotée par l’État. Même au temps de la lutte âpre qui fut engagée par le prince Bismarck contre le Vatican, il ne fut jamais question d'une séparation entre l'Église et l'État mais au contraire d'une réglementation plus étroite de l’Église par l’État.

Ces temps sont d'ailleurs bien oubliés aujourd'hui : presque toutes les dispositions des fameuses "lois de mai" ont été abrogées ; les traitements du clergé catholique, dont le montant avait été mis sous séquestre, et qui formait un total de plus de 16 millions, ont été restitué au clergé par la loi du du 24 juin 1891. Les traitements des membres du clergé catholique et du clergé protestant ont été augmentés par deux lois du 2 juillet 1898 .

Dans tous les États allemands, les cultes catholique et protestants sont, comme en Prusse, largement dotés par l'État; en outre, des taxes spéciales sont perçues dans certains États sur les fidèles pour subvenir aux frais de chaque culte. En Autriche, les rapports entre l'Église catholique et l'État sont réglés par la loi du 7 mai 1874, dont l'article 1er abroge la pestante du 5 novembre 1855 portant promulgation du concordat du 18 août précédent. La loi du 20 mai 1874 est relative aux communautés religieuses autres que l'église catholique et qui sont reconnues par l'État. En fait, sinon en droit strict, l'Église catholique est véritablement une religion officielle.

Les hauts dignitaires de l'Église jouissent des revenus immenses de leurs bénéfices ecclésiastiques et sont au nombre des plus riches pro- 
priétaires fonciers de l'Europe. Les autres membres du clergé sont rétribués au moyen des revenus des propriétés des cures, du "fonds de religion” (Religionsfond) provenant de la confiscation des biens des congrégations, ordonnée par Joseph II, et enfin, en cas d'insuffisance de ces ressources, au moyen d'une dotation de l'État.

Une loi du 19 avril 1885 a fixé le montant des traitement et pensions du clergé catholique. Les autres communautés religieuses reconnues par l'État couvrent les frais du culte au moyen de taxes spéciales perçues dans les mêmes formes que les impôts publics. La Hongrie a fait dans la voie de la laïcisation un pas considérable au cours des quinze dernières années. Les lois de 9 décembre 1894 sur le mariage, la religion des enfants (en cas de mariage mixte) et les actes de l'état civil ont définitivement sécularisé l'état civil. La loi du 26 novembre 1895 organise le régime des cultes. L'article 1er de cette loi proclame la liberté de conscience et la liberté des cultes, et l'article 5 reconnaît à toute personne le droit de sortir d'une communion religieuse.(Le rapport distingue l'Autriche et la Hongrie ; il serait donc intéressant de remarquer des législations et des états d'esprit très différents dans ce qui était l'empire d'Autriche-Hongrie, empire qui explosera après la Première Guerre mondiale)

Tous les cultes reçus ou légalement reconnus constituent des communions ou des associations religieuses des "corps religieux publics" placés sous la protection et le contrôle de l'État. Or, ces cultes reconnus étaient fort nombreux à la date de la promulgation de la loi (culte catholique romain, catholique grec, protestants de la confession d'Augsbourg, réformé, grec non uni, unitaire, israélite, etc.) ; et tous les autres cultes peuvent être reconnus moyennant production de leurs statuts et s'ils remplissent certaines conditions limitativement énumérées par la loi.

Les communions religieuses peuvent s’administrer librement, prélever des taxes sur les fidèles, recueillir des fonds, mais elle ne peuvent posséder d'autres immeubles que ceux servant à l'exercice du culte, au logement des ministres, à des œuvres scolaires et charitables, et des cimetières. Les pasteurs et administrateurs de paroisse sont choisis sans aucune intervention de l'autorité, mais ils doivent être de nationalité hongroise. Le ministre compétent a le droit d'exercer une 
haute surveillance sur les biens de la des communions religieuses et sur les fondations dont elles sont en possession ; il doit veiller à ce que les biens soient réellement affectés aux buts (religieux, scolaire, charitable) qui sont autorisés par la loi.

Cette législation établit, on le voit, une parfaite égalité entre les divers cultes; elle ne laisse subsister que des liens très lâches entre l’État et les Églises ; il n’y est pas fait mention d'allocations fournies par l’État.

Sans doute le budget des cultes est incorporé dans le budget de l'État qui se charge du payement des dépenses afférentes aux divers cultes; mais ces dépenses sont couvertes par le montant des taxes d’Église perçues spécialement sur les fidèles de chaque culte. En sorte que les ressources générales du budget ne sont point affectées aux cultes et que les citoyens "sans confession" ne participent aux frais d'aucun culte. Une semblable législation présente, avec un régime légal de séparation, de grandes analogies. Toutefois, l'Église catholique demeure en Hongrie une religion officielle : elle celle de la couronne, sinon de la majorité de la population (sur 19254000 habitants, il n'y a que 9919000 catholiques romains). Les hauts dignitaires de cette Église touchent comme les membres du haut clergé autrichien les revenus d'un patrimoine foncier très considérable, accumulé depuis de longs siècles, et, à l'égard duquel n'est intervenue jusqu’à présent aucune loi de sécularisation.

Il y deux pays voisins du nôtre où les idées de la laïcité et de neutralité de l'État ont fait, au siècle dernier, des progrès bien plus sensibles que dans la plupart des États de l'Europe centrale et orientale, mais où l'on aurait tort néanmoins de vouloir chercher des exemples d'une séparation véritable entre l'Église et l'État : ces deux pays sont l'Italie et la Belgique. Italie.- C'est, on le sait, le grand ministre italien Cavour qui a repris et rendu célèbre la formule de Montalembert : l'Église libre dans un État libre. On a dit parfois que dans sa pensée cette formule visait presque exclusivement les rapports de la dynastie de savoie avec le pape résidant dans la capitale du royaume italien. En réalité, Cavour et les hommes politique qui collaborèrent à son œuvre, tels que Minghetti auteur d'un ouvrage célèbre sur la séparation de l'Église et de l'État (Statuto e Chiesa - traduit en français par L. Bor- 
guet), entendaient appliquer la même formule aux rapports avec le clergé séculier tout entier et l'ensemble des catholiques. Mais leur idéal n’a point encore été réalisé. La législation italienne ne présente que l'ébauche d'une séparation.

L’Église ne possède point une complète indépendance ; L'État est bien loin d'avoir rompu tout lien avec elle. L'article 1er du Statuo (Constitution) du royaume Sarde, promulgué en 1848, déclarait que "la religion catholique apostolique et romaine est la seule religion de l'État" et que "les autres cultes existants sont tolérés conformément aux lois" ; et cet article est encore l'un des textes constitutionnels du royaume d'Italie. Assurément il a cessé depuis longtemps d'être appliqué à la lettre. Les principes de l'égalité et de la liberté des cultes et de la liberté de conscience sont hautement reconnus en Italie; les questions religieuses ne jouent aucun rôle en ce qui touche l'aptitude aux fonctions et emplois publics ; les principaux services publics (état civil, instruction, assistance) ont un caractère laïque. Pourtant l'ancienne disposition du Statuo n'est point tout à fait oubliée ; le parti clérical l'invoque dans les polémiques présentes relatives à l'obligation de l'enseignement religieux dans les école primaires (voir le Courrier européen du 27 janvier 1905)

Le clergé séculier jouit d'une très grand liberté ; toute restriction à l'exercice du droit de réunion des membres du clergé catholique a été aboli par l'article 14 de la loi du 13 mai 1871 (loi des garanties) dont le titre 1er est consacré aux prérogatives du saint-Siège et le titre II aux rapports de l'État avec l'Église. Le libre exercice du culte est donc garanti aux catholiques. Il l'est d'ailleurs aussi aux non catholiques (protestants, israélites). Le code pénal édicté en 1889, punit par des dispositions spéciales (articles 140,141) la répression de tout trouble apporté à l'exercice du culte, de tout outrage envers l'un des cultes admis par l'État : l'article 142 punit quiconque, par mépris de l'un des cultes admis par l'État, détruit, dégrade ou profane dans un lieu publique des objets destinés au culte ou bien use de violence contre un ministre du culte ; enfin l'article 143 punit toute détérioration de monuments, peintures, statues, etc. ; placés dans un lieu destiné au culte. La contre-partie de ces dispositions se trouve dans les articles 182 et 183 du même code qui répriment les délits commis par les ministres des cultes dans l'exercice de leurs fonctions (blâme ou censure publique 
des institutions ou des lois de l’État, excitation au mépris des institutions, à l'inobservation des lois, des prescriptions de l'autorité ou des devoirs inhérents à une fonction publique, etc.) ; l'article 184 prévoit en outre que, pour tout délit autre que ceux spécifiés aux articles précédents la peine est augmentée d'un sixième à un tiers, si c'est un ministre du culte qui, en se prévalant de sa qualité, a commis le délit. Dans la pensée des hommes d'État italiens qui, continuant l'œuvre de Cavour, ont achevé l'unification de l'Italie en donnant au nouveau royaume une législation pénale uniforme, la formule "l’Église libre dans l’État libre” n'excluait pas, on le voit, les dispositions très précises concernant la police des cultes.

L’organisation intérieure de l'Église est en partie indépendante de l'action de l'État. Les évêques sont dispensés de toute prestation de serment. Le roi n’a ni le droit de nommer, ni celui de proposer les titulaires des bénéfices ecclésiastiques, sauf en ce qui touche la collation de certains bénéfices dits “de patronat royal” (et c'est là, à vrai dire, une exception importante). Les titulaires de bénéfices ecclésiastiques doivent dans toute l'Italie, sauf à Rome, être de nationalité italienne. Le pouvoir civil se refuse se refuse à prêter l'appui du bras séculier pour l'exécution des actes des autorités ecclésiastiques, en matière spirituelle et disciplinaire ; ces actes ne produisent d'autres effets juridiques que ceux qui sont reconnus par les tribunaux civils. En revanche, la publication des actes des actes des autorités ecclésiastique en matière spirituelle est dispensée de toute autorisation administrative. En tant que puissance spirituelle, l'Église catholique se trouve ainsi réellement séparée de l'État. C'est en ce qui touche l'administration temporelle des cultes que les rapports subsistent. Au budget italien ne figurent sans doute sans doute ni les traitements ni les pensions des membres du clergé. Mais c'est une administration de l'État, celle du fonds pour le culte (Fondo per il culto) qui pourvoit au payement des traitements et pensions dont le taux est fixé par des lois et des décrets royaux (une loi du 4 juin 1899 a augmenté le traitement des curés). Le fonds pour le culte a été constitué en 1866, au début de la grande sécularisation des biens ecclésiastiques (le produit des deux tiers du patrimoine ecclésiastique sécularisé a été affecté à ce fonds. L'administration du Fondo per il culto n'est pas la seule qui soit chargée des affaires ecclésiastiques. Il existe, en outre, une administration du patrimoine ecclésiastique de laquelle dépendent les économats 
et subéconomats des bénéfices vacants. La gestion des biens temporels affectés au culte est, en effet, en cas de vacance du siège, conservé par l'autorité civile ; de même que tous les actes des autorités ecclésiastiques (pape et évêques) concernant le temporel des cultes (collation des bénéfices ecclésiastiques, administration des biens ecclésiastiques) sont soumis à l'approbation gouvernementale ou préfectorale (exequatur royal et placet royal)

Ce qui achève de donner à l'église catholique le caractère d'une institution publique, sinon une institution d'État, c'est que les fabriques des églises paroissiales et cathédrales, les sanctuaires, oratoires, etc., ont échappé à la suppression générale des corporations et institutions religieuses effectuées dans la seconde moitié du dix-neuvième siècle ; il subsiste ainsi un nombre considérable d'établissements doués de la personnalité juridique, pouvant recevoir des dons et legs, bref tout à fait semblables aux établissements publics préposés aux cultes qu'a institué notre droit concordataire. La législation de l'époque napoléonienne est d'ailleurs encore en vigueur dans une partie de l'Italie, et les règles relatives à l'acquisition et à l'aliénation des biens des établissements du culte sont, dans le code civil italien, les mêmes que dans notre code civil.

La législation concernant les rapports de l'Église et l'État en Belgique, seraient, si l'on s'en rapportait aux déclarations faites tant par les catholiques que par les libéraux lors de l'élaboration de constitution belge, en 1830, inspiré par le principe de la séparation ; mais ici, plus encore qu'en Italie, il s'agit plutôt de l'indépendance de l'Église, considérée comme pouvoir spirituel, à l'égard de l'État, que d'une séparation réelle et complète ; comme institution temporelle l'Église est subventionnée par l’État.

La constitution, après avoir proclamé et garanti la liberté de conscience, la liberté des cultes et leur exercice public (art 14 et 15), déclare que l'État n'a pas le droit d'intervenir dans la nomination, ni dans l'installation des ministres d'un culte quelconque, ni de défendre à celui-ci de correspondre avec leurs supérieurs et de publier leurs actes. Mais l'article 117 de cette même Constitution met à la charge de l'État les traitements des ministres des cultes. Le budget des cultes a constamment augmenté, surtout dans les vingt dernières années, pen- 
dant lesquelles le parti clérical a été au pouvoir. Il s'élève, si l'on tient compte des allocations des provinces pour l'entretien des cathédrales et des séminaires, et de celles des communes pour les dépenses du culte paroissial en cas d'insuffisance des revenus des fabriques, à plus de huit millions et demi. Une loi du 24 avril 1900 a réglementé à nouveau les pensions et les traitements ecclésiastiques. Les traitements fixés par cette loi sont très supérieurs à ceux du clergé catholique en France. Le logement du ministre du culte est à la charge des communes.

Cet appui financier n'est pas le seul privilège dont jouisse l’Église. Tandis que les associations d'un caractère laïque, qui peuvent se constituer librement et sans aucune déclaration ni autre mesure préalable (art. 20 de la Constitution) ne possèdent aucune capacité juridique, n’ont point la personnalité ou la "personnification civile", comme on dit en Belgique, il en est tout autrement en ce qui concerne les Églises. La législation datant de l'époque où la Belgique faisait partie de l'Empire français et considérée comme toujours en vigueur : les fabriques d'Église continuent à être régies par le décret du 30 décembre 1809 et sont de véritables établissements publics préposés au cultes qui acquièrent et accumulent des biens de mainmorte dans les mêmes conditions qu'en France sous le régime concordataire.

Une loi du 4 mars 1870 a réglé le mode de gestion des bien paroissiaux et la comptabilité des conseils de fabrique. Les autres cultes reconnus (protestants, israélite et anglican) dont les fidèles sont d'ailleurs très peu nombreux jouissent aussi de la personnalité civile et sont soumis à une réglementation analogue à celle prévue pour le culte catholique.

Bref, on peut dire avec le grand jurisconsulte belge Laurent (L'Église et l'État depuis la révolution) : "Le système belge ne consacre pas la vraie séparation de l’Église et de l'État : l'État a des obligations sans avoir aucun droit tandis que l'Église a des droits sans avoir aucune obligation.”

Il convient de noter qu'en belgique, comme en Italie, la liberté de l'exercice des cultes est garantie d'une part et d'autre part limité par des dispositions pénales : l'article 267 du code pénal belge punit les 
ministres des cultes qui, hors les cas formellement exceptés par la loi procède à la bénédiction nuptiale avant la célébration du mariage civil ; l'article 267 punit celui qui, dans l'exercice de son ministère, et en assemblée publique, attaque le gouvernement, une loi, un arrêté royal ou tout autre acte de l'autorité publique. Les articles 142 à 146 reproduisent presque textuellement les articles 260 à 264 de notre code de 1810 qui réprime les atteintes au libre exercice des cultes.

La législation ecclésiastique des Pays-Bas ne diffère guère de celle de la Belgique. La constitution proclame la liberté des opinions religieuses et déclare qu'une protection égale est accordée à toutes les communions religieuses. Mais il y a trois religions privilégiées, subventionnées par l'État: ce sont les cultes catholique, protestants et israélite.

Il les deux pays d'Europe dont il nous reste à parler, on rencontre, à côté des Églises officielles, des Églises libres et séparées de l’État ; et, particularité intéressante, l'Église catholique est au nombre de ces Églises libres.

Ces deux pays dont il s'agit sont : la Grande-Bretagne et la Suisse. Grande-Bretagne et Irlande. - Il y a, dans le pays, deux Églises officielles, "établies" : ce sont l'Église anglicane (Church of England) en Angleterre, et l'Église presbytérienne en Ecosse. Le souverain en est le chef suprême. On sait que la hiérarchie ainsi que les dogmes et les rites de l'Église anglicane diffèrent assez peu de ceux du catholicisme romain, tandis que l'église établie d'Ecosse est organisée d'après le système électif généralement adopté par les sectes protestantes. Ces Églises officielles sont spécialement protégées par l’État, mais non pas subventionné par lui. Il n'y a pas de budget des cultes. Les revenus des dotations immobilières attachées depuis de longs siècle aux divers titres ecclésiastiques (archevêchés, évêchés, chapitres et cures) le produit des dîmes, les contributions des fidèles constituant les ressources de l'Église anglicane. Mais on ne peut s'attarder ici à l'étude de ces Églises établies. Il est plus utile d'examiner la condition juridique des Églises séparées et libres et aussi de rappeler dans quelles conditions a été opéré, il y a trente-six ans une véritable séparation d'une Église et de l'État, à savoir le Disestablishment de l'Église protestante d'Irlande. 
I.- Il y a dans le Royaume-Uni beaucoup d’Églises protestantes qui ne sont rattachées par aucun lien avec l'État et n'on jamais été “établies”. On range leurs fidèles sous la dénomination générique de dissenters (dissidents) et de non-conformistes. Dans tout le pays de Galles, les six septième de la population (qui est d'environ 1574000 habitants) se rattachent à des sectes non-conformistes (méthodiste, congrégationaliste, wesleyenne, baptiste, etc.). En Écosse, les fidèles des Églises indépendantes de l'État sont beaucoup plus nombreux que ceux de l'Église presbytérienne établie. Enfin, l’Église catholique romaine compte environ 5750000 fidèles, dont 3308000 en Irlande. Pendant de longs siècles, non-conformistes et catholiques furent soumis à un régime d'exception ; l'exercice de leur culte était à peine toléré et ils étaient privés d'une partie de leurs droits civils et de tous droits politiques. Il ne reste aujourd'hui que des vestiges de cette législation draconienne, issue des guerres religieuses du seizième et du dix-septième siècle. Des lois de 1791 et de 1829 ont accordé aux catholiques presque tous les droits civils et tous les droits politiques. Seules quelques hautes fonctions de l'État demeurent interdites aux dissidents et aux catholiques romains; encore la question est-elle controversée. L'exercice du culte dans les églises et les temples est libre pour toutes les secte dissidentes, mais cet exercice doit être public. Depuis 1832 aucun “enregistrement”, aucune déclaration n’est plus obligatoire pour l'ouverture d'un lieu de culte. Mais quand les temples sont déclarés, ces édifices sont exemptés d'impôts, et les ministres qui sont attachés à ces temples jouissent de certains privilèges analogues à ceux qui appartiennent aux ministres de l'Église anglicane (exemption du jury, du service dans la milice, etc.). Une ancienne loi exempte du péage sur les chemins à péage tout ministre d'un culte et tout fidèle qui se rend les dimanches et jour de fêtes religieuses de son domicile au lieu du culte, ou qui en revient. Enfin l'article 26 de la loi du 6 août 1861 (Ann. 24-25 Metoria, chap. 100), qui est applicable à tous les ministres du culte sans distinction, punit de deux ans de prison avec ou sans travaux forcés (hard labour) ceux qui troublent ou menacent un ecclésiastique dans l'exercice de ses fonctions, soit au cours d'une cérémonie du culte, soit pendant un convoi funèbre, et ceux qui commettent des violences à l'égard d'un ecclésiastique dans les mêmes circonstances. La police des cultes existe donc plutôt pour protéger la liberté des cultes que pour la limiter. 
Rien n’est plus fréquent en Angleterre, on le sait, que des prédications ou réunion d'un caractère religieux, en plein air et sur la voie publique. Les ministres des divers cultes jouissent d'une entière liberté de parole, interviennent dans les affaires politiques ; on en a vu pendant la guerre du Transvaal, apprécier en chaire, dans les termes les plus sévères, les actes du gouvernement. La multiplicité des sectes, la faiblesse numérique relative de chacune d'elles servent de contrepoids, en quelque sorte, à cette liberté de parole presque illimitée accordée aux ecclésiastiques. L’Église catholique bénéficie comme les sectes protestantes de ce régime très bienveillant. Elle est toutefois soumise à quelques restrictions particulières ; on n’a point abrogé la disposition de 1829 qui interdit aux prêtres catholiques, sous peine de 1250 fr. d'amande d'exercer leur culte ou de porter des habits sacerdotaux ailleurs que dans les lieux réservés à cet exercice (ce qui équivaut à l'interdiction des processions).

L'organisation de l'Église catholique et des Églises protestantes non établies est, dans le Royaume-Uni, celle d'associations libres vivant chacune suivant ses propres règles. L'autorité gouvernementale n'intervient pas dans le fonctionnement de ces associations. Les difficultés qui peuvent s'élever à ce sujet sont du ressort des tribunaux. Un schisme s'est produit récemment au sein de l'Église presbytérienne libre d'Ecosse : la majorité des fidèles et des pasteurs a décidé de s'unir à l'Église presbytérienne unie, autre fraction du presbytérianisme qui est également indépendante de l'État (la seule Église unie à l'État est l'église presbytérienne “établie”). A la suite de ce schisme, le patrimoine très considérable qui provenait de fondations pieuses et charitables a naturellement fait l'objet de revendications contradictoires. Le litige a été portée devant la cour d’Édimbourg et en appel devant la chambre des lords ; et cette haute juridiction a attribué la totalité du patrimoine à la minorité composée de quelques pasteurs et d'un petit nombre de fidèles. Ce n'est pas la première fois, loin de là, que de semblables procès, où les questions d'ordre religieux et même dogmatique doivent être examinés, sont soumis aux tribunaux anglais.

L’Église catholique a constitué en Angleterre l'organisation hiérarchique qui lui est particulière. Sans doute, ses évêchés et ses paroisses ne sont pas érigées en personnes morales, en corporations ; mais elle 
participe indirectement à tous les avantages de la personnalité civile. La législation anglaise du moyen âge réprimait très sévèrement les abus de la mainmorte ; mais elle a, pour ainsi dire, disparu grâce à l'institution du fidéicommis, et spécialement du fidéicommis charitable (charitable trust) qui permet d'affecter à perpétuité à l'un des buts autorisés par la loi une libéralité déterminée. Depuis la loi de 1601 promulguée sous le règne de d’Élisabeth jusqu'à celles de 1888 et 1891, le nombre des charitable trusts admis par les législateurs s'est beaucoup accru : on reconnaît notamment que tout legs fait dans un but religieux entre dans cette catégorie. Le Roman catholic charities act de 18.. autorise spécialement les catholiques à instituer toutes sortes de fondations charitables et religieuses. Toutefois, il faut que tout bien immobilier faisant l'objet d'une fondation charitable ou religieuse soit vendu ou converti en valeurs mobilières dans l'année du décès du testateur. Il n'est fait exception qu'à l'égard de terrain devant servir à la construction d'un temple ou d'un autre bâtiment nécessaire au fonctionnement de l'œuvre. Enfin la jurisprudence anglaise refuse de valider certains dons ou legs d'un caractère religieux, telles que les fondation à charge de dire des messes pour le repos d'une âme : on les considère comme des usages superstitieux (superstitious uses) et comme étant à ce titre entachés de nullité. Le testateur doit, d'après cette jurisprudence, se borner à faire un legs en vue de l'exercice et du maintient du culte ; il peut exprimer le désir qu'un ecclésiastique dise des prières à son intention, mais en stipulant expressément, à peine de nullité du legs, que ce désir ne crée aucune obligation légale.

Il n'est contesté par personne que, depuis l'émancipation des catholiques, en 1829, la puissance matérielle de l'Église catholique en Angleterre n’a fait que s'accroître, que chapelles, églises, couvents, écoles confessionnelles s'y sont multipliés. Les ordres monastiques se rattachant au catholicisme romain n'ont et ne peuvent avoir aucune capacité juridique en tant qu'êtres collectifs ; mais ils s'enrichissent par l'intermédiaire de leurs membres, ni la loi, ni la jurisprudence n'ayant pris de précautions sérieuses contre les fraudes dues à l'interposition de personnes.

II.- La séparation en Irlande (Disetablishment de l'Église d'Irlande). - L’Église anglicane s'était imposée par la conquête en Irlande. “Cette Église, dit Minghetti (L’État et l'Église - déjà cité), 
petite par le nombre de ses fidèles, mais puissante par sa hiérarchie, fortement organisée, se partageant l'île entière et liguée avec les possesseurs du sol, avec l'Église d'Angleterre et avec l'État, dominait une nation de catholiques, réduite au dernier degré de misère.” Par la loi du 26 juillet 1869 (Ann. 32-33, Victor, chap. 42), l’Église d’Irlande cessa d'être une Église officielle et devint une Église libre. L'article 3 chargea de la liquidation des biens de l'Église trois "commissaires du temporel de l'Église d’Irlande”, au nom desquels fut transférée toute la propriété ecclésiastique. Les “corporations” existantes (personnes morales correspondant aux établissements publics de notre droit), telles qu'archevêchés, évêchés, etc., furent dissoutes à partir du 1er janvier 1871. L'œuvre de sécularisation, de “dédotation” disendowment de l'Église d'Irlande est aujourd'hui presque achevée. Le patrimoine ecclésiastique, que Gladstone évaluait à 360 millions en capital, s'est retrouvé être en réalité plus considérable encore. Le payement des rentes viagères et allocations dues aux évêques et autre dignitaire, aux curés, etc., d'une indemnité globale de 11250000 fr. remis au corps représentatif de la nouvelle Église libre pour compensation de la perte des dotations privées, terres et dîmes, des dépenses afférentes aux édifices, et de divers autres indemnités a absorbé une somme totale de 279 millions, supérieur d'un tiers environ à celle qui avait été promise en 1869. Et après avoir ainsi pourvu d'une manière extrêmement large aux besoins de l'Église "désétablie" il a été possible d'affecter une somme de 135 millions aux besoins de l'Irlande, notamment à l'instruction et à l'assistance publique de l'île. La même loi de 1869 supprime tous les droits de patronage, royaux et autres, afférents à la collation des fonctions ecclésiastiques. Elle accorde au clergé pleine liberté de se réunir et de s'associer. Elle décide que les statuts et règles dogmatiques ou disciplinaires de l'Église d'Irlande ne vaudront qu'à l'égard des fidèles, et à titre de stipulation librement consenties dans les conditions du droit commun. Pour les édifices du culte, l'article 25 de la loi contient les dispositions suivantes : les édifices religieux ne servant plus au culte, mais devant être conservés à titre de monuments historiques, sont remis à l'administration des travaux publics (Commissionners of Public Works) de l'Irlande, avec charge de veiller à leur conservation ; les églises qui seront réclamées pour le service du culte par les représentants de l’Église leur sont attribuées ; les églises non réclamées par ces représentants de l’Église et enlevées aux frais d'un particulier sont remis au donateur, sur sa demande, ou aux héri- 
tiers du testateur, pourvu toutefois que le décès du testateur soit à l'année 1800. Dans les autres cas, les commissaires peuvent disposer de ces édifices comme ils l'entendent. On le voit, dans un pays voisin du nôtre, la séparation d'une église officielle et de l'État a été légalement opérée ; et l'application de la loi n’a soulevé aucune difficulté particulière ; la question agraire seule, à l'exclusion de la question religieuse, et celle de l'autonomie législative (Home Rule) sont demeurées en Irlande des causes d'agitation. L’Église protestante d'Irlande ne paraît pas d'ailleurs avoir souffert des modifications ordonnées par la loi, et la disparition de ses privilèges et de son caractère officiel n'a pas nui à son développement ; et elle s'est reconstituée, depuis la séparation, un patrimoine considérable.

III.- Projets de séparation en Angleterre.- Il y a en Angleterre, surtout depuis une trentaine d'années, un courant d'opinion assez marqué en faveur de la séparation entre l'Église et l'État. La liberation society, société fondée en vue de libérer la religion du patronage et du contrôle de l'État, poursuit avec une inlassable ténacité la campagne de brochures, de manifestes, de publications de toute espèce qu'elle a entreprise. D'après les estimations des "libérationnists", c'est à dire partisans de la séparation, les revenus capitalisés de l'Église anglicane et les églises et cathédrales représenteraient au total une somme de 220 millions de livres (5 milliards de francs). On estime qu'en privant l'Église de ses dotations, moyennant de larges compensations calculées d'après les mêmes bases que pour l'Église d'Irlande en 1869, l'État pourrait disposer d'environ 3 milliards. Tout un plan a été élaboré ; il comporte l'attribution au domaine des terres de rapport, l'attribution des anciennes églises (antérieures à 1818) aux habitants des paroisses, qui pourraient les employer au mieux de leurs intérêts ou les aliéner ; l'attribution des églises modernes aux groupes de fidèles qui les ont construites, ou aux particuliers qui les ont fait élever à leurs frais, s'ils sont encore vivants (Ayral, la Séparation des Églises et de l'État en Angleterre - Annales de l'école libre des sciences politiques, année 1886).

Les “libérationnists” n’ont jamais espéré ni obtenu que l'appui politique du parti libéral. Le parti conservateur leur est nettement hostile. Même si les libéraux revenaient au pouvoir, les partisans de la séparation ne pourraient sans doute pas songer à la réalisation complète et 
immédiate de leur programme, qui est la suppression de toute Église officielle, même en Angleterre ; mais peut-être ferait-on de nouveaux efforts pour obtenir le "Disetablishment" dans le pays de Galles et en Écosse. Des propositions en ce sens ont été faites déjà à diverses reprises au Parlement anglais et n’ont été repoussées qu’à une très faible majorité. Il est certain que le maintien d'une Église anglicane officielle dans le pays de Galles, où cette Église possède des revenus importants et perçoit pour plus de 5 millions de francs de dîmes, ne s'explique guère, alors que l'immense majorité de la population est détachée de cette Église.

Suisse.- La Constitution fédérale de la confédération suisse déclare inviolable la liberté de conscience et garanti la liberté des cultes dans les limites compatibles avec l'ordre public et les bonnes mœurs (art. 49 et 50). Elle autorise la confédération et les cantons à prendre des mesures pour le maintien de l'ordre public et la paix entre les membres des diverses communautés religieuses, ainsi que contre les empiétements des autorités ecclésiastiques sur les droits des citoyens et de l'État. Elle s'abstient de toute ingérence dans l'organisation et le fonctionnement des Églises, sauf sur un point: le dernier paragraphe de l'article 50 stipule qu'il ne peut être érigé d'évêchés sur le territoire suisse sans l'approbation de la confédération. Enfin, l'article 49, paragraphe 6 , porte que nul n'est tenu de payer les impôts dont le produit est spécialement affecté aux frais du culte d'une communauté religieuse à laquelle il n'appartient pas. De l'ensemble de ces prescriptions on ne doit point inférer qu'un régime analogue à celui de la séparation des Églises et de l'État est établi en Suisse. Si la liberté de conscience et la liberté du culte sont pleinement assurées dans chaque canton conformément aux principes posés par la Constitution fédérale, la disposition relative à la participation aux frais du culte est à peu près inapplicable. Les subventions allouées par beaucoup de cantons à certains cultes étant payées sur les ressources générales du budget et non pas fournies par des impôts spéciaux, les contribuables participent ainsi nécessairement aux frais d'un culte non pratiqué par eux.

Il y a dans tous les cantons des Églises nationales, réglementées et, souvent subventionnées par l'État. Rien, au surplus, n’est moins uniforme que la législation politico-ecclésiastique des cantons suisses. La scission qui s'est produite après 1870 entre les vieux catholiques et les 
catholiques romains, les tentatives faites par les gouvernements de certains canton, à Genève notamment, en vue de constituer des Églises catholiques nationales ont rendu les rapports de fait et de droit entre les Églises et les cantons plus complexes encore.

D’une manière générale on peut dire que les Églises reconnues et officielles de chaque canton, c'est à dire l’Église protestante dans les uns, l'Église catholique dans les autres, les deux Églises dans d'autres encore, sont subventionnées par l'État. Quand les revenus d'anciennes fondations, qui existent dans presque tous les cantons où les taxes perçues sur les fidèles ne suffisent pas pour l'entretien du culte, des allocations sont fournies par les cantons. Les traitements des ministres des cultes figurent dans la plupart des budgets cantonaux. Il y a des cantons (Argovie, Zurich, Fribourg, etc.) où des taxes spéciales pour les frais du culte sont perçues sur les fidèles de chaque Église dans la même forme que les impôts.. En général, les édifices des cultes appartiennent aux cantons ou aux communes, qui les mettent gratuitement à la disposition des cultes.

La situation légale de l'Église catholique romaine résulte d'anciennes coutumes dans certains cantons, dans d'autres d'une législation ayant un caractère concordataire : ainsi, pour le Tessin, des conventions ont été conclues avec le saint-Siège les 1er et 27 septembre 1884 par le gouvernement fédéral (dont les relations diplomatiques avec le Vatican étaient cependant rompues depuis dix ans) et par les autorités cantonales du Tessin. Ailleurs, enfin, cette situation est uniquement réglée par la loi cantonale.

Parfois l’Église s'est soumise sans difficulté à la législation civile ; dans le canton de Thurgovie, par exemple, elle a accepté l'organisation synodale (comportant l'élection des curés par les fidèles), que la loi lui avait imposée, et elle est restée dans ces conditions Église officielle. Mais le plus souvent elle a refusé de se plier à la réglementation faite par le pouvoir civil et a renoncé à tous les droits et privilèges d'une Église officielle. Les catholiques romains se sont alors constitués en associations libres, entièrement séparée de l’État. Les Églises catholiques et officielles subventionnées par les cantons n’ont, depuis ce moment, compté d'autres fidèles que les vieux catholiques, ou catholiques chrétiens dont le nombre est fort réduit (On n’en 
compte guère plus de 40000 dans toute la Suisse : le total de la population catholique est d'environ 1379 000. Il y a près de 2 millions de protestants). Telle est la situation qui s'est produite notamment à Bâle, à Berne et à Genève. Dans le canton de Genève c'est une association privée, l'œuvre du clergé, qui recueille les souscriptions des fidèles et paye les curés et vicaires. Pour remplacer les églises mises à la disposition des vieux catholiques de nouveaux édifices ont été construits aux frais des fidèles. Toutefois les relations entre l'Église catholique et les autorités civiles de Genève, de Berne et de Bâle, fort tendues il y a une trentaine d'années, se sont beaucoup améliorées. Des édifices communaux sont mis gratuitement à la disposition des catholiques romains dans plusieurs communes du canton de Genève, à Bâle et dans le canton de Berne.

L'Église catholique n'est pas la seule n'est pas la seule qui vive séparée de l'État dans certains canton suisses ; il y a également à Genève, dans les canton de Vaud et de Neuchâtel, des Églises protestantes libres à côté des Églises protestantes nationales. Là, comme pour les catholiques, l'initiative de la séparation est venue non du pouvoir civil, mais du groupement religieux.

En ce qui touche la police des cultes, on rencontre également en Suisse les régimes les plus divers. Dans le canton de Berne a été promulgué, le 14 septembre 1875, une loi sur la "répression des atteintes portées à la paix confessionnelle”. L'article 2 de cette loi punit de l'amende et de la prison tout ecclésiastique faisant des institutions politiques ou des décisions des autorités de l'État l'objet d'une publication ou d'un discours de nature à mettre en danger la paix publique ou l'ordre publique (disposition reproduisant presque textuellement l'article 130 du code pénal allemand). L'article 5 interdit sous peine d'amende et d'emprisonnement les processions et autre cérémonies religieuses en dehors des églises, chapelles et autres locaux privés. Saisis d'un recours contre ces dispositions de la loi cantonale, le conseil fédéral déclara, le 13 mai 1875, qu'elles ne portaient pas atteinte aux principes de la liberté de conscience et de la liberté des cultes inscrits dans les articles 49 et 50 de la constitution fédérale. A Genève, la loi du 28 août 1875 contient des dispositions analogues à la loi bernoise. Les processions sont également interdites dans le canton de Vaud. Elles sont, au contraire, autorisées dans le Valais et dans 
les autres cantons catholiques. Dans le Tessin, notamment, l'administrateur apostolique, délégué discret du saint-Siège, a des pouvoirs très étendus ; il peut faire ordonner des prières publiques et des processions (convention de 1884 conclues avec le saint-Siège). En vertu des mêmes conventions, les autorités civiles doivent prêter leur concours aux autorités ecclésiastiques pour l'exécution des mesures prises par elles.

Le régime de la séparation des Églises et de l’État, encore si faiblement et incomplètement mis en pratique en Europe, est, au contraire, largement adopté dans le Nouveau Monde ; le Canada (où une loi de 1854 a sécularisé certains ecclésiastiques et enlevé à l'Église anglicane tout caractère officiel), les États-Unis, le Mexique n'en connaissent point d'autre. On le rencontre encore dans la jeune république de Cuba, dans trois républiques du Centre-Amérique et enfin dans le plus important des États de l'Amérique du Sud: les États-Unis du Brésil.

États-Unis.- Les rapports entre les pouvoirs civils et les religions aux États-Unis ont été, dans ces dernières années, fréquemment exposés. Les ouvrages de MM. le vicomte de Meaux (l'église catholique et la liberté), Claudio Jannet (les États-Unis contemporains), P. G. La Chesnais (trois exemples de séparation), de Bryce (la République américaine - traduit en français - tome IV), de l'abbé Félix Klein (Au pays de la vie intense) fournissent à cet égard de nombreux éléments d'information qu'on doit compléter par l'examen des textes constitutionnels ou législatifs. Le principe de la laïcité et de la neutralité de l’État est consacré dans la constitution fédérale, qui décide qu'aucune déclaration de foi religieuse ne peut être requise comme condition d'aptitude pour l'obtention des charges publiques dépendant du gouvernement fédéral (article 6) et qui interdit au congrès de faire aucune loi à l'effet d'"établir" (c'est à dire reconnaître officiellement) une religion ou d'interdire son libre exercice (même article, amendement I). Ces mêmes principes, qui, au début du dix-neuvième siècle, n'étaient pas encore appliqués dans tous les États de l'Union sont aujourd'hui uniformément proclamés et mis en pratique sur tout le territoire de la République. Presque toutes les constitutions des États déclarent que nul ne doit être forcé de contribuer aux dépenses d'une Église ou de se rendre à ses offices ; beaucoup prohibent toute mar- 
que de préférence à l'égard d'une secte particulière. L'égalité des divers cultes est aussi complète que leur liberté. Mais la neutralité de l'État ne comporte, en Amérique, ni hostilité ni même indifférence à l'égard des religions. C'est de l'incompétence du pouvoir laïque en matière religieuse et d'un sentiment profond de l'égalité que dérivent ces législations excluant toute religion officielle. La neutralité de l'État est essentiellement une neutralité bienveillante à l'égards des religions dont l'utilité est généralement reconnue. Ainsi que l'a très justement fait observer Migheti, il y a une séparation juridique, mais une véritable union morale entre l’État et les Églises et M. Bryce a pu aller jusqu'à dire que le "christianisme est en fait considéré comme étant, sinon la religion légalement établie, du moins la religion nationale". "Les fondateurs de notre gouvernement et les auteurs de notre constitution ont reconnu qu'entre la religion chrétienne et un bon gouvernement il y a une intime connexion et que cette religion est le fondement le plus solide d'une saine morale.” Ainsi s'exprimait un juriste un juriste américain dans une étude sur le régime légal des Églises dans l'État de New-York. Ces citations, auxquelles on pourrait en ajouter bien d'autres, permettent de comprendre quelle est la conception spéciale de la laïcité qui est admise aux États-Unis.

On s'explique ainsi le caractère très favorable aux Églises, aux “corporations religieuses” des législations qui les régissent.

On s’explique ainsi certaines dérogations au principe de la neutralité qui pourraient, au premier abord, paraître (illisible) les allocations accordées par les (illisible) à des chapelains appartenant à des confessions chrétiennes, et (illisible) prières au début de chaque (illisible) proclamation annuelle du Président (illisible) ordonnant des actions de grâce (illisible) analogues des gouverneurs d'(illisible) des jours pour la célébration de cérémonies religieuses ; les honneurs publiques (illisible) et les égards officiellement témoignés par le Président de la république et toutes les autorités civiles aux dignitaires ecclésiastiques, notamment aux archevêques et cardinaux de l’Église romaine, etc.

La police des cultes est fortement organisée, mais presque uniquement en faveur des religions. Dans un certain nombre d'États, des lois punissent le blasphème, interdisent de travailler le dimanche ; dans presque tous les États tout désordre causé au cours de l'exercice d'un 
culte, toute entrave au libre exercice des cultes, toute vente de marchandises, vins ou spiritueux aux alentours des églises et temples, des lieux destinés à des réunions religieuses ou prédications en plein air (camp-meeting) sont punis de l'amende et de la prison. Les cérémonies religieuses et processions sur les voies publiques sont également autorisées; pourtant une loi de 1880 les a interdites dans l'État de New-York.

Il n’y a, d'autre part, aucune loi dans les États de l'Union qui réprime spécialement des délits commis par des ecclésiastiques. Il faut dire que jusqu'à présent les ministres des divers cultes se sont presque toujours renfermés dans leur mission. La neutralité de l’État en matière religieuse coïncide réellement et effectivement, aux États-Unis, avec la neutralité des Églises en matière politique. C'est un principe unanimement reconnu que "l'Église est un corps spirituel existant dans un but spirituel et se mouvant dans des voies purement spirituelles.” (Bryce, la République américaine, tome IV, p. 461) “On n’admet pas, dit le même auteur, qu'un clergyman s'immisce dans les affaires politiques et traite en chaire aucun sujet séculier" (ibid., p. 474). On ne peut qu'envier la grande démocratie américaine de ce que la sanction de l'opinion publique y soit suffisante, sans aucune disposition pénale, pour réprimer certains excès.

L’organisation intérieure des diverses Églises protestantes et de l'Église catholique est celle d'associations libres et volontaires ; toutes les questions de propriété, celles de discipline et de juridiction ecclésiastiques sont, lorsqu'on les soumet aux tribunaux, résolues suivant les règles du droit commun. Il est à peine besoin de dire que le pouvoir civil n'intervient à aucun degré dans la nomination des dignitaires ecclésiastiques. Les Églises protestantes élisent leurs pasteurs, leurs évêques, suivant les règles adoptées par chacune d'elles. Les curés catholiques sont choisis par les évêques ; les évêques sont désignés par la curie romaine sur une double liste de présentation dressée par les curés du diocèse et les évêques de la province.

Comme la législation anglaise, la législation américaine est peu défiante à l'égard des établissements de mainmorte ; le bénéfice de la personnalité civile, qui emporte le droit de posséder et celui d'acquérir des biens à titre gratuit, est donc très libéralement accordé aux asso- 
ciations religieuses. Celles-ci peuvent soit ne pas se faire "incorporer", c'est-à-dire transformer en personnes morales, et se borner à constituer des fidéicommissaires (trustees) qui assurent la conservation des biens, soit devenir des corporations, des personnalités juridiques en vertu d'une déclaration faite devant une autorité administrative ou judiciaire, ou en vertu d'une loi spéciale. Mais des garanties sont prises contre l'accroissement illimité des biens de ces associations. Dans certains États, la loi détermine le maximum du capital qu'elles peuvent posséder (Alabama, Colorado, Tennessee : 250000 fr.; Michigan, Caroline du Sud : 500000 fr., etc.) ; dans d'autres, c'est le maximum du revenu des biens qui est fixé (maryland, New-Jersey: 10000 francs de revenu; Delaware : 1500 fr. de revenu provenant d'immeubles et 3000 fr. de revenu provenant de valeurs mobilières ; Californie : 100000 fr. ; New-Hampshire : 25000 fr. ; Caroline du Nord, 30000 fr. ; New-York : 500000 fr.). Ailleurs, la loi limite le nombre d'acres de terrain que peut posséder une Église : dans le district de Columbia, chaque association religieuse ne peut posséder qu'un acre de terrain pour y construire des églises et autres établissements servant à l'accomplissement du but de la société; dans l'Illinois, chaque association ne peut posséder d'autres immeubles que ceux servant au fonctionnement de l'association ; dans l'Iowa, nul ne peut donner ou léguer à une association religieuse plus du quart de sa fortune.

On voit que, sous des formes très diverses, les législations américaines ont pris des précautions contre l'accroissement des biens de mainmorte. Les corporations religieuses sont toutefois traitées avec beaucoup de bienveillance, on ne saurait trop le répéter. leurs biens sont parfois parfois partiellement exemptés d'impôts. Dans certains États (Maine, Massaschussets) elles sont autorisées non seulement à réclamer des cotisations, des taxes aux fidèles, mais encore à faire percevoir ces taxes dans les mêmes formes que les impôts d'État ou les impôts communaux.

Enfin, outre les lois générales, les législatures des États ont fréquemment édicté des lois spéciales relatives à telle ou telle Église protestante ou à l'Église catholique afin de donner à chacune d'elle l'organisation particulière qui lui convient le mieux. L'Église catholique a largement bénéficié de ces dispositions bienveillantes et a, dans 
beaucoup d'États, fait créer ainsi, à son profit, un droit spécial, qu'elle préfère au droit commun des associations. Un jurisconsulte catholique faisait naguère remarquer que l'association, c'est-à-dire le libre groupement de citoyen associés pour exercer un culte, "est la négation pratique et le renversement de la hiérarchie catholique. (Voir rapport sur les projets de loi relatifs à la séparation adressé par M. G. Théry, ancien bâtonnier au barreau de Lille à l'archevêque de Cambrais, dans le Siècle du 1er janvier 1905.) Or aux États-Unis le désir de ne refuser aucune concession au sentiment religieux l'a emporté sur le respect dû aux principes démocratiques. L’Église catholique a dans certains États fait reconnaître et consacrer par la loi, l'organisation hiérarchique et autoritaire qui lui est chère. Ainsi dans l'État de New-York, à la suite de la campagne menée par l'évêque Hugues, une loi du 25 mars 1863 a admis que la paroisse catholique, qui constitue une "corporation", c'est-à-dire une personne morale, serait administrée par l'évêque du diocèse, un vicaire général, le curé de la paroisse et deux laïques nommés par les trois premiers membres.

Le vicaire général et le curé étant eux-mêmes nommés par l'évêque, celui-ci a en réalité les pouvoirs les plus complets quant à l'administration de la paroisse. La personnalité civile de l'évêché ou du diocèse, que l'Église a fait tant d'efforts pour faire reconnaître en France depuis le Concordat, a été obtenue dans plusieurs États ; tantôt des lois spéciales ont reconnu la personnalité juridique de certains archevêchés ou évêchés nominativement désignés (Michigan : loi du 27 mars 1867. - Massachusetts : loi du 11 juin 1897) ; tantôt les lois déclarent en termes généraux que l'évêque ou tout autre chef spirituel d'une communion religieuse peut constituer ce que le droit anglosaxon appelle corporation sole, c'est-à-dire une personnalité juridique apte à posséder et à acquérir à titre gratuit des biens affectés à un but religieux et devant être transmis aux titulaires successifs de la fonction ecclésiastique (Californie, Oregon).

Néanmoins toute ingérence des fidèles dans l'administration temporelle des Églises n’a pas été entièrement écartée : généralement le sermon d'un dimanche par an est remplacé par un compte rendu de gestion aux fidèles. 
Un semblable régime légal a, bien entendu, eu pour conséquence un accroissement rapide de la puissance morale et matérielle des Églises et notamment de l'Église catholique. Jusqu'à présent aucun parti politique ne paraît songer à y mettre obstacle. Le nombre des non-croyants est néanmoins considérable aux États-Unis. Si les interventions des Églises dans les affaires politiques devenaient plus fréquentes et moins discrète, si les efforts d'ailleurs couronnés de succès qu'a fait l'Église catholique en vue de constituer un enseignement primaire strictement confessionnel, apparaissait un jour comme dangereux à certains égards, notamment au point de vue du retard qui en résulte pour l'assimilation des émigrés catholiques et leur fusion avec les autres races (Voir un article de M. P.-G. La Chesnais dans l'Européen du 14 janvier 1905), peut-être les Américains connaîtraient-ils à leur tour cette question cléricale qu'ils considèrent avec un dédain un peu superficiel et avec la confiance d'un peuple jeune, n'ayant point encore fait certaines expériences, comme occupant une trop grande place dans les préoccupations politiques du vieux monde. Peut-être viendrat-il un jour où il y aura parmi eux non seulement des non-croyants, des “agnostiques” mais des anticléricaux.

(Chaque matin aux USA les écoliers doivent réciter une déclaration d'allégeance qui définit le pays comme "une nation sous la loi de Dieu'”.

Un athée, Michael Newdow, a intenté, en 2002, une action en justice qui a soulevé une tempête de protestations et généré un gigantesque débat dans le pays tout entier.

Mexique.- La séparation des Églises et de l’État apparaît dans la législation du Mexique sous un tout autre aspect qu'aux États-Unis. On ne peut parler ici d'une étroite union morale entre l'État et l'Église tempérant ou altérant les effets de la séparation juridique.

Rappelons en quelques mots les origines historiques de la séparation au Mexique que M. P.-G. La Chesnais a exposées très complètement dans son intéressante brochure intitulée Trois exemples de séparation, publiée par les soins des Pages libres. 
Le clergé catholique, peu nombreux, mais tout-puissant par ses immenses richesses, possédait au milieu du dix-neuvième siècle un tiers des biens fonciers de la nation. Après la guerre d'indépendance, qui libéra le Mexique de la suzeraineté de l’Espagne, il ne cessa point d'intervenir dans les luttes politiques.

Le parti fédéraliste devint un parti nettement anticlérical. En 1856, ce parti, parvenu au pouvoir, supprima la mainmorte ecclésiastique en autorisant les tenanciers à devenir propriétaires des terres louées par les titulaires de bénéfices ecclésiastiques; puis il fit disparaître les congrégations d'hommes, nationalisa les édifices du culte, laïcisa l'état civil, supprima enfin la légation mexicaine près le Vatican. Pour conserver ses richesses, le clergé déchaîna la guerre civile, puis la guerre étrangère. On sait comment se termina tragiquement le règne éphémère de l'archiduc Maximilien à qui Napoléon III avait cru devoir offrir l'appui d'une armée française. Le parti fédéraliste fédéraliste définitivement vainqueur avec Juarez, édicta une loi de laïcisation qui établissait notamment une séparation complète entre l'État et l'Église. Il convient de citer ou d'analyser les dispositions de cette loi, promulguée le 14 décembre 1874. (Voir le texte complet dans l'Annuaire de législation étrangère, publiée par la société de législation comparée, année 1879.)

“L’État et l'Église, dit l'article 1er, sont indépendants l'un de l'autre. Il ne pourra être fait de loi établissant ou prohibant aucune religion ; mais l'État exerce son autorité sur chaque religion en ce qui concerne l'ordre public et les institutions."

L'article 2 est ainsi conçu: “L’État garantit l'exercice des cultes dans la République. Il ne punira que les actes et pratiques qui, bien qu'autorisés par quelque culte, constituent une contravention ou un délit conformément aux lois pénales.”

L'article 3 déclare que les autorités publiques ne prendront plus part officiellement aux cérémonies d'un culte quelconque. Ne sont plus reconnus comme jours fériés que ceux ayant pour objet exclusif la célébration d'événements purement civils. Toutefois, le dimanche demeure désigné comme jour de repos pour les bureaux et administrations publiques. 
L'article 5 n'autorise la célébration publique d'un acte religieux que dans l'intérieur d'un temple, et ce sous peine d'une amende de 10 à 200 piastres et d'une incarcération de deux à quinze jours ; un emprisonnement de deux à six mois peut être prononcé si l'acte a un caractère solennel et s'il y est procédé en violation d'une injonction de l'autorité en ordonnant l'interruption immédiate. Hors des temples, le port de vêtements et d'insignes est interdit tant aux ministres des cultes qu'aux fidèles, sous peine de 10 à 200 piastres d'amende.

L'usage des cloches n'est autorisé qu'en tant qu'il est strictement nécessaire pour appeler les fidèles à l'office ; il peut faire l'objet de règlement de police (art. 6)

Les Temples doivent faire l'objet d'une déclaration ou enregistrement. Ils jouissent alors, tant qu'ils demeurent affectés à l'exercice du culte, de la protection accordée aux lieux de culte par l'article 969 du code pénal du district fédéral. Ce code contient huit articles relatifs à aux atteintes à la liberté des cultes (art. 968 à 975) ; l'article 969 punit le trouble apporté à l'exercice du culte dans un lieu affecté à cet exercice, et l'article 971 réprime l'outrage envers un ministre du culte dans l'exercice de ses fonctions ; des dispositions analogues se rencontrent dans les codes pénaux des divers États mexicains.

Les ministres des cultes ne jouissent, depuis la séparation, d'aucun privilège qui les distingue des autres citoyens et ne sont soumis à aucune prohibition autre que celles résultant des lois et de la Constitution (loi de 1874, art. 10)

"Les discours prononcés par les ministres des cultes, qui contiendront le conseil de désobéir aux lois ou la provocation à quelque crime ou délit rendent illicite la réunion où ils se tiennent et cette réunion, cessant de jouir du privilège contenu en l'article 9 de la Constitution, peut être dissoute par l'autorité. L'auteur du discours restera dans ce cas soumis à la disposition du titre VI, chapitre VIII, livre 3 du code pénal du district fédéral applicable, dans ce cas, à toute la République. Les délits commis à l'instigation ou à la suggestion du ministre du culte dans les cas ci-dessus constituent ce dernier auteur principal du fait” (art. 11). 
"Toutes les réunions qui auront lieu dans les temples seront publiques et soumises à la surveillance de la police et l'autorité pourra y exercer les pouvoirs qui lui appartiennent si les circonstances l'exigent” (art. 12).

Les organisations religieuses s'organisent hiérarchiquement comme il leur convient et leur supérieur les représente devant l'autorité (art. 13). Elles ne peuvent acquérir et posséder des biens-fonds et des capitaux à eux attachés, exception faite pour les temples consacrés d'une façon directe au service public du culte et pour les annexes et dépendances des temples qui sont strictement nécessaires au service du culte (art. 14). Elles peuvent recevoir des aumônes et des donations mobilières, mais non des legs. Les quêtes ne sont permises que dans l'intérieur des temples. Toute infraction à cette prescription est punissable d'une amende pouvant s'élever jusqu'à 1000 piastres (art. 15).

Les temples, nationalisés par la loi du 12 juillet 1859, demeurent propriété de l'État ; ils sont laissés à l'usage exclusif des institutions religieuses qui doivent veiller à leur conservation et à leur amélioration (art. 16). Les temples appartenant à l'État sont exempts de contributions.

Telles sont les dispositions régissant au Mexique l'exercice des cultes.

La même loi du 14 décembre 1874 a supprimé l'enseignement religieux et les exercices religieux dans les écoles et tous les établissements publics (art. 4). Elle refuse aux ministres des cultes la capacité d'être institués héritiers ou légataires par ceux à qui ils ont prêté leurs secours spirituels (art. 8 et 9). Elle interdit enfin les ordres monastiques (art. 19 et 20), supprime le serment religieux (art. 21), refond les lois antérieures sur la laïcisation de l'état civil et le mariage civil (art. 22, 23 et 24), sur la laïcisation des cimetières, etc., prohibe tout pacte ou convention ayant pour objet la perte ou le sacrifice irrévocable de la liberté de l’individu.

Le Mexique possède ainsi la législation laïque la plus complète et la plus harmonique qui ait jamais été mise en vigueur jusqu'à ce jour. Il 
est délivré depuis tente ans de la question cléricale et a pu se vouer entièrement à son développement économique : il connaît réellement la paix religieuse. L’Église catholique ne parait pas avoir souffert, d'ailleurs, du régime légal assez strict mais non oppressif sous lequel elle vit. "Le clergé n'est pas à plaindre. Les curés des paroisses rurales ont une situation plutôt meilleure que sous l'ancien régime. Les dons, les quêtes dans les églises, le casuel suffisent à soutenir les frais du culte et entretenir les ministres et les séminaires... Les églises fort délabrées et mal desservies en 1857, ont recouvré leur splendeur.”(P.-G. La Chesnais, op. cit. p. 89) Le gouvernement du président Porfirio Diaz n'a cessé d'appliquer, sans hostilité à l'égard de l'Église mais avec fermeté, la législation de 1874 ; et, s’il faut en croire une correspondance récemment adressée de Rome au Journal des Débats, il a toujours opposé une fin de non-recevoir aux démarches officieuses faites assez fréquemment par le saint-Siège en vue de la conclusion d'un nouveau concordat.

Cuba.- La République de Cuba, dont la population est d'environ 1572000 habitants est presque entièrement catholique, offre un exemple unique assurément. La séparation complète de l'État et de l'Église s'y est faite "sans phases", pourrait-on dire, sans promulgation d'aucune loi ni d'aucun décret, sans agitation anticléricale, sans protestation de la part de l’Église.

Les États-Unis, en intervenant militairement dans l'île en 1899, n’ont pas seulement donné aux cubains la liberté et l'indépendance ; ils ont substitué, sans mot dire, au régime espagnol de la religion d'État le régime américain de la séparation. Sous la domination espagnole les frais du culte catholique (traitements, pensions, entretien des édifices) étaient supportés par le budget ; les autres cultes n'étaient que tolérés et leur exercice n'étaient permis que dans des locaux privés. Dès le début de l'intervention américaine l'Église catholique cessa d'être subventionnée par l'État ; l'exercice de tous les cultes devint libre. Ce changement radical s'opéra sans bruit, sans difficulté d'aucune sorte. Et depuis l'établissement définitif de la république cubaine (20 mai 1902) aucune loi n’est intervenue à l'effet de régler cette situation nouvelle. Les seuls textes qui aient trait à la question sont un règlement relatif aux cimetières, qui fut édicté le 12 avril 1899 par l'autorité militaire américaine, un acte notarié intervenu entre le 
gouvernement américain et les représentants de l’Église catholique pour reconnaître à celle-ci la propriété de certains immeubles qu'avait confisqués le gouvernement espagnol, et enfin l'article 26 de la Constitution de la nouvelle république. Cet article déclare que l'exercice de tous les cultes est libre, que l'Église est séparée de l'État et que l'État ne peut en aucun cas subventionner un culte quelconque.

Le règlement du 12 avril 1899 a confié aux municipalités l'administration des cimetières construits aux frais des communes, et à l'église celle des cimetières construits à ses frais. L'article 5 spécifie en termes généraux que tous les édifices du culte ou autres bâtiments servant à un but religieux ; dont les ministres du culte ou les représentants d'une Église sont en possession, seront considérés comme propriétés de l'Église tant qu'il n’en aura pas été décidé autrement par l'autorité compétente ; et ce texte provisoire parait avoir suffi à trancher jusqu'à présent toute difficulté.

Les processions et manifestations extérieures du culte ne sont aucunement réglementées. On admet généralement qu’il appartient aux autorités municipales de les autoriser ou de les interdire.

Brésil.- Une récente étude de M. Louis Gullaine, parue dans la $\boldsymbol{R} \boldsymbol{e}$ vue politique et parlementaire du 10 janvier 1905, et à laquelle nous empruntons une notable partie des renseignements qui vont suivre, expose dans quelles conditions la séparation des Églises et de l'État a été établie et réalisée au Brésil.

Le Brésil est, comme le Mexique, presque exclusivement peuplé de catholiques (15 millions et demi sur une population de 16 millions). Avant la révolution de de 1899, la monarchie brésilienne reconnaissait la religion catholique romaine comme religion d'État. Jusqu'en 1881, les non-catholiques étaient exclus de tout mandat législatif. Depuis la révolution, le Brésil est une république fédérative et décentralisée où les principes de la laïcité de l’État et de la liberté des cultes ont été reconnus.

Les textes qui organisèrent le nouveau régime sont le décret du gouvernement provisoire du 7 janvier 1890, la Constitution du 24 février 1891 et la loi sur les associations du 10 septembre 1893. 
L'article 2, paragraphe 2, de la Constitution interdit aux États de l'union d'établir, de protéger ou d'entraver les cultes religieux.

L'article 72, paragraphe 7, interdit toute subvention officielle en faveur d'une Église, tous rapports officiels avec une Église.

L'article 72, paragraphe 3 consacre, comme l'avait fait l'article 2 du décret du 7 janvier 1890 le principe du libre exercice - privé ou public - de tout culte.

L'article 72, paragraphe 28, porte que nul citoyen brésilien ne pourra, en raison de ses croyances ou de ses fonctions religieuses, être privé de ses droits politiques ni se soustraire à l'observation de ses devoirs de citoyen.

Le budget des cultes est, on le voit, entièrement supprimé. Il s'élevait, avant 1889, à environ 2500000 fr. et comprenait, outre le traitement des ministres du culte, les allocations qui étaient accordées aux bienheureux saint Sébastien et saint Antoine à raison de leurs titres de majors de l'armée brésilienne. C'est le prieur d'un couvent de Rio-Janeiro qui touchait ces traitements au nom de leurs célestes titulaires.

Au début, le nouveau régime fut assez mal accueilli par le haut clergé dont certains membres prirent part à des conspirations antirépublicaines. Mais peu à peu l'Église s'est ralliée à la nouvelle législation qui, d'ailleurs, depuis la promulgation de la Constitution, n’a été ni complétée par des textes ni appliquée par les pouvoirs publics dans un sens anticlérical. L’Église a perdu les subventions budgétaires, mais elle est délivrée de la tutelle parfois très dure que le pouvoir civil exerçait, avant la proclamation de la république, sur l'épiscopat brésilien. Presque aucune précaution n'est prise pour empêcher l'accroissement de ses biens. L'acquisition de toute de toute espèce de biens est permise aux associations religieuses qui ont acquis la personnalité juridique par un enregistrement au bureau des hypothèques. C'est seulement en cas d'extinction d'une association, et si aucune association analogue n'est apte à recueillir son patrimoine, que celle-ci passe au domaine de l'État. Chaque Église a d'ailleurs conservé la 
propriété des édifices consacrés au culte et des autres immeubles dont elle était en possession sous l'ancien régime (décret du 7 janvier 1890, art. 5).

Aucune disposition légale ne limite le libre exercice des cultes. Les processions et autres manifestations extérieures sont autorisées, et l'article 72, paragraphe 7, de la Constitution est si peu strictement appliqué que les autorités civiles figurent dans les processions et que l'archevêque de Rio-Janeiro est assis aux côtés du président de la république dans les cérémonies civiles. Les prêtres et séminaristes ne font pas de service militaire ; le mariage civil ne doit pas obligatoirement précéder le mariage religieux. Bref, on a pu dire que "la séparation faite en théorie est loin d'être achevée dans la pratique”. Et l'on ne s'en étonne point si l'on songe que la séparation des Églises et de l'État n'a été décrété qu'il y a quelques années ; qu'elle n’a pu changer subitement les croyances et les mœurs d'un peuple profondément catholique, et qu'enfin elle n'a pas été l'œuvre d'anticléricaux ou tout au moins libres penseurs peu favorables aux Églises, mais d'un groupe de positivistes ennemis de tout religion officielle et partisans déclarés de la liberté absolue et illimitée des diverses religions. (Voir à ce sujet, dans le Courrier européen du 6 janvier 1905, une lettre de M. Miguel Lomos, chef de “L’Église positiviste” du Brésil.

Équateur.- La république de l’Équateur était demeurée jusqu’à la fin du dix-neuvième siècle une véritable théocratie. Les moines y étaient tout puissants :ils avaient accumulé une énorme fortune ; ils étaient les maîtres occultes des administrations et du gouvernement. L’Église catholique était la religion de l'État ; un concordat avait été conclu avec le Vatican en 1862. Par l'intermédiaire des moines, le saint-Siège dominait en réalité la république ; le clergé séculier dépendait étroitement des ordres monastiques, et des prélats allemands, italiens, espagnols étaient envoyés dans le pays pour y occuper les hauts emplois ecclésiastiques. Une révolution, survenue en 1895, amena le parti clérical au pouvoir. Et, en moins de dix ans, par un changement d'une singulière soudaineté, cette république théocratique est devenue un État laïque.

Le mariage civil a été rendu obligatoire ; le divorce (non encore admis dans les autres républiques hispano-américaines qui ont institué 
le mariage civil) a été autorisé ; la légation près le Vatican a été supprimée. Enfin, une loi sur les cultes est intervenue le 12 octobre 1904. L'article final de cette loi abroge le concordat. L'article 1er proclame la liberté et l'égalité des cultes. La loi exige que tous les évêques, curés, vicaires et autres ministres des cultes soient de nationalité équatorienne. Elle interdit la fondation de nouveaux couvents, l'immigration des moines étrangers, elle supprime par extinction les couvents cloîtrés en leur interdisant de recevoir des novices. Les biens des ordres monastiques sont placés sous le contrôle du gouvernement. Ils ne peuvent plus être aliénés sans son autorisation ; ils doivent tous être loués aux enchères publiques ou administrés par des commissaires gouvernementaux.

Les revenus de ces biens sont affectés, en première ligne, aux besoin des membres des ordres religieux ; en seconde ligne, à l'exercice et à l'entretien du culte et du clergé régulier ; s’il y a un excédent, il est attribué dans chaque province à des œuvres de bienfaisance ou d'utilité publique. Si,au contraire, les revenus de ces biens sont insuffisants pour pour pourvoir tout à la fois aux besoin du clergé régulier et à l'entretien du culte, l'État doit fournir une subvention complémentaire pour cet entretien ; mais c'est là un cas exceptionnel, dont on ne prévoit guère la réalisation, étant donné l'importance du patrimoine des ordres religieux ; aussi la loi considère-t-elle cette subvention éventuelle de l'État comme rentrant au nombre des dépenses extraordinaires. Et il n'y a pas normalement de budget des cultes.

Bref, on peut dire que la république de l'Équateur, qu'on appelait encore il y a dix ans “la république de Sacré-Cœur”, a décrété tout à la fois la sécularisation des biens du clergé, la limitation du monarchisme, la neutralité et la laïcité de l’État, la suppression du budget des cultes et l'abrogation du concordat.

On voit que sous des formes diverses, et avec des caractères différents, le régime de la séparation est aujourd'hui en vigueur dans la plus grande partie du nouveau monde. Certaines républiques sudaméricaines, qui ne l'ont pas encore adopté, l'adopteront peut-être dans un avenir peu éloigné (on signalait récemment au Chili une vive agitation en faveur de la suppression du budget des cultes). D'autre part, plusieurs colonies anglaises n’ont jamais connu d'autre régime, 
par exemple, la Nouvelle-Zélande ; et dans la plupart des colonies où des liens unissait l'État à l’Église ces liens ont été rompus : au Canada (on l'a déjà signalé) en 1854, dans les colonies australiennes en 1863, 1866 et 1870, à la Jamaïque en 1870, dans les autres Antilles en 1868, 1871 et 1873, au Cap en 1875, à Ceylan en 1881 (Voir The Case for disetablishment p.257-262 - publication de la Liberation Society).

Ce qui a été ébauché en Europe et réalisé en Amérique et dans tout l'empire colonial anglais n'est pas inconnu en Extrême-Orient. Il est piquant de constater qu'une tentative d'instaurer une religion d'État a été faite au Japon, dans les trente dernières années et qu'elle a échoué. Le ministère des cultes a été supprimé et deux bureaux du ministère de l'intérieur ont été chargé des affaires religieuses. L'égalité et la liberté des divers cultes (bouddhiste, shintoïste et chrétien) ont été proclamées. La séparation complète des Églises et de l'État compte de nombreux partisans et une fraction du Parlement japonais s'est prononcé en faveur de cette réforme il y a cinq ans (Alexandra Myrial. La Question religieuse au Japon - Courrier européen du 10 février 1905).

On disait récemment que la politique historique de la France tendait à la distinction complète du domaine civil et du domaine religieux. En réalité, c’est là que tend la politique de toutes les nations civilisées. 


\section{V \\ Analyse des propositions et projets de loi.}

\begin{tabular}{|l|l}
\hline Proposition Dejante & Proposition Réveillaud \\
Proposition Ernest Roche & Proposition Grosjean et Berthoulat \\
Proposition de Pressensé & Proposition Sénac \\
Proposition Hubbard & Premier texte de la commission \\
Proposition Flourens &
\end{tabular}

\section{Début}

$\underline{\text { Retour à la table des matières }}$

Telle est, dans les principales nations du monde, l'état de la législation appliquée aux diverses religions ; telle est, en France, la situations des trois cultes reconnus au moment où vous êtes appelés à résoudre l'un des plus gros problèmes politiques qui aient jamais sollicité l'attention du législateur. Ce problème, votre commission a pu l'étudier et s'efforcer à le résoudre en toute impartialité comme en toute sérénité d'esprit.

Le moment où elle a été constituée, les conditions dans lesquelles elle a entrepris et poursuivi son œuvre la mettaient à l'abris des coups de passion et lui permettaient d'envisager sa tâche avec le calme et le sang froid désirables. Le 18 juin 1903, date à laquelle elle a été nommée, les événements n'avaient pas pris encore le caractère aigu et pressant que les conflits avec le saint-Siège lui ont donné depuis. La question de la séparation n'était pas posée dans le domaine des faits : 
elle restait sous la seule influence des considérations théoriques et des raisons de principe. C'est à dire que l'on pouvait croire encore lointaine la solution qui s’impose aujourd'hui.

La majorité de la commission, favorable en principe à la réforme, ne travaillait donc pas pour un résultat immédiat ; la fièvre du succès prochain ne risquait pas de troubler ses délibérations. Si elle ne se désintéressa à aucun moment de la tâche que vous lui aviez confiée c'est que, d'abord, elle comprit toute la valeur de la propagande que pourraient avoir dans le pays et au sein du Parlement même, ses efforts ; c'est qu'ensuite elle ne tarda pas à se laisser prendre toute entière par le vif intérêt des travaux. Les membres de la minorité eux-même n'échappèrent pas à cette attraction et c'est leur honneur, pendant les trente neuf séances qui ont été consacrées par la commission à l'accomplissement de son mandat, collaboré loyalement, avec un zèle persistant et une entière sincérité, avec leurs collègues de la majorité dans la recherche des solutions qui vous sont aujourd'hui proposées.

Nous pouvons dire que le projet finalement adopté est l'œuvre de la commission toute entière. Beaucoup de ses dispositions portent l'empreinte de la minorité, dont le succès a souvent couronné les efforts, attestant que l'esprit systématique et le parti pris étaient exclus des délibérations communes. S'il en avait été autrement, les travaux de votre commission eussent été frappés de stérilité. de par sa composition même, elle semblait, en effet, dès l'origine, vouée à une incurable impuissance, et l'on ne peut pas reprocher à son honorable président de s'être montré exagérément pessimiste quand, après avoir accepté une fonction qui ne devait pas être pour lui une sinécure, il prononça ces paroles peu rassurantes :

"Aucun de vous ne se dissimule les conditions très spéciales, pour ne rien dire de pis, dans lesquelles notre commission aborde sa tâche.

"Elle est venue au jour sous des auspices peu favorables, les augures sont unanimes à lui prédire la vie difficile. Ils ne s'entendent d'ailleurs que sur un point : que peu faire d'utile une commission partagée par moitiés égales à une unité près ? La discussion y sera, dirent les uns, si passionnée, la lutte à chaque séance si acharnée, que le temps passera en longue querelle sans issue, et que la commission se 
perdra dans le bruit. Au contraire, disent les autres, le sentiment même de l'inutilité des débats qui ne peuvent pas aboutir, paralysera vite, des deux parts, l'ardeur des combattants : la commission se perdra dans le silence."

Si cette sombre prédiction ne s'est pas réalisée, si votre commission a pu conduire à bonne fin la tâche lourde et difficile que vous lui aviez confiée, c'est, je le répète, grâce à la bonne volonté réciproque dont n’ont cessé de faire montre les membres de la minorité et de la majorité.

Dans sa première réunion constitutive, la commission avait élu pour président $M$. Ferdinand Buisson ; pour vice-présidents MM. Bepmale et Baudon ; pour secrétaires MM. Gabriel Deville et Sarraut ; pour rapporteur provisoire le signataire de ce rapport. Aussitôt après, elle adoptait à la majorité de 17 voix contre 15, un ordre du jour proposé par MM. Allard et Vaillant, et ainsi conçu :

“La commission décide qu’il y a lieu de séparer les Églises et l’État, et de commencer l'examen des systèmes divers proposés pour remplacer le régime du Concordat”.

C'était, dès le premier jour, les travaux de la commission nettement orientés dans le sens de la séparation. Les séances qui suivirent furent consacrées à l'examen des diverses propositions de loi qui avaient été déposées au cours de la législature sur le bureau de la Chambre et renvoyées à la commission. Ces propositions, il convient de les rappeler ici, dans leur ordre chronologique, et de leur consacrer une rapide analyse.

Elles ont ouvert ou jalonné la voie que la commission a suivie, et par leur influence directe ou indirecte, certainement concouru à ses conclusions finales. 


\section{Proposition Dejante.-}

Retour à la table des matières

La première en date est celle de $\mathrm{M}$. Dejante, déposée à la à la séance du 27 juin 1902. Elle reproduit la proposition de notre collègue Zévaès sous la précédente législature et se caractérise par une économie des plus simples. Elle a pour objet la dénonciation du Concordat, la suppression immédiate de toutes les congrégations religieuses, la reprise par l'État des biens appartenant aux congrégations et aux établissements ecclésiastiques. Les capitaux et les ressources rendus disponibles par la suppression du budget des cultes seraient affectés à la constitution d'une caisse des retraites ouvrières.

\section{Proposition Ernest Roche.-}

Très succinctement aussi est libellée la proposition de M. Ernest Roche, du 20 octobre 1902. Elle prononce la dénonciation du Concordat, supprime le budget des cultes et l'ambassade auprès le Vatican. Les associations formées pour l'exercice des cultes sont soumises au droit commun. Les immeubles dont les églises ont actuellement la disposition feraient l'objet de baux librement conclus avec l'État ou les communes. Les ressources devenues disponibles par ce nouveau régime seraient remises comme premier apport à une caisse des retraites ouvrières constituée sans délai. Une loi spéciale déterminerait les mesures transitoires rendues nécessaires par l'application de ces dispositions.

Ces deux propositions, assez laconiques, avaient surtout dans la pensée de leurs auteurs la caractère de projets de résolution. Elles devaient permettre à la Chambre de se prononcer sur le principe même de la séparation des Églises et de l’État. C’est dans sa séance du 20 octobre que la chambre, après avoir repoussé l'urgence sur les propositions de MM. Dejante et Roche, adoptait la motion de M. Réveillaud qui instituait une commission de trente-trois membres chargée d'examiner tous les projets relatifs à un nouveau régime des cultes. 


\section{Proposition de Pressensé.-}

Retour à la table des matières

Le premier qui fut déposé depuis fut celui de M. Francis de Pressensé, le 7 avril 1903.

Il serait difficile de rendre un hommage exagéré à un travail aussi savant et aussi consciencieusement réfléchi.

M. de Pressensé s'est donné pour tâche, et a eu le très grand mérite de poser nettement toutes les principales difficultés soulevées en aussi grave matière, et d'envisager résolument le problème dans toute son étendue.

Les solutions qui ont été adoptées dans la suite peuvent être différentes, souvent même divergentes de celles qu'il indiquait lui-même ; il n'en demeure pas moins que sa forte étude a contribué beaucoup à faciliter les travaux de la commission.

La caractéristique du projet est de réaliser radicalement la séparation des Églises et de l'État en tranchant tous les liens qui les rattachent. Il garanti expressément la liberté de conscience et de croyance. Dénonciation du Concordat, cessation de l'usage gratuit des immeubles affectés aux services religieux et au logement des ministres des cultes, suppression du budget des cultes et de toutes subventions par les départements ou les communes, telles sont les mesures générales par lesquelles serait assurée la laïcisation complète de l'État. Des dispositions spéciales et une période de transition déterminent les pensions allouées aux ministres des cultes en exercice, sous certaines conditions très strictes d'âge et de fonction. Les immeubles, provenant des libéralités exclusives des fidèles, seraient attribués à des "société civiles” formées pour l'exercice du culte. ; tous les autres feraient retour à l'État ou aux communes, selon qu'ils sont actuellement diocésains ou paroissiaux. Les Églises et presbytères pourraient être pris en location par les sociétés cultuelles.. 
Selon une disposition intéressante, dont certains n'ont peut-être pas bien compris le but éloigné de toute arrière pensée de vexation, l'État ou les communes pourraient insérer dans les baux des stipulations leur réservant le droit, à certains jours, en dehors des heures de culte et de réunion religieuse, d'user des immeubles loués, pour des cérémonies civiques, nationales ou locales.

Les sociétés cultuelles se formeraient selon le droit commun. Elles ne pourraient cependant posséder plus de cathédrales, évêchés, presbytères, que les établissements ecclésiastiques n'en ont aujourd'hui à leur disposition, proportionnellement au nombre de fidèles, ni plus de capitaux que ceux produisant un revenu égal aux sommes nécessaires pour la location des édifices religieux et le traitement des ministres du culte.

Les sociétés cultuelles doivent rendre public le tarif des droits perçus ou des prix fixés pour les cérémonies du culte et pour la location des chaises. Ce tarif ne pourra, en aucun cas, s'élever au-dessus du tarif en cours à l'époque de la promulgation de la loi.

La police des cultes est déterminée, dans ce projet, avec un soin précis, pour empêcher toute action ou manifestation étrangère au but religieux des sociétés cultuelles.

Par des dispositions minutieuses relatives aux privilèges, dispenses, incompatibilités dont les ministres du culte sont actuellement l'objet, aux aumôneries, au serment judiciaires, aux pompes funèbres, toutes les particularités inscrites encore dans la législation pour des motifs religieux, toutes les manifestations ou signes extérieurs du culte sont supprimés.

Une analyse exacte et complète de ce texte étendu exigerait des développements que nous ne pouvons malheureusement lui consacrer. Son rédacteur a cherché, tout en sauvegardant fermement les intérêts de la société laïque, à effectuer une séparation nette et décisive entre l’État et les Églises. 


\section{Proposition Hubbard.-}

$\underline{\text { Retour à la table des matières }}$

L'originale proposition de M. Hubbard présentée le 26 mai 1903 ne tendait pas uniquement à ce but. Elle assimile les associations religieuses aux associations ordinaire et s'efforce de les rapprocher en fait. Elle supprime tous les textes relatifs au régime des cultes et le budget des cultes. Les prêtres, pasteurs et rabbins qui justifieraient de ressources personnelles insuffisantes recevraient pendant deux ans une indemnité. Celle-ci serait payée au titre à titre viager aux vieillards et infirmes. Les biens des menses seraient repris par l'État, ceux des fabriques par les communes, sauf revendications des donateurs pour les dons et legs recueillis depuis moins de trente ans.

Mais l'idée toute nouvelle de la proposition est la création qu'elle prescrit, dans chaque commune et chaque arrondissement urbain d'un conseil communal d'éducation sociale. Ce conseil, composé en partie de femmes (qui n'auront le droit de vote qu'en 1945), administrerait les biens affectés gratuitement aux cultes et à leurs ministres et en réglerait l'usage. Il aurait de même des droits et obligation de gérance pour tous les immeubles servant aux cérémonies et au fonctionnement de toutes les associations d'enseignement ou de prédication morale, philosophique ou religieuse. Toute les manifestations extérieures du culte, toutes réunions seraient régies par le droit commun.

Nous ne pouvons entrer dans le détail de cette organisation. M. Hubbard a voulu rapprocher dans la pratique toutes les formes de la vie religieuse et de la vie intellectuelle ou morale et leur donner comme des guides communs. Son projet est, dans le fond comme dans l'expression, particulièrement philosophique. 


\section{Proposition Flourens.-}

Retour à la table des matières

La proposition de M. Flourens, du 7 juin 1903, réalise l'indépendance absolue et légalise la création ou la résurrection de toutes les associations religieuses quelconques. L’État, une période de transition écoulée, ne subventionnerait aucune de ces associations. Encore devrait-il, sur simple demande de celles-ci, mettre à leur disposition les édifices actuellement affectés à l'usage religieux, sous la seule condition de ne pas les détourner de cette affectation. La partie caractéristique de cette proposition est sans nulle doute celle qui est relative aux œuvres et fondations charitables des associations cultuelles et à la propagation et l'enseignement des doctrines.

Toutes les formes de pareilles manifestations de la vie ecclésiastique sont réalisables; les associations sont libres sans restriction et sans qu'il y ait lieu de chercher si leurs adhérents ou ceux qui sont à leur service ont appartenu à des congrégations ou communautés autorisées ou non autorisées.

Il apparaît immédiatement que l'effet certain d'un tel projet serait la libération sans garantie de l'Église, sa mise à l'abri de toute règle légale d'intérêt public, et la reconstitution définitive et inébranlable de toutes les congrégations.

\section{Proposition Réveillaud.-}

La proposition que de M. Réveillaud présentée le 25 juin 1903, est marquée par le caractère vraiment libéral, mais tient compte des nécessités et des droits de la société civile.

Suivant un plan très net, elle garantie la liberté religieuse. et n'y marque d'autre limite que celles demandées par l'intérêt public.

Les associations sont régies par la loi de 1901. 
Les édifices religieux ou affectés au logement des ministres des cultes, qui appartiennent à l'État ou aux communes, sont laissés à la disposition des associations cultuelles, sous la condition de payer une redevance annuelles de $1 \mathrm{fr}$. par an destinée à assurer la pérennité du droit de propriété des concédants. Les meubles et immeubles appartenant aux menses, fabriques et consistoires seraient dévolus, sans frais, aux associations nouvelles. Les ministres des cultes actuellement salariés par l'État toucheraient la totalité de leurs traitement leur vie durant, s'ils ont plus de cinquante ans d'âge ; la moitié s'ils ont de trente à cinquante ans et le quart s'ils ont moins de trente ans. La police des cultes est strictement assurée et fixe, pour chaque infraction, des peines mesurées avec modération.

L'exercice du culte est réglementé suivant des dispositions puisées dans une proposition de M. Edmond de Préssensé, votée en première lecture par l'Assemblée nationale, et qui a fait au Sénat l'objet d'un rapport favorable d'Eugène Pelletan.

La proposition de M. Réveillaud contient un article dont le principe a été repris et adopté par la commission.

Il fixe le maximum des valeurs mobilières placées en titres nominatifs au capital produisant un revenu ne pouvant dépasser la moyenne des sommes dépensées pendant les cinq derniers exercices.

\section{Proposition Grosjean et Berthoulat.-}

$\underline{\text { Retour à la table des matières }}$

Ce qui caractérise la proposition de MM. Grosjean et Berthoulat du 29 juin 1903 est le soucis de laisser aux Églises le maximum de libertés et d'avantages compatibles avec les garanties indispensables à l'ordre public.

le droit commun d'association leur est applicable. 
Les édifices appartenant à l'État ou aux communes sont mis gratuitement à la disposition des communautés religieuses. Il en résulte du silence de la proposition que les grosses réparations de ces édifices gratuitement concédés resteraient à la charge de l’État ou des communes propriétaires.

L’ouverture des édifices religieux et la tenue des réunions religieuses ne sont soumises qu'à une seule et simple déclaration faite à la municipalité.

Les ministres du culte ayant dix ans de fonction jouiraient à vie du traitement qu'ils reçoivent actuellement. Les dispositions relatives à la police des cultes reproduisent les règles unanimement admises avec des peines modérées pour les infractions prévues.

D’après cette proposition, un budget des cultes considérable resterait durant de longues années nécessaire pour le service des pensions du clergé.

En outre, les édifices religieux, loin de produire le moindre revenu, seraient pour leurs propriétaires nominaux, l’État ou les communes la cause de dépenses élevées.

\section{Proposition Sénac.-}

La proposition de M. Sénac, déposée le 31 janvier 1903, la dernière en date, s'inspire de toute autre préoccupation. En maintenant provisoirement l'état actuel des choses, elle vise à donner à toute heure au Gouvernement le droit de briser l'action individuelle ou collective des membres des associations cultuelles, qui pourraient être contraire aux intérêts de la République.

L’État, les départements et les communes auraient la propriété de tous les édifices religieux. Ceux-ci resteraient à la disposition des diverses cultes qui en jouissent actuellement, mais les propriétaires pourraient leur en retirer à volonté l’usage. 
Les ministres des cultes recevraient, à titre de subvention, leur traitement actuel, mais il devrait leur être annuellement accordé. Les ministres des cultes, non encore en fonctions, recevraient sous certaines conditions des secours ou indemnité. Ces traitements, subventions et secours pourraient à tout moment être supprimés et celui qui aurait été l'objet de pareille mesure ne pourrait plus exercer son ministère dans un édifice public affecté au culte. Cette proposition, qui a pour objet évident la défense laïque, établit plutôt un régime de police des cultes qu'elle ne réalise la séparation des Églises et de l’État.

Tels sont les divers projets émanant de l'initiative parlementaire, qui, présentés à la Chambre au cours de cette législature, ont été renvoyés à la commission. Celle-ci a entendu tous leurs auteurs, sauf $\mathrm{M}$. Sénac, dont la proposition fut déposée au moment même où la commission mettait la dernière main à ses travaux.

La première discussion ouverte sur ces propositions révéla qu'aucune d'elle ne répondait pleinement aux vœux de la commission. Celle-ci manifesta la volonté d'établir elle-même un texte complet qui serait, en son nom, proposé à la Chambre. Mais, dans une matière aussi délicate, où tant de questions graves et complexes se posaient, il était indispensable qu'un plan de discussion clair et méthodique fût arrêté d'abord, selon lequel la commission pourrait discuter et faire connaître ses vues sur chacune des difficultés essentielles du problème à résoudre.

Le rapporteur provisoire proposa aux délibérations de ses collègues le plan suivant qui fut adopté à l'unanimité :

$1^{\circ}$ Le projet devra-t-il se borner à établir un régime de séparation des Églises et de l'État à l'exclusion de toute disposition concernant les congrégations?

$2^{\circ}$ Le projet s’inspirera-t-il exclusivement du droit commun ou bien édictera-t-il, au moins à titre transitoire, des mesures de précaution dans l'intérêt à la foi de l’État et de l’Église ? 
$3^{\circ}$ Les associations constituées en vertu de la loi de 1901 pour assurer l'exercice des différents cultes auront-elles la faculté :

a) De se fédérer entre elles régionalement et nationalement ?

b) De recevoir des dons de l'État, des départements et des communes?

$4^{\circ}$ A quel régime seront soumis les édifices publics affectés au culte?

$5^{\circ}$ Le projet abrogera-t-il toutes les législations antérieures par une seule disposition générale ou devra-t-il, par des articles spéciaux et précis, régler chaque point particulier?

Après avoir discuté longuement et minutieusement sur chacune des questions posées, la commission se détermina dans le sens de l'affirmative sur la première. Le projet à rédiger ne devra contenir aucune disposition relative aux congrégations

Sur la deuxième, il fut décidé à l'unanimité que le régime de séparation devrait être établi selon "la liberté la plus large dans le droit commun ; qu'il convenait de n'en s'écarter que le moins possible et seulement dans l'intérêt de l'ordre public”.

Sur la troisième, la commission conclut au droit pour les associations cultuelles de s'organiser en fédérations régionales et nationales. Elle se prononça contre toute subvention de l'État au profit des cultes, mais elle ne put formuler une opinion sur le droit à accorder ou à refuser aux départements et aux communes de subventionner les églises. Treize de ses membres avaient voté pour l'affirmative et treize contre.

Il fut également impossible à la commission démettre un avis formel sur les deux dernières questions posées. Elle décida de s'en remettre à son rapporteur provisoire du soin de rédiger, en tenant compte des indications recueillies au cours des dernières discussions, un avant-projet complet qui servirait de base aux délibérations ultérieures. 
Ainsi fut-il fait. Et cet avant-projet, après des débats nombreux et approfondis au cours desquels plusieurs dispositions furent amendées sur les propositions de membres tant de la majorité que de la minorité, fut finalement adopté en première lecture par la commission. En voici le texte :

\title{
Premier texte de la commission
}

\author{
Titre 1er PRINCIPES
}

Article 1er

$\underline{\text { Retour à la table des matières }}$

La république assure la liberté de conscience.

Elle garantit le libre exercice des cultes sous les seules restrictions ci-après, dans l'intérêt de l'ordre public.

Art. 2

La République ne protège, ne salarie, ni ne subventionne, directement ou indirectement, sous quelque forme et pour quelque raison que ce soit, aucun culte.

Elle ne reconnaît aucun ministre du culte.

Elle ne fournit, à titre gratuit, aucun local pour l'exercice d'un culte ou le logement de ses ministres. 
Titre II

ABROGATION DES LOIS ET DÉCRETS SUR LES CULTES.DÉNONCIATION DU CONCORDAT.- LIQUIDATION

Art. 3

A dater de la promulgation de la présente loi, la loi du 18 germinal an X est abrogé ; la convention passée à Paris, le 26 messidor an IX, entre le gouvernement français et le pape Pie VII est dénoncée.

Sont également abrogés : le décret-loi du 26 mars 1852 et les arrêtés du 10 septembres 1852 et du 20 mai 1853 ; la loi du 1er août 1879, les décrets des 12-14 mars 1880, 12-14 avril 1880 et 25-29 mars 1882 ; les décrets du 17 mars 1808 relatifs à l'exécution du règlement du 19 décembre 1805 ; la loi du 8 février 1831 et l'ordonnance du 24 mai 1844.

Art. 4

L'ambassade auprès le Vatican et la direction des cultes sont supprimés.

Art. 5

A partir du 1er janvier qui suivra la promulgation de la présente loi seront et demeureront supprimés: toutes dépenses publiques pour l'exercice ou l'entretien d'un culte, tous traitements, indemnités, subventions ou allocations accordés aux ministres des cultes, sur les fonds de l’État, des départements ou des communes.

\section{Art. 5 bis}

Les sommes rendues disponibles par la suppression du budget des cultes seront employées à la détaxe de la contribution foncière des propriétés non bâties, à la culture desquelles participent effectivement les propriétaires eux-mêmes. 
Seront appelés à bénéficier de la remise les cotes uniques ou totalisées qui ne sont pas supérieures à 40 fr., à la condition que la part revenant à l'État sur la contribution personnelle mobilière, à laquelle sont assujettis les contribuables dans leurs diverses résidences ne dépasse pas $25 \mathrm{fr}$.

Art. 6

A partir de la même date, cessera de plein droit l'usage gratuit des édifices religieux : cathédrales, églises paroissiales, temples, synagogues, etc., ainsi que des bâtiments des séminaires et des locaux d'habitation : archevêchés, évêchés, presbytères, mis à la disposition des ministres des cultes par l'État, les départements ou les communes.

Art. 7

Les biens mobiliers et immobiliers appartenant aux menses épiscopales ou curiales, aux fabriques, consistoires ou conseils presbytéraux et autres établissements publics des différents cultes seront, dans un délai de six mois à partir de la promulgation de la présente loi, répartis par les établissements précités, existant à cette date, entre les associations formées pour l'exercice et l'entretien du culte dans les diverses circonscriptions religieuses. Cette répartition ne donnera lieu à la perception d'aucun droit au profit du Trésor.

Les biens immobiliers qui proviennent de dotations de l'État feront retour à l’État.

Art. 7 bis

Les biens appartenant aux fabriques, consistoires ou conseils presbytéraux, qui ont été spécialement affectés par l'auteur d'une libéralité à une œuvre de bienfaisance seront, dans le délai de six mois, attribués par les établissements précités, soit aux bureaux de bienfaisance, soit aux hospices, soit à tous autres établissements de bienfaisance publics ou reconnus d'utilité publique.

Le choix de l'établissement bénéficiaire de la dévolution devra être ratifié par le conseil d’État, s'il est conforme à la volonté du donateur 
ou du testateur. Cette attribution ne donnera lieu à aucun droit au profit du Trésor.

Art. 8

Aux ministres des cultes, actuellement en exercice, archevêques, évêques, curés, desservants, aumôniers, pasteurs, rabbins, présidents de consistoires, inspecteurs ecclésiastiques, suffragants et vicaires des églises réformées et de la confession d'Augsbourg ; directeurs et professeurs de séminaires, doyens et professeurs des facultés de théologie, qui auront au moins quarante cinq ans d'âge et vingt ans de fonctionnement de fonctions rémunérées par l'État, les départements ou les communes, il sera alloué une pension viagère. Réserve est faite des droits acquis en matière de pension par application de la législation antérieure.

Art. 9

Cette pension basée sur le traitement et proportionnelle au nombre des années de fonctions rétribuées par l’État, les départements et les communes, ne pourra être supérieure à $1200 \mathrm{fr}$.

Elle ne pourra, en aucun cas, dépasser le montant du traitement actuel de l'ayant droit, ni se cumuler avec toute autre pension ou tout autre traitement à lui alloué à un titre quelconque par l'État, les départements ou les communes.

Art. 10

Le payement des pensions ecclésiastiques aura lieu par trimestre. La jouissance courra au profit du pensionnaire du premier jour de l'exercice qui suivra la promulgation de la présente loi. Les arrérages des pensions inscrites se prescrivent par trois ans. La condamnation à une peine afflictive et infamante entraîne de plein droit la privation de la pension. Les pensions et leurs arrérages sont incessibles et insaisissables, si ce n'est jusqu'à concurrence d'un cinquième pour dettes envers le Trésor public et d'un tiers pour les causes exprimées aux articles 203,205 et 214 du code civil. 
Titre III

PROPRIÉTÉ ET LOCATION DES ÉDIFICES DU CULTE

Art. 11

Les édifices antérieurs au Concordat qui ont été affectés à l'exercice des cultes ou au logement de leurs ministres, cathédrales, églises paroissiales, temples, synagogues, archevêchés, évêchés, presbytères, bâtiment des séminaires ainsi que les objets mobiliers qui les garnissaient au moment où lesdits édifices ont été mis à la disposition des cultes, sont et demeurent propriétés de l'État ou des communes.

Pour les édifices postérieurs au Concordat, construits sur des terrains qui appartenaient aux établissements publics des cultes ou avaient été achetés par eux avec des fonds provenant exclusivement de collectes, quêtes ou libéralités des particuliers, sont la propriété des établissements.

\section{Art. 12}

Dans un délais d'un an à partir de la promulgation de la présente loi, ils seront dévolus par lesdits établissements à l'association civile de la circonscription religieuse intéressée.

Art. 13

Les édifices servant ou ayant servi aux cultes, qui appartiennent à l'État ou aux communes, sont inaliénables, sauf dans les cas d'expropriation pour cause d'utilité publique.

La location n'en peut être faite qu'à titre onéreux et pour une durée maximum de dix ans.

Art. 14

Pendant une période d'une année à partir de la promulgation de la présente loi, l'État et les communes sont tenus de consentir pour une 
durée de dix ans la location de ces édifices aux associations formées pour assurer l'exercice et l'entretien du culte.

Le prix du loyer ne pourra être supérieur à 10 p. 100 du revenu annuel moyen de la circonscription religieuse intéressée, telle qu'elle se trouve actuellement constituée.

Le revenu sera calculé sur la moyenne des cinq dernières années.

Tous les frais de répartitions locatives, d'entretien et de grosses réparations, sauf celles qui seraient causées par un sinistre ne pouvant être couvert par un contrat d'assurances sont à la charge des locataires.

Toutefois, pour plus de garanties et sans déroger à la responsabilité générale prévue dans le paragraphe ci-dessus, les locataires seront tenus de contracter une assurance contre les risques spéciaux de l'incendie et de la foudre.

La résiliation est de droit dans les cas où les lieux loués ne seraient pas entretenus en bon état.

Art. 15

Les lois, décrets et règlements relatifs à la conservation et l'entretien des monuments ou objets historiques continueront à être appliqués à tous les immeubles et meubles servant au culte rentrant ou pouvant rentrer dans cette catégorie.

Titre IV

ASSOCIATIONS POUR L'EXERCICE DU CULTE

Art. 16

Les associations formées pour subvenir aux frais et à l'entretien des cultes sont soumises aux prescriptions de la loi du 1er juillet 1901, sous la réserve des modifications ci après. 


\section{Art. 17}

Elles pourront recevoir, en outre des cotisations prévues par l'article 6 de cette loi, le produit des quêtes et collectes pour les frais et l'entretien du culte, percevoir des taxes (même par fondation) pour les cérémonies ou service religieux, pour la location des bancs et siège, pour la fournitures des objets destinés au service des funérailles dans les édifices religieux et à la décoration intérieure et extérieure de ces édifices.

Art. 18

Lesdites associations ne pourront, sous quelque forme et pour quelque raison que ce soit, recevoir de subventions de l'État, des départements et des communes.

La prestation de meubles et immeubles servant au culte, consentie dans les conditions des articles 13 et 14, ne constitue pas une subvention.

Art. 19

Ces associations pourront, dans les formes déterminées par l'article 7 du décret du 18 août 1901, constituer des unions avec administration ou direction centrale.

\section{Art. 20}

Les valeurs mobilières disponibles des associations formées pour assurer l'exercice du culte seront placées en titres nominatifs. Leur revenu total ne pourra dépasser la moyenne annuelle des sommes dépensées pendant les cinq dernières exercices pour les frais et l'entretien du culte.

Toutefois, ce capital ne pourra être augmenté de sommes qui, placées en titres nominatifs déposés à la caisse des dépôts et consignations, seront, après avis du conseil d'État, exclusivement affectés, compris les intérêts, à l'achat, à la construction ou à la réparation 
d'immeubles ou meubles jugés indispensables pour les besoins de l'association.

Art. 20 bis

Les biens meubles et immeubles appartenant aux associations seront soumis aux mêmes impôts que ceux des particuliers.

Ils ne seront pas assujettis à la taxe d'accroissement. Toutefois, les immeubles, propriétés de ces associations, seront passibles de la taxe de mainmorte.

Titre V

POLICE DES CULTES

Art. 21

Les cérémonies pour la célébration d'un culte sont assimilées aux réunions publiques. Elles sont dispensées des formalités de l'article 8, mais resteront à la surveillance des autorités dans l'intérêt de l'ordre public. La déclaration en sera faite dans les formes de l'article 2 de la loi du 30 juin 1881. Une seule déclaration suffira pour l'ensemble des cérémonies ou assemblées cultuelles permanentes ou périodiques. Toute réunion non comprises dans la déclaration, toute modification dans le choix du local devront être précédées d'une déclaration nouvelle.

Art. 22

Il est interdit de se servir de l'édifice consacré au culte pour y tenir des réunions politiques. Toute infraction sera punie d'une amende de 100 à 1000 fr. et d'un emprisonnement de quinze jours à trois mois ou de l'une de ces deux peines en la personne des auteurs responsables.

Art 23

Seront punis d'une amende de 50 à $500 \mathrm{fr}$. et d'un emprisonnement de quinze jours à trois mois ou de l'une de ces deux peines, ceux qui, 
par injures, menaces, violences ou voie de fait, tenteront de contraindre une ou plusieurs personnes à contribuer aux frais d'un culte ou à célébrer certaines fêtes religieuses ou bien de les empêcher de participer à l'exercice d'un culte, d'observer tel ou tel jour de repos, ou de s'abstenir de les observer, soit en les forçant à ouvrir ou fermer leurs ateliers, boutiques, magasins, ou de quelque manière que ce soit.

Art. 24

Ceux qui auront empêché, retardé, ou interrompu les exercices d'un culte par des troubles ou des désordres dans l'édifice servant au culte, ou qui auront, par des paroles ou gestes, outragé les objets d'un culte dans le temple même affecté à l'exercice de ce culte, seront punis d'une amende de 16 à 300 fr. et d'un emprisonnement de six jours à un mois ou de l'une de ces deux peines.

Lesdites peines pourront être portées au double en cas de voie de fait contre les personnes.

\section{Art. 25}

Les dispositions de l'article ci-dessus ne s'appliquent qu'aux troubles, outrages ou voie de fait dont la nature ou les circonstances ne donneront pas lieu à de plus fortes peines d'après les autres dispositions du code pénal.

\section{Art. 26}

Tout les ministres du culte qui, dans l'exercice de ses fonctions et en assemblée publique aura, soit en lisant un écrit contenant des instructions pastorales, soit en tenant lui-même un discours, outragé ou diffamé un membre du Gouvernement, des Chambres ou une autorité publique, sera puni d'une amende de 500 à 3000 fr. et d'un emprisonnement d'un mois à un an, ou de l'une de ces deux peines.

Art. 27

Si un discours prononcé ou un écrit lu par un ministre du culte dans l'exercice de ses fonctions et en assemblé publique contient une pro- 
vocation directe à résister à l'exécution des lois ou aux actes légaux de l'autorité publique, ou s'il tend à soulever ou ou a armer une partie des citoyens contre les autres, le ministre du culte qui l'aura prononcé sera puni d'un emprisonnement de trois mois à un an, si la provocation n'a été suivie d'aucun effet, et d'un emprisonnement d'un an à trois ans si elle a donné lieu à une résistance autre, toutefois, que celle qui aurait dégénéré en révolte, sédition ou guerre civile.

\section{Art. 28}

Lorsque la provocation aura été suivie d’une sédition, révolte ou guerre civile dont la nature donnera lieu, contre un ou plusieurs coupables, à des peines plus graves que celles portées à l'article précédent, cette peine, quelle qu'elle soit, sera appliquée au ministre du culte coupable de provocation.

Art. 29

L'auteur de l'écrit qui aura été lu par le ministre du culte dans les conditions ci-dessus indiquées, sera, en cas de complicité établie, puni des peines portées aux articles précédents contre le ministre du culte coupable.

Art. 29 bis

Dans le cas de poursuites exercées par application des articles 27 et 28, l'association constituée pour l'exercice du culte locataire de l'immeuble dans lequel le délit aura été commis, sera assignée en responsabilité civile.

Art. 30

L'article 463 du code pénal et la loi de sursis sont applicables à tous les cas dans lesquels la présente loi édicte des pénalités.

\section{Art. 31}

Dans tous les cas de culpabilité prévus et punis par la présente loi, le contrat de location de l'édifice, propriété de la commune ou de 
l’État, où le délit aura été commis par un ministre du culte, pourra être résilié.

Titre VI § 1er.MANIFESTATIONS ET SIGNES EXTÉRIEURS DU CULTE

Art. 32

Les processions et autres cérémonies ou manifestations extérieures du culte ne peuvent avoir lieu qu'en vertu d'une autorisation du maire de la commune. Les sonneries de cloches sont réglées par arrêté municipal.

Art. 33

La formule du serment judiciaire est libre. Nul ne peut être tenu de prêter serment sur un emblème philosophique ou religieux, ou dans les termes susceptibles de porter atteinte à la liberté de conscience.

Art. 34

Aucun signe ou emblème particulier d'un culte ne peut être élevé, érigé, fixé et attaché en quelque emplacement public que ce soit, à l'exception de l'enceinte destinée aux exercices du culte, des cimetières, sous les conditions ci-après, et des musées. Ceux qui existent contrairement à la présente disposition pourront être enlevés par les autorités publiques compétentes, sauf dans le cas où il s'y attacherait une valeur ou un intérêt artistique ou historique spécial.

Il est interdit d'en rétablir ou établir sous peine d'une amende de 100 à 2000 fr. 


\section{§ 2.- CIMETIÈRES}

Art. 35

Les cimetières appartiennent aux communes. L'autorité en a la garde, la police, l'entretien.

\section{Art. 36}

Il est interdit de bénir, consacrer ou de faire bénir ou consacrer par une cérémonie religieuse, un cimetière tout entier ou une portion de cimetière contenant plusieurs tombes.

Il est interdit d’y ériger des emblèmes religieux ayant un caractère collectif, sauf sur la sépulture unique consacrée à une famille ou à une collectivité.

Toute infraction sera punie d'une amende de 100 à 500 fr. et, en cas de récidive, de deux à cinq jours de prison.

La destruction de l'emblème illégalement érigé sera ordonnée. Elle aura lieu aux frais du coupable.

\section{Art. 37}

Les ornements et inscriptions funéraires sur les tombes ou monuments particuliers demeurent soumis à l'autorité municipale. Toutefois, ils ne peuvent être interdits, supprimés ou modifiés qu'au cas où ils porteraient atteintes aux lois, aux bonnes mœurs et à la paix publique.

\section{Art. 38}

Tout concessionnaire ou membre de la famille, enlevant, détruisant ou faisant enlever ou détruire un emblème philosophique ou religieux déposé en vertu de la volonté du défunt, même par un étranger, sera puni des peines portées contre la violation de sépulture à l'article 360 du code pénal. 


\section{Art. 39}

Il est interdit aux autorités publiques d'assigner des heures spéciales ou des modes particuliers pour la cérémonie des obsèques, sous quelque prétexte philosophique ou religieux que ce puisse être ;

D’assigner des places spéciales aux suicidés ou aux personnes non baptisées ou de religion différente de celle de la majorité des habitants de la commune ;

Ou de faire quoi que ce soit de nature à déshonorer la mémoire d'une personne, de quelque façon qu'elle soit morte, ou qu'elle se fasse ensevelir, ou qu'elle ait vécu.

Toute infraction à ces dispositions entraînera la révocation du magistrat municipal qui s’en sera rendu coupable.

Art. 40

Un règlement d'administration publique déterminera les mesures propres à assurer l'exécution de la présente loi.

La commission en était là de ses travaux : elle procédait déjà à une deuxième et dernière délibération sur son texte quand, le 10 novembre 1904, lui fut envoyé le projet de loi ci-dessous que M. Émile Combes, président du conseil, ministre de l'intérieur et des cultes, venait de déposer, au nom du Gouvernement, sur le bureau de la Chambre. 


\section{Projet Combes}

(déposé le 10 novembre 1904. J'en rajoute l'exposé des motif qui ne figurait pas dans le rapport de M. Briand) EXPOSE DES MOTIFS

Messieurs, le projet de loi qui vous est soumis reproduit, sous une forme législative, les appréciations émises par le président du conseil devant la commission de la séparation des Églises et de l’État au sujet de la proposition adoptée par la commission relativement à cette question importante.

Nous pouvons nous référer, en ce qui touche l'exposé des motifs que le projet comporte, à la discussion récente qui a eu lieu dans cette enceinte au début même de la session.

En vous montrant le Concordat systématiquement et journellement violé par le pouvoir religieux, le Gouvernement vous a fait connaître qu'il ne lui paraissait pas possible de maintenir plus longtemps un régime qu'il était seul à respecter, et il vous a indiqué dans quel esprit et d'après quels principes il était résolu à vous proposer de consacrer un régime nouveau, le régime de la séparation des Églises et de l’État. Vous trouverez ses vues nettement précisées dans les articles dont la teneur suit :

Titre 1er

\section{SUPPRESSION DES DÉPENSES DES CULTES \\ - RÉPARTITION DES BIENS - PENSIONS}

Art. 1er

A partir du 1er janvier qui suivra la promulgation de la présente loi, sont et demeurent supprimés: toutes les dépenses publiques pour l'exercice ou l'entretien d'un culte ; tous les traitements, indemnités, 
subventions ou allocations accordés aux ministres d'un culte sur les fonds de l'État, des départements, des communes ou des établissements publics hospitaliers.

Art. 2

Pendant deux ans à partir du 1er janvier qui suivra la promulgation de la présente loi, la jouissance gratuite des édifices du culte sera laissé aux associations dont il sera parlé au titre II ci-après.

Après cette période de temps écoulée, cessera de plein droit l'usage gratuit des édifices religieux : cathédrales, églises, temples, synagogues, ainsi que des bâtiments des séminaires et des locaux d'habitation : archevêchés, évêchés, presbytères, mis à la disposition des ministres des cultes par l'État, les départements et les communes.

Art. 3

Les biens mobiliers et immobiliers appartenants aux menses, fabriques, consistoires, conseils presbytéraux et autres établissements publics préposés aux cultes antérieurement reconnus, seront concédés à titre gratuit aux associations qui se formeront pour l'exercice d'un culte, dans les anciennes circonscriptions ecclésiastiques où se trouvent ces biens.

Ces concessions, qui n’auront d'effet qu'à partir du 1er janvier qui suivra la promulgation de la présente loi, seront faites dans les limites des besoins de ces associations, par décret en conseil d'État ou par arrêté préfectoral, suivant que la valeur des biens s'élèvera ou non à 10000 fr., pour une période de dix années et à charge d'en rendre compte à l'expiration de cette période. Elles pourront être renouvelées dans les mêmes conditions pour des périodes de même longueur ou d'une longueur moindre.

Ne pourront être compris dans ces concessions : $1^{\circ}$ les immeubles provenant de dotation de l'État, qui lui feront retour; $2^{\circ}$ les biens ayant une destination charitable, qui seront attribués par décret en conseil d’État ou arrêté préfectoral, suivant la distinction précitée, aux 
établissements publics d'assistance situés dans les communes ou dans l'arrondissement.

Les biens non concédés dans un délai d'une année, à dater de la promulgation de la présente loi, ou dont la concession ne serait pas redemandée, seront attribués dans les mêmes formes entre les établissements d'assistance ci-dessus visés.

Art. 4

Les ministres du culte qui, par application de la présente loi, cesseront de remplir des fonctions rétribuées par l'État, recevront les pensions et allocations suivantes :

$1^{\circ}$ Les curés et desservants, vicaires généraux et chanoines, âgés de plus de soixante ans et comptant vingt-cinq années de service au moins, 900 fr. ; les vicaires remplissant les mêmes conditions, 300 fr.

$2^{\circ}$ Les curés et desservants, vicaires généraux et chanoines, âgés de plus de cinquante ans et comptant au moins vingt ans de services, 750 fr. ; les vicaires remplissant les mêmes conditions, 300 fr.

$3^{\circ}$ Les curés et desservants, vicaires généraux et chanoines, âgés de plus de quarante ans et comptant au moins quinze ans de services au moins, 600 fr. ; les vicaires remplissant les mêmes conditions, 250 fr.

$4^{\circ}$ Les curés et desservants, âgés de moins de quarante ans, recevront pendant quatre ans une allocation de $400 \mathrm{fr}$.

Les ministres des cultes protestants et israélites, les directeurs et professeurs des séminaires de ces cultes auront les mêmes pensions et allocations que celles attribuées aux curés et desservants, suivant les distinctions précités et à des taux calculés dans les mêmes proportions que ci-dessus par rapport aux traitements actuels.

Les archevêques et évêques, le grand rabbin du consistoire central auront une pension de $1200 \mathrm{fr}$. 
Ces pensions et allocations cesseront de plein droit en cas de condamnation à une peine afflictive ou infamante ou pour un des délits visés par les articles 17 et 19 de la présente loi.

Les conditions de payement de ces pensions et allocations, ainsi que toutes les mesures propres à assurer l'exécution du présent article, seront déterminées par un règlement d'administration publique.

Art. 5

Les édifices et autres biens affectés aux cultes antérieurement reconnus, qui appartiennent à l'État, aux départements ou aux communes, seront concédés, à titre onéreux, aux associations qui se formeront pour l'exercice d'un culte, dans les anciennes circonscriptions ecclésiastiques où se trouvent ces biens.

Ces concessions, qui n'auront d'effet que deux ans à partir du 1er janvier qui suivra la promulgation de la présente loi, seront faites dans les limites des besoins de ces associations par décret en conseil d'État ou par arrêté préfectoral, suivant que les biens appartiendront soit à l'état, soit aux départements ou aux communes, pour une période de dix années et à charge d'en rendre compte à l'expiration de cette période et de supporter les frais d'entretien et de grosses réparation.

Elles pourront être renouvelées, sous les mêmes conditions, pour des périodes de même longueur ou des périodes moindres.

Le prix de la concession ne pourra dépasser le dixième des recettes annuelles de l'association constatées d'après les dispositions de l’article 9 de la présente loi.

Des subventions pour grosses réparations pourront être accordées aux départements et aux communes dans la limite du crédit inscrit annuellement au budget du ministère de l’intérieur.

Les biens non reconnus utiles pour les besoins des associations d'un culte ou dont la concession n'aura pas été redemandée pourront dans les mêmes formes être concédés à un autre culte ou affectés à un service public. 
Les conseils municipaux et les conseils généraux seront appelés à donner leur avis pour la concession des biens communaux ou départementaux.

Titre II

ASSOCIATION POUR L’EXERCICE D’UN CULTE

Art. 6

Les associations formées pour subvenir aux frais et à l'entretien d'un culte devront être constituées conformément aux articles 5 et suivants de la loi du 1er juillet 1901 ; elles seront soumises aux autres prescriptions de cette loi sous réserve des dispositions ci-après :

Elles devront avoir exclusivement pour objet l'exercice d'un culte.

Elles ne pourront employer aucun étranger dans les fonctions de ministre du culte.

Les administrateurs ou directeurs devront être Français, jouir de leurs droits civils, et avoir leur domicile dans le canton où se trouvent les immeubles consacrés à l'exercice du culte.

Art. 7

Outre les cotisations prévues par l'article 6 de la loi du 1er juillet 1901, elles pourront recevoir le produit des quêtes et collectes faites pour les frais d'entretien d'un culte, dans les édifices consacrés à l'exercice public de ce culte, percevoir des taxes ou rétribution, même par fondations, pour les cérémonies et service religieux, pour la location des bancs et siège, pour la fourniture des objets destinés au service des funérailles dans les édifices religieux et à la décoration de ces édifices.

Art. 8

Ces associations pourront, dans les formes déterminées par l'article 7 du décret du 7 août 1901, constituer des unions. 
Ces unions ne pourront dépasser les limites du département.

Art. 9

Les associations tiennent un état de leur de leurs recettes et de leurs dépenses ; elles dressent chaque année le compte financier de l'année écoulée et l’État inventorié de leurs biens, meubles et immeubles.

Elles peuvent constituer un fonds de réserve dont le montant ne devra pas être supérieur au tiers de l'ensemble de leurs recettes annuelles.

Ce fonds de réserve sera placé soit à la caisse des dépôts et consignations, soit en titres nominatifs de rentes françaises ou de valeurs garanties par l'État.

A défaut par une association de remplir les charges de réparation qui lui sont imposées par l'article 5 pour les immeubles concédés, le fond de réserve pourra être employé par arrêté préfectoral pris après mise en demeure restée sans effet, à réparer lesdits immeubles.

Outre ce fonds de réserve, elles pourront verser à la caisse des dépôts et consignations d'autres sommes, mais seulement en vue de l'achat ou de la construction d'immeubles nécessaires à l'exercice du culte.

Elles seront tenues de représenter sans déplacement, sur toute réquisition du préfet lui-même ou à son délégué, les comptes et états cidessus prévus.

Art. 10

Sont passibles d'une amende de 16 à 1000 fr. et d'un emprisonnement de six jours à un an, ou de l'une de ces deux peines seulement, les directeurs et administrateurs d'une association ou d'une union qui auront contrevenu aux dispositions des articles 6, 7, 8 et 9 . 
Titre III

POLICE DES CULTES ET GARANTIE

DE LEUR LIBRE EXERCICE

Art. 11

Les cérémonies d'un culte, les processions et autres manifestations religieuses ne peuvent avoir lieu sur la voie publique, ni dans aucun lieu public, à l'exception des cérémonies funèbres, ni dans aucun édifice public autre que ceux concédés à un culte dans les conditions déterminées par la présente loi.

Il est interdit, à l'avenir, d'élever ou d'apposer aucun signe signe ou emblème religieux sur les monuments publics ou en quelque emplacement public que ce soit, à l'exception des édifices concédés pour l'exercice d'un culte, des terrains de sépulture privée dans les cimetières, ainsi que des musées ou expositions publics.

\section{Art. 12}

Les réunions pour la célébration d'un culte ne peuvent avoir lieu qu'après déclaration faite dans les conditions et les formes prescrites pour les réunions publiques, par l'article 2 de la loi du 30 juin 1881. Outre les noms, qualités et domiciles des déclarants, la déclaration indiquera ceux des ministres du culte appelés à l'exercice de leur ministère.

Une seule déclaration suffit pour un ensemble de cérémonies ou assemblées cultuelles permanentes ou périodiques. Elle cesse de produire effet à l'expiration d'une année.

Toute réunion non comprise dans la déclaration, tout modification dans le choix du local ou des ministres du culte doivent être précédées d'une déclaration nouvelle.

Les représentants ou délégués de l'autorité publique ont toujours accès dans les lieux de réunion pour l'exercice d'un culte. 


\section{Art. 13}

Il est interdit de se servir de l'édifice consacré à un culte pour y tenir des réunions politiques.

\section{Art. 14}

Les contraventions aux trois articles précédents sont punis d'une amende de 50 à 1000 fr. et les infractions à l'article 13 peuvent être, en outre, punies d'un emprisonnement de quinze jours à trois mois.

Sont passibles de ces peines, dans le cas des articles 12 et 13, ceux qui ont organisé la réunion, ceux qui ont participé en qualité de ministre du culte et ceux qui ont fourni le local.

\section{Art. 15}

Sont punis d'une amende de 100 à 1000 fr., et d'un emprisonnement de 6 jours à trois mois, ou de l'une de ces deux peines seulement, ceux qui, soit par menace ou abus d'autorité, soit en faisant craindre à autrui de perdre son emploi ou d'exposer à un dommage sa personne, sa famille ou sa fortune, auront tenté de contraindre ou d'empêcher une ou plusieurs personnes d'exercer un culte, de contribuer aux frais de ce culte, de célébrer certaines fêtes, d'observer tel ou tel jour de repos et, en conséquence, d'ouvrir ou de fermer leurs ateliers, boutiques ou magasins, et de faire ou quitter certains travaux.

\section{Art. 16}

Sont punis des mêmes peines ceux qui auront empêché, retardé ou interrompu les exercices d'un culte par des troubles ou désordres dans un édifice consacré à un culte conformément à la loi.

\section{Art. 17}

Sera puni des mêmes peines tout ministre d'un culte qui, dans l'exercice de ce culte, se rendra coupable d'actes pouvant compromettre l'honneur des citoyens et dégénérer contre eux en oppression, en 
injure ou en scandale public, notamment par des inculpations dirigées contre les personnes.

\section{Art. 18}

Tout ministre d'un culte qui, dans les lieux où s'exerce ce culte, aura par des discours prononcés, des lectures faites, des écrits distribués ou des affiches apposés en public, soit outragé ou diffamé un membre du Gouvernement ou des Chambres, ou une autorité publique, soit cherché à influencer le vote des électeurs ou à les déterminer à s'abstenir de voter, sera puni d'une amende de $500 \mathrm{fr}$. à $3000 \mathrm{fr}$. et d'un emprisonnement d'un mois à un an, ou de l'une de ces deux peines seulement.

\section{Art. 19}

Si un discours prononcé ou écrit affiché, lu ou distribué publiquement dans les lieux où s'exerce le culte, contient une provocation directe à résister à l'exécution des lois ou aux actes légaux de l'autorité publique, ou s'il tend à soulever ou à armer une partie des citoyens contre les autres, le ministre du culte qui s'en sera rendu coupable sera puni d'un emprisonnement de trois mois à deux ans, sans préjudice des peines de la complicité dans le cas où la provocation aurait été suivie d'une sédition, révolte ou guerre civile.

\section{Art. 20}

Dans le cas des poursuites exercées par l'application des articles 12, 13, 17, 18 et 19, l'association propriétaire, concessionnaire ou locataire de l'immeuble dans lequel le délit a été commis, et ses directeurs et administrateurs sont civilement et solidairement responsables.

Si l'immeuble a été concédé en vertu de la présente loi, la concession en peut être retirée dans les formes où elle a été faite.

La fermeture du local peut être immédiatement ordonnée par l'autorité judiciaire, qui prononce une condamnation pour infraction aux articles 13, 17, 18 et 19. 
Titre IV

DISPOSITIONS GÉNÉRALES ET TRANSITOIRES

Art. 21

Un règlement d'administration publique déterminera les mesures propres à assurer l'application de la présente loi. Il réglementera en outre les sonneries des cloches.

Art. 22

L'article 463 du code pénal est applicable à tous les cas dans lesquels la présente loi édicte les pénalités.

Art. 23

Les congrégations religieuses demeurent soumises aux loi du 1er juillet 1901, du 4 septembre 1902 et du 7 juillet 1904 .

Art. 24

La direction des cultes continuera à fonctionner pour assurer l'exécution de la présente loi.

Art. 25

Sont abrogées toutes dispositions législatives ou réglementaires contraires à la présente loi et notamment :

$1^{\circ}$ La loi du 18 germinal an $\mathrm{X}$ qui a déclaré que la convention du 26 messidor an IX entre le Gouvernement français et le pape, ensemble les articles organiques de ladite convention, seraient promulgués et exécutés comme des lois de la République ;

$2^{\circ}$ Le décret du 26 mars 1852 et la loi du 1er août 1879 sur les cultes protestants ; 
$3^{\circ}$ Les décrets du 17 mars 1808, la loi du 8 février 1831 sur le culte israélite ;

$4^{\circ}$ Les décrets des 22 septembre 1812 et 19 mars 1859 ;

5 Les articles 201 à 208, 260 à 264, 294 du code pénal

$6^{\circ}$ Les articles 100 et 101, les paragraphes 11 et 12 de l'article 136 de la loi du 5 avril 1834.

Il suffisait de lire ce projet pour constater que son économie générale était sensiblement différente de celle du projet provisoirement adopté par la commission. En ce qui concerne, par exemple, le régime de la propriété et de la location des édifices du culte, celui des associations cultuelles, le système de pensions, les solutions proposées par le Gouvernement étaient en désaccord flagrant avec celles de la commission.

Pour l'attribution de la propriété des biens immobiliers des Églises, constitués à leur profit depuis le Concordat par dons et libéralités provenant en tout ou en partie des fidèles, la commission proposait une solution qui n'était peut-être pas très juridique, mais avait, du moins, le mérite de trancher la question une fois pour toutes, d'une façon nette et définitive. Elle avait fait deux parts des édifices : ceux qui ont été construits sur des terrains de l'État ou des communes ou achetés au moyen de leurs subventions ; ceux, au contraire, qui ont été bâtis sur des terrains donnés par les fidèles ou achetés avec le produit de leurs dons et libéralités. Les premiers étaient déclarés propriété de l’État ou des communes ; les seconds propriétés des Églises.

Le système proposé par le Gouvernement ne tranchait pas la question de propriété. Des biens ecclésiastiques, mobiliers ou immobiliers, qui sont postérieurs au Concordat, il faisait un lot que l'État, après prélèvement des biens donnés par lui ou ayant une destination charitable, répartirait par voie de concessions décennales renouvelables, entre les associations cultuelles dans la limite de leurs besoins. L'avantage de ce système serait de permettre la constitution, au profit des paroisses pauvres, d'un patrimoine pour assurer le service du culte. Grâce à cette manière de procéder, l’État étant juge et maître de la répartition 
aurait sur l'emploi de ces biens un droit de contrôle qui n'est certes pas négligeable. Mais ce système devait avoir pour conséquence de perpétuer l'immixtion de l'État dans l'administration des choses ecclésiastiques. D’où la nécessité, dans le projet du Gouvernement, de conserver la direction des cultes que la commission, se plaçant à un autre point de vue, avait cru devoir supprimer.

En tout cas, si sur ce point, le projet du Gouvernement pouvait paraître acceptable, il n'en était pas de même quant au silence gardé par lui sur la question de propriété relative aux biens mobiliers et immobiliers antérieurs au Concordat. Il était imprudent et dangereux de ne pas affirmer avec force et netteté, comme l'avait fait la commission, la propriété de l’État ou des communes.

M. Combes n’avait pas cru nécessaire d'affirmer le droit de propriété de l'État et des communes, parce qu'il lui avait paru suffisamment établi par une jurisprudence constante. Mais la jurisprudence, c'est pure affaire d'interprétation, et celle-ci peut varier selon les cas, les temps et les juges. Jusqu'à ce jour, il est bien vrai que les décisions de justice ont été conformes au droit de l'État et des communes ; qui pourrait assurer que demain il n'en serait autrement?

Puis, un jugement, un arrêt, valent seulement pour les cas qu'ils ont appréciés ; leur force exécutoire est strictement limitée à l'espèce jugée. Il en résulte que projet du Gouvernement, une fois transformé en loi, rencontrerait des difficultés d'application presque insurmontables. Partout, dans les paroisses, l’Église revendiquerait la propriétés de édifices antérieurs au Concordat. Avant que l'État pût en disposer, il faudrait que cette question préjudicielle fût tranchée. Ce serait des procès innombrables et interminables.

Puisqu'une occasion s’offrait de consacrer l'œuvre de la Révolution en affirmant, une fois pour toutes, et sans contestation possible, le droit de l'État et des communes, pourquoi ne pas la saisir?

Mais c'est aussi quant à la disposition des biens mobiliers et immobiliers antérieurs au Concordat, que les solutions de la commission et du Gouvernement apparaissaient divergentes. Alors que la première rendait à l'État et aux communes, après une période de location de dix 
ans obligatoire, la libre disposition de leur propriété, celle du gouvernement édictait, au profit des associations cultuelles, un système de concessions décennales indéfiniment renouvelables, même pour les immeubles des départements ou des communes qui se seraient montrés hostiles au renouvellement. Il en résultait une grave atteinte au principe de la séparation. Cette obligation indéfinie, imposée aux communes et aux département, de laisser leurs biens entre les mains des représentants des Églises, prenait, en effet, le caractère d'une véritable subversion en faveur des cultes. C'était en outre, là aussi, l’immixtion de l'État qui se perpétuait dans les affaires ecclésiastiques.

Sur le chapitre des pensions aux ministres des cultes, la dissemblance était tout entière dans la question de mesure. Le projet de la commission ne pensionnait que les ministres des cultes qui réalisaient certaines condition d'âge et de durée de services concordataires. Celui du Gouvernement, beaucoup moins exigeant, tant pour l'âge que pour la durée des services, allait jusqu'à accorder, pendant une période de quatre années, à tous les curés et desservants concordataires sans exception, une pension de $400 \mathrm{fr}$. D'après l'application de ce système de pension, faite par les soins de la direction des cultes, il devait entraîner pour l'État une dépense annuelle de 22444000 fr., qui irait, naturellement, en décroissant chaque année.

Quant au régime des associations cultuelles, la différence la plus importante entre les deux textes était relative aux unions. Alors que la commission les avait autorisées, même nationales, le projet du Gouvernement, par son article 8, les enfermait dans les limites du département. C'était imposer aux Églises une formation arbitraire qui, en les contraignant à modifier leur organisation intérieure, pouvait entraîner pour elles les difficultés les plus graves. Les Églises protestantes dont les fidèles, peu nombreux relativement, sont disséminés sur tous les points de la France, n'auraient pas pu s'accommoder de ce régime. Il en eût été de même pour la religion israélite.

Enfin, au chapitre de la police des cultes, pour ne noter que l'innovation la plus grave apportée par le projet Combes, nous signalons l'article 17 dont les termes imprécis et vagues étaient de nature à 
inquiéter les consciences par l'interprétation arbitraire auquel ils pouvaient donner lieu.

Le premier examen du projet du Gouvernement provoqua, au sein de la commission, les résistances les plus vives. Finalement, les membres de la majorité consentirent à délibérer sur les articles, mais après de fortes réserves, et seulement parce que les circonstances commandaient d'éviter un conflit qui, en ajournant de plusieurs mois la discussion devant la Chambre, eût irrémédiablement compromis, au moins dans cette législature, le succès de la réforme. mais s’ils consentaient à adopter le projet soumis à leur délibération c'était à la condition expresse que des modifications fussent consenties par le Gouvernement sur les points de divergence les plus graves.

Le rapporteur fut chargé de s’entremettre auprès du président du conseil à fin de transaction. Dès la première entrevue, il devint évident que $\mathrm{M}$. Combes, animé du plus vif désir de conciliation, acceptait d'entrer dans les vues de la commission pour le règlement de la plupart des difficultés qui lui étaient signalées. Il consentit successivement : $1^{\circ}$ à insérer en tête de son projet une déclaration de principe conforme à celle du texte de la commission ; $2^{\circ}$ à affirmer que le doit de propriété de l'État et des communes sur tous les biens mobiliers et immobiliers antérieurs au Concordat; $3^{\circ}$ à remettre à l'État et aux communes la libre disposition de ces biens dès l'expiration de la période de dix ans obligatoire pour la location aux associations cultuelles ; $4^{\circ}$ à n'imposer aux unions d'autres limites que celles des circonscriptions ecclésiastiques existantes ; $5^{\circ}$ à supprimer les délits spéciaux crées par l’article 17.

Il ne restait plus à régler que la question des pensions et quelques points de détails relatifs à l'ingérence de l'administration préfectorale dans les affaires ecclésiastiques pour aboutir à l'accord complet et définitif. Le rapporteur ne désespérait pas d'y réussir, et déjà il se proposait de tenter une dernière démarche dans ce but, quand le ministère Combe prit la résolution de quitter le pouvoir.

L'un des premiers actes de son successeur fut de saisir la Chambre d'un nouveau projet sur la séparation des Églises et de l'État. Déposé 
le 9 février 1905, il fut renvoyé à l'étude de votre commission. En voici le texte.

\section{Projet du Gouvernement}

(Je rajoute l'exposé des motif qui ne figurait pas dans le rapport de M. Briand)

Début

$\underline{\text { Retour à la table des matières }}$

présenté au nom de M. Émile Loubet, Président de la République française,

par M. Rouvier, président du conseil, ministre des finances ;

par M. Bienvenu Martin, ministre de l' instruction publique des beaux-arts et des cultes ;

par M. Delcassé, ministre des affaires étrangères, et par M. Étienne, ministre de l’intérieur.

\section{EXPOSÉ DES MOTIFS}

Messieurs, le séparation des Églises et de l'État est une des réformes essentielles à la réalisation desquelles le Gouvernement, par sa déclaration du 27 janvier dernier, s’est engagé à consacrer ses efforts. Fidèle à ses promesses, il vous apporte aujourd'hui un projet de loi qui détermine les conditions dans lesquelles la séparation lui parait devoir être opérée.

Dans la rédaction de ce projet, nous nous sommes rapprochés, autant que possible, des dispositions qui avaient été adoptées par la commission de la Chambre chargée d'examiner diverses propositions portant sur le même objet. 
Comme la commission, nous voulons garantir le libre exercice des cultes et cette liberté ne doit avoir d'autres limites que celles imposées par l'ordre public.

Le texte que nous vous présentons est la consécration de ce double principe.

En même temps il édicte un certain nombre de mesure qui sont destinées à assurer sans secousse le passage du régime ancien au régime nouveau.

Tel est l'objet des articles qui règlent la dévolution des biens des établissements ecclésiastiques supprimés, la mise des édifices religieux à la disposition des associations cultuelles, les pensions aux ministres du culte.

Dans ces conditions, nous espérons que le Parlement n’hésitera pas à nous donner son concours pour l'accomplissement d'une réforme qui ne saurait être différée et que le Gouvernement désire fermement voir aboutir.

\section{Titre Ier Principes}

\section{Article 1er}

L’État ne reconnaît, ne salarie ni ne subventionne aucun culte.

Les établissements publics des cultes actuellement reconnus sont supprimés, sous réserve des dispositions énoncées à l’article 3.

Seront également supprimés des budgets de l'État, des département et des communes, à partir du 1er janvier qui suivra la promulgation de la présente loi, toute dépense relative à l'exercice des cultes

Art. 2

L'exercice des cultes est libre sous les seules restrictions édictées ci-après dans l'intérêt de l'ordre public. 
Titre II

Dévolution des biens appartenant

aux établissements publics des cultes -, pensions

\section{Article 3}

Les établissements dont la suppression est ordonnée par l'article 1er continueront provisoirement de fonctionner, conformément aux dispositions qui les régissent actuellement, jusqu’à la dévolution de leurs biens aux associations prévues par le titre IV et au plus tard jusqu'à l'expiration du délai ci-après.

\section{Article 4}

Dans le délai d'un an, à partir de la promulgation de la présente loi, les biens mobiliers et immobiliers appartenant aux menses, fabriques, conseils presbytéraux, consistoires et autres établissements ecclésiastiques seront attribués par les représentants légaux de ces établissements aux associations qui se seront légalement formées pour l'exercice du culte dans les anciennes circonscriptions desdits établissements.

Toutefois, les mobiliers et immobiliers provenant de la dotation de l’État feront retour à l’État.

Les mobiliers et immobiliers grevés d'une affectation charitable ou de toute autre affectation étrangère à l'exercice du culte seront attribués par les représentants légaux des établissements ecclésiastiques, dans la limite de leurs circonscription respectives, aux services ou établissements publics dont la destination est conforme à celle desdits biens. Cette attribution devra être approuvée par le préfet du département où siège l'établissement ecclésiastique. En cas de nonapprobation, il sera statué en conseil d’État. 


\section{Article 5}

Faute par un établissement ecclésiastique d'avoir, dans le délai fixé par l'article précédent, procédé aux attributions ci-dessus prescrites, il y sera pourvu par le préfet

\section{Article 6}

En cas de dissolution d'une association, les biens qui lui auront été dévolus en exécution des articles 4 et 5 seront attribués par elle à une association analogue existant soit dans la même circonscription soit dans les circonscriptions limitrophes.

A défaut d'accord, cette attribution est faite, à la requête de la partie la plus diligente, par le tribunal de l'arrondissement où l'association à son siège.

\section{Article 7}

Les attributions prévues par les articles précédents ne donnent lieu à aucune perception au profit du Trésor.

\section{Article 8}

Les ministres des cultes actuellement salariés par l'État, recevront, à partir de la cessation de leur traitement, une pension viagère annuelle qui sera égale à la moitié ou aux deux tiers de leur traitement, suivant qu'ils compteront au moins vingt ou trente ans de service rétribué par l'État, sans toutefois que cette pension puisse être inférieur à 400 fr. ni supérieur à 1200 fr.

Les ministres des cultes, qui compteront moins de vingt années de services rétribués par l'État, recevront une allocation annuelle de 400 fr. pendant un temps égal à la moitié de leurs services.

Les pensions et allocations seront incessibles et insaisissables dans les mêmes conditions que les pensions civiles. Elles cesseront de plein droit en cas de condamnation à une peine afflictive ou infamante. El- 
les seront suspendues pendant un délai de deux ans en cas de condamnation pour l'un des délits prévus aux articles 26 et 27 de la présente loi.

\section{Titre III Des édifices des cultes}

\section{Article 9}

Les édifices antérieurs au Concordat, qui ont été affectés à l'exercice des cultes ou au logement de leurs ministres, cathédrales, églises, chapelles, temples, synagogues, archevêchés, évêchés, presbytères, séminaires, ainsi que leurs dépendances immobilière et les objets mobiliers qui les garnissaient au moment où lesdits édifices ont été mis à la disposition des cultes, sont et demeurent propriétés de l'État ou des communes, qui devront en laisser la jouissance gratuite, pendant deux années à partir de la promulgation de la présente loi, aux établissements ecclésiastiques ou aux associations formées pour l'exercice du culte dans les anciennes circonscriptions des établissements ecclésiastiques supprimés.

L'État et les communes seront soumis à la même obligation en ce qui concerne les édifices postérieurs au Concordat, dont ils seraient propriétaires.

A l'expiration du délai ci-dessus fixé, l'État et les communes devront consentir aux associations, pour une durée n’excédant pas dix ans, la location de ces édifices.

Le loyer ne pourra être supérieur à 10 p. 100 du revenu annuel moyen des établissements supprimés, ledit revenu calculé d'après les résultats des cinq dernières années antérieures à la promulgation de la présente loi.

La location pourra être renouvelée au profit des associations par périodes successives de dix ans au maximum. Chaque renouvellement ne pourra avoir lieu que dans les deux dernières années du bail en cours. 
Les réparations locatives et d'entretien seront à la charge des établissements ou des associations qui seront tenus, en outre, de contracter une assurance contre les risques de l'incendie et de la foudre.

En cas d’inexécution de ces prescriptions, la location sera résiliée de plein droit.

Les associations locataires ne pourront se prévaloir contre l'État et les communes des dispositions de l'article 1720 du code civil.

Article 10

Les édifices du culte, dont les établissements ecclésiastiques seraient propriétaires, seront, avec les objets mobiliers les garnissant, attribués aux associations dans les conditions déterminées par le titre II

Art. 11

Les objets mobiliers mentionnés au paragraphe 1er de l'article 9, qui n'auraient pas encore été inscrits sur la liste de classement dressée en vertu de la loi du 30 mars 1887, sont, par l'effet de la présente loi, ajoutés à ladite liste. Toutefois, il sera procédé par le ministre de l'instruction publique et des beaux-arts, dans le délai de trois ans, au déclassement de ceux de ces objets dont la conservation ne présenterait, au point de vue de l'histoire ou de l'art, un intérêt suffisant.

En outre, les immeubles et les objets mobiliers, attribués en vertu de la présente loi aux associations, pourront être classés dans les mêmes conditions que s'ils appartenaient à des établissements publics.

Il n'est pas dérogé, pour le surplus, aux dispositions de la loi du 30 mars 1887. 


\section{Titre IV}

Des associations pour l'exercice des cultes

Article 12

Les associations formées pour l'exercice d'un culte devront être constituées conformément aux articles 5 et suivants de la loi du 1er juillet 1901 ; elles seront soumises aux autres prescriptions de cette loi, sous réserve des dispositions ci-après.

\section{Article 13}

Elles devront avoir exclusivement pour objet l'exercice d'un culte.

Elles pourront recevoir, en outre, des cotisations prévues par l'article 6 de la loi du 1er juillet 1901, le produit des quêtes et collectes pour les frais du culte, percevoir des rétributions même par fondation pour les cérémonies et services religieux ; pour la location des bancs et sièges ; pour la fourniture des objets destinés au service des funérailles dans les édifices religieux et à la décoration de ces édifices.

Elles ne pourront, sous quelque forme que ce soit, recevoir des subventions de l'État, des départements et des communes. Ne sont pas considérées comme subventions les sommes que l'État, les départements ou les communes jugeront convenables d'employer aux grosses réparations des édifices du culte loués aux associations.

\section{Article 14}

Ces associations peuvent, dans les formes déterminées par l'article 7 du décret du 16 août 1901, constituer des unions ayant une administration ou une direction centrale; ces unions seront réglées par les article 12 et 13 de la présente loi ; toutefois les unions qui s’étendent sur plus de dix départements sont dépourvues de toute capacité juridique. 


\title{
Article 15
}

Les valeurs mobilières disponibles des associations et unions seront placées en titres nominatifs. Leur revenu total ne pourra dépasser la moyenne annuelle des sommes dépensées pensant les cinq derniers exercices pour les frais d'entretien du culte.

Toutefois, ce capital pourra être augmenté de sommes qui, placées en titre nominatifs déposés à la caisse des dépôts et consignations, seront exclusivement affectés, y compris les intérêts, à l'achat, à la construction ou à la réparation d'immeubles ou meubles destinés aux besoins de l'association ou de l'union.

\section{Article 16}

Seront passibles d'une amende de 16 à 200 fr. et d'un emprisonnement de six jours à trois mois, ou de l'une de ces deux peines seulement, les directeurs ou administrateurs d'une association ou d'une union qui auront contrevenu aux articles 12, 13, 14 et 15.

Les tribunaux pourront, en outre, à la requête de tout intéressé ou du ministère public, prononcer la dissolution de l'association ou de l'union.

\section{Article 17}

Les immeubles appartenant aux associations et unions seront soumis à la taxe de mainmorte.

\author{
Titre V \\ Police des cultes
}

\section{Article 18}

Les réunions pour la célébration d'une culte ne peuvent avoir lieu qu'après une déclaration faite dans les formes de l'article 2 de la loi du 8 juin 1881 et indiquant le local dans lequel elles seront tenues. 
Une seule déclaration suffit pour l'ensemble des réunions permanentes, périodiques ou accidentelles qui auront lieu dans l'année.

Article 19

Il est interdit de tenir des réunions politiques dans les locaux servant habituellement à l'exercice d'un culte.

Article 20

Les processions et autres manifestations extérieures d'un culte ne peuvent avoir lieu qu'en vertu d'une autorisation du maire de la commune.

Les sonneries des cloches seront réglées par arrêté municipal.

Article 21

Il est interdit, à l'avenir, d'élever ou d'apposer aucun signe ou emblème religieux sur les monuments publics ou en quelque emplacement public que ce soit, à l'exception des édifices servant au culte, des terrains de sépulture privée ainsi que des musées ou expositions.

Article 22

Les contraventions aux articles précédents sont punies des peines de simple police.

Sont passibles de ces peines, dans le cas des articles 18, 19 et 20, ceux qui ont organisé la réunion ou manifestation, ceux qui y ont participé en qualité de ministres du culte et, dans le cas des articles 18 et 19, ceux qui ont fourni le local.

\section{Article 23}

Sont punis d'une peine d'amende de 16 fr. à 200 fr. et d'un emprisonnement de six jours à deux mois ou de l'une de ces deux peines seulement ceux qui, soit par voies de fait, violences ou menaces contre un individu, soit en lui faisant craindre de perdre son emploi ou 
d'exposer à un dommage sa personne, sa famille ou sa fortune, l'auront déterminé à exercer ou à s'abstenir d'exercer un culte, à contribuer ou à s'abstenir de contribuer aux frais d'un culte, à ouvrir ou fermer ses ateliers, boutiques ou magasins et à faire ou quitter certains travaux.

\section{Article 24}

Seront punis des mêmes peines ceux qui auront empêché, retardé ou interrompu les exercices d'un culte par des troubles ou désordres causés dans le local servant à ces exercices.

\section{Article 25}

Les dispositions des deux articles précédents ne s’appliquent qu'aux troubles, outrages ou voies de fait, dont la nature ou les circonstances ne donneront pas lieu à de plus fortes peines d'après les dispositions du Code pénal.

\section{Article 26}

Tout ministre d'un culte qui, dans les lieux où s'exerce ce culte, aura par des discours prononcés, des lectures faites, des écrits distribués ou des affiches apposées en public, soit outragé ou diffamé un citoyen chargé d'un service public, soit cherché à influencer le vote des électeurs ou à les déterminer à s'abstenir de voter, sera puni d'une amende de 500 francs à 3000 francs et d'un emprisonnement de un mois à un an, ou de l'une de ces deux peines seulement.

\section{Article 27}

Si un discours prononcé ou un écrit affiché, ou distribué publiquement dans les lieux où s'exerce le culte, contient une provocation directe à résister à l'exécution des lois ou aux actes légaux de l'autorité publique, ou s'il tend à soulever ou à armer une partie des citoyens contre les autres, le ministre du culte qui s'en sera rendu coupable sera puni d'un emprisonnement de trois mois à deux ans, sans préjudice des peines de la complicité, dans le cas où la provocation aurait été suivie d'une sédition, révolte ou guerre civile. 
Article 28

Dans le cas de poursuites intentées devant les tribunaux de simple police ou de simple police correctionnelle par application des articles 18 et 19, 26 et 27, l'association constituée pour l'exercice du culte dans l'immeuble où l'infraction a été commise et se directeurs et administrateurs seront civilement et solidairement responsables.

Si l'immeuble a été loué à l'association par l’État ou les communes en vert de la présente loi, la résiliation du bail pourra être demandée.

Titre VI

Dispositions générales

Article 29

L'article 463 du Code pénal et la loi du 26 mars 1891 sont applicables à tous les cas dans lesquels la présente loi édicte des pénalités.

Article 30

Les congrégations religieuses demeurent soumises aux lois des 1er juillet 1901, 4 décembre 1902 et 7 juillet 1904.

\section{Article 31}

Un règlement d'administration publique rendu dans les trois mois qui suivront la promulgation de la présente loi déterminera les mesures propres à assurer son application.

\section{Article 32}

Sont et demeurent abrogées toutes les dispositions relatives à l'organisation publique des cultes antérieurement reconnus par l'État, ainsi que toutes dispositions contraires à la présente loi et notamment :

$1^{\circ}$ La loi du 18 germinal an $\mathrm{X}$; portant que la convention passée le 26 messidor an IX entre le pape et le Gouvernement français, en- 
semble les articles organiques de ladite convention et des cultes protestants, seront exécutés comme des lois de la République ;

$2^{\circ}$ Le décret du 26 mars 1852 et la loi du 1er août 1879 sur les cultes protestants ;

$3^{\circ}$ Les décrets du 18 mars 1808, la loi du 8 février 1831 et l'ordonnance du 25 mars 1844 sur le culte israélite ;

$4^{\circ}$ Les décrets des 22 septembre 1812 et 19 mars 1859 ;

5 Les articles 201 à 208, 260 à 264, 294 du code pénal

$6^{\circ}$ Les articles 100 et 101, les paragraphes 11 et 17 de l'article 137 et l'article 166 de la loi du 5 avril 1884 ;

Il pouvait être procédé d'autant plus vite et plus facilement à l'examen de ce projet que la plupart des dispositions essentielles reproduisaient celles qu'avaient elle-même adoptées la commission antérieurement au dépôt du projet Combes. Quelques différences existaient bien entre les deux textes, notamment pour les pensions, pour la disposition des archevêchés, évêchés, presbytères, séminaires ; mais ces différences d'ordre secondaires n'apparaissaient pas irréductibles. En effet, dès sa première entrevue avec la commission, l'honorable $\mathrm{M}$. Bienvenu Martin, ministre de l'instruction publique et des cultes, avait fait connaître que le désir du Gouvernement était de collaborer étroitement avec elle à la rédaction d'un texte commun. Dans ces conditions, l'entente devenait facile. Elle fut réalisée dans la séance du 4 mars dernier, au cours de laquelle fut adopté le projet de loi ci dessous, que nous avons l'honneur de vous présenter au nom de la commission. Toutefois, nous devons vous faire remarquer qu'au moment du vote les membres de la minorité et plusieurs membres de la majorité réservèrent expressément leur droit de soutenir devant la Chambre par le moyen d'amendements ou de contre-projets, leur opinion personnelle sur la question. ( $D$ ' ailleurs, bien que le rapport fut déposé le 4 mars, la commission a émis, jusqu'au 14 juin, des modifications dans la rédaction de certains articles... qui furent votés tels quels, ou avec peu de changements) 
Début

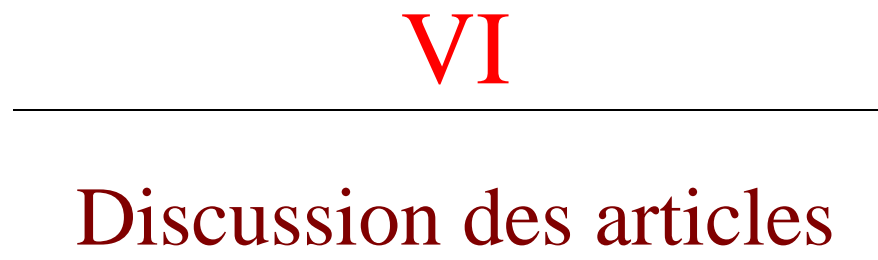

Titre Ier PRINCIPES

\begin{abstract}
Article 1er
$\underline{\text { Retour à la table des matières }}$

"La République assure la liberté de conscience. Elle garantit le libre exercice des cultes sous les seules restrictions édictées ci-après dans l'intérêt de l'ordre public."
\end{abstract}

Au moment où il pénètre dans le domaine sacré de la conscience, où il pose et résout un problème aussi complexe que celui de l'organisation des cultes et se prépare à régler les manifestations collectives de sentiments aussi intimes que les croyances religieuses, le législateur a pour premier devoir d'indiquer les principes qui l'ont inspiré et qu'il a voulu appliquer.

Le régime nouveau des cultes, qui vous est proposé, touche à des intérêts si délicats et si divers, il opère de si grands changements dans des coutumes séculaires, qu'il est sage, avant tout, de rassurer la susceptibilité éveillée des "fidèles", en proclament solennellement que, non seulement la République ne saurait opprimer les consciences ou gêner dans ses formes multiples l'expression extérieure des sentiments religieux, mais encore qu'elle entend respecter et faire respecter la liberté de conscience et la liberté des cultes. 
Ainsi la Révolution et la première République précédaient noblement, sur le seuil de chaque grave réforme, par l'affirmation de principes généraux.

Mais il n’y a pas seulement ici un retour à une tradition républicaine. Si minutieusement rédigée soit une loi aussi considérable, dont tous les effets doivent être prévus par des dispositions de droit civil, de droit pénal et de droit administratif, elle contient inévitablement des lacunes et soulève des difficultés nombreuses d'interprétation. Le juge saura, grâce à l'article placé en vedette de la réforme, dans quel esprit tous les autres ont été conçus et adoptés. Toutes les fois que l'intérêt de l'ordre public ne pourra être légitimement invoqué, dans le silence des textes ou le doute sur leur exacte application, c'est la solution libérale qui sera la plus conforme à la pensée du législateur.

Le libre exercice des cultes tel qu'il est prévu et garanti par le projet réalise un progrès notable dans la voie du libéralisme.

L'article 1er du Concordat porte que "la religion catholique et romaine sera librement exercée en France”, et que "son culte sera public en se conformant aux règlements de police que le gouvernement jugera nécessaires pour la tranquillité publique”.

La liberté ainsi octroyée au culte catholique, étendue à certains cultes protestants et au culte israélite, comportait des restrictions considérables que le projet de loi supprime en proclamant la liberté d'association religieuse (Titre IV, art. 16 et suivant), liberté de réunion (Titre V, art. 23 et suivants) et la liberté des lieux de culte (Titre VI, art. 37, portant abrogation des décrets des 22 décembre 1812, 19 mars 1859 et de l'article 294 du code pénal).

Il n'y a plus d'autres limites au libre exercice des cultes que celles qui sont expressément édictées dans l'intérêt de l'ordre public par le projet de loi lui-même.

\section{Article 2}

La République ne reconnaît, ne salarie ni ne subventionne aucun culte. En conséquence, à partir du 1er janvier qui suivra la promulga- 
tion de la présente loi, seront supprimées des budgets de l’État, des départements et des communes, toutes dépenses relatives à l'exercice des cultes.

Les établissements publics du culte sont supprimés, sous réserve des dispositions énoncées à l'article 3.

Cet article, dont le projet de loi dépend et découle, réalise la séparation absolue des Églises et de l'État. Et encore cette formule est-elle insuffisante, car l'État, au sens stricte du mot, n'est pas seul en cause. Il s’agit bien de la séparation des Églises et de la République ellemême ainsi que le dit le texte rédigé par votre commission. Le principe établi est poussé jusqu’à ses extrêmes conséquences; il s'applique à tous les services publics de l'État, des départements ou des communes.

Ce n'est pas le lieu ici de discuter la théorie de l’acte de séparation lui-même et de le légitimer.

L'article 2 l'accomplit radicalement et pose un double principe :

Désormais aucun culte ne sera plus reconnu - c'est la neutralité et la laïcité absolue de l'État - et, conséquence immédiate et nécessaire, aucun culte ne sera plus officiellement salarié.

Il faut examiner successivement chacun de ces principes.

La République ne reconnaissant plus aucun culte, l'organisation officielle de l'Église catholique, de l'Église réformée de France, de l'Église de la confession d'Augsbourg et des communautés israélites, telle qu'elle est établie par les lois, décrets et ordonnances en vigueur, est abolie.

Cela résulte d'ailleurs également de l'article 37, aux termes duquel "sont et demeurent abrogées toutes les dispositions relatives à l'organisation publique des cultes antérieurement reconnus par l'État, ainsi que toutes les dispositions contraires à la présente loi”. 
Les immeubles officiellement affectés aux cultes ou au logement des ministres du culte sont désaffectés et ne restent à leur disposition aux termes des articles 10 et suivant que dans un intérêt privé.

La loi ne reconnaître les cultes et les cérémonies cultuelles qu'en tant qu'elles n'intéresseront pas l'ordre public. Mais, par a contrario, toutes les dispositions civiles ou pénales ayant un caractère d'ordre public, restent en vigueur. Ainsi, pour ne citer que cet exemple, celles qui ont pour objet d'assurer la célébration du mariage civil avant le sacrement religieux.

Par une conséquence nécessaire, les ministres des cultes seront, pour tout ce qui concerne leur ministère ou en dérive, légalement ignorés. Toute la législation d'exception qui leur est actuellement applicable est abrogée implicitement, sous la réserve, toujours, de l'intérêt de l'ordre public. Les incompatibilités et privilèges dont ils sont l'objet disparaissent. Ils pourront être jurés, deviendront éligibles aux conseils municipaux et généraux, au sénat. Ils ne seront plus dispensés des fonctions de tuteur; l'article 259 du code pénal ne sera plus applicable au port du costume ecclésiastique.

Il est presque inutile d'ajouter que tous les règlements sur les honneurs de présence et visite des corps cesseront de viser les ministres de cultes ; ceux-ci n'auront plus rang officiel.

Toutes les exceptions de procédure (attributions aux cours d'appel de la connaissance de la connaissance des délits commis par les archevêques, évêques et président de consistoires), comme en matière d’impôt, de réquisition militaire, etc., deviendront lettre morte.

Le principe posé par cet article est si extensif qu'il est impossible d’en prévoir à l'avance toutes les applications pratiques.

Cependant, l'article 906 du code civil, qui édicte pour les ministres du culte l'incapacité de recevoir dons et legs des malades auxquels ils ont apporté, dans la dernière maladie, les secours de leur ministère reste indubitablement en vigueur. Cette disposition s'inspire de raisons pratiques qui subsistent et s'applique d'ailleurs aujourd'hui 
même aux ministres des cultes non reconnus, ainsi qu'aux médecins et aux pharmaciens dont la profession n'a pas un caractère officiel.

Tous les établissements ecclésiastiques chargés de la gestion des intérêts des cultes actuellement reconnus sont supprimés. Cette disposition se combine cependant avec celle de l'article 3, qui prévoit pour eux un prolongement d'existence légale pour assurer la liquidation de leurs biens. Nonobstant cette surveillance temporaire ces établissements doivent disparaître purement et simplement. Il ne sauraient être maintenus même à titre officieux : seules les associations prévues par le titre IV peuvent à l'avenir gérer les intérêts des cultes, quelle qu'en soit la nature.

La république ne salariant, ne subventionnant plus aucun culte, toutes dépenses inscrites à un titre quelconque au budget de l'État, des départements ou des communes doivent être supprimées. Les pensions accordées par mesure transitoire, ne font pas échec à ces stipulations, elles n’ont qu'un caractère absolument précaire.

Il ne faut pas considérer comme une exception à ce principe la disposition finale de l'article 17 qui prévoit certaines subventions que l'État, les départements ou les communes jugeraient utile d'employer aux grosses réparations des édifices religieux leur appartenant. Ces subventions ne sont pas ne sont pas accordées dans l'intérêt des associations cultuelles, mais dans celui des propriétaires, pour la conservation des biens dont ils recouvreront la libre disposition.

Le Parlement a le droit et le devoir d'interdire ainsi aux départements et aux communes l'inscription de certaines dépenses à leur budget.

Il importe de ne pas se laisser se perpétuer dans certaines régions les rapports entre officiels entre l'Église, les communes et les départements. La séparation doit être simultanément un fait accompli sur tout le territoire français. Les services départementaux et communaux ne jouissent nullement, en pareille matière, d'une autonomie absolue. Certaines dépenses sont obligatoirement inscrites à leur budget, d'autres leur sont actuellement interdites. 
Mais tout ce que nous avons dit ne s'applique pas qu'aux budgets ordinaires. Il faut aller plus loin et admettre qu'aucune dépense relative à l'exercice du culte ne pourra être comprise dans les budgets spéciaux rattachés pour ordre ou non aux budgets généraux de l’État, des départements ou des communes. Ainsi, les aumôneries des asiles publics, des lycées, collèges, etc., ne peuvent faire l'objet de crédits permanents et réguliers dans les budgets précités. Lorsqu'un de ces établissements fera appel, dans l'intérêt privé d'un pensionnaire ou d'un membre du personnel, aux offices d'un ministre du culte, celui-ci pourra être légitimement rémunéré, mais comme le serait un fournisseur ordinaire, par exemple un médecin occasionnel.

Tous les crédits budgétaire doivent être supprimés à partir du 1er janvier qui suivra la promulgation de la loi. Jusqu'au 1er janvier, ils seront régulièrement maintenus, et les sommes qu'ils indiquent devront être intégralement payés. Après cette date, ils disparaîtront, et les établissements publics des cultes dont la survivance est prévue par l'article 3 ne pourront pas en réclamer à leur profit le maintien pendant la dernière période de leur fonctionnement.

Cette date du 1er janvier était la seule normale, l'exercice annuel étant clos au 31 décembre.

Telle est rapidement analysée l’économie et la portée de l'article 2.

Mais une question se pose ici pour le législateur soucieux de l'équité. Ne lèse-t-il pas des droits acquis?

En ce qui concerne les ministres des cultes protestants et israélites, il n'est pas douteux que les traitements et allocations qu'ils reçoivent n’ont d'autre raison d'être que la volonté du législateur. Consentis d'année en année, ils peuvent être supprimés à la fin de l'exercice.

Pour le clergé catholique on a prétendu et soutenu que le traitement qui est alloué à ses membres n'est que l'acquittement annuel des arrérages d'une dette perpétuelle. Certains n’ont même pas hésiter à déclarer que refuser de payer cette dette serait, à cet égard, pour l'État faire banqueroute de ses engagements. 
Nous ne pouvons ici discuter cette théorie dans tous ses détails (On consultera avec fruit sur ce point comme sur beaucoup d'autre l'intéressant et suggestif ouvrage de M. Grunebaum-Ballin, la Séparation des Églises et de l'État, Paris 1905). Il est cependant impossible de la passer absolument sous silence. Il n'est pas douteux qu'en droit public les gouvernements successifs assument chacun les charges dont leurs prédécesseurs ont grevé les finances publiques. Il faut donc rechercher si l'article 2 peut se légitimer en droit et en équité.

On a vu dans la partie historique du rapport que le 2 novembre 1789 (la veille de la déclaration des droits de l’homme), l'Assemblée constituante avait voté une motion proposée par Mirabeau et ainsi conçue :

"Les biens ecclésiastiques sont à la disposition de la nation à la charge de pourvoir d'une manière convenable aux frais du culte, à l'entretien de ses ministres et au soulagement des pauvres."

Il est difficile de saisir exactement ce qu'entendait le grand orateur, en proposant un texte rédigé en termes aussi peu juridiques.

Il faut constater tout d'abord qu'il n'y a pas eu de contrat. C'est une simple déclaration par laquelle l’Assemblée décide de remettre entre les mains de la nation les biens ecclésiastiques, et ajoute libéralement qu'elle prend à sa charge les frais du culte, l'entretien des ministres et le soulagement des pauvres.

Il résulte des documents de l'époque et des travaux préparatoires, que l'assemblée constituante ne pensait ni ne voulait dépouiller l'Église d biens qu'elle possédait ; elle entendait restituer à la nation propriétaire l'administration et l'usufruit des biens ecclésiastiques dont l’Église jouissait.

Comme le dit la motion même les biens ecclésiastiques (appartenant à l'État et mis à la disposition de l'Église catholique) sont simplement remis à la disposition de la nation. D'accord avec ses principes et dans l'intérêt de la paix publique la constituante prenait aussi les résolutions de pourvoir aux frais du culte, à l'entretien des ministres et au soulagement des pauvres. 
Elle estimait, en effet, que l'exercice de la religion et de la charité constituaient des nécessités sociales qui devaient faire l'objet de services publics. Reprenant à ceux qui étaient chargés de ce service les biens qui leur permettaient de vivre, elle inscrivait au budget général les crédits pour rémunérer leurs fonctions jugées indispensables.

Il y avait en outre une préoccupation de sage politique, afin que le culte fût exercé partout sans aucune suspension possible et afin que les œuvres charitables entreprises par l'Église à l'aide de ces ressources fussent continuées. Il y avait aussi une pensée bienfaisante en faveur des membres du clergé qui avaient cru pouvoir compter toujours pour eux-mêmes sur les bienfaits mis à leur disposition.

Mais il ne pouvait y avoir, dans l'allocation prévue, aucun caractère d'indemnité.

L’indemnité ne se conçoit et ne peut se concevoir lorsqu'il y a faute ou quasi-délit. L'allocation eût été l'aveu d'une spoliation. Rien, ni dans la discussion qui a précédé la motion, ni dans l'analyse de la motion elle-même, ne permet de prétendre que la Constituante a cru léser quelque droit acquis en remettant entre les mains de la nation ce qui n’avait cessé de lui appartenir. Elle n’a voulu et n'a fait qu'exercer un droit certain et imprescriptible.

Il est vrai que la théorie de la charge perpétuelle est d'origine récente et n'avais cours ni sous la Révolution ni au début du dernier siècle, qu'en 1816 la Chambre introuvable elle-même repoussait la proposition d'une création de dotation permanente en faveur du clergé.

La résolution de la Constituante pour les cultes et leurs ministres était un acte gracieux de l'autorité législative, et à ce titre essentiellement précaire.

Il est probable qu'à l'origine le budget des cultes avait pour les Églises un caractère transitoire, et pour leurs ministres un caractère viager. On voulait en reprenant les biens ecclésiastiques donner viagèrement au clergé en exercice, un traitement suffisant. 
Aussi, la Constitution de 1791 porte-t-elle cette disposition : "Sous aucun prétexte les fonds nécessaire à l'acquittement de la dette nationale ne pourront être refusés ou suspendus. Le traitement des ministres du culte catholique pensionnés, conservés, élus ou nommés en vertu de décret de l'Assemblée constituante fait partie de la dette nationale.” ce texte aussi précis prouve, à l'évidence, qu'il ne s’agissait que des ministres régulièrement admis à ce moment par la Constituante. La loi stipulait pour le passé et non pour ceux qui seraient nommés à l'avenir.

C'était une disposition semblable à celle du projet actuel pour les pensions allouées aux ministre des cultes en fonctions.

Ces traitements et pensions auraient pris fin, mais l'article $14 \mathrm{du}$ Concordat créa un régime nouveau. Il porte : "Le Gouvernement assurera un traitement convenable aux évêques et curés”. Il n'est pas douteux que si le budget des cultes avait le caractère d'une charge perpétuelle assumée en raison de la reprise des biens ecclésiastiques, le Concordat eût pris soin de le rappeler et de confirmer un droit aussi important.

Il décide, au contraire, comme s'agissant d'un droit nouveau et purement contractuel, il ne dit rien du passé et ne stipule que pour l'avenir. Le silence du Concordat sur la dette de l'État vis-à-vis de l'Église catholique est décisif. Le sort de l'article 14 est lié à celui du pacte lui-même ; il tombe avec lui.

Et d'ailleurs pourquoi discuter en théorie? En admettant même cette erreur certaine que le budget des cultes a eu le caractère d'indemnité, il y a aurait lieu d'apprécier si le total de ces indemnités payées à ce jour n’a pas suffi à compenser le préjudice subi.

Remarquons tout d'abord que si indemnité il y a, elle doit être payée tout à la fois aux Églises, aux ministres des cultes et aux pauvres. Elle continue à être payée aux pauvres qui sont les créanciers indivis et solidaires du clergé. Il y a même lieu de croire que la République lui a donné à cet égard des proportions que les contractants de la dette n’avaient pas prévues. 
Mais pour l'Église elle-même, le budget des cultes, de 4 millions en 1803, a atteint sous le second empire le chiffre de 50 millions. Il est aujourd'hui de plus de 40 millions.

Que l'on calcule ce qui a été payé par la nation à l’Église catholique depuis la Constituante ; qu'on y ajoute la libre et pratique disposition de tous les édifices religieux appartenant à l'État ou aux communes, les traitements alloués aux innombrables membres du clergé non concordataires, les indemnités de logement et toutes les allocations inscrites au budget des communes et l'on ne sera pas éloigné de conclure que, loin d'être spoliée, l'Église se trouverait, dans un pareil règlement de compte, débitrice de la République. Celle-ci lui a assuré depuis assez longtemps une assez riche dotation pour pouvoir supprimer le budget des cultes en toute sérénité.

Titre II Dévolution des biens, pensions

\section{Article 3}

Les établissements dont la suppression est ordonnée par l'article 2 continueront provisoirement de fonctionner, conformément aux dispositions qui les régissent actuellement, jusqu’à la dévolution de leurs biens aux associations prévues par le titre IV et au plus tard jusqu'à l'expiration du délai ci-après.

Les établissements ecclésiastiques dont ma suppression est prononcée par l'article 2 sont provisoirement maintenus en exercice pour procéder à l'attribution de leurs biens dans les conditions déterminées par l'article 4.

Aussi longtemps que durera ce fonctionnement temporaire, ils demeureront régis par les lois et règlements actuels. Le maintien provisoire des établissements ecclésiastiques ne peut durer plus d'une année.

Trois cas peuvent se présenter dans la pratique.

$1^{\circ}$ Les établissements publics du culte, par l'organe de leurs représentants légaux, opèrent la dévolution de leurs biens aux associations 
cultuelles, sans que se produise aucune contestation. Ils cessent immédiatement d'exister ;

$2^{\circ}$ Les établissements publics du culte opèrent cette dévolution, mais des contestations et réclamations sont soulevées ; le tribunal civil est saisi et ces établissements sont supprimés avant même que le délai d’un an soit expiré ;

$3^{\circ}$ Les établissements publics du culte restent dans l'inaction absolue. A l'expiration du délai d'un an à partir de la promulgation de la loi le tribunal est saisi, il place les biens sous séquestre et les établissements n’ont plus d'existence légale.

En toute hypothèse donc, l'organisation actuelle des cultes ne peut subsister après ce délai d'un an ; elle se désagrégera peu à peu en fait, à chacune dévolution des biens ecclésiastiques.

\section{Article 4}

Dans le délai d'un an, à partir de la promulgation de la présente loi, les biens mobiliers et immobiliers des menses, fabriques, conseils presbytéraux, consistoires et autres établissements publics du culte seront, avec toutes les charges et obligations qui les grèvent et avec leur affectation spéciale, attribués par les représentants légaux de ces établissements aux associations qui se seront légalement formées pour l'exercice du culte dans les anciennes circonscriptions desdits établissements.

Toutefois, ceux des biens désignés à l'article précédent qui proviennent de l'État et qui ne sont pas grevés d'une fondation pieuse feront retour à l’État.

A défaut d'une association apte à recueillir les biens d'un établissement ecclésiastique, ceux de ces biens qui ne sont pas grevés d'une fondation pieuse, pourront être réclamés par la commune où l'établissement à son siège, à charge pour elle de les affecter à des œuvres d'assistance ou de prévoyance. 
Les attributions de biens ne pourront être faites par les établissements ecclésiastiques qu'un mois après la promulgation du règlement d'administration publique prévu à l'article 36. Faute de quoi la nullité pourra en être demandée devant le tribunal civil par toute partie intéressée ou par le ministère public.

\section{Article 5}

Les biens mobiliers ou immobiliers grevés d'une affectation charitable ou d'une toute autre affectation étrangère à l'exercice du culte seront attribués, par les représentants légaux des établissements ecclésiastiques, aux services ou établissements publics ou d'utilité publique, dont la destination est conforme à celle desdits biens. Cette attribution devra être approuvée par le préfet du département où siège l'établissement ecclésiastique. En cas de non-approbation, il sera statué par décret en Conseil d’État.

Toute action en reprise ou en revendication devra être exercé dans un délai de six mois à partir du jour de la dévolution prévue au paragraphe précédent.Elle ne pourra être intentée qu'en raison de donation ou de legs et seulement par les auteurs et leurs héritiers en ligne directe.

\section{Article 6}

Faute par un établissement ecclésiastique d'avoir, dans le délai fixé par le premier paragraphe, procédé aux attributions ci-dessus prescrites, il y sera pourvu par le tribunal civil du siège de l'établissement..

A l'expiration dudit délai et à la requête des intéressés ou du ministère public, les biens à attribuer seront, jusqu'à leur dévolution, placés provisoirement sous séquestre par décision du président de ce tribunal.

Dans le cas où les biens d'un établissement seront, soit dès l'origine, soit dans la suite, réclamés par plusieurs associations légalement formées pour l'exercice du même culte, l'attribution que l'établissement en aura été faite pourra être contestée devant le tribunal civil qui statuera comme dans le cas du premier paragraphe du présent article. 
Pour la commodité du texte, il a fallu répartir en plusieurs articles les dispositions insérées dans las articles 4, 5 et 6, mais pour la clarté du commentaire et de l'analyse, il y a tout intérêt à les grouper dans une commune explication.

Il s’agit ici de la dévolution des biens appartenant aux établissements publics des cultes.

Ces établissements disparaissant, à qui devaient être attribués leurs meubles et immeubles?

On aurait pu, à la suppression de leurs propriétaires actuels, considérer les biens ecclésiastiques comme des biens vacants. D’après le droit commun, l'État les aurait recueillis et en aurait disposé suivant des règles à déterminer.

Votre commission n’a pas cru que ce principe et cette méthode fussent équitables.

Une partie des biens qui sont en possession des établissements public du culte ont été constitués par les fidèles pour le culte ; la commission a estimé qu'en droit naturel, leur propriétaire était la collectivité des fidèles. Cette collectivité est personnalisée aujourd'hui par les Églises; elle le sera demain par les associations cultuelles ; elle ne disparaît pas à la suppression des établissements ecclésiastiques.

Il n’y a pas, dans la réalité des faits équitablement appréciés, disparition pure et simple de personnes morales sans héritiers légitimes. il n’y a qu'une transformation, imposée par le législateur lui-même, dans la forme juridique de ces personnes morales.

Tel est le principe posé et respecté par votre commission.

Tous les biens constitués par les fidèles pour le culte doivent rester à la disposition des fidèles.

Les autres suivent une destination normale que nous indiquerons dans la suite. 
Il fallait ici envisager et résoudre trois questions principales :

$1^{\circ}$ Qui doit opérer la dévolution des biens actuellement possédés par les établissements du culte?

$2^{\circ}$ Dans quel délais?

$3^{\circ}$ Comment et à qui cette dévolution doit-elle être faite ?

I - Qui doit opérer la dévolution des biens actuellement possédés par les établissements du culte?

Votre commission, avons-nous dit, a estimé que les établissements publics du culte détenaient actuellement ces biens en quelque sorte au nom et pour le compte des fidèles.

Représentants légaux de ces fidèles, ils ont pari tout naturellement désignés pour transmettre les biens aux associations appelées à leur succéder. Cette solution offrant, en pratique, les avantages les plus appréciables. Si l'État avait fait, par l'organe de ses préfets ou autres, la dévolution nécessaire, ou aurait pu prétendre que certaines attributions, cependant consciencieusement faites, avaient été inspirées par une arrière-pensée politique.

Comme, vraisemblablement, dans de nombreux cas les mêmes personnes qui administrent l'établissement public du culte composeront l'association nouvelle, c'était simplifier considérablement la procédure que de laisser aux intéresser eux-même le soin d'effectuer légalement la transmission.

Il était aussi plus logique, à l'heure où l'on proclamait la séparation de l'Église et de l'État, de ne pas laisser à l'État la responsabilité de liquider la fortune de l’Église.

Ce seront donc les membres de l'administration de l'établissement public du culte qui feront librement la dévolution, et cela dans tous les cas. Ils joueront en quelque sorte le rôle de liquidateur à l'heure de la distribution des deniers aux créanciers vérifiés. 
Les biens grevés d'une affectation charitable ou étrangère à l'exercice du culte seront attribués aux services publics ou d'utilité publique. Ici, cependant, l'attribution ne sera pas libre absolument. Il s'agit, en effet, de biens appartenant, en droit naturel, non à la collectivité religieuse, mais aux pauvres, ou, pour les biens scolaires, aux écoliers. Il était juridique, et il était prudent de soumettre à l'approbation du préfet, tuteur légal des établissements publics ou d'utilité publique, appelé à recevoir ces nouvelles ressources, l'affectation qui en était faite.

A défaut d'une telle disposition, l'établissement public du culte aurait pu détourner tout ou partie de ces biens de leur destination normale.

Mais pour qu'en sens contraire, le préfet n’exerce pas abusivement les pouvoirs qui lui sont ainsi conférés, l'article 5 stipule qu'en cas de non approbation il sera statué en conseil d’État.

Quant aux biens qui ont une destination strictement religieuse, l'établissement public du culte les transmet toujours, et librement, à l'association cultuelle de son choix. Si une contestation s'élève au sujet de la dévolution ainsi faite, le tribunal civil décide, saisi par le ministère publique ou tout intéressé.

Le tribunal civil n'est pas dans ce cas seulement arbitre, il est juge au sens complet du mot. C'est-à-dire qu'il statue suivant la procédure du droit commun. C'est une nouvelle compétence qui lui est attribué par le projet de loi. Les parties intéressées pourront faire appel du jugement d'après les règles du code de procédure et se pourvoir en cassation. Mais ici, une observation est nécessaire.

Le tribunal civil s'inspirera pour sa décision de trois motifs principaux. Deux de droit: Les associations sont-elles légalement formées dans les termes de la loi de 1901 et de la loi de séparation de l’Église et de l'État? La dévolution des biens a-t-elle été faite régulièrement et dans les délais prescrits? 
L'autre de fait : Ces associations sont-elles sérieuses ? Quelle est celle, ou quelles sont celles qui continuent à représenter les fidèles et peuvent légitimement revendiquer au nom de leur collectivité ? IL n'est pas douteux que, pour ce troisième point, le nombre des membres qui composent l'association et leur personnalité elle-même fourniront des présomptions précieuses.

Devant la cour de cassation la preuve du fait n'étant point admise, les pourvois ne pourront se former que pour composition illégale des associations auxquelles les tribunaux civils auraient donné gain de cause pour défaut de motif ou pour violation des règles essentielles à la validité des décisions judiciaires.

C'est dans ces conditions que les tribunaux sont appelés à statuer sur la dévolution des biens lorsque celle-ci est sujette à contestation.

Il est facile de légitimer l'attribution de compétence qui leur est faite.

La loi pouvait désigner, pour trancher la difficulté, soit par acte gouvernemental, le préfet, soit par décision contentieuse, le conseil d’État ou le conseil de préfecture.

Il y avait en théorie et en pratique les plus grands inconvénients à laisser les juridictions administratives décider en matière aussi délicate. En principe, la séparation étant accomplie, il faut rompre le plus tôt possible et le plus radicalement possible tous les rapports entre l'État et les Églises. ; en pratique on aurait toujours suspecté l'équité gouvernementale dans ces dévolutions et la moindre erreur aurait servi de prétexte pour une agitation antirépublicaine.

Le conseil d'État, éloigné de chaque paroisse et n'ayant d'autre moyens d'information que les rapports officiels et l'expertise, aurait difficilement réglé la tâche qui lui eût été assignée.

Les conseils de préfecture, composés de membres amovibles, eussent été l’objet d’inévitables suspicions. 
Le tribunal civil avait, dans cette circonstance, le triple avantage : d'être situé sur les lieux mêmes du litige, d’être composé de juges inamovibles et de rendre des décisions, après débats contradictoires, emportant force de chose jugée. D’ailleurs, il s'agira en définitive de question de propriété et les tribunaux judiciaires sont juges de droit commun en ces matières.

\section{II - Délais dans lequel la dévolution doit s’opérer.}

Il fallait ici éviter un double inconvénient. Le plus grave était la possibilité pour les établissements publics du culte de perpétuer leur existence en ne procédant pas à la mission qui leur est confiée. Le projet, pour éviter pareil attitude, fixe à un an, le délai dans lequel la dévolution doit être faite. Si, à l'expiration de l'année, l'établissement public n'a pas rempli sa tâche, il cesse, par le fait même de la loi, d'exister, et, le tribunal civil est saisi par le ministère public ou tout intéressé. $\quad$ Mais ce délai d'un an est un délai maximum. L'article 4 a voulu ainsi poser un terme avant lequel normalement la transmission des biens devra être effectuée.

L'autre inconvénient pouvait résulter de l'envoi en possession précipité, octroyé par l'établissement public du culte à une association hâtive.

Parmi les fidèles, quelques personnes avisées pourraient préparer avant le vote de la loi, et fonder immédiatement après, une petite association, réduite au minimum de membres et rigoureusement fermée à toute adhésion. De connivence avec les administrateurs de l'établissement public du culte, ils recevraient, sans délais, les biens ecclésiastiques et toute autre association, moins diligente et cependant plus nombreuse, plus sérieuse, représentant plus véritablement dans la paroisse la masse des coreligionnaires, se trouverait par ce moyen dépouillée de ressources sur lesquelles elle avait pu légitimement compter.

Pour permettre à toutes les associations éventuelles le moyen et leur donner le temps de se constituer, votre commission a, dans le texte élaboré (art. 6), prescrit, à peine de nullité absolue, que les attributions de biens ne pourront être faite par les établissement qu'un 
mois après la promulgation du règlement d'administration publique prévu à l'article 36.

Ce règlement doit être rendu dans les trois mois. Le délai maximum de l'article 6 sera donc de quatre mois. Le règlement d'administration publique exigera sans doute une étude assez prolongée pour que le danger d’une dévolution hâtive soit écarté.

\section{III - Comment et à qui cette dévolution doit-elle être faite ?}

Le règlement d'administration publique à intervenir déterminera la forme juridique dans laquelle les biens seront transmis, les formalités qui devront qui devront être observées, en particulier pour l' inventaire qu'il faudrait dresser. L'établissement public du culte procédera à ces formalités et cessera immédiatement après d'exister ; l'association ou les associations cultuelles qui recueilleront les biens pourvoieront, sans interruption, à l'exercice du culte. L'établissement public du culte désignera, ainsi qu'il a été dit plus haut, même en cas de compétition entre plusieurs associations cultuelles, celle qui recueillera les biens. Si des procès s'ensuivent, l'association à laquelle aura été faite la dévolution restera en possession et jouissance jusqu'au règlement du litige. C'est seulement dans le cas où la dévolution n'aurait pas été faite dans le délai prescrit que les biens seront, conformément au paragraphe 2 de l'article 6 , placé sous séquestre par décision du président du tribunal.

Pour déterminer à qui les biens seront dévolus dans ces conditions, il faut distinguer suivant leur nature et leur convenance.

Le projet de loi (art. 4 et 5) distingue entre les biens servant directement ou indirectement à l'exercice du culte, les biens grevés d'une fondation pieuse et les biens grevés d'une affectation charitable ou de toute autre affectation étrangère à l'exercice du culte.

Le patrimoine entier des établissements publics du culte, à l'exception des biens provenant de l'État, ou grevés d'une affectation étrangère à l'exercice du culte, est transmis par l'établissement public à une ou à des associations cultuelles de son choix. Nous avons dit de quel principe la commission s'est inspirée pour établir une semblable 
règle. Il lui a paru que, d'une part, le possesseur naturel de ce patrimoine, les communautés religieuses, ne disparaissait pas à la suppression de l'établissement public du culte et que dès lors la théorie des biens vacants et sans maître avait contre elle, ici, le droit et l'équité ; elle a pensé aussi que le besoin social pour la satisfaction duquel ce patrimoine a été constitué existait indéniablement encore, avec des exigences impérieuses et qu'une sage politique devait la respecter et lui laisser toute liberté et toute satisfaction légitime.

Ce patrimoine constitué depuis le Concordat est considérable (en 1902 la statistique officielle appréciait à 50290 hectares l'étendue des immeubles appartenant aux établissements publics du culte.) Pour la partie mobilière les documents ne sont pas précis, mais elle est certainement de plus de 100 millions.

L’Église, dans le nouveau régime des cultes, ne sera pas dès lors, du jour au lendemain sans ressources. Il y a lieu d'ailleurs, dans un esprit libéral, de s’en réjouir pour le maintien de la paix publique.

Ces biens dévolus aux associations cultuelles seront transmis avec toutes les charges et obligations qui les grèvent actuellement. Les fondations pieuses devront continuer à être respectées dans toutes les conditions suivantes lorsqu'elles ont été consenties. Le passif des établissements publics du culte sera supporté par les associations nouvelles dans la même mesure que l'actif.

Rien ne sera donc changé ni dans la destination des biens ecclésiastiques ni dans leurs modalités juridiques; le principe est simple et facilement applicable.

Toutefois, les biens qui proviendront de l'État et qui ne seront pas grevés d'une fondation pieuse retourneront à l'État. Ce sont tous les biens, sans distinction, pour lesquels il est ainsi disposé. Pour les meubles "meublant", l'article 2279 du code civil sera naturellement observé ; pour les autres dotations mobilières ou immobilières (tout particulièrement les biens nationaux concédés aux fabriques et menses curiales sous le premier empire), elle reviennent à l’État. 
On comprend à merveille les raisons qui ont motivé cette disposition. Si l'on met à part les fondations pieuses, ces biens ont été non pas aliénés, mais concédés par l'État pour un service public. Ce service public disparaissant, l'État n'a plus les mêmes obligations ; il a le droit de considérer ses concessions comme sans objet ; il reprend ses dotations, pour leur donner une autre destination publique. On conçoit qu'au lendemain de la séparation, chacun des contractants reprenne son apport.

Aux bien grevés d'une affectation charitable ou étrangère à l'exercice du culte (scolaire par exemple), il n'était pas conforme au droit public de les transmettre aux associations cultuelles.

Le communautés religieuse les avaient recueillis en violation du principe de la spécialité des établissements publics ou d'utilité publique. Les avis du conseil d'État en date des 13 avril, 13 juillet et 4 mai 1881 ont remis en vigueur ce principe, à l'application duquel échappaient jusque là, les établissements publics des cultes. Il exige que chaque personne morale se consacre et consacre toutes ses ressources au sel but pour lequel elle a été constituée. Les nouvelles associations cultuelles ne devront avoir pour objet que l'exercice du culte. Leur patrimoine devra être entièrement affecté à ce but. Elles n'avaient aucune qualité pour recevoir les biens constitués par les établissements publics du culte antérieurement à 1881.

Cependant, par une mesure toute d'équité, le projet de loi laisse aux représentants légaux des établissements publics des cultes le soin de transmettre eux même les biens charitables ou autres à des services, des établissements publics ou d’utilité publique.

Les préfets tuteurs de ces établissements devront approuver ces attributions ainsi que nous l'avons indiqué. Leur rôle se bornera à examiner si la présente loi a été observée et si le principe de la spécialité est respecté. Il convient de faire deux remarques sur le texte même adopté par votre commission. Elle a cru devoir admettre les établissement d'utilité publique à bénéficier des attributions faites en vertu de l'article 5. Les biens charitable ou autres ont été, en effet, confiés aux établissements ecclésiastiques par des donateurs ou légataires qui ont évidemment désiré, par une telle mesure, les affecter au profit de leur 
coreligionnaires. Les adeptes de chaque culte ayant fondé un assez grand nombre d'œuvres reconnues d'utilité publique, il sera possible dans presque tous les cas, de respecter la pensée et la volonté des donateurs des biens dévolus.

Il faut observer aussi que l'article 3 ne limite pas aux établissements publics ou d'utilité publique, situé dans la circonscription ou les circonscriptions voisines de celles des établissements des cultes, le bénéfice de ses dispositions. C’est une facilité de plus donnée aux établissements publics des cultes de conserver aux biens qu'ils ne peuvent transmettre aux associations cultuelles leur destination intégrale.

Tous ces biens seront recueillis aussi, grevés de toutes les charges et obligations dont ils étaient affectés antérieurement à leur transmission.

Tel est le mode de dévolution des biens composant aujourd'hui le patrimoine des établissements ecclésiastiques. Il sera effectué dans les conditions que nous venons de préciser.

Il restait cependant à prévoir deux cas. Fallait-il les actions en reprise ou revendication des biens donnés ou légués ? Votre commission a adopté la solution libérale ; elle a reconnu la légitimité de ces actions. La loi de 1901 sur les associations avait pris une disposition semblable à propos des biens possédés par les congrégations. Le projet pose cependant une condition et une restriction au droit de revendication : en ce qui concerne les bien grevés d'une affectation charitable ou de toute autre affectation étrangère à l'exercice du culte, l'action doit être exercée dans les six mois à dater du jour de leur dévolution. Il eût été fâcheux de laisser trop longtemps les établissements qui recevront ces biens sous la menace d'une dépossession éventuelle au profit des donateurs ou de leurs héritiers.

L'action en revendication ne peut être intentée que par les auteurs mêmes de la donation ou par leurs héritiers en ligne directe.

Pour les auteurs, c’était le droit commun ; pour leurs héritiers on a admis qu'ils continuaient en quelque sorte leurs personne. Mais les simples légataires ou héritiers en ligne collatérale n’ont pas le même caractère. C’eût été ouvertement violer la volonté expresse du dona- 
teur ou du testateur que d'attribuer à ces collatéraux des biens dont les auteurs les avaient délibérément privés pour leur donner une destination bienfaisante.

En dehors de ces conditions, le projet de loi ne soumet à aucune disposition spéciale la revendication éventuelle des dons et legs à la suite de la transmission des biens des établissements ecclésiastiques. Le droit commun s'appliquera, et il appartiendra aux tribunaux, suivant les circonstances de chaque espèce, de décider si, alors que les charges et conditions continuent à être exécutées et qu'il s'est produit seulement un changement dans la personne morale chargée d'y pourvoir, il y a cependant matière à révocation.

Nous savons déjà que si plusieurs associations cultuelles sérieuses se forment, elles pourront réclamer devant le tribunal civil tout ou partie des biens attribués par les établissements public du culte à l'une d'elles. Le tribunal appréciera, en fait, quelle est celle, ou quelles sont celles, qui représentent véritablement la collectivité des fidèles pratiquant le même culte.

Mais cette hypothèse ne pas être seulement prévue pour le lendemain de la promulgation de la loi. Il peut arriver aussi que, dans la suite, une scission se produise dans une association cultuelle et donne naissance à un conflit pour la possession et la jouissance de ces biens. La loi serait incomplète si elle ne prévoyait pas une aussi grave difficulté et n'indiquait pas un juge pour la trancher. ce sera encore le tribunal civil qui statuera en pareil cas sur des éléments d'appréciation que nous avons indiqués plus haut.

Une dernière difficulté devait être prévue et solutionnée. Il se peut que dans la description d'un établissement public, du culte aucune association cultuelle ne se forme. Il n'est pas absurde de concevoir qu'en certaines régions les habitants soient si complètement détachés des habitudes religieuses que les sept personnes majeures et domiciliées, suffisantes pour constituer une association, ne se rencontrent pas. Il est encore plus vraisemblable d'admettre que dans d'autres régions ou l'esprit clérical et combatif dominera, on pourrait chercher à faire échec à la loi en faisant en quelque sorte la grève des fidèles et en refusant de constituer les associations cultuelles prévues par le pro- 
jet. Il fallait bien, en pareil cas, déterminer le mode de dévolution des biens ecclésiastiques. A qui seraient-ils attribués ? Pour ne pas dépouiller de leur bénéfice les régions même où ils sont actuellement possédés, l'article 4 décide qu'à l'exception de ceux qui ne sont pas grevés d'une fondation pieuse, ils pourront être réclamés par la commune, à charge pour elle de les affecter à des œuvres d'assistance ou de prévoyance. Ainsi, à défaut d'un usage religieux pour le maintien duquel les anciens paroissiens de l'église n'auront manifesté aucune volonté expresse, le patrimoine qui servait aux besoins du culte pourra en quelque manière augmenter le bien-être des pauvres et des travailleurs. LIbres penseurs et croyants seront unanimes à approuver une telle disposition.

\section{Article 7}

En cas de dissolution d'une association, les biens qui lui auront été dévolus en exécution des articles 4 et 6 seront attribués par elle à une association analogue existant soit dans la même circonscription soit dans les circonscriptions les plus voisines.

Faute d'attribution régulière et dans le cas ou plusieurs associations formées légalement pour l'exercice d'un même culte revendiqueraient les biens, l'attribution sera faite, à la requête de la partie la plus diligente, par le tribunal de l'arrondissement où l'association dissoute avait son siège.

A défaut de toute association apte à recueillir les biens de l'association dissoute, ceux de ces biens qui ne seront pas grevés d'une fondation pieuse pourront être réclamés par les communes dans les conditions fixées au paragraphe 3 de l'article 4 .

Il fallait prévoir la dévolution des biens des biens des associations qui seraient dissoutes. Les personnes morales, même religieuses, ne jouissent pas, en fait, d'une existence infinie et les associations cultuelles peuvent disparaître à la suite de mort naturelle ou de mort violente. La mort naturelle sera l'effet du nombre insuffisant de membres de l'association (art. 17) ; la mort violente sera le résultat de la dissolution prononcée par les membres eux même ou par décision de 
justice, en vertu de l'article 7 de la loi du 1er juillet 1901, ou par application des dispositions contenues dans le projet de loi (art. 21).

Si l'on s'en était référé purement et simplement au droit commun, tel qu'il résulte de la loi du 1er juillet 1901 (art. 9) et du décret du 16 août 1901 (art. 14), l'association cultuelle, en cas de dissolution volontaire ou forcée, aurait été libre d'attribuer, comme elle l'aurait entendu et à qui elle aurait voulu, les biens provenant des établissements ecclésiastiques auquel elle avait succédé. Il y aurait eu des déplacements anormaux de capitaux dans un but ou avec des effets parfois regrettables.

Aussi a-t-il paru prudent à votre commission de spécifier que les biens en pareil cas seraient dévolus à une association analogue à celle qui se dissoudrait, soit dans la même circonscription, soit dans les circonscriptions les plus voisines. Si les associés ne s'entendent pas sur cette attribution, elle sera opérée en justice conformément aux règles fixées par l'article 5.

Il en sera de même si quelque association formée pour l'exercice du culte, et située dans les circonscriptions précitées, revendique ces biens. La commission a estimé ici encore que ceux-ci appartenaient plutôt à l'ensemble des fidèles d'un culte qu'aux établissements publics et aux associations qui les remplaceront. Ces associations représentent en quelque sorte et personnalisent le corps des coreligionnaires. Si elles ne remplissent pas exactement le mandat tacite qui leur est comme dévolu il faut laisser aux groupements religieux intéressés le droit de faire valoir leurs revendications. La sauvegarde de la justice qui prononce parait indispensable.

"Mais il fallait aussi prévoir le cas ou aucune association cultuelle n’existerait, capable de recueillir les biens possédés par l'association dissoute, par suite de l'indifférence de la population ou encore par un acte de résistance concertée à la loi.

Ceux de ces frères qui seront grevés d'une fondation pieuse suivront leur destination normale pour laquelle ils ont été constitués, les autre pourront être réclamés par la commune qui devra les affecter, 
sous le contrôle de l'autorité administrative, à des œuvres d'assistance et de prévoyance (article 5).

\section{Article 8}

Les attributions prévues par les articles précédents ne donnent lieu à aucune perception au profit du Trésor.

La dévolution des biens appartenant soit aux établissements ecclésiastiques supprimés, soit aux associations cultuelles, a un caractère forcé. Elle a pour but de laisser à l'ensemble des fidèles d'un culte la disposition des meubles et immeubles constitués par ceux dont ils sont les continuateurs. Il n’y a pas véritablement transmission de propriété de la part d'un ancien au profit d'un nouveau propriétaire ; il n'y a qu'un changement juridique, exigé par la loi, dans la forme et selon les modalités de la propriété. L'article 8 ne fait d'ailleurs qu'étendre aux attributions opérées en vertu des articles 4, 5, 6 et 7 du projet de loi, les immunités fiscales dont les acquisitions réalisées par voie d'expropriation pour cause d'utilité publique bénéficient par application de l'article 58 de la loi du 3 mai 1841.

Les actes de toute nature se rapportant aux attributions des biens d'établissements ecclésiastiques ou d'associations cultuelles seront donc dressés sur papier libre et dispensés de tous droits d'enregistrement. Leur transcription sera gratuite. La procédure devant les tribunaux sera suivie sans frais de justice. Il n'y aura d'inscription que pour les honoraires d'avoués.

Il faut distinguer cependant entre la dévolution régulière, normale, des biens faite à des associations cultuelles, et la revendication de ces biens exercée par les héritiers en ligne directe des donateurs.

Dans ce dernier cas il y a véritablement changement de propriétaire au profit d'une personne qui recueille des biens étrangers, malgré la volonté expresse d'un donateur ou testateur ; il y a aussi changement d'affectation de ces biens qui ne suivent plus la destination déterminée par leur légitimes propriétaires, aucune raison de droit ni de fait n’oblige le Trésor faire bénéficier ces actions en revendication des dispositions de l'article 8. 


\section{Article 9}

Les ministres des cultes qui compteront vingt-cinq années de fonctions rémunérées par l'État, les départements ou les communes, dont vingt années au moins au moins au service de l'État, recevront une pension annuelle et viagère égale à la moitié de leur traitement ; cette pensions ne pourront pas être inférieure à 400 fr., ni supérieure à $1.200 \mathrm{fr}$.

Les ministres des cultes actuellement salariés par l’État, qui ne seront pas dans les conditions exigées pour la pension recevront, pendant quatre ans à partir de la suppression du budget des cultes, une allocation égale à la totalité de leur traitement pour la première année, aux deux tiers pour la deuxième, à la moitié pour la troisième, au tiers pour la quatrième.

Les départements et les communes pourront, sous les mêmes conditions que l'État, accorder aux ministres des cultes actuellement salariés par eux, des pensions ou des allocations établies sur la même base et pour une égale durée.

Réserve et faite des droits acquis en matière de pensions par application de la législation antérieure. Les pensions ne pourront se cumuler avec toute autre pension ou tout autre traitement alloué, à titre quelconque par l’État les départements ou les communes.

Ces pensions et allocations seront incessibles et insaisissables dans les mêmes conditions que les pensions civiles. Elles cesseront de plein droit en cas de condamnation à une peine afflictive ou infamante et elles pourront être suspendues pendant un délai de deux à cinq ans en cas de condamnation pour l'un des délits prévus aux articles 31 et 32 de la présente loi.

Le système que votre commission a adopté pour les pensions accordées par mesure transitoire aux ministres du culte se différencie de celui que le Gouvernement avait formulé dans l'article de son premier projet. Il y a eu sur ce point transaction et accord pour la rédaction d'un texte commun. 
Le Gouvernement divisait les ministres du culte salariés par l'État en trois classes. Ceux qui ont trente ans d'exercice, ceux qui ont vingt ans d'exercice, ceux qui ont moins de vingt ans d'exercice. Les premiers recevaient à dater de la cessation de leur traitement une pension viagère annuelle égale aux deux tiers de ce traitement. Elle ne pouvait supérieure à 1200 fr., ni inférieure à 400 fr.

Les seconds auraient une pension viagère annuelle égale à la moitié de leur traitement, mais de $400 \mathrm{fr}$. au moins et de $1200 \mathrm{fr}$. au plus. Enfin les derniers auraient droit pendant un temps égal à la moitié de la durée de leurs services rétribués par l'État à une allocation annuelle de $400 \mathrm{fr}$.

Ce système a paru présenter certains inconvénients dont le plus gros serait de maintenir pendant longtemps un véritable budget des cultes nécessitant des crédits importants. On pouvait lui reprocher aussi de ne donner aux ministre des cultes qui ont moins de vingt années de service rémunérés par l'État, et qui sont les plus nombreux, qu'une allocation insuffisante dès le lendemain de la séparation des Églises et de l’État.

Sur le principe même des pensions et allocations à accorder aux ministres du culte, il ne peut y avoir de contestation sérieuse. sans discuter la question de savoir s'ils sont ou non des fonctionnaires, sans chercher d'avantage s'il leur est dû une indemnité au lendemain de la suppression de leurs services publics, on s'accordera à admettre qu'il est juste de prévenir les infortunes de ceux qui espéraient recevoir toujours un traitement officiel.

Mais, d'autre part, la séparation des Églises et de l'État ne serait qu'un vain mot pendant longtemps, et la suppression du budget des cultes qu'une illusion, si on était contraint durant de longues années de maintenir des crédits considérables pour le service des pensions. Il fallait pourtant assurer, sans contre-coup trop pénible pour les ministres des cultes, le passage de l'ancien au nouveau régime.

La commission accorde tout d'abord des pensions aux ministres des cultes âgés. Tous ceux qui sont actuellement pensionnés continuent à 
jouir de leurs droits acquis ; ils gardent leurs pensions sans les cumuler avec celles du nouveau régime.

Ceux qui ne sont pas pensionnés et qui ont vingt-cinq ans de services (dont vint seulement rémunérés par l'État) auront droit à une pension annuelle viagère égale à la moitié de leur traitement. On a fait abstraction de l'âge des ecclésiastiques pour n’envisager que la durée de leurs services.

Il peut être intéressant toutefois d'observer pour le culte catholique que, l'ordination n'ayant lieu en principe qu'à partir de vingt-cinq ans (décret du 28 février 1810, art. 3 et 4) les vingt ou vingt-cinq ans de service rétribués par l'État correspondent à un minimum de quarante ou quarante-cinq ans d’âge, inférieur à celui qui est exigé pour les retraités civils.

Cette pension ne pourra être inférieure à 400 fr., ni supérieure à 1 $200 \mathrm{fr}$.

Si l'on tient compte de ce que les ministres de cultes, contrairement aux autres fonctionnaires, ne subissent sur leur traitement aucun prélèvement pour la retraite ; si l'on calcule dans les retraites civiles, la part incombant à l'État, en dehors de l'intérêt des sommes accumulées à capital perdu, par chaque fonctionnaire et par prélèvement sur son salaire, on constate que la pension ainsi proposée pour les ministres des cultes est proportionnellement supérieure à celle dont bénéficient les fonctionnaires civils.

Tous les autres ministres des cultes actuellement salariés par l'État recevront dès la suppression du budget des cultes, pendant une année leur traitement intégral, la seconde année, les deux tiers, la troisième année la moitié, la quatrième année le tiers.

Les sommes ainsi réparties en quatre ans sont à peu près égales à celles prévues par le projet du Gouvernement.

Mais le système que votre commission vous propose à l'unanimité de ses membres, et, avec l'approbation du Gouvernement qui s'y est rallié, a un double avantage. Le budget important des pensions (celui 
relatif aux ministres des cultes ayant au moins vingt-cinq ans d'exercice excepté), ne sera obligatoire que pendant quatre ans. Ainsi quatre année après le vote de la loi, le budget de l’État sera libéré de la plus lourde charge des crédits pour les cultes et leurs ministres.

Au point de vue fiscal, comme au point de vue politique, il y a un intérêt de premier ordre à ne pas perpétuer les liens qui unissent l'État aux Églises. Plus la séparation sera nette et rapide et moins elle sera difficile et douloureuse. Les mesures les plus radicales sont parfois les mesures les plus habiles.

D’ailleurs elles se concilient ici heureusement avec l'intérêt véritable des ministres des cultes eux-mêmes. Le projet du Gouvernement accordait au plus grand nombre pendant assez longtemps une allocation de $400 \mathrm{fr}$. Celle-ci était absolument insuffisante pour les faire vivre. Au lendemain de la séparation si une crise financière s'était produite dans l'Église, les ministres en auraient souffert et l'allocation de 400 fr. aurait été pour eux un pauvre secours.

Quant aux ministres qui désireraient quitter le sacerdoce et trouver une situation laïque, ils n'auraient pu avec leur trop modeste subvention aller à la recherche d'une position convenant mieux à leurs aptitudes. Ils eussent été liés à l’Église.

Avec l'article 9 du projet, ils recevront la première année la totalité de leur traitement. Pour eux il ne peut y avoir durant ce temps de crise financière. La seconde année, les deux tiers représentant encore une somme appréciable. Le budget des pensions et indemnités diminuera insensiblement chaque année, et ainsi les ministres du culte passeront sans secousse de l'ancien au nouveau régime. Peu à peu le budget officiel sera remplacé par les dons des croyants.

Les départements ou communes pourront, pour les ministres des cultes, salariés par eux, établir ou accorder des pensions sur les mêmes bases que celles de l'État.

Toutes ces pensions et allocations sont insaisissables et incessibles. Cependant elles cesseront, de plein droit, en cas de condamnation à une peine afflictive ou infamante. L'État ne peut s'imposer des sacri- 
fices pour des indignes. Elles pourront être suspendues pendant un délai de deux à cinq ans en cas de condamnation pour des délits prévus aux articles 31 et 32 du projet de loi.

Les tribunaux auront à apprécier, suivant la faute et les circonstances du délit, si la suspension doit être prononcée.

Titre III

Des édifices des cultes

Article 10

Les édifices antérieurs au Concordat, servant à l'exercice public des cultes ou au logement de leurs ministres, cathédrales, églises, chapelles de secours, temples, synagogues, archevêchés, évêchés, presbytères, séminaires, ainsi que leur dépendances immobilières, et les objets mobiliers qui les garnissaient au moment où lesdits édifices ont été remis aux cultes, sont et demeurent propriétés de l'État, des départements, des communes qui devront en laisser la jouissance gratuite, pendant deux années à partir de la présente loi, aux établissements ecclésiastiques puis aux associations formées pour l'exercice du culte dans les anciennes circonscriptions des établissements ecclésiastiques supprimés.

L’État, les départements et les communes seront soumis à la même obligation en ce qui concerne les édifices postérieurs au Concordat dont ils seraient propriétaire, y compris les faculté de théologie protestante.

Il ne peut être sérieusement contesté que les églises métropolitaines et cathédrales rendues au culte catholique en exécution du Concordat soient la propriété de l’État ainsi que les palais épiscopaux, archiépiscopaux, les presbytères et les bâtiments séminaires.

La Constituante avait fait de tous les biens ecclésiastiques - qui étaient distingués de biens du clergé, plus exactement des bénéfices la propriété de l'État. Avant elle, les églises paroissiales et les presbytères avaient un caractère mixte, communal et ecclésiastique. La Législative remit ces dernières aux municipalités. (Décrets des 4 et 14 
septembre 1792.) Les décrets des 3 ventôses et 11 prairial an III, en rétablissant le libre exercice des cultes déclarèrent à nouveau le droit de possession des églises par les communes.

Le 3 nivôse et 2 pluviôse an XIII, des avis du conseil d'État, approuvés par l'empereur et exécutés comme force de loi furent solennellement émis en ces termes :

"Le conseil d'État... sur la question de savoir si les communes sont devenues propriétaires des églises et des presbytères qui leur ont été abandonnés en exécution de la loi du 18 germinal an $\mathrm{X}$ est d'avis que lesdits Églises et presbytères doivent être considérés comme propriétés communales."

D’autres textes ont rappelé ou proclamé les mêmes principes.

Depuis lors le conseil d'État et la cour de cassation ont consacré dans une jurisprudence constante ce principe "que les églises métropolitaines et cathédrales sont propriétés de l'État, les églises paroissiales et presbytères sont la propriété des communes.”

Les édifices d'origine ancienne rendus aux cultes protestants lors du rétablissement de ces cultes par application de la loi du 18 germinal an $\mathrm{X}$ ou attribués au culte israélite lors de son organisation par décret du 17 mars 1808 appartiennent également aux communes.

L'article 10 fait donc une appréciation juridique et conforme aux règles séculaires, en distinguant, pour le régime auquel seront soumis les édifices des cultes, les immeubles religieux antérieurs au Concordat et ceux qui sont possédés par les établissements publics depuis le Concordat. Le droit de propriété de l'État ou des communes n'est pas crée, il est simplement confirmé. cette confirmation, cette nouvelle consécration législative, n’étaient pas inutiles. On n’aurait pas manqué de tirer argument du silence de la loi pour contester un droit même aussi indéniable.

L'État ne pouvait d'ailleurs abandonner aux associations cultuelles cette propriété. Aucune raison ne permettait de diminuer ainsi le patrimoine de la société toute entière au profit de certains groupements 
religieux, et surtout n'autorisait le Parlement à faire de pareilles largesses aux dépens des communes.

Pour les édifices postérieurs au Concordat, votre commission a finalement décidé de ne tracer aucune règle pour résoudre les questions de propriété qui pourraient se poser entre l'État, les départements et les communes d'une part et les établissements ecclésiastiques de l'autre.

On décidera, d'après le droit commun de propriété et spécialement d'après l'article 552 du code civil. Les dispositions qu'on eût pu inscrire dans la loi, n'auraient aucunement facilité la solution de ces difficultés. Le recours à la justice ne pouvant être évité, il n’y avait aucun intérêt à ajouter aux règles du code civil de nouvelles stipulations.

Les tribunaux décideront d'après les titres ou, à défaut, par tous les modes de preuve admis en pareille matière. Les droits des établissements des cultes, comme ceux de l'État ou des communes, ont été ainsi mieux réservés. Les juges trouveront dans les délibérations des conseils municipaux et dans celles des conseils de fabrique de précieux éléments d'appréciation.

Les édifices servant à l'exercice des cultes ou au logement de leurs ministres, quels qu'ils soient, qu'ils appartiennent à l'État, aux départements ou aux communes, antérieurs ou postérieurs au Concordat, les facultés de théologie protestantes, seront laissés pendant deux ans gratuitement à la disposition des établissements publics des cultes ou aux associations cultuelles qui continueront l'exercice du culte dans les circonscriptions ecclésiastiques des établissements publics supprimés. Les deux ans courront à partir de la promulgation de la loi.

On a voulu ainsi, pendant deux ans donner aux associations cultuelles toute facilité pour se constituer, se développer et réunir, à l'abri de toute dépense immédiate, une certaine réserve. Si l'on tient compte de ce que, pendant un an, les ministres du culte recevront leur traitement intégral et pendant la deuxième année les deux tiers de ce traitement, on constatera dans quel esprit de véritable libéralisme et de prudente politique cette disposition a été conçue. Le lendemain de la promulgation, rien ne sera changé en fait. L'exercice du culte sera continué sans aucune interruption. La transformation sera juridique et de principe, 
avant d'être réalisée en pratique. Aucune application brutale et inattendue ne sera de nature à susciter une agitation ou une inquiétude chez les croyants. Si quelques troubles se produisent, on aura le droit de les considérer comme factices, et la responsabilité ne pourra en incomber au législateur.

\section{Article 11}

A l'expiration du délais ci-dessus fixé, L’État, les départements et les communes devront consentir aux associations, pour une durée n'excédant pas cinq ans, la location des presbytères et pour une durée n’excédant pas dix ans, la location des cathédrales, églises, chapelles de secours, temples, synagogues ainsi que des objets mobiliers qui les garnissent.

Le loyer ne sera pas supérieur à 10 p. 100 du revenu annuel moyen des établissements supprimés, ledit revenu calculé d'après les résultats des cinq dernières années antérieures à la promulgation de la présente loi, déduction faite des recettes supprimées par la loi du 28 décembre 1904.

Les réparations locatives et d'entretien ainsi que les frais d'assurance seront à la charge des établissements et associations.

En cas d’inexécution de ces prescriptions, la location sera résiliable.

Les associations locataires ne pourront se prévaloir contre l'État et les communes des dispositions de articles 1720 et 1721 du code civil. Elles pourront demander la résiliation du bail dans le cas où le bailleur se refuserait à exécuter les grosses réparations indispensables pour assurer la jouissance de l’immeuble.

Les édifices actuellement à la disposition d'établissements publics pour l'exercice du culte et qui sont al propriété de l'État, des départements ou des communes devront, à l'expiration de la jouissance gratuite concédée pendant deux ans, être loués, sur leur demande, aux associations cultuelles. 
Observons tout d'abord qu'on s'est abstenu de prescrire pour ces édifices aucune règle d'inaliénabilité. Les monuments historiques demeurent soumis à leur régime particulier à ce point de vue comme à tous autres. Mais pour ceux qui ne sont point classés à ce titre, ils font, par le fait même de l'article 2, partie du domaine privé, et les déclarer inaliénables eût été créer sans raison sérieuse une législation spéciale à leur égard. Il n’y avait aucun intérêt, au contraire, à les maintenir dans les limites du droit commun, car l'État, les départements et les communes pourront ainsi, selon leur libre volonté, les céder aux associations cultuelles.

Pendant dix ans, ces édifices seront loués ainsi que leur mobilier moyennant un prix extrêmement modéré qui peut être abaissé jusqu’à un chiffre de pur principe, et qui ne peut dépasser 10 p. 100 du revenu annuel moyen des établissements supprimés, ce revenu calculé d'après le résultat des cinq dernières années. On déduit même, et c'est justice, les recette supprimées par la loi du 28 décembre 1904. Ainsi, pour une fabrique dont le revenu moyen aurait été de 3000 fr., le loyer ne pourra pas être supérieur à 300 fr. ; il pourra être abaissé au gré des parties jusqu’à $1 \mathrm{fr}$.

Les cas de loyers fictifs ainsi consentis à des établissements publics ou des œuvres d'utilité publique ou d'intérêts collectifs, sont nombreux. Il ne fallait pas le jour même de la fondation d'une association cultuelle lui imposer des dépenses trop fortes qui eussent risqué souvent d'en faire une institution mort-née. Il ne fallait pas surtout, dès l'instant où l'on reprenait les édifices servant à l'exercice du culte depuis de longs siècles, sans rémunération aucune, donner à cet acte de reprise un caractère vexatoire. Cette période de dix ans, pendant laquelle on pourra réclamer aux associations un loyer, modeste pour les édifices mis à leur disposition, suffira dans la plupart des cas pour permettre ces associations de se développer et de faire face à toutes les charges qui, dans la suite, pourraient légitimement leur être imposées.

Elle est prévue pour tous les édifices sans exception, affectés au culte : cathédrale, église, chapelles de secours, temples et synagogues.

Les archevêchés, évêchés, séminaires, facultés de théologie protestantes ne bénéficient pas de ces dispositions. 
Il a paru à votre commission qu'aucune raison de principe ni de politique ne permettait après deux ans de jouissance gratuite, de les comprendre dans un régime d'exception et de faveur. Toutefois, par un sentiment de bienveillance à l'égard des paroisses et de leurs desservants, les presbytères seront loués pendant cinq ans aux associations cultuelles d'après les règles déterminées pour les édifices du culte. En raison du faible traitement accordé aux curés, pasteurs et rabbins, on ne pouvait leur imposer du jour au lendemain la charge d’un loyer élevé.

Durant la jouissance gratuite de la période de location de tous ces immeubles, les réparations locatives et d'entretien, ainsi que les frais d'assurance, seront à la charge des établissements et des associations. Il faut éviter que par l'insouciance et l'incurie des directeurs des associations, les propriétaires des immeubles assistent impuissants à la dépréciation de leur propriété. C'est pourquoi, si l'association locataire laisse dépérir volontairement les immeubles qu'on lui a cédés à bail pour un loyer aussi modeste, la location sera résiliable. Les tribunaux apprécieront en fait s’il y a eu faute lourde commise.

Les grosses réparations restent à la charge de l’État ou des communes. Mises à la charge des associations cultuelles elles auraient entraîné pour elles des dépenses considérables auxquelles, dans bien des cas, ces associations récentes n'auraient pu suffire et qui ont finalement paru à votre commission inconciliables avec la jouissance de courte durée prévue dans le projet de loi. Il eût été aussi excessif de cumuler cette charge avec le loyer exigé des établissements et associations. Mais votre commission a jugé qu'étant donné la modicité de ce loyer, il serait raisonnable de laisser à la charge des associations, en outre des réparations locatives, celles d'entretien. C'est une exception au droit commun. Mais le droit commun, si on l'invoque, laisse au propriétaire le libre choix du locataire avec le plein droit de fixer le prix de ses loyers. Il les calcule d'après ses charges et les réparations d'entretien ne sont pas la moindre. En enlevant à l'État et aux communes tous les droits, tous les avantages de la propriété, eût-il été juste de ne leur laisser que les inconvénients ? 
Votre commission n’a pas cru devoir imposer les grasses réparations à l'État et aux communes. Ils n'y procéderont que s’ils considèrent que tel est leur intérêt. On a, dans ce but, apporté une dérogation aux articles 1720 et 1724 du code civil. Mais l'équité exigeait que les associations locataires ne fussent pas contraintes de respecter leur bail si l'on négligeait d'effectuer les grosses réparations nécessaires pour assurer la jouissance de l'immeuble.

Dans ce cas, le bailleur serait considéré comme violant à l'égard du locataire les bases mêmes du contrat et ce dernier pourrait réclamer la résiliation du bail.

Nous verrons à l'article 17 que des crédits sont prévus au budget de l’État et des communes pour ces grosses réparations.

Article 13

Les édifices du culte, dont les établissements ecclésiastiques seraient propriétaires, seront, avec les objets mobiliers les garnissant, attribués aux associations dans les conditions déterminées par le titre II

\section{Article 14}

Quand plusieurs associations légalement formées pour l'exercice du même culte réclameront la jouissance ou la location des mêmes édifices et objets mobiliers, il sera pourvu au règlement du litige par le tribunal civil du ressort.

Ces articles se bornent à assimiler les édifices du culte et les objets mobiliers qui les garnissent, appartenant aux établissements ecclésiastiques, aux autres biens de ces établissements dont la dévolution est réglée par le titre II

Pour la clarté de la loi, il était indispensable de distinguer entre les biens ordinaires dont les établissements ecclésiastiques publics ont aujourd'hui la possession ou la disposition, et les édifices du culte. Il était nécessaire, pour ceux de ces derniers qui appartiennent à ces établissements, de les soumettre expressément au même mode de dévo- 
lution que les biens ordinaires. Le silence du texte sur ce point aurait suscité des interprétations diverses.

\section{Article 15}

Les objets mobiliers ou les immeubles par destination mentionnés aux articles 10 et 13, qui n'auraient pas encore été inscrits sur la liste de classement dressée en vertu de la loi du 30 mars 1887, sont, par l'effet de la présente loi, ajoutés à ladite liste. Il sera procédé par le ministre de l'instruction publique et des beaux-arts, dans le délai de trois ans, au classement définitif de ceux de ces objets dont la conservation présenterait, au point de vue de l'histoire ou de l'art, un intérêt suffisant. A l'expiration de ce délai, les autres objets seront déclassés de plein droit.

En outre, les immeubles et les objets mobiliers, attribués en vertu de la présente loi aux associations, pourront être classés dans les mêmes conditions que s’ils appartenaient à des établissements publics.

Il n’est pas dérogé, pour le surplus, aux dispositions de la loi du 30 mars 1887.

C'est par soucis de l'intérêt historique et artistique qui s'attache aux édifices et aux objets servant au culte que cette disposition a été inscrite dans le projet de loi.

Les chefs d'œuvres que nous ont légué les siècles passés font partie du patrimoine artistique de la nation et le devoir du législateur est d'en assurer l’intégrale conservation.

Les monuments par lesquels l'art religieux a caractérisé à chaque époque lointaine une forme spéciale de beauté : les statues, les tableaux, les meubles, "trésors" de toute sorte qui ornent encore nos églises où ils ont été accumulés par des milliers d'artistes disparus, doivent être protégés contre toute atteinte et toute dilapidation.

Il était utile, pour réaliser ce but, de compléter ici la loi du 30 mars 1887. 
Les édifices du culte qui appartiennent à l'État ou aux communes ne courent aucun risque. Tous ceux qui présentent un intérêt historique ou artistique ont été classés.

Il n'en est pas de même des objets qui les garnissent. Un grand nombre de ces objets n'ont pas été classés et l'on ne saurait songer à leur appliquer, au lendemain de la séparation, la procédure ordinaire de classement qui est assez longue et assez compliquée. Par mesure générale, il a paru à votre commission qu'il était prudent de classer provisoirement en bloc, par l'effet même de la loi, en vue d'en empêcher l'aliénation, la détérioration ou la perte, les objets mobiliers et les immeubles par destination loués aux associations cultuelles. Dans un délai de trois ans on fera la révision et le classement régulier, et tout ce qui n’aura pas été classé définitivement se trouvera déclassé de plein droit.

Dans la législation actuelle, les biens appartenant à des particuliers ou même à des établissements d'utilité publique, ne peuvent être classés sans le consentement du propriétaire (loi du 30 mars 1887, art. 3). La loi sur ce point aurait donc été mise en échec : on se serait trouvé en tout cas en présence de dispositions inconciliables.

Aussi la commission a-t-elle ajouté que les immeubles et les objets mobiliers attribués aux associés pourraient être classés dans les conditions déterminées au paragraphe 1er de ce même article, comme s'ils appartenaient à des établissements publics.

En dehors de ces dispositions spéciales, la loi du 30 mars 1887 s’applique avec toute sa force.

Titre IV

Des associations pour l'exercice des cultes

\section{Article 16}

Les associations formées pour subvenir aux frais, à l'entretien et à l'exercice public d'un culte devront être constituées conformément aux articles 5 et suivants de la loi du 1er juillet 1901. Elles seront, en 
outre, soumises aux prescriptions de la présente loi, sous réserve des dispositions ci-après.

L'article 2 du projet abolit le régime actuel des cultes et fait pour ainsi dire table rase de l'organisation légale des églises. Sous quelles formes celles-ci allaient-elles renaître ; fallait-il créer pour elle une législation spéciale?

Votre commission n'a pas cru devoir entrer dans cette voie ; elle n’a pas hésité à adopter la solution la plus libérale et, dès le premier article du titre IV, elle soumet les associations religieuses au droit commun. Suivant cette règle celui-ci sera-t-il adapté aux formes particulières de chaque culte ? Quelles exceptions doit-on apporter aux règles générales en tenant compte à la foi de l'intérêt de l'ordre public et de celui des cultes ? C'est ce que nous verrons à propos des divers articles de ce titre IV.

Mais, s’il y a des exceptions inévitables, il n’y a pas de régime exceptionnel. La loi des associations qui aura qui aura été la préface de la séparation des Églises et de l'État en sera aussi la charte. Dans tous les cas où la loi présente n’aura pas statué, c'est la loi de 1901 qui devra servir de règle pour tout ce qui concerne l'organisation des associations religieuses.

La loi doit laisser les Églises, et c'est pour elles une liberté aussi essentielle que la liberté du culte, s'organiser selon leurs tendances, leurs traditions et leur gré. La constitution de chacune d'elles est adéquate à ses principes et comme la conséquence de ses dogmes. Intervenir dans cet organisme serait dans bien des cas - nous le montrerons plus particulièrement à propos de l'article 18 - s'immiscer dans l'expression ecclésiastique des croyances religieuses. Il faut prendre garde aussi que toutes les dispositions transitoires de la loi seront dans quelques années lettre morte et n'appartiendront qu'à l'histoire ; il ne restera en vigueur que l'application de ces deux principes : liberté de conscience et liberté d'association. Le second est le corollaire du premier.

Le projet a eu pour but de laisser ainsi les communautés cultuelles, s'organiser librement pour l'accomplissement intégral de leur but 
strictement religieux. Aucune des exceptions admises ne peut apporter à leur œuvre, ainsi définie et limitée, aucune entrave : il n’en est pas qui puisse les gêner en aucune manière dans leur indépendance.

Les associations cultuelles doivent être, en effet, des associations déclarées, en conformité avec les articles 5 et suivants de la loi du 1er juillet 1901. Cette obligation est inévitable puisqu'en vertu de l'article 17, elles jouissent de la personnalité civile et de la capacité juridique.

\section{Article 17}

Elles devront être composées au moins de sept personnes majeures et domiciliées ou résident dans la circonscription religieuse et avoir et avoir exclusivement pour objet l'exercice d'un culte.

Elles pourront recevoir, en outre, des cotisations prévues par l'article 6 de la loi du 1er juillet 1901, le produit des quêtes et collectes pour les frais du culte, percevoir des rétributions : pour les cérémonies et services religieux même par fondation ; pour la location des bancs et sièges ; pour la fourniture des objets destinés au service des funérailles dans les édifices religieux et à la décoration de ces édifices.

Elles pourront verser, sans donner lieu à perception de droits, le surplus de leurs recettes à d'autres associations constituées pour le même objet.

Elles ne pourront, sous quelque forme que ce soit, recevoir des subventions de l'État, des départements et des communes. Ne sont pas considérées comme subventions les sommes que l'État, les départements et les communes jugeront convenable d'employer aux grosses réparations des édifices du culte loués par eux aux associations.

L'article 17 détermine certaines règles spéciales aux associations cultuelles et dont les unes sont extensives, les autres restrictives du droit commun. Elles procèdent toutes d'un juste souci de la liberté des Églises et de l'ordre public.

La première règle est relative à la composition des associations. Elles ne seront légalement formées que si elles comptent sept membres 
au moins, majeurs, domiciliés ou résidant dans la circonscription religieuse.

Il faut, en d'autres termes, que l'association soit sérieuse. Comment aurait-on pu attribuer les biens appartenant aux établissements publics du culte, comment aurait-on pu conférer les droits qui découlent du projet de loi, à une association fantôme de moins de sept membres ? La condition de domicile ou de résidence n'est pas moins indispensable.

Quelques étrangers à la circonscription auraient pu fonder une association dans le but secret, en acquérant les biens ecclésiastiques, d'exercer une influence prépondérante sur toute une région. Il y aurait eu lieu de craindre que cette influence ne fût pas exclusivement religieuse. L'intrusion de ces associés auraient été de nature parfois à spolier de tout ou partie de leurs droits les associations locales. Quelques personnes aussi auraient pu trouver dans la loi le moyen, par leur inscription à un grand nombre d'associations, d'exercer une action illégitime.

L'association doit être sérieuse par son caractère et sa composition. On ne saurait considérer comme telle une association qui n'aurait pas, en fait, pour but certain l'exercice du culte dont elle se réclame. Donc, pour être conforme à la loi, il faut qu'elle puisse réaliser ce but. C'est ainsi qu'on ne peut concevoir une association catholique qui n'aurait pas pas à sa disposition un prêtre, ou une association israélite sans rabbin.

Mais il ne suffisait pas de dire que par leurs membres et leur objet les associations doivent être sérieuses et sincères et non pas la caricature ou la contrefaçon d'un groupement religieux, il fallait aussi les limiter dans leur action. Sous le couvert de la religion, elles auraient pu cacher des intentions suspectes. Aussi l'article 17 dispose-t-il qu'elles doivent avoir pour but exclusif l'exercice d'un culte. Elles sont appelées à bénéficier des établissements ecclésiastiques et à jouir des édifices du culte appartenant à l'État ou aux communes; il est naturel qu'elles soient limitées à l'objet qui leur vaut ces avantages et qu'elles ne puissent utiliser ces biens et ces édifices pour une autre destination. 
Elles ont aussi une capacité plus étendue que les associations ordinaires déclarées. cette extension sans laquelle les Églises ne pourraient ni vivre ni se développer, ne leur est accordée qu'en raison de leur caractère cultuel. Elle ne doit pas servir à d'autres fins que celle en vue de laquelle elle est instituée.

Le second paragraphe de cet article énumère les diverses sources de revenu des associations. Celles qui sont prévues explicitement par la loi de 1901 n'auraient pas suffi pour assurer la continuation de l'exercice des cultes; d'autres pouvaient apparaître excessives, et qu'il fallait cependant conserver par respect pour les pratiques religieuses.

Aussi votre commission vous convie-t-elle à décider que les associations cultuelles pourront recevoir d'autres fonds que les cotisations de leurs membres. Ces dernières ne leur fourniraient pas des moyens suffisants d'existence.

Ces ressources nouvelles seront les quêtes et collectes, limitées à leur objet : les frais du culte. Il s'agit ici de dons manuels qui, d'après la jurisprudence, sont distingués des dons et legs pour lesquels une autorisation est nécessaire.

Ces quêtes et collectes ne sont pas limitées quant aux endroits où elles peuvent être faites. On n'a pas cru devoir les prohiber, comme il avait été proposer, en dehors des édifices consacrés à l'exercice des cultes, car, au lendemain de la séparation, tout local pourra, moyennant une déclaration préalable, servir à cet exercice. N'y aurait-il pas dès lors quelque illogisme alors que le culte peut être célébré partout, à localiser en certains endroit les quêtes et collectes ? Du reste, pareille prohibition fût restée vaine. On ne peut saisir ni surprendre nulle part les dons manuels ; et, en définitive, pourquoi empêcher ceux qui, malades, infirmes ou même non pratiquants personnellement, ne fréquentant pas les églises de participer cependant s'ils le veulent, a des collectes pour l'entretien du culte? 
Les associations pourront aussi percevoir des rétributions pour les cérémonies et service religieux. Il y a là rémunération d'un service demandé et reçu.

Les fondations pour les mêmes objets sont également autorisées. Il s’agit ici de fondations pour cérémonies religieuses et messes.

C’eût été blesser gravement les sentiments intimes de ceux qui, de leur vivant ou après eux, veulent assurer la célébration de certaines cérémonies (comme messes pour les morts, etc.) que d'interdire ces fondations. Elle n'ont rien de contraire à l'ordre public et leur objet est nettement délimité. Les associations cultuelles n'ayant pas la capacité de recevoir des dons et legs, cette exception en faveur des fondations était indispensables. La question de savoir si ces fondations représentent simplement le prix des services et des cérémonies, sera une question d'espèce, car, après la séparation, il n'y aura plus, comme aujourd'hui, des tarifs d'oblation approuvés par le gouvernement (loi du 18 germinal an $\mathrm{X}$, art. 69). La rémunération des services et cérémonies sera libre sous la seule condition de ne pas dissimuler une libéralité.

Le droit de puiser d'autres ressources dans la location des bancs et siège, la fourniture des objets destinés au service des funérailles dans les édifices religieux et à la décoration de ces édifices est simplement le maintien du droit acquis qui passe des fabriques et consistoires aux associations cultuelles. Il faut noter cependant que ma séparation entraînera la suppression de la tarification officielle existant actuellement pour le service intérieur des pompes funèbres.

La commission n'a pas cru devoir accorder aux associations cultuelles la faculté de recevoir des donations et des legs. Elle a redouté la création de puissance financière excessive.

En possession de capitaux trop considérables et de ressources trop abondantes, les associations religieuses auraient pu multiplier les lieux de culte et augmenter hors de proportion le nombre des membres du clergé. Il eût été à craindre que l'influence acquise à prix d'argent ne restât pas strictement religieuse. Il n'était pas inutile non plus, dans l'intérêt même des familles, de faire obstacle aux tentatives de captation. 
Les biens religieux dont la manifestation demeure libre amèneront des ressources correspondantes. La religion ne doit pas se maintenir par les héritages des morts, mais par les libéralités volontaires des vivants. C’est la règle des fidèles qui fera vivre l’Église et qui réglera l'étiage de sa fortune.

Il faut aussi observer que la loi du 1er juillet 1901 a entendu faire de la capacité de recevoir des dons et legs un privilège exclusivement attaché à la reconnaissance d'utilité publique. Or, sous le régime de la séparation, sous peine de contradiction flagrante, il faut conserver aux associations cultuelles un caractère purement privé.

Nulle autre source de revenus que celles que nous venons d'énumérer ne pourra être utilisée par les associations cultuelles. Elle ne pourront recevoir aucune subvention de l'État, des départements ou des communes.

Les crédits inscrits aux budgets affectés aux grosses réparations des édifices religieux n’ont pas ce caractère de subvention. Nous savons qu'ils ne sont alloués que pour assurer la conservation de ces édifices dans l’intérêt des propriétaires.

Les fonds recueillis par chaque association cultuelle, peuvent, dans certains cas dépasser les besoins de cette association et dans d'autres être insuffisant.

Il n'est pas douteux en fait, qu'une solidarité étroite unit les diverses paroisses. La loi qui eût empêché les plus riches de secourir les pauvres, et l'opulence des uns de venir en aide à la pénurie des autres, eût été véritablement injuste. Pour les minorités religieuses cette raison est plus sensible encore. Les israélites, par exemple, sont très groupés et très riches en certaines villes ; dans d'autres, ils sont très peu nombreux et de condition modeste. Pourquoi interdire à la communauté riche de venir en aide, pour l'exercice du culte, aux communautés moins favorisées ? Aussi l'article 17 décide-t-il, que, sans donner lieu à perception de droit, le surplus des recettes d'une association pourra être versé à une autre association ayant le même objet. 
Il y a même intérêt d'ordre public à permettre ainsi aux associations cultuelles de dépenser au jour le jour leurs ressources au lieu de thésauriser.

Cette dernière disposition de l'article 17 ne présente donc que des avantages.

\section{Article 18}

Ces associations peuvent, dans les formes déterminées par l'article 7 du décret du 16 août 1901, constituer des unions ayant une administration ou une direction centrale; ces unions seront réglées par les articles 16 et 17 de la présente loi.

Cette importante disposition se différencie du projet primitivement déposé par le Gouvernement.

Celui-ci autorisait aussi des unions ayant une direction ou administration centrale, mais déclarait que les unions étendues sur plus de dix départements seraient dépourvues de toute capacité juridique.

L'article 18, que votre commission a cru devoir, à diverses reprises, maintenir dans son projet, décide au contraire, que les unions d'associations cultuelles auront la même capacité juridique que les associations elles-mêmes, capacité définie et délimité par les articles 16 et 17.

Le motif qui pourrait inspirer une limitation de capacité pour les unions d'associations est simple : on redoute, non pas tant pour les minorités religieuses trop peu nombreuses, que pour les grandes unions ou l'union générale des associations catholiques, une accumulation de ressources considérables en même temps qu'une puissance sociale incompatible avec le souci de l'ordre public.

Votre commission n'a pas cru pouvoir sacrifier à cette inquiétude les considérations d'équité élémentaire qui militent en faveur du droit pour les associations de se fédérer. 
S’il est, en effet, une liberté que la loi doive accorder aux églises, c'est la liberté d'organisation. Dans toutes les dispositions légales relatives au droit des associations cultuelles, le principal souci du législateur doit être de respecter les principes ecclésiastiques de toutes les communautés religieuses existant actuellement.

Il n’eût été ni juste ni loyal de refuser aux associations cultuelles la faculté de s'organiser selon des formations qui tiennent aux règles essentielles de l'Église et à sa constitution même. C'eût été faire obstacle à l'exercice de la religion et, par là, porter la plus grave atteinte à la liberté de conscience. L’Église catholique, en effet, n'est pas seulement divisée en paroisses ; elle l'est aussi en diocèses. Cette dernière formation, pour subsister, implique forcément, au profit des associations paroissiales, le droit de se fédérer par région diocésaine. Or, tous les diocèses sont reliés hors de France par une direction unique bien autrement redoutable que celle qui pourrait venir de l'association nationale. Alors, à quoi servirait-il d'interdire celle-ci, et comment le pourrait-on ? Ne serait-il pas, au contraire, plus dangereux encore de ne permettre aux associations de ne prendre contact qu'à Rome pour toute l'administration des affaires ecclésiastique de France ?

Raisonnablement, il n'était pas possible de refuser à l'Église ce large droit d'association. Mais, le lui accordant, il devenait indispensable de prendre des précautions sérieuses contre l'abus qu'elle serait tenté d'en faire. Ces précautions, elles sont d'abord dans l'impossibilité pour l'Église de constituer une caisse noire par l'accumulation illimitée de capitaux. Le projet fait obstacle à la mainmorte par l'interdiction aux associations des cultes de posséder au-delà d'un capital déterminé, calculé d'après les besoins annuels normaux de la circonscription religieuse. Comme garantie de sécurité, c’est beaucoup. Mais il y a, en outre, au titre de la police des cultes, des dispositions visant les abus que pourrait faire l'Église des libertés qui lui sont octroyées. Si les temps héroïques sont passés, le temps des martyrs l'est aussi. Malgré les excitations des meneurs, les membres du clergé français, avant de violer la loi, hésiteront devant les pénalités à encourir.

Observons, en outre, que, pour que les Églises protestantes, le droit d'union s’imposait. En fait, elles sont dispersées et disséminées dans la France entière. De nombreux départements ne comptent que quel- 
ques centaines de fidèles. Agglomérés dans certaines grandes villes comme Paris, Nîmes, Lyon, ils sont répandus dans toutes les autres régions en nombre extrêmement faible.

L’Église protestante de beaucoup la plus nombreuse, l’Église réformée de France, ne compte au total que la moitié environ d’adeptes du diocèse catholique le moins peuplé. Le protestantisme aussi, par son principe de libre examen, a provoqué la création de nombreuses petite communautés indépendantes de 1000,2 000, et la plus nombreuse 20000 membres dispersés par groupe parfois de 10 ou de 100 fidèles. A défaut d'union générale et de caisse centrale, constituée pour donner un centre commun à cette poussière de paroisses, la plupart seraient condamnées à disparaître et se déclareraient légitimement en butte à de véritables mesures d'oppression religieuse.

Le budget des cultes constitue actuellement pour toutes les Églises protestantes reconnues le centre commun indispensable. Le jour de son abrogation, il faudra le remplacer.

Mais en droit, plus encore qu'en fait, les protestants réclament avec raison l'union générale pour la conservation de leur constitution séculaire.

Elle l'ont toutes établies sur des bases semblables. La plus importante, l’Église réformée, a, ainsi que nous l'avons expliqué, une organisation parlementaire et démocratique. La paroisse nomme au suffrage universel son ou ses pasteurs et représentants (conseil presbytéral). Les conseils presbytéraux nomment les délégués au consistoire. $\mathrm{Au}$ dessus du consistoire se trouve le synode régional, et, enfin, l'Église entière est gérée par un synode national, dont la légalité a été reconnue par avis solennel du conseil d'État. Ce synode national où les laïques sont en majorité, a tous les pouvoirs d'un véritable, ecclésiastique et financier. L'anéantir serait priver l’Église réformée de ce qui forme sa caractéristique particulière. Louis XIV, seul, par la révocation de l'édit de Nantes, a cru devoir le faire. L'union générale avec sa capacité juridique peut seule respecter la constitution protestante en ce qu'elle a d'essentiel et de caractéristique. 
Les israélites, tout aussi dispersés et possédant aujourd'hui légalement un consistoire central, réclament à juste titre, les mêmes dispositions, non pas bienveillantes, mais simplement équitables.

Et si l'on songe que demain des dissidents catholiques, protestants ou israélites, des adeptes de religions nouvelles, peuvent fonder des associations cultuelles ; si l'on prévoit que leurs adhérents seront au début recrutés un peu parmi tous les fidèles de France sur tout le territoire, et vraisemblablement peu nombreux dans un premier temps, on devra conclure que pour permettre la naissance et le développement de ces nouvelles associations cultuelles, il faut leur donner le droit de fonder, alors qu'elles sont faibles encore, leur foyer commun et leur budget commun.

Tout le monde reconnaît que ce qui est accordé aux uns doit l'être à tous ; c'est pourquoi, sans distinction de confession religieuse, votre commission a cru devoir admettre les unions générales d'associations cultuelles avec capacité juridique.

Pour en revenir à l'Église catholique, si les militants parmi les fidèles voulaient exercer un rôle politique et social, ils ne le feraient pas par le moyen d'associations cultuelles, mais par le moyen d'associations ordinaires qui, elles, ont bien sans limitation le droit de se fédérer.

Le projet tel qu'il est conçu ne leur permettrait pas sans danger d'agir avec succès sous le couvert de communautés religieuses. Nous le répétons, trop de précautions sont prises à cet effet.

Au point de vue financier, les ressources des associations cultuelles ne proviennent que de certains revenus spécialisés.

Ceux-ci doivent être affectés uniquement à l'exercice du culte. Les associations ne peuvent recevoir ni dons ni legs. Leurs comptes sont soumis à un contrôle financier et précis, éclairé et sévère.

La violation des règles financières peut entraîner la dissolution de l'association. 
Au pont de vue politique et social, les associations ne peuvent servir à d'autres fins que l'exercice du culte. Leurs actes collectifs sont soumis à des règles très strictes : ni elles-mêmes, ni leurs directeurs ou ministre ne peuvent poursuivre un but différent de celui qui est déterminé par leurs statuts. Les paroles même de ces ministre encourent dès qu'elles sont subversives des pénalités sévères. Toute contravention peut entraîner la dissolution de l'association ou de l'union.

En présence de telles mesures et de précautions aussi minutieuses on est en droit de dire que le danger qui pourrait résulter de l'union générale d'associations trop nombreuses ou trop riches est, sinon illusoires, au moins très atténué.

Il n'est pas tel que l'on doive limiter les fédérations des associations catholiques et briser l'organisation traditionnelle des minorités religieuses ; le maintien de l'union des associations avec la capacité juridique prévue par le projet de loi s’impose donc au législateur. Le Gouvernement s'est rallié, sur ce point encore, aux vues de la commission.

\section{Article 19}

Les associations et les unions tiennent un état de leurs recettes et de leurs dépenses ; elles dressent chaque année le compte financier de l'année écoulée et l'état inventorié de leurs biens, meubles et immeubles.

Le contrôle financier est exercé sur les associations par l'administration de l'enregistrement et sur les unions par la cour des comptes.

Dans le but de maintenir les règles édictées par le projet de loi, le mode de perception et l'affectation des ressources des associations cultuelles, la commission a pris des dispositions pour que leurs comptes soient dressés et contrôlés avec soin.

Les associations et les unions noteront toute recettes et dépenses, feront annuellement l'inventaire complet de leurs biens, meubles et immeubles, et le compte financier de l’année écoulée. 
L'administration de l'enregistrement, pour les associations, vérifiera et contrôlera toute cette gestion financière. Elle dressera des procèsverbaux pour les infractions à la loi. Le contrôle des unions d'associations sera exercé par la cour des comptes. Les associations cultuelles trouveront dans l'administration de l'enregistrement et à la cour des compte tous les éléments d’une vérification éclairée et juste.

\section{Article 20}

Les associations et unions peuvent employer leurs ressources disponibles à la constitution d'un fonds de réserve dont le montant pourra jamais dépasser la moyenne annuelle des sommes dépensées pendant les cinq derniers exercices pour les frais et l'entretien du culte.

Indépendamment de cette réserve, qui devra être placée en valeurs nominatives, elles pourront constituer une réserve spéciale dont les fonds devront êtres déposés à la Caisse des dépôts et consignations pour y être exclusivement affectés, y compris les intérêts, à l'achat, à la construction, à la décoration ou à la réparation d'immeubles ou meubles destinés aux besoins de l'association ou de l'union.

La loi du 1er juillet 1901, permettant par son article 6, aux associations d'administre les sommes qu'elles sont admises à recevoir, leur a concédé la faculté de se constituer des fonds de réserve, et comme ces fonds ne sont alimentés qu'au moyen de ressources étroitement limitées, ils n’ont pas été limités eux-mêmes.

La capacité de recevoir des associations cultuelles étant plus étendue, il devenait nécessaire de prévoir un maximum pour ce fonds de réserve. Tel est l'objet de l'article 20. Le fonds de réserve est tel qu'il puisse permettre à une association cultuelle de vivre, au besoin, une année entière sans rien recevoir des fidèles. Il peut atteindre la moyenne annuelle des sommes dépensées pendant les cinq derniers exercice pour les frais et l'entretien du culte.

Il faut remarquer que cette réserve éventuelle, constituée par les excédents de recettes annuels, est indépendante du capital provenant des 
biens qui auront été dévolus à l'origine par les établissements publics des cultes.

Les fonds de la réserve seront placés en valeurs nominatives afin que le montant global en puisse être facilement contrôlé.

Mais ces ressources n'auraient pas suffi. En dehors de l'exercice du culte les associations pourront parfois se trouver en présence de dépenses considérables pour l'acquisition, la réparation ou la décoration des immeubles nécessaires au but de l'association.

A cet effet, la loi autorise la constitution d'une réserve spéciale à la caisse des dépôts et consignations.

Il n'est peut-être pas inutile de remarquer que le patrimoine légal des associations actuelles pourra être beaucoup plus considérable que celui des associations de droit commun et des syndicats professionnels (Loi du 21 mars 1884)

\section{Article 21}

Seront passibles d'une amende de 16 à 200 fr., et d'un emprisonnement de six jours à trois mois, ou de l'une de ces deux peines, les directeurs ou administrateurs d'une association ou d'une union qui auront contrevenu aux articles 16, 17, 18, 19 et 20.

Les tribunaux pourront, dans le cas d'infraction au paragraphe 1er de l'article 20, condamner l'association ou l'union à verser à l'État l'excédent constaté par le contrôle financier.

Ils pourront, en outre, dans tous les cas prévus au paragraphe 1er du présent article, prononcer la dissolution de l'association ou de l'union.

Les associations cultuelles fonctionnent librement ; elles sont soustraites, dans l'accomplissement de leurs actes à tout contrôle préventif.

Dès lors, la seule manière d'assurer le respect des dispositions des articles 16, 17, 18, 19 et 20 était d'organiser un système répressif. 
C’est d'ailleurs le système le plus libéral qui ne présume pas la fraude à la loi et qui laisse le maximum de liberté aux associations qu’il régit.

Ce sont les directeurs et administrateurs qui seront rendus responsables des infractions commises.

Lorsque la réserve dépassera le chiffre légal, les tribunaux pourront condamner l'association ou l'union à verser à l'État l'excédent constaté. Mais ce n'est qu'une faculté. On pourra obliger l'association à le dépenser immédiatement pour l'exercice du culte ou le transmettre à une autre association. similaire.

Dans les cas les plus graves, lorsque les infractions seront telles que l'existence de l'association et de l'union paraîtra constituer un danger pour l'ordre public, les tribunaux pourront en prononcer la dissolution.

Article 22

Les biens meubles et immeubles, propriété des associations et unions, sont soumis aux mêmes impôts que ceux des particuliers.

Ils ne sont pas assujettis à la taxe d'abonnement ni à celle imposée aux cercles par l'article 33 de la loi du 8 août 1890.

Toutefois les immeubles appartenant aux associations et unions sont soumis à la taxe de mainmorte.

L’impôt de 4 p. 100 sur le revenu établi par les lois du 28 décembre 1880 et du 29 décembre 1884 ne frappe pas les biens des associations déclarées pour l'exercice et l'entretien du culte. Il est transformé en une taxe de statistique de 1 centime p. $100 \mathrm{fr}$., perçue sur le revenu des titres et valeurs mobilières desdites associations.

La commission a entendu par l'article 22 soumettre les immeubles les immeubles appartenant aux associations cultuelles ou aux unions d'associations aux mêmes impôts que les immeubles appartenant aux particuliers et à un impôt spécial : la taxe de mainmorte. 
Il n'y avait aucune raison pour leur imposer la taxe d'accroissement prévue par les lois des 28 décembre 1880, du 29 décembre 1884 et du 16 août 1886. En effet, le but des associations n'est pas lucratif. Elles ne peuvent accumuler de capitaux. Il n’y a point de bénéfices répartis flectivement ou réellement entre leurs membres ni aucune clause de réversibilité dans l'intérêt des membres restants. On ne pourrait les assimiler à des congrégations religieuses.

Il a paru sage, la loi l’a fait pour beaucoup de sociétés, de les exonérer de la taxe spéciale sur les cercles, qui porte sur des lieux de réunion permanente d'un caractère tout différent.

Cependant elles supporteront une taxe dite de statistique de 1 centime p. 100 fr. sur le revenu de leurs titres et valeurs mobilières.

Cet impôt permettra la vérification constante du montant de ces titres.

\section{Titre V Police des cultes}

\section{Article 23}

Les réunions pour la célébration d'une culte tenues dans les locaux appartenant à une association cultuelle ou mis à sa disposition sont publiques. Elles sont dispensées des formalités de l'article 8 de la loi du 30 juin 1881, mais restent placées sous la surveillance des autorités dans l'intérêt de l'ordre public. Elles ne peuvent avoir lieu qu'après une déclaration faite dans les formes de l'article 2 de la même loi et indiquant le local dans lequel elles seront tenues

Une seule déclaration suffit pour l'ensemble des réunions permanentes, périodiques ou accidentelles qui auront lieu dans l’année.

Cet article inaugure le titre V relatif à la police des cultes.

Ce titre n'indique nullement que les dispositions qu'il contient sont toutes destinées à réprimer les infractions commises par les associations cultuelles ou leur directeurs et ministres. 
Certaines ont, au contraire, pour objet de garantir leur liberté et de les protéger.

Lorsqu'une personne morale se constitue, elle exerce une action spéciale à son but et qui dépend de son fonctionnement. Lorsque la personne morale devient très puissante, elle crée pour elle comme un doit particulier. Au point de vue pénal, elle peut commettre des délits qui résultent de son caractère distinctif ; on peut aussi commettre à son préjudice des actes d'une nature spéciale.

Il devient dès lors nécessaire de régler dans le droit écrit ces manifestations diverses et de prévoir ces délits nouveaux.

Mais il ne s’agit pas ici du droit pénal. Il fallait légiférer sur une matière administrative très délicate: la tenue des réunions pour l'exercice du culte.

D’après le projet ces réunions devront être publiques.

Inutile de dire que toute manifestation cultuelle ne sera pas soumise à cette condition : Le chrétien qui prie dans sa chambre et à l'église, le prêtre qui dit sa messe sur un autel privé, les réunions familiales ou intimes pour la célébration d'un culte à domicile ou dans une chapelle privée, ne seront pas passibles des pénalités légales. C'est la réunion des fidèles pour l'exercice d'un culte qui devra être publique.

Les communautés religieuses ne pourront s'en plaindre, car elles atteindront ainsi même les profanes et réaliseront un de leurs buts qui est la propagande religieuse.

La publicité des réunions cultuelles devenait indispensable pour assurer l'application du principe inscrit dans la loi, qu'elles resteront placées sous la surveillance des autorités dans l'intérêt de l'ordre public. En l'absence de cette prescription, toutes les fois qu'une association aurait voulu échapper à la loi de police des cultes, même par des actes contraires à l'ordre public, elle n'aurait au qu'à organiser une réunion privée à l’abri des témoins redoutés. 
La publicité de la réunion résultera simplement du maintien des portes ouvertes qui permettra la surveillance et le contrôle et mettra les fidèles à l'abri du chantage politique qu'à l'aide de la religion on pourrait être tenté d'exercer sur eux.

Il pourrait sembler au premier abord que pour tous les exercices publics du culte, on aurait dû conserver l'application du droit commun des réunion publiques, tel qu’il résulte de la loi du 30 juin 1881.

Cette solution simpliste n'a pas paru possible. La loi de 1881 contient certaines exigences qui auraient constitué de véritables entraves à l'exercice des cultes. Il aurait fallu une déclaration spécifiant non seulement le lieu mais aussi le jour et l'heure des réunions. On voit mal une déclaration ainsi nécessaire pour chaque messe ou chaque vêpres. Les réunions n'auraient pu avoir lieu que vingt-quatre heures après la déclaration. Elles n'auraient pas dû se prolonger au delà de onze heures du soir (art. 6). Un bureau composé d'au moins trois personnes auraient été nécessaire (art. 8).

On n’a retenu de la loi de juin 1881, que la nécessité d'une déclaration limité au local où s'exercera le culte. Aucune autorisation ne reste nécessaire, et ceci est une réforme très considérable et très libérale de nos principes traditionnels et de notre législation. Une seule déclaration, pour toutes les réunions d'une année suffira sans qu'il y ait lieu d'énoncer les jours et les heures. Les cérémonies accidentelles, comme les mariages, baptêmes, enterrements n'auraient pu être tenues d'après ces règles. On ne pourrait les limiter par avance à certains jours et à certaines heures.

Votre commission n'a pas cru prolonger ce délai d'un an pendant lequel aucune autre déclaration n'est indispensable. Certains administrateurs ou directeurs de l'association peuvent changer de domicile, mourir ou démissionner, perdre leurs droits civils et politiques ; il est nécessaire, à raison de la responsabilité qui leur incombe, qu'ils soient remplacés à bref délai.

Si l'on rapproche l'article 23 du projet de l'article 37, on constate que ses dispositions, comme l'abrogation des décrets des 22 décembre 1812, 19 mars 1859 et de l'article 294 du code pénal établissent dans 
notre législation une liberté nouvelle : la liberté des lieux de cultes. Désormais les cultes pourront s'exercer dans tous les locaux sous condition unique de déclaration préalable.

Cette réforme, réclamée depuis longtemps par les esprits libéraux et dont l'importance et la portée seraient difficilement exagérées, libère les Églises d'une sujétion sévère et réalise la neutralité de l'État à l'égard de toutes les manifestations religieuses.

\section{Article 24}

Il est interdit de tenir des réunions politiques dans les locaux servant habituellement à l'exercice d'un culte.

Les raisons qui ont motivé la rédaction de cet article se conçoivent et s’imposent sans difficulté.

Les associations cultuelles doivent conformer leur action à leur but spécial et précis. Les réunions de leurs membres ne sauraient avoir d'autre objet que l'exercice du culte ou le fonctionnement et l'administration de l'association. Les réunions cultuelles jouissant d'un régime de faveur, les locaux qui leur sont destinés ne doivent pas servir à un autre usage que le culte et ne sauraient tout particulièrement donner asile à des réunions d'un caractère politique. Si l'État demeure neutre à l'égard des Églises, celles-ci doivent observer une neutralité absolue à l’égard de l’État.

L'article 24 n'interdit pas seulement aux associations cultuelles de tenir des réunions politiques, il interdit d'une façon rigoureuse toutes réunions publiques dans les locaux servant à l'exercice du culte.

Ainsi l'association ne peut consentir à ce que ces réunions soient organisées même par des tiers : elle doit veiller sous sa responsabilité à ce que nul n'emprunte ses locaux dans un but interdit par la loi.

\section{Article 25}

Les cérémonies, processions et autres manifestations extérieures d'un culte ne peuvent avoir lieu sur la voie publique. 
Les cérémonies funèbres seront réglées dans toutes les communes par arrêté municipal dans les conditions de la loi du 15 novembre 1887.

Les sonneries des cloches seront réglées par arrêté municipal.

L’article 25 dont la sévérité n’est qu’apparente en présence du libéralisme de l'article 23, est la conséquence nécessaire et immédiate du principe fondamental du projet.

Les Églises sont séparées de l’État; leurs manifestations de toute nature, conformes à leur objet, sont libres ; elles n'ont plus aucun caractère officiel ni public ; leur patrimoine, leur fonctionnement sont du domaine privé.

Elles peuvent tenir partout leurs réunions cultuelles sous la seule obligation d'une déclaration annuelle, elles peuvent construire des édifices aussi nombreux, aussi vastes qu'elles désirent, elles peuvent, pour les cérémonies en plein air, acquérir des jardins ou des espaces extrêmement étendus, mais elles n'ont pas le droit d'emprunter la voie publique pour les manifestations de leur culte et d'imposer ainsi aux indifférents, aux adeptes d'autres confessions religieuses le spectacle inévitable de leurs rites particuliers. L'article 25 apparaît ainsi comme la consécration du principe de liberté et de neutralité.

La séparation entre le monde religieux et le monde laïque, comme entre les divers groupements religieux, doit être absolue et décisive.

Les processions et cérémonies ne pourront avoir lieu ni dans les rues, boulevards, squares, ni dans aucune dépendance de la voie publique.

Il est sage d'enlever aux conseils municipaux la responsabilité d'autoriser ou d'interdire les manifestations religieuses sur la voie publique. Elles ne sont pas indispensables à l'exercice du culte et sont susceptibles de troubler l'ordre et la paix pour le plus grand préjudice même des associations cultuelles. La loi, par cette disposition générale, sera pacificatrice. 
Une exception est faite en faveur des cérémonies funèbres ; elles seront réglées par arrêté municipal, mais conformément à la loi du 15 novembre 1887.

La question de l'usage des cloches des édifices religieux doit être envisagé à un double point de vue. Les cloches ne sont pas seulement destinées à annoncer les cérémonies du culte, elles sont utiles dans d'autres circonstances, par exemple pour donner l'alarme en cas de sinistre et dans certains événements graves ou exceptionnels.

Les sonneries religieuses et civiles font actuellement, en vertu de l'article 100 de la loi du 5 avril 1884, l'objet de règlements concertés entre l'évêque ou les consistoires et le préfet en vue de concilier les intérêts civils et les intérêts religieux. Ce système est incompatible avec le régime de la séparation. L'autorité gouvernementale ne peut intervenir spontanément. Le maire, selon les principes administratifs, a la police de la commune pour faire respecter les intérêts publics ou privés. Ce sera lui qui aura tout pouvoir pour la réglementation des sonneries, sauf au préfet, par application de l'article 9 de la même loi, à annuler les arrêtés municipaux pris en cette matière ou en suspendre l'exécution, si les arrêtés n'étaient pas de nature à ménager les divers intérêts en présence.

\section{Article 26}

Il est interdit, à l'avenir, d'élever ou d'apposer aucun signe ou emblème religieux sur les monuments publics ou en quelque emplacement public que ce soit, à l'exception des édifices servant au culte, des terrains de sépulture privées ainsi que des musées ou expositions.

L'interdiction formulée par cet article s’inspire toujours des mêmes principes que les précédentes dispositions : réaliser la neutralité stricte de la part ou à l'égard des associations cultuelles. Elle est indispensable pour prévenir les troubles et les désordres qui peuvent être occasionnés par la présence d'emblèmes ou de signes religieux. Mais l'interdiction n'est prononcée que sous ces réserves qui respectent les coutumes et les sentiments intimes des populations. 
Les emblèmes religieux déjà élevés ou apposés demeurent et sont régis par la législation actuelle. L'article ne dispose que pour l'avenir. Ils pourront être placés dans et sur les édifices servant au culte, sur les terrains de sépulture privée, ainsi que dans les musées ou expositions.

Il fallait que les édifices religieux pussent être reconnus extérieurement grâce à des signes ou des emblèmes spéciaux. La liberté des cultes exige que les adeptes des différentes religions aient le droit d'affirmer leurs croyances sur leurs sépultures particulières. Ce qui doit être prohibé seulement au nom de la neutralité, ce sont les emblèmes et les signes qui tendraient à consacrer l'ensemble d'un cimetière à un culte déterminé et porteraient ainsi atteinte à la liberté de conscience de ceux qui ne professent pas ce culte.

C'est dans l'intérêt de l'art et de la science historique que les musées et expositions ont fait aussi l'objet d'une exception formelle.

\section{Article 27}

Les contraventions aux articles précédents sont punies des peines de simple police.

Sont passibles de ces peines, dans le cas des articles 23, 24 et 25, ceux qui ont organisé la réunion ou manifestation, ceux qui y ont participé en qualité de ministres du culte et, dans le cas des articles 23 et 24, ceux qui ont fourni le local.

Les peines de police, les plus modérées dans l'échelle pénale, ont paru suffisantes pour réprimer les infractions qui seraient commises aux articles 23, 24, 24, 25 et 26.

Mais encore fallait-il que ces pénalités fussent efficaces.

C'est pourquoi le second paragraphe du présent article spécifie que certaines personnes, en cas de contraventions relatives aux réunions du culte, aux réunions tenues dans les édifices religieux, aux cérémonies, processions et sonneries des cloches, seront de plein droit punissables en vertu d'une présomption légale de culpabilité. Ces personnes sont ainsi rendues légalement responsables ; elles devront faire elle- 
même la preuve de leur innocence. Il va de soi d'ailleurs que d'autres pourront aussi, selon les circonstances, être poursuivies si leur participation aux faits constitutifs de la contravention vient à être établie par les moyens ordinaires de la preuve.

\section{Article 28}

Sont punis d'une peine d'amende de 16 fr. à 200 fr. et d'un emprisonnement de six jours à deux mois ou de l'une de ces deux peines seulement, ceux qui, soit par voies de fait, violences ou menaces contre un individu, soit en lui faisant craindre de perdre son emploi ou d'exposer à un dommage sa personne, sa famille ou sa fortune, l'auront déterminé à exercer ou à s'abstenir d'exercer un culte, à contribuer ou à s'abstenir de contribuer aux frais d'un culte.

\section{Article 29}

Seront punis des mêmes peines ceux qui auront empêché, retardé ou interrompu les exercices d'un culte par des troubles ou désordres causés dans le local servant à ces exercices.

\section{Article 30}

Les dispositions des deux articles précédents ne s’appliquent qu'aux troubles, outrages ou voies de fait, dont la nature ou les circonstances ne donneront pas lieu à de plus fortes peines d'après les dispositions du Code pénal.

Ces articles tendent à garantir tout à la fois la liberté des cultes et la liberté de conscience. Ils remplaceront, pour les cas qu'ils prévoient, les articles 260, 261 et 264 du code pénal qui sont abrogés par l'article 37 du projet. La rédaction de l'article 260 du code pénal a été transportée dans l'article 28 du projet qui l'a complétée en s'inspirant de l'article 39 du décret organique du 2 février 1852

Les articles 262 et 263 du code pénal qui avaient pour objet de réprimer, au moyen de peines spéciales, les outrages adressé soit aux objets du culte, soit au ministres de ce culte, ainsi que les coups portés aux ministres des cultes dans l'exercice de leurs fonctions, sont abro- 
gés purement et simplement par l'article 37 du projet de loi, sans qu'on ait fait revivre tout ou partie leurs dispositions qui ne cadraient pas avec le régime de séparation des Églises et de l’État, où les objets et ministres du culte ne sauraient avoir droit à une protection particulière et où il suffit que le libre exercice des cultes soit garanti.

Les pénalités de droit commun suffiront, à défaut de pénalités exceptionnelles pour réprimer les voies de fait auxquelles s’appliqueraient les articles 262 et 263 du code pénal.

Il est d'ailleurs expressément spécifié dans l'article 30 du projet que pour les troubles, outrages ou voie de fait punis par le code pénal des peines plus fortes que celles prévues dans le projet de loi, ils continueront à être réprimés par la législation antérieure.

Il résulte des nouvelles dispositions que toute personne pourra exercer le culte qu'elle aura librement choisi ; le fait de l'avoir déterminée ou d'avoir voulu la déterminer à s'abstenir d'exercer un culte constituera un délit.

Mais en sens contraire le fait de peser sur la détermination d'une personne pour l'amener à exercer un culte ou contribuer à son exercice sera de même considéré comme délictueux. Ces différents actes, procédant d'une intolérance, sont à bon droit punis des mêmes peines.

\section{Article 31}

Tout ministre d'un culte qui, dans les lieux où s'exerce ce culte, aura publiquement par des discours prononcés, des lectures faites, des écrits distribués ou des affiches apposées, outragé ou diffamé un citoyen chargé d'un service public, sera puni d'une amende de $500 \mathrm{fr}$. à 3000 fr. et d'un emprisonnement d'un mois à un an, ou de l'une de ces deux peines seulement.

\section{Article 32}

Si un discours prononcé ou un écrit affiché ou distribué publiquement dans les lieux où s'exerce le culte, contient une provocation directe à résister à l'exécution des lois ou aux actes légaux de l'autorité 
publique, ou s'il tend à soulever ou à armer une partie des citoyens contre les autres, le ministre du culte qui s'en sera rendu coupable sera puni d'un emprisonnement de trois mois à deux ans, sans préjudice des peines de la complicité, dans le cas où la provocation aurait été suivie d'une sédition, révolte ou guerre civile.

Ces articles sont destinés à remplacer les articles 201, 202, 203, 204, 205 et 206 du code pénal, abrogés par l'article 37 du projet de loi.

Ces articles du code pénal avaient trait aux critiques, censures et provocations dirigées par les ministres du cultes contre l'autorité publique dans des discours ou écrits pastoraux.

Les articles 107 et 106 du même code qui tendaient à réprimer les correspondances des ministres des cultes avec des puissances étrangères ont été supprimés purement et simplement par l'article 37 du projet sans qu'il ait paru utile de les remplacer. Les dispositions des articles 75 et suivants du code pénal relatives aux crimes et délits contre la sûreté intérieur ou extérieure de l'État sont suffisantes en effet pour réprimer à ce point de vue les agissements des ministres des cultes.

La commission a cherché par des textes précis à interdire aux ministres des cultes et à leurs complices d'user de leur influence dans un but politique contre des personnalités publiques ; de transformer la chaire en tribune et l’Église en asile séditieux.

Dans le cas où les paroles ou les actes punis et réprimés par ces articles auraient été suivis d'effet, les complices des ministres des cultes pourront être poursuivis et condamnés selon les règles visant la complicité.

De telles dispositions n'ont rien d'antilibéral, elles ne peuvent atteindre les ministres du culte exclusivement soucieux de leur œuvre religieuse. Elles étaient indispensable, car ici, le droit commun restait insuffisant. Il était impossible de traiter sur le pied de l'égalité, quand il s'agit de l'exercice du droit de la parole, le prêtre dans sa chaire et le simple citoyen dans une tribune de réunion publique. Le délit commis par celui-ci, qu'il s'agisse d'outrages, de diffamation envers les per- 
sonnes ou d'excitation à la violence, n'est en rien comparable, comme gravité, au délit commis par un ministre des cultes en pareil cas. Le lieu, les circonstances du délit, l'autorité morale de celui qui la commet, sont des éléments dont il est impossible de ne pas tenir compte. Aucune assimilation n'est à faire entre la portée, les conséquences d'un discours de réunion publique devant un auditoire averti, où toutes les opinions sont le plus souvent en présence, où l'on est habitué à faire la part des exagérations, où la contradiction, toujours possible, offre toutes garanties de mise au point, et celles d'un sermon prononcé par un ministre du culte devant des auditeurs livrés inertes et sans défense par la croyance ou la superstition aux suggestions d'une parole qui tient sa force des siècles et n’a jamais été affaiblie par la controverse.

Du reste, en quoi cette restriction au droit commun pourrait-elle faire obstacle au libre exercice des cultes ? Un prêtre, un pasteur, un rabbin sont-ils donc exposés fatalement, de par leurs fonctions mêmes, à tomber sans cesse sous les coups de ces pénalités pour des délits de cette nature ? Si non, ils n'auront rien à redouter de la loi, ne seront en rien gênés par elle ; dans le cas contraire, c'est qu'alors l'Église n'est pas seulement, comme le prétendent ses défenseurs, l'expression vivante de la religion, mais aussi et surtout une force organisée au service d'intérêts politiques. Dans ce dernier cas, toutes les précautions prises par l'État dans l'intérêt de sa défense ne peuvent qu'être justifiées.

\section{Article 33}

Dans le cas de condamnation par les tribunaux de police ou de police correctionnelle en application des articles 23 et 24, 31 et 32, l'association constituée pour l'exercice du culte dans l'immeuble où l'infraction a été commise et ses directeurs et administrateurs sont civilement et solidairement responsables.

Si l'immeuble a été loué à l'association par l’État, les départements ou les communes en vertu de la présente loi, la résiliation du bail pourra être demandée par le bailleur. 
Pour que les condamnations fussent effectives, il fallait rendre responsable les directeurs et administrateurs de l'association. On sera ainsi assuré qu'ils veilleront à l'observation de la loi et rempliront leur mandat avec scrupule. Ils pourront, bien entendu, être astreints à d'autres responsabilités civiles.

En cas d'infraction à la police des cultes, la résiliation des baux consentis par l'État, le département ou la commune, peut devenir une mesure nécessaire, parfois même urgente. Mais cette résiliation sera prononcée en justice. C’est une sanction accessoire qui n'a pas lieu de plein droit, comme dans le cas prévu à l'article 11 où elle est prescrite à titre impératif. L'État, le département ou la commune demanderont, s’ils le jugent à propos, la résiliation pour la quelle une décision judiciaire doit intervenir.

Titre VI

Dispositions générales

Article 34

L’article 463 du Code pénal et la loi du 26 mars 1891 sont applicables à tous les cas dans lesquels la présente loi édicte des pénalités.

\section{Article 35}

Les congrégations religieuses demeurent soumises aux lois des 1er juillet 1901, 4 décembre 1902 et 7 juillet 1904.

\section{Article 36}

Un règlement d'administration publique rendu dans les trois mois qui suivront la promulgation de la présente loi déterminera les mesures propres à assurer son application.

Cette disposition est encore de style dans toute œuvre législative établissant en quelque matière un régime nouveau. 
La loi ne peut pas prévoir et édicter tous les détails de procédure qu'entraîne son application. Il appartiendra au Gouvernement, par la voie d'un règlement d'administration publique d'en préciser tous les détails. Ce règlement, pour ne pas laisser trop longtemps la volonté du législateur en suspens, devra être rendu dans les trois mois, à dater de la promulgation de la loi.

\section{Article 37}

Sont et demeurent abrogées toutes les dispositions relatives à l’organisation publique des cultes antérieurement reconnus par l'État, ainsi que toutes dispositions contraires à la présente loi et notamment :

$1^{\circ}$ La loi du 18 germinal an $\mathrm{X}$; portant que la convention passée le 26 messidor an IX entre le pape et le gouvernement français, ensemble les articles organiques de ladite convention et des cultes protestants, seront exécutés comme des lois de la République ;

$2^{\circ}$ Le décret du 26 mars 1852 et la loi du 1er août 1879 sur les cultes protestants ;

$3^{\circ}$ Les décrets du 17 mars 1808, la loi du 8 février 1831 et l’ordonnance du 28 mai 1844 sur le culte israélite ;

$4^{\circ}$ Les décrets des 22 septembre 1812 et 19 mars 1859 ;

5 Les articles 201 à 208, 260 à 264, 294 du code pénal

$6^{\circ}$ Les articles 100 et 101, les paragraphes 11 et 12 de l'article 136 et l'article 167 de la loi du 5 avril 1884 ;

$7^{\circ}$ Le décret du 30 décembre 1809 et l'article 78 de la loi du 26 janvier 1892.

Le dernier article du projet reproduit la formule traditionnelle par laquelle se trouvent annulées toutes les dispositions légales ou réglementaires antérieures qui seraient contraires à la présente loi. 
Mais il a paru nécessaire d'abroger expressément, par une disposition spéciale, certains textes relatifs au régime ou à la police des cultes. Nous les avons signalés un à un au cours de notre commentaire toutes les fois qu'une disposition nouvelle était destinée à les remplacer. Il serait oiseux d’y revenir.

Constatons seulement que désormais il n'y aura plus aucune organisation officielle des cultes, que ceux-ci seront libres dans les limites de l’ordre public déterminée par le projet.

Mais il est une disposition de l'article 37 au sujet de laquelle un commentaire s'impose.

Il s'agit de l'abrogation de la loi du 18 germinal an X, portant que la convention passée à Paris le 26 messidor an IX entre le pape et le gouvernement français sera exécutée comme loi de la République.

L’abrogation du Concordat pouvait-elle être valablement prononcée par un acte unilatéral et sous quelle forme?

Il faut distinguer entre la loi qui a rendu exécutoire en France le Concordat, et la convention elle-même conclue avec le saint-Siège. La loi peut être abrogée par une autre loi et ne peut l'être autrement. L'acte législatif est libre et le parlement a toujours le droit de l'accomplir.

Le Concordat, convention sui generis, est indéniablement un contrat synallagmatique, dont la durée n’a pas été déterminée conventionnellement, qui s'exécute par des actes continus et successifs, et pour les difficultés d'interprétation ou d'application duquel aucun tribunal ne peut être compétent.

Est-il perpétuel ? Qu’on le considère comme un traité diplomatique, ou comme de droit privé, s’il portait clause de perpétuité, celle-ci, en vertu de notre droit moderne, devrait être considéré comme non écrite. Les États ne peuvent, pas plus que les individus, obliger indéfiniment leurs successeurs et les lier par des liens indissolubles. 
Mais pareille clause n'existe pas dans le Concordat ; il garde simplement le silence sur la rupture des accords qu'il consacre, et prévoit seulement le cas où le chef de l'État français ne serait pas catholique et où il y aurait lieu de procéder à une nouvelle convention (XVII).

Comment pourrait-il prendre fin ?

Par la volonté exprimée de l'une des parties de ne pas remplir ses engagements ; par la volonté présumée de l'une des parties de ne plus se conformer à ses obligations (article 1184 du code civil); par une entente entre les deux parties.

Il n'y a pas entre le Gouvernement français d'entente proprement dite avec le pape. Il n'y a pas eu de volonté expressément notifiée par une des parties de ne plus exécuter la convention. Mais il y a eu certains actes de la papauté qui ont été interprétés par le Gouvernement français en ce sens qu'elle se refusait sur les matières à propos desquelles ces actes avaient été accomplis, à observer les obligations du Concordat.

Il est vrai qu'un tribunal n'a pas été appelé à juger ce différend. Mais aucun tribunal n'avait pareille compétence et ce défaut de juge ne pouvait donner au Concordat une pérennité contraire au droit privé, public et international.

Nous n'avons pas ici à chercher si le Gouvernement français a eu raison d'apprécier l'attitude du pape, en certaines circonstances, comme un refus de se conformer au Concordat. Il y a un acte gouvernemental interprétant ainsi les agissements de la papauté. C'est là un fait accompli. Le Concordat est considéré et doit être considéré comme rompu par la volonté présumée et unilatérale du pape, qui a agi de telle sorte que le Gouvernement de la République a considéré ses actes comme une inexécution délibérée du contrat.

Dès lors, le Gouvernement peut et doit convier le parlement à abroger la loi déclarant le Concordat exécutoire comme loi française.

L’article 37 a cet objet. 
S’il est vrai qu'une dénonciation diplomatique de la convention eût été conforme au droit international, elle est aujourd'hui impossible, les relations diplomatiques étant rompues entre la République française et le pape.

Du reste avant la rupture de ces relations une note du ministre des affaires étrangères officiellement notifiée au cardinal secrétaire d’État, en date du 29 juillet 1904, avertissait solennellement le Vatican que le Gouvernement de la république française "a prévenu le saint-Siège de la conclusion qu’il serait amené à tirer de la méconnaissance persistante de ses droits" (concordataires) et que "obligé de constater... que le saint-Siège maintient les actes accomplis à l'insu du pouvoir avec lequel il a signé le Concordat, le Gouvernement de la république a décidé de mettre fin à des relations officielles qui, par la volonté du saint-Siège, se trouvent sans objet”.

C'est dire, en termes diplomatiques, que le Gouvernement considérait que, par la volonté du saint-Siège, le Concordat n'était plus observé et que, par suite, les relations existant entre la République et le pape devenaient sans objet.

Dès lors la dénonciation du Concordat devient fautile, les agissements du saint-Siège ayant été tels que le Gouvernement français a pu en déduire l'intention du pape de ne plus exécuter intégralement la convention signée par Bonaparte et Pie VII 


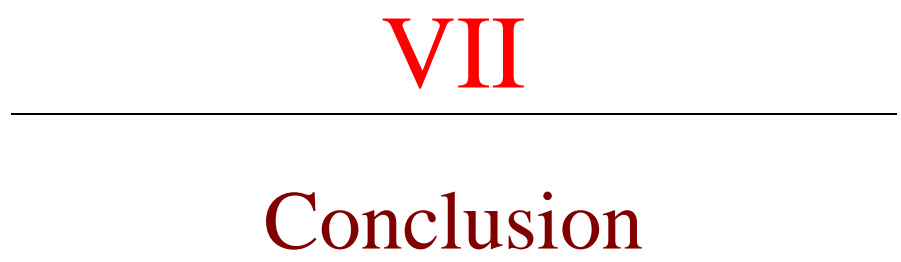

$\underline{\text { Retour à la table des matières }}$

Ce n'est plus l'heure d'insister sur les considérations théoriques qui militent en faveur de la séparation des Églises et de l’État. Elles ont été abondamment, et de tout temps, produites par des écrivains et des orateurs dont on essaierait vainement de dépasser on même d'égaler l'éloquence. Aujourd'hui, il n'est plus personne pour contester sérieusement que la neutralité de l'État en matière confessionnelle ne soit l'idéal de toutes les sociétés modernes. Dans une démocratie surtout, dont les institutions ont pour base le suffrage universel, c'est à dire le principe de la souveraineté du peuple, le maintien d'un culte officiel est un tel défi à la logique et au bon sens qu'on a le droit de se demander comment la République française a pu pendant trente-quatre ans s'accommoder de ce régime équivoque.

C'est que, plus forte et plus décisives que toutes les raisons de principe, les considérations de fait ou d'opportunité ont toujours prévalu jusqu'ici.

Depuis l'avènement de la troisième République les hommes d'État qui se sont succédé au pouvoir ont persisté dans la poursuite de cette chimère : asservir à leurs desseins la puissance politique de l’Église. Et la plupart se sont bercés de cette illusion que le Concordat pouvait leur en donner les moyens. La faculté de suspendre ou de supprimer les traitements, l'appel comme d'abus, surtout le droit de faire des évêques leur paraissaient des prérogatives énormes au service de la République. On a vu, par l'histoire de ces trente dernières années, 
combien sont restées inefficaces, aux mains des gouvernements républicains, ces prétendues armes concordataires. Elles n’ont jamais pu faire obstacle aux heures décisives, c'est-à-dire chaque fois que la République a été en danger ou qu'elle a entrepris la réalisation d'un progrès laïque, aux tentatives d'insubordination du clergé français et de ses chefs. Le "préfet violet" a rarement pardonné à ce régime les brigues humiliantes du curé d'antan, et toute occasion a été bonne pour essayer de faire oublier à Rome les excès de zèle concordataire du candidat à la mitre. Si la République a vécu, si elle a progressé c’est malgré l'Église, contre ses effort et grâce à l'indifférence religieuse qui, croissant de jour en jour, a fini par rendre ce pays impénétrable aux excitations du clergé.

Cependant, malgré toutes les leçons du passé, peut-être les rapports officiels entre les Églises et l'État eussent-ils duré encore au-delà de toute prévision, si des événements n'avaient surgi dont la force brutale a changé brusquement le cours des choses. Ce que n'aurait osé la timidité gouvernementale ou parlementaire, en quelques mois la foi ardente et combative d'un pape audacieux l'a réalisé. Le Concordat, ce pacte sacro-saint, devant lequel pendant trente-quatre ans avait capitulé tous les principes républicains, il a suffit à Pie $\mathrm{X}$ de deux ou trois accès d'absolutisme pour le déchirer et le réduire en miettes.

Devant le fait accompli, il fallait bien s’incliner. Le régime concordataire étant aboli, il ne restait plus qu'une issue à une situation devenue intenable : la séparation. Les républicains les plus modérés ont dû avouer que le problème se posait désormais d'une façon si pressante qu'il devenait impossible d'en ajourner la solution.

Votre commission ne croit pas que vous puissiez prendre en considération l'idée de remettre à un an, c'est à dire jusqu'après les élections générales, toute détermination sur la situation présente. Lier, pour un si long temps, dans les circonstances actuelles, les mains au Gouvernement, ce serait, on en conviendra, faire au saint-Siège la partie belle et facile; ce serait vouloir mettre la République dans une posture singulièrement humiliante et dangereuse. Faire dépendre du résultat des prochaines élections législatives l'issue du conflit, autant vaudrait offrir une prime à l'agitation cléricale. Un an d'impuissance imposé au Gouvernement de la République, d’émancipation électorale 
accordée au clergé ; quel est le républicain soucieux des intérêts de ce régime qui oserait envisager sans inquiétude une telle perspective?

Puis, sur quoi le corps électoral serait-il consulté ? Sur le principe même de la réforme ? Mais tous les électeurs républicains sont, théoriquement, favorables à la séparation. Une réponse par oui ou par non à une question de cette nature ne vous apporterait pas les éléments d'appréciation désirables pour l'étude d'un régime qui vaudra surtout par les modalités selon lesquelles il aura été réalisé. Est-ce donc sur ces modalités mêmes que la consultation devrait avoir lieu ? Mais chacun reconnaît que le problème est si délicat, si complexe, que ce ne sera pas trop de toute la bonne volonté, de tout l'effort du Parlement, pour le résoudre. Peut-on raisonnablement penser qu'en pleine effervescence électorale, le suffrage universel serait à même de se prononcer sur cette matière, et jusque dans la minutie des détails, le jugement réfléchi que quelques-uns semblent attendre de lui ?

Tout le monde s'accorde à proclamer que la question doit être posée, discutée et tranchée dans le calme, avec sang froid. Au sortir d'une période électorale, qui n'aurait pu être qu'effroyablement agitée, la chambre se trouverait-elle dans les conditions désirables pour aborder l'examen du problème ?

Il serait puéril et peu digne de vous, dans une aussi grave occurrence, de recourir à des moyens dilatoires pour esquiver les responsabilités de l'heure. Vous êtes des hommes politiques aux prise avec des difficultés d'un problème posé par des événements qu'il n’a pas été en votre pouvoir d'éviter. Ce problème, vous avez le devoir de lui donner la prompte solution que comportent à la fois les principes et les intérêts de la République.

Le projet que vous présente la majorité des membres de votre commission est de nature à vous faciliter la tâche. Conçu, discuté, voté avec un large esprit de tolérance et d'équité, il sauvegarde tout ensemble les légitimes respectables préoccupations des consciences et les intérêts des personnes et les droits supérieurs de l'État. Ce n’est pas une œuvre de passion, de représailles, de haine, mais de raison, de justice et de prudence combinées, à laquelle votre commission vous demande de vous associer. 
On y chercherait vainement la moindre trace d'arrière-pensée de persécution contre la religion catholique. Les trois cultes reconnus en France y reçoivent un traitement égal. Toutes les dispositions concernant le régime des édifices, celui des associations, les précautions d'ordre public, la situation des ministres leur sont communes.

Le projet adopté par votre commission ne s'écarte du droit commun que dans l'intérêt de l'ordre public.

Il est bien vrai qu’il édicte des pénalités plus ou moins sévères selon les cas, contre les ministres des cultes qui, dans l’intérieur des édifices religieux, au cours des cérémonies, se laisseraient entraîner à prêcher la révolte contre l'exécution des lois, contre les institutions publiques, ou bien à outrager, à diffamer les agents de l'autorité. Mais, par contre, il réprime aussi tous les actes - cris, manifestations, violences - qui pourraient troubler les cérémonies religieuses et faire entrave au libre exercice du culte.

En faisant cesser, par la suppression du budget spécial, toute contrainte pour les citoyens de participer de leurs deniers, sous la forme de l'impôt, à l'entretien du culte, il consacre la liberté de conscience dans la réalisation d'un de ses principes essentiels. Mais, soucieux en même temps de ne porter aucune atteinte aux droits acquis, il assure aux intéressés des indemnités et des pensions généreuses proportionnées à l'importance et à la durée des services rendus.

Enfin, par tout un ensemble de dispositions libérales et prévoyantes, appliquées à l'usage des édifices religieux, il rend possible, sans tâtonnements ni heurts, le passage de l'état des choses actuel au régime nouveau.

En le votant, vous ramènerez l'État à une juste appréciation de son rôle et de sa fonction ; vous rendez la République à la véritable tradition révolutionnaire et vous aurez accordé à l'Église ce qu'elle a seulement le droit d'exiger, à savoir la pleine liberté de s'organiser, de vivre, de se développer selon ses règles et par ses propres moyens, sans autre restriction que le respect des lois et de l'ordre public. 
Texte présenté aux députés (avec les modifications des 12 et 19 avril, 22 mai, 13 et 14 juin)

(J'y ai rajouté le texte voté et le texte actuel)

\author{
Maurice Gelbard \\ 9, chemin du clos d'Artois \\ 91490 Oncy sur École
}

Fin du texte 